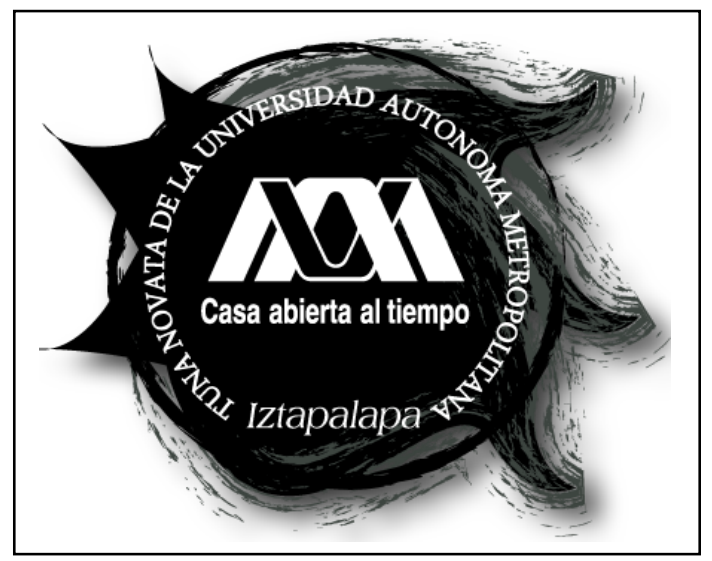

\title{
UAM-I
}

\section{MACROCICLOS TETRAPIRROLICOS}

\section{COVALENTEMENTE UNIDOS A}

\section{XEROGELES TRANSPARENTES DE ÓXIDO DE ZIRCONIO Y TITANIO.}

Tesis que presenta

M. en C. Eduardo Salas Bañales

Para Obtener el Grado de

Doctor en Ciencias (Química)

Asesor

Dr. Miguel Ángel García Sánchez

Departamento de Química

Universidad Autónoma Metropolitana-

Iztapalapa

Posgrado en Ciencias (Química)

8 de Septiembre de 2017. 


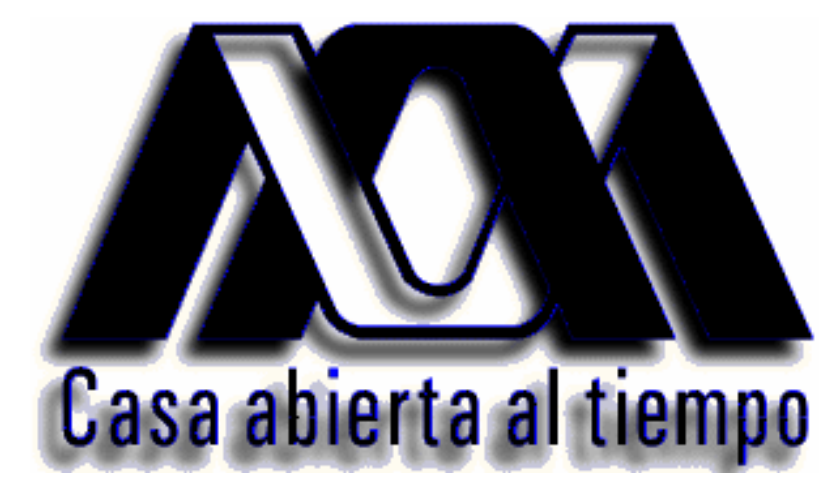

UNIVERSIDAD AUTÓNOMA METROPOLITANA

IZTAPALAPA

División de Ciencias Básicas e Ingeniería

MACROCICLOS TETRAPIRROLICOS COVALENTEMENTE UNIDOS A XEROGELES TRANSPARENTES DE ÓXIDO DE ZIRCONIO Y TITANIO.

Tesis que presenta

M. en C. Eduardo Salas Bañales

Para obtener el grado de

Doctor en Ciencias (Química)

Dirigida por

Dr. Miguel Ángel García Sánchez

Fecha: 8 de Septiembre de 2017 
La presente investigación se realizó en el departamento de Química de la Universidad Autónoma Metropolitana - Iztapalapa, en el laboratorio R-101 del área de Química Inorgánica bajo el acompañamiento y asesoría del profesor investigador.

\section{Dr. Miguel Ángel García Sánchez}

JURADO

\section{Dr. Antonio Campero Celis}

Presidente

Dr. Rubén Arroyo Murillo Secretario
Dra. María Luisa Ojeda Martínez

Vocal

Dr. Celso Velásquez Ordoñez

Vocal 


\section{DEDICATORIAS.}

A mi padre Dios por haberme concedido la vida hasta hoy para poder devolver a mi familia un poco de la paz y la felicidad que les arrebate en el pasado.

A mi Abuela Feliciana Soriano Peláez por darme toda la vida solo amor y enseñarme que la fe no solo es una palabra, en donde quiera que te encuentres muchas gracias, espero volver a verte y abrazarte fuerte una vez más.

A mi padre Felipe Enrique Salas Soriano a quien no le alcanzo la vida para ver a su hijo nuevamente de pie, a ti papa donde quiera que estés, espero algún día volver a verte, abrazarte fuerte y decirte lo mucho que te extrañe.

A mi Madre Rosa María Bañales Alvare z por caminar hasta hoy a mi lado, por conocer a mis hijos, por su ejemplo, su valor y sabiduría, gracias ma espero caminemos juntos muchas más playas, recordando el pasado y viviendo el presente.

A mis abuelos Amelia Álvarez y Rosalio Bañales por ser los pilares de un gran familia y a quienes no les alcanzo la vida para saborear los frutos de su trabajo y disciplina, gracias en donde quiera que se encuentren por todo su amor y cuidados cuando niño.

A mis hijos Omar y Alejandro Salas Mendoza por complementar mi felicidad todos los días, por su inocencia, su gracia, su sonrisa, su sabiduría, su amor y su respeto. A ustedes mis dos hijos.

A mi Amada Esposa Guadalupe Mendoza Ricardo por mantenerse a mi lado impulsando siempre mis proyectos, por su comprensión y cuidados, a ti mi amor por ser buena madre y excelente compañera, te amo.

A mi hermana Rosalba Salas Bañales y sus hijos Edson y Dana por su cariño y respeto, a ti carnala por tu amor y compañía cuando pequeños.

A mi hermano Omar Salas Bañales por que hoy día aún sigo esperando el milagro, a ti carnal por tu respeto y admiración cuando niños.

A mi tío Hector Bañales Alvarez por todas las veces que jugamos juntos cuando niño, por tu ejemplo, disciplina y carácter. A ti tío por el amor que me brindaste por llevar la misma sangre.

A mi Gran Amigo y compadre Rolando Sanchez Moya y su adorable familia Paty, B renda e Iván por seguir creciendo conmigo aunque crezcamos separados, por tu humildad y lealtad, a ti mi amigo, muchas gracias por seguir creyendo en mí.

A mis Tíos, Primos y Sobrinos de mis dos adorables familias (Salas y Bañales) por aceptarme como soy. A ustedes gracias por todo. 


\section{AGRADECIMIENTOS.}

Al Dr. Miguel Ángel García Sánchez por todo su apoyo en esta etapa de mi formación, por guiar en todo momento esta investigación y por sus valiosas aportaciones a la misma, pero sobre todo por mostrarme que se puede ser humilde y sabio a la vez, que dios le de muchos años de vida para que continúe transformando este país con sus brillantes ideas y su singular manera de trans mitirlas, muchas gracias doctor.

Al Dr. Fernando Rojas González por estar siempre al pendiente de este trabajo y por sus valiosas aportaciones en la discusión de los resultados.

Al Dr. Alberto Estrella Gonzáles por su amistad incondicional, sus discusiones y valiosas sugerencias a este trabajo, por sus interesantes charlas que hicieron más amena mi estancia en esta universidad y abrieron mis ojos a nuevos panoramas.

A mi compañera la Dra. Iris Quiroz Segoviano por su camaradería y colaboración para la realización de esta investigación.

A la Dra. Sandra Cipagauta por su amistad y su valiosa ayuda en este trabajo.

A mis compañeros de laboratorio R-101. El Químico Luis Ale jo, el Ingeniero Luis Felipe, el Dr. Armin, el M. en C. Osiris, la I.Q. Ana, las M en C. Obdulia , Reyna y el M. en C. Isaac por su camaradería y ayuda al requerirla.

A los Doctores David y Diana por su amistad.

A mis compañe ros y amigos de CBT No. 2 Isaac Guzmán Valdivia, Chimalhuacán de quienes solo he recibido apoyo en esta etapa de mi formación profesional.

Al jurado

Dr. Antonio Campero Celis

Dr. Rubén Arroyo Murillo

Dra. María Luisa Ojeda Martínez

Dr. Celso Velásque z Ordoñez

Dr. Maximiliano J. Asomoza Palacios

Por sus valiosas aportaciones a esta tesis.

Al Consejo Nacionla de Ciencia y Tecnología (CONACyT) por la beca recibida para realizar este trabajo de investigación.

Y por supuesto a todos aquellos que otra vez creyeron en mí aun conociéndome, GRACIAS. 


\section{Resumen}

Las Porfirinas y Ftalocianinas son moléculas macrocíclicas tetrapirrólicas naturales y sintéticas cuya propiedades ópticas, catalíticas, optoelectrónicas y químicas las hacen muy interesantes y útiles en la moderna tecnología de materiales. En ocasiones, para que estas propiedades puedan ser aprovechadas más eficientemente, se hace necesario soportar tales especies en matrices sólidas diversas como polímeros u óxidos inorgánicos. El método sol-gel es una interesante opción para atrapar estos compuestos en una red inorgánica mediante una ruta suave y de baja temperatura.

El presente trabajo muestra una metodología para la síntesis de materiales híbridos metalorgánicos micro o mesoporosos de mediana resistencia, obtenidos a partir del uso de propóxido de zirconio y titanio con especies macrocíclicas, como tetrasulfoftalocianinas, $\mathrm{MTSPc}(\mathrm{M}=\mathrm{Co}, \mathrm{Cu}, \mathrm{Fe}$, $\mathrm{Ni}, \mathrm{Al}$ ), atrapadas físicamente dentro de las matrices de los óxidos, realizando el análisis del comportamiento de cada una de las especies dentro de los dos óxidos y comparando a manera de referencia lo ocurrido en sistemas similares de $\mathrm{SiO}_{2}$.

Debido a que se ha demostrados que las interacciones entre las especies atrapadas y la matriz de los óxidos provocan alteraciones en las emisiones y absorciones de las moléculas, atribuyendo este hecho a los grupos $-\mathrm{MOH}$ remanentes en la matriz de los óxidos, se exploró la posibilidad de unir de manera covalente a la matriz de los xerogeles de óxido de zirconio y titanio, las especies CoTSPcAPTES, tetraquis-(para-carboxifenil) porfirina $\mathrm{H}_{2} \mathrm{~T}(p-\mathrm{COOH}) \mathrm{PP}-\mathrm{APTES}$ y la Clorofila $a$-APTES con el fin alejar las moléculas de los poros e inhibir en la medida de posible estos efectos.

Por último y con el mismo objetivo se unió de manera covalente la especie $\mathrm{H}_{2} \mathrm{~T}(\mathrm{p}-\mathrm{COOH}) \mathrm{PP}-\mathrm{Fa}$ xerogeles órgano modificados de óxido de zirconio y titanio sustituyendo los grupos hidroxilo superficiales por grupos alquilo o arilo procedentes de alcóxidos órgano-sustituido (OSA), comparando nuevamente lo ocurrido en sistemas similares de $\mathrm{SiO}_{2}$.

La base de la caracterización de los materiales obtenidos es la espectroscopía UV-Vis, ya que las ftalocianinas y porfirinas son compuestos que manifiestan intensas absorciones en la región del UV y Visible y son muy sensibles al ambiente químico en el que se encuentran inmersos. Los xerogeles obtenidos se caracterizan por espectroscopia, UV-Vis, FTIR, NIR, Fluorescencia, Difracción de rayos X de polvos y microscopía de barrido de alta resolución (HRSE) así como análisis de electrones dispersos (EDS). 


\section{Objetivos:}

\section{General:}

Desarrollar la metodología de síntesis de materiales híbridos a base de macrociclos tetrapirrólicos, unidos covalentemente a xerogeles de óxido de zirconio y titanio, obtenido por el método sol-gel. Lo anterior se realiza tendiente a optimar la conservación en sistemas sólidos de las propiedades ópticas, químicas y catalíticas que compuestos como las ftalocianinas, porfirinas o naftalocianinas manifiestan en disolución.

\section{Particulares:}

a) Desarrollar la metodología para sintetizar xerogeles transparentes de óxido de titanio y óxido de zirconio.

b) Elegir, caracterizar y usar una molécula sonda para determinar las condiciones de atrapamiento físico de macrociclos tetrapirrólicos en xerogeles monolíticos translúcidos y resistentes de $\mathrm{ZrO}_{2}$ y $\mathrm{TiO}_{2}$.

c) Extender la metodología a la unión covalente de macrociclos al xerogel de $\mathrm{ZrO}_{2}$ y $\mathrm{TiO}_{2}$.

d) Unir de manera covalente macrociclos tetrapirrolicos a xerogeles de $\mathrm{ZrO}_{2}$ y $\mathrm{TiO}_{2}$ órgano modificados.

e) Caracterizar por técnicas espectroscópicas o químicas los materiales obtenidos, enfatizando el estudio comparativo de las propiedades que los macrociclos exhiben en solución y atrapados en $\mathrm{ZrO}_{2}$ y $\mathrm{TiO}_{2}$.

f) Realizar un análisis comparativo de las propiedades que los macrociclos exhiben al unirse covalentemente a $\mathrm{ZrO}_{2} \quad \mathrm{~T} \mathrm{TiO}_{2}$ con aquellas propiedades desplegadas en xerogeles de sílice previamente reportadas.

g) Realizar un análisis comparativo de las propiedades que los macrociclos exhiben al unirse covalentemente a xerogeles translúcidos órgano modificado de $\mathrm{ZrO}_{2}$ o $\mathrm{TiO}_{2}$ con aquellas propiedades desplegadas en xerogeles de sílice previamente reportadas. 


\section{Índice.}

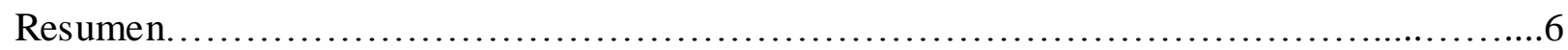

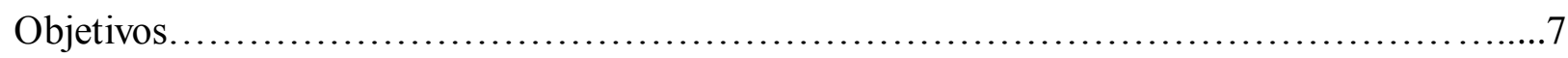

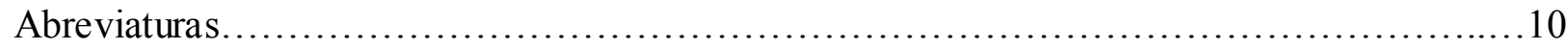

\section{CAPITULO I}

\section{GENERALID ADES}

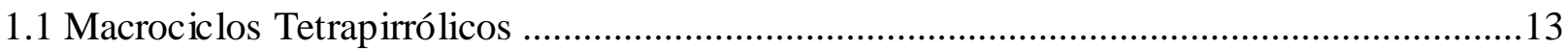

1.2 Propiedades y aplicaciones de macrociclos tetrapirrólicos.....................................................14

1.3 Inserción de ftalocianinas en matrices sólidas....................................................................14

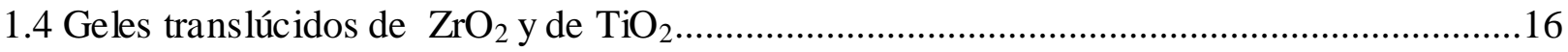

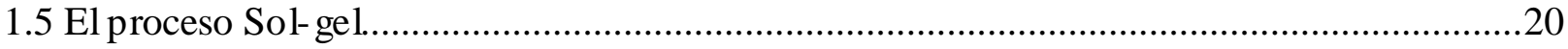

1.6 Encapsulamiento de moléculas diversas en geles................................................................24

1.7 Unión covalente de moléculas diversas en geles.................................................................25

\section{CAPITULO II}

\section{CONDICIONES DE INSERCIÓN DE MTSPc EN XEROGELES DE $\mathrm{ZrO}_{2} \mathrm{Y} \mathrm{TiO}_{2}$.}

2.1 Determinación de las condiciones de síntesis de xerogeles translúcidos de $\mathrm{ZrO}_{2}$ y

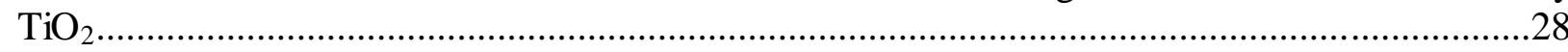

2.2 Caracterización de Xerogeles translúcidos de $\mathrm{ZrO}_{2}$ y TiO

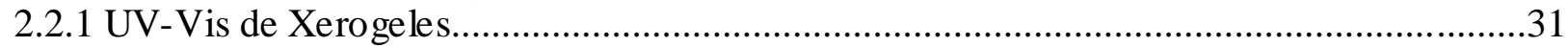

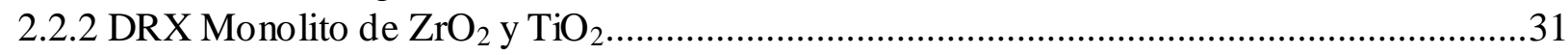

2.2.3 Diámetro de poro y área superficial .................................................................................3

2.2.4 NIR (Rehidratación de xerogeles monolíticos y transparentes de $\mathrm{ZrO}_{2}, \mathrm{TiO}_{2}$ y

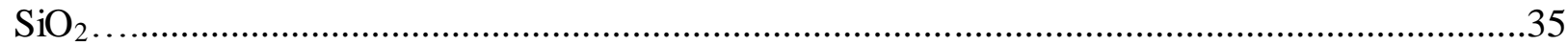

2.3 Síntesis de xerogeles translúcidos de $\mathrm{ZrO}_{2}$ y $\mathrm{TiO}_{2}$ con la especie $(\mathrm{OH}) \mathrm{AlTSPc}$

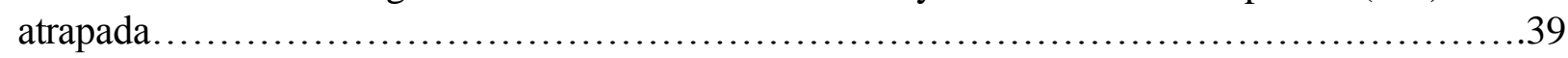
2.4 Caracterización de xerogeles translúcidos de $\mathrm{ZrO}_{2}$ y $\mathrm{TiO}_{2}$ con la especie $(\mathrm{OH}) \mathrm{AlTSP}$

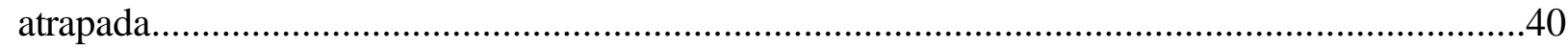

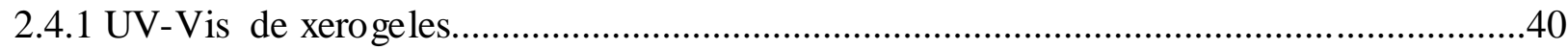

2.4.2 Diámetro de poro y área superficial en los dos óxidos......................................................43

2.4.3 Microscopia de Barrido (SEM), Análisis EDS Y TEM ……………………………........4

2.5 Atrapamiento de especies MTSPc $\left(\mathrm{M}=\mathrm{Co}, \mathrm{Cu}, \mathrm{Fe}, \mathrm{Zn}\right.$ y $\mathrm{Al}$ ) en xerogeles de $\mathrm{ZrO}_{2}$ y

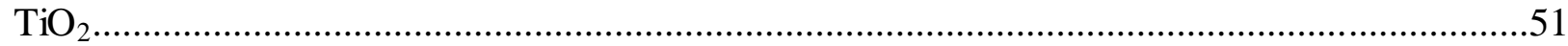

2.6 Caracterización de xerogeles translúcido de $\mathrm{ZrO}_{2} \quad$ y $\mathrm{TiO}_{2}$ con especies (MTSPc)

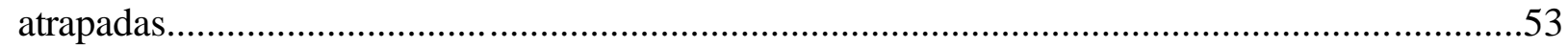

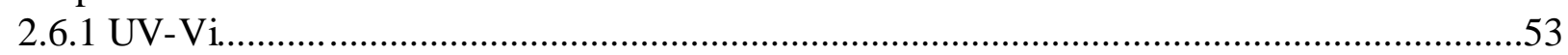

2.6.2 Diámetro de poro y área superficial..................................................................................55

2.6.3 Microscopia de Barrido (SEM) y Análisis EDS y TEM.....................................................60 
CAPITULO III

UNIÓN COVALENTE DE ESPECIES MACROCÍCLICAS EN XEROGELES DE $\mathrm{ZrO}_{2}$ $\mathrm{Y} \mathrm{TiO}_{2}$.

3.1Unión covalente de la especie $\mathrm{H}_{2} \mathrm{~T}(p-\mathrm{COOH}) \mathrm{PP}$ con APTES en $\mathrm{ZrO}_{2}$ y $\mathrm{TiO}_{2} \ldots \ldots \ldots \ldots \ldots \ldots \ldots . . . . .64$

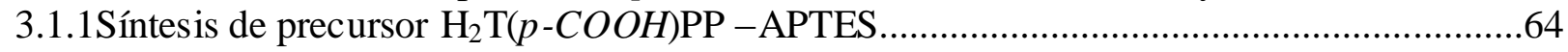

3.2 Síntesis de Xerogeles de $\mathrm{ZrO}_{2} \mathrm{H}_{2} \mathrm{~T}(p$-COOH $)$ PP-APTES y $\mathrm{TiO}_{2} \mathrm{H}_{2} \mathrm{~T}(p-\mathrm{COOH}) \mathrm{PP}$-APTES

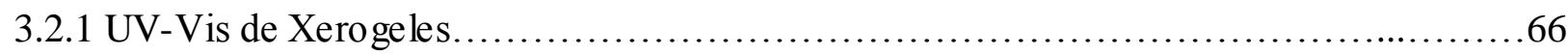

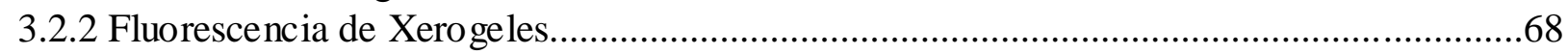

3.2.3 Diámetro de poro y área superficial en los dos óxidos......................................................

3.2.4 Microscopía Electrónica de Barrido (SEM) y Análisis EDS...............................................74

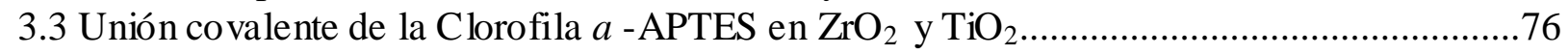

3.3.1 Síntesis de precursor Clorofila $a$-APTES.......................................................................76

3.4 Síntesis de Xerogeles de $\mathrm{ZrO}_{2}$-Clorofila a -APTES y $\mathrm{TiO}_{2}$ - Clorofila $a$-APTES con $\Phi$ -

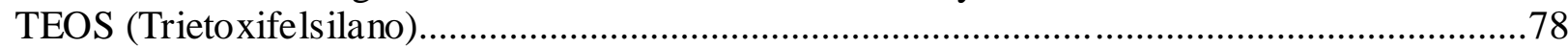

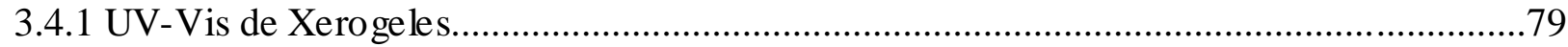

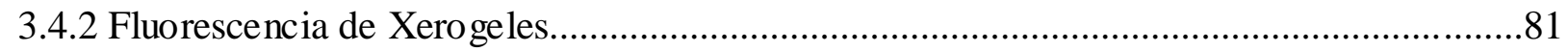

3.4.3 Diámetro de poro y área superficial en los dos óxidos....................................85

3.4.4 Microscopía Electrónica de Barrido (SEM) y Análisis EDS ..............................89

CAPITULO IV

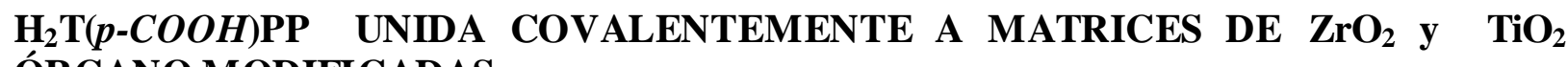
ÓRGANO MODIFICADAS.

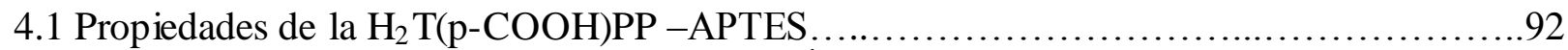

4.2 Síntesis de Xerogeles de $\mathrm{ZrO}_{2}$ y $\mathrm{TiO}_{2}$ Órgano modificados con $\mathrm{H}_{2} \mathrm{~T}(\mathrm{p}-\mathrm{COOH}) \mathrm{PP}-$

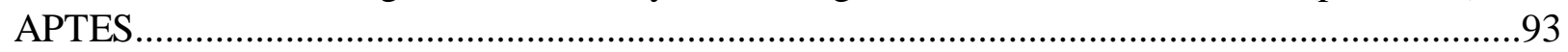

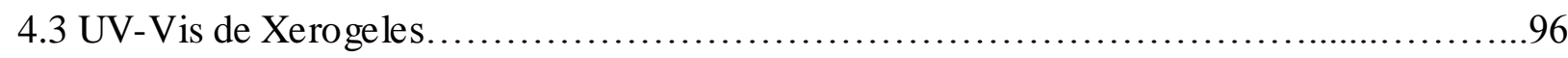

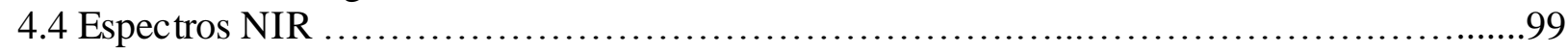

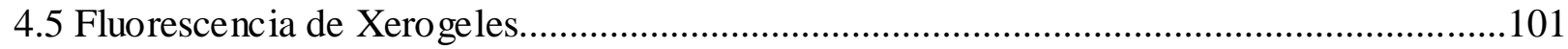

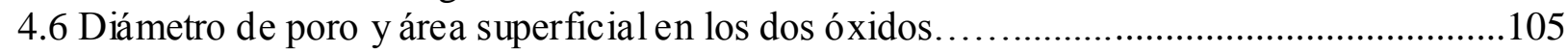

4.7 Microscopía Electrónica de Barrido (SEM) y Análisis EDS ....................................111

4.8 Contraste de los xerogeles con las especies $\mathrm{H}_{2} \mathrm{~T}(p-\mathrm{COOH}) \mathrm{PP}$ unidas a $\mathrm{ZrO}_{2}$ y $\mathrm{TiO}_{2}$ y

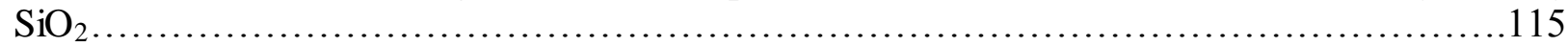

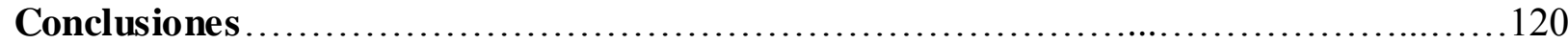

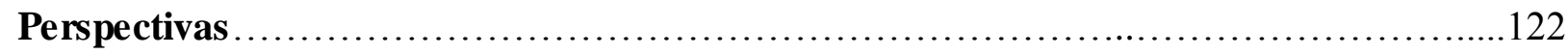

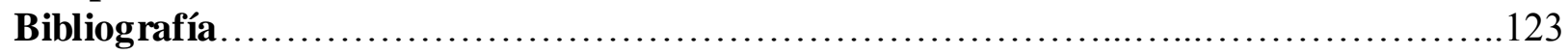




\section{Abreviaturas}

Acac: Acetilacetona.

Aly TMOS = AllyTMOS : Alil-trimetóxisilano, $\mathrm{Si}\left(\mathrm{CH}_{2}-\mathrm{CH}=\mathrm{CH}_{2}\right)\left(\mathrm{OCH}_{3}\right)_{3}$.

AmTEOS: Amil-trietoxilano, $\mathrm{Si}\left(\mathrm{C}_{5} \mathrm{H}_{11}\right)\left(\mathrm{OC}_{2} \mathrm{H}_{5}\right)_{3}$.

AOS: Alcóxidos órgano sustituidos.

APTES : 3-aminopropiltrietóxisilano.

Banda de Soret: Estados excitados de mayor energía traslapados de las porfirinas.

Bandas Q (QI, QII, QIII y QIV). Los dos primeros estados electrónicamente excitados y típicamente degenerados de las porfirinas.

DMF: NN-dimetil formamida

dMeDEOS: Dimetil-dietóxisilano, $\mathrm{Si}\left(\mathrm{CH}_{3}\right)_{2}\left(\mathrm{OC}_{2} \mathrm{H}_{5}\right)_{2}$.

DMF: Dimetilformamida.

DoTEOS : Dodecil-trie tóxisilano, $\mathrm{Si}\left(\mathrm{C}_{12} \mathrm{H}_{25}\right)\left(\mathrm{OC}_{2} \mathrm{H}_{5}\right)_{3}$.

EDS (Por sus siglas en inglés). Espectroscopia de energía dispersiva.

EtTEOS: Etil-trietóxisilano, $\mathrm{Si}\left(\mathrm{C}_{2} \mathrm{H}_{5}\right)_{2}\left(\mathrm{OC}_{2} \mathrm{H}_{5}\right)_{3}$.

DRX: Difracción de rayos X.

Ф-TEOS: Feniltrietóxisilano.

$\mathbf{H}_{2} \mathbf{P}-\mathbf{F}$ : Precursor sintetizado a partir de la especie 5,10,15,20-[tetrakis(p-carboxi)fenilporfirina] y el alcóxido funcionalizado 3-aminopropiltrietóxisilano.

HRSEM (Por sus siglas en inglés): Microscopía Electrónica de Barrido de Alta Resolución. 
$\mathbf{H}_{2} \mathbf{T}(\boldsymbol{p}$-COOH)PP: 5,10,15,20-[tetrakis(p-carboxi)fenilporfirina].

$\lambda_{\text {exc }}$ : Longitud de onda de excitación.

MTSPc: Tetrasulfoftalocianinas metaladas

nm: nanómetros $10^{-9} \mathrm{~m}$

NIR (Por sus siglas en inglés): Infrarrojo Cercano.

Pc: Ftalocianina

Rayos X: Patrón de difracción de polvos.

$\operatorname{Ti}\left(\operatorname{OPr}^{\mathrm{n}}\right)_{4}$ : Propóxido de titanio

TEOS: Tetraetóxisilano.

UV- Visible : Región Ultravioleta y visible del espectro electromagnético.

VyTEOS: Vinil-trie tóxisilano, $\mathrm{Si}\left(\mathrm{CH}=\mathrm{CH}_{2}\right)\left(\mathrm{OC}_{2} \mathrm{H}_{5}\right)_{3}$.

$\left(\mathbf{Z r}\left(\mathbf{O P r}^{\mathrm{n}}\right)_{4}\right)$ : Propóxido de zirconio 


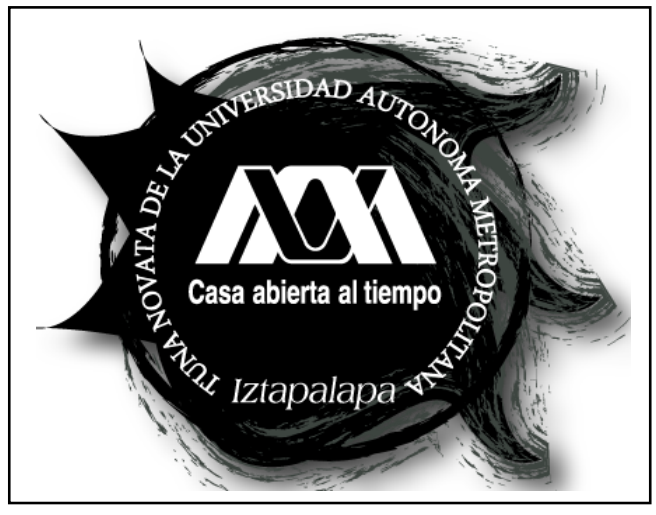

\section{Capítulo I}

\section{Generalidades}

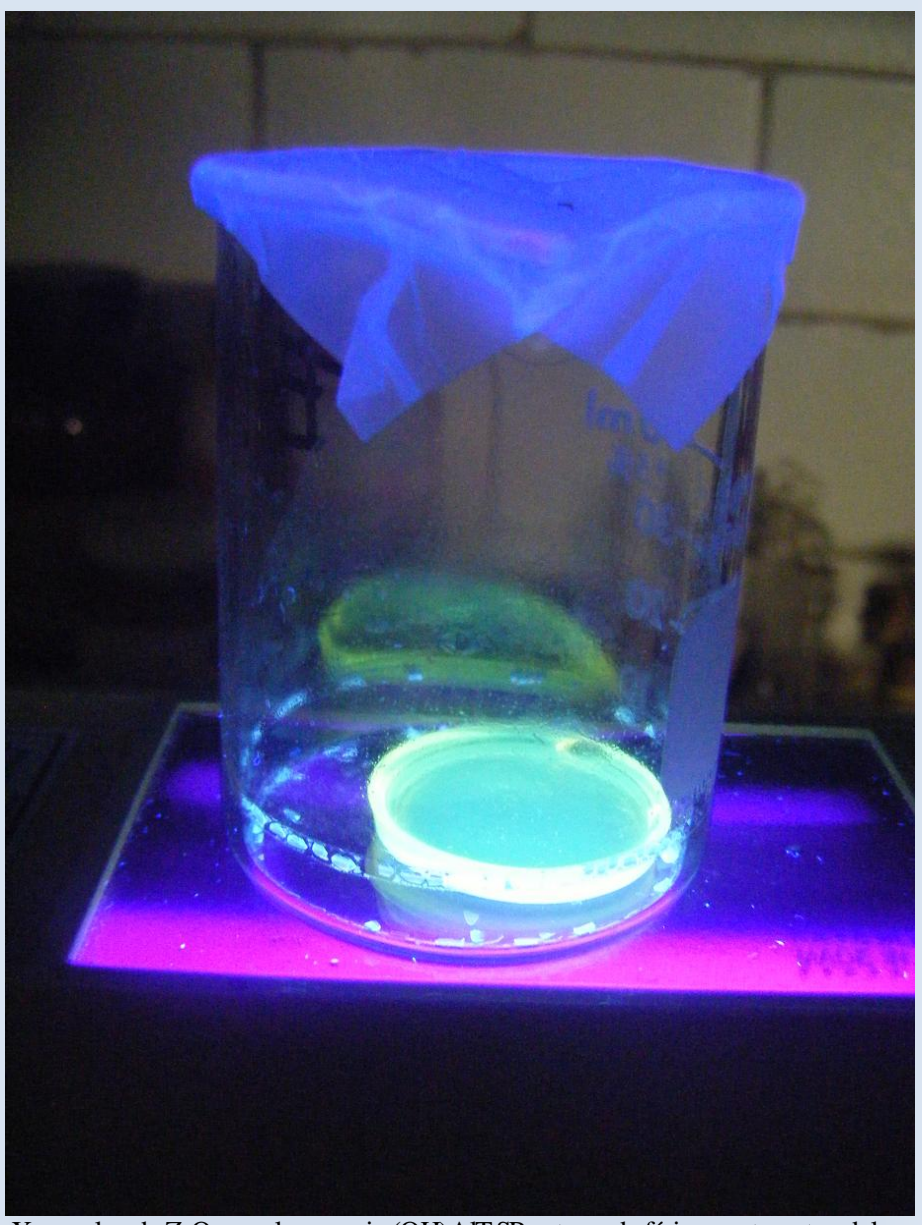

Xerogeles de $\mathrm{ZrO}_{2}$ con la especie $(\mathrm{OH}) \mathrm{AIT} \mathrm{SPc}$ atrapada físicamente antes del trat amient o térmico. 


\subsection{Macrociclos Tetrapirrólicos.}

Los macrociclos tetrapirrólicos (Fig.1.1) son un grupo de moléculas ligantes tetradentadas, planas y con un sistema de electrones $\pi$ conjugados que les confieren importantes propiedades fisicoquímicas. Miembros destacados de este grupo son las porfirinas $\left(\mathrm{H}_{2} \mathrm{P}\right)$, ftalocianinas $\left(\mathrm{H}_{2} \mathrm{Pc}\right)$, naftalocianinas $\left(\mathrm{H}_{2} \mathrm{NPc}\right)$, azoporfirinas $\left(\mathrm{H}_{2} \mathrm{AP}\right)$ y tetrabenzoporfirinas $\left(\mathrm{H}_{2} \mathrm{TBP}\right)$. Las ftalocianinas metálicas son moléculas macrocíclicas que poseen una gran variedad de propiedades debido a su estructura y a la gran estabilidad química que les confiere ésta. La primera ftalocianina fue obtenida por accidente en 1907 por Braun y Tcherniac, pero no se le prestó atención hasta 1927 en que Diesbach y Von der Weid obtuvieron un complejo similar muy estable a altas temperaturas, de color azul y con cobre íntimamente ligado [1-3]. En 1928, un compuesto de color azul oscuro se encontró en los recipientes de hierro que la Scottish Dyes Ltd (Escocia) usaba para la síntesis de ftalamida. En la década de los 30 Linstead [4,5] inició el estudio sistemático de estos compuestos a los que llamó ftalocianina, según las raíces griegas nafta (aceite de roca) y cianuro (azul oscuro) y descubrió que su estructura consta de cuatro unidades de isoindol en un sistema altamente conjugado.

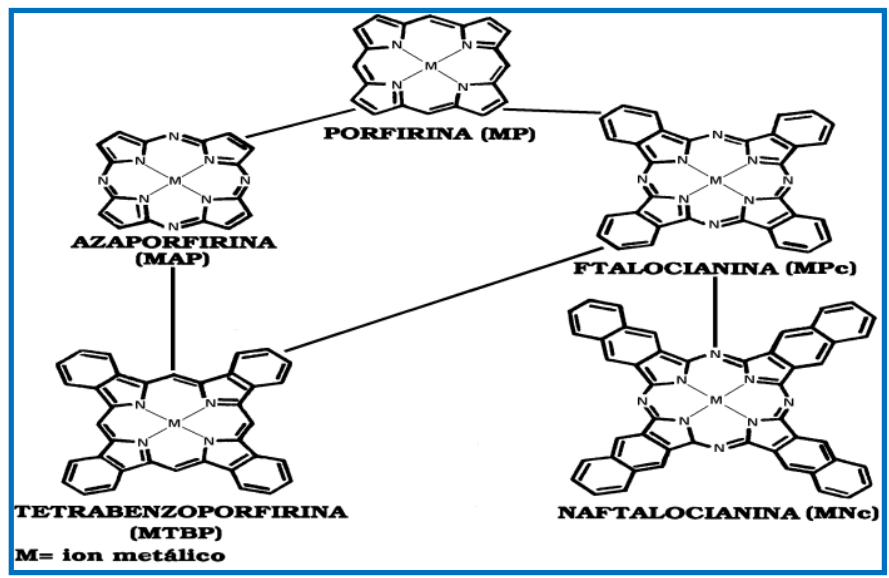

Figura 1.1 Estructura y acrónimos de los principales macrociclos tetrapirrólicos [6]. 


\subsection{Propiedades y aplicaciones de macrociclos tetrapirrólicos.}

En primera instancia, las ftalocianinas sirvieron como pigmentos estables y resistentes (el azul ftalo es ftalocianina de cobre), posteriormente fueron los primeros semiconductores orgánicos [7] y más tarde se les descubrieron propiedades de luminiscencia [8]. Debido a que la estructura de las ftalocianinas es muy parecida a la de las porfirinas, que además son más sensibles a la unión axial [9] (complejos $\mu$-oxo), oligomerización y solvatación, se les utiliza como modelos para estudiar procesos como el transporte de $\mathrm{O}_{2}$ en la hemoglobina (reacciones redox), de otros gases como $\mathrm{NO}, \mathrm{NO}_{2}, \mathrm{CO}, \mathrm{CO}_{2}$, etc., catálisis enzimática, fotosíntesis y metabolismo. Weber y Busch $[10,11]$ informaron que la ftalocianinas tetrasulfonadas de hierro (II), $\mathrm{Fe}(\mathrm{II}) \mathrm{TSP}$ disueltas en agua y ácido sulfúrico fumante, pueden acarrear oxígeno fijándolo a su estructura. Así mismo, la ftalocianina tetrasulfonada de cobalto(II), CoTSPc, al ser soportada en un electrodo de grafito en medio alcalino, puede reducir al oxigeno al aplicársele voltaje [12]. Las ftalocianinas son estructuras planas que pueden formar compuestos unidimensionales, por lo cual son candidatos muy atractivos para ser donadores en superconducción y forman parte de una serie de compuestos que por sus notables características se nombraron metales moleculares [13].

\subsection{Inserción de ftalocianinas en matrices sólidas.}

Las ftalocianinas, tetrafenilporfirinas y azoporfirinas libres, sustituidas y poliméricas (de Fe (II)) y Co(II)), atrapadas en carbón activado, sirven para reducir el oxígeno en celdas de combustible [14] o para oxidar tioles en el tratamiento del petróleo. Las ftalocianinas incorporadas por impregnación en $\gamma-\mathrm{Al}_{2} \mathrm{O}_{3}$ y $\mathrm{SiO}_{2}$ pueden servir como catalizadores de la oxidación de tioles, quimisorción de oxígeno y adsorción de amoniaco. También se han realizado estudios de estos macrociclos incorporados en sólidos inorgánicos como $\mathrm{CdS}$ y $\mathrm{ZnO}$. Una ruta interesante es la síntesis de ftalocianinas metálicas a partir de ftalonitrilo y en presencia de zeolitas (faujasita) que proporcionan el ión central. La investigación del atrapamiento de ftalocianinas libres o metálicas en geles de óxidos metálicos, y los problemas que implica, ha sido poca e inconstante; por ejemplo, se ha intentado inhibir la agregación de la 
tetrasulfoftalocianina de cobre atrapada en aluminosilicato mediante el control del $\mathrm{pH}$ de la mezcla gelificante, o atrapadas en xerogelde sílice.

En 1998 M.A García y A. Campero [15] reportan un estudio sobre el encapsulamiento de tetrasulfoftalocianinas metalicas (MTSPc) en geles monolíticos transparentes por el método solgel con el objeto de aprovechar sus propiedades ópticas para el diseño de sensores. Posteriormente, en el año 2000 estos mismos autores en su artículo [16] "Aggregation properties of metallic tetrasulfophthalocyanines embedded in sol-gel silica" muestran las condiciones para el encapsulamiento de varias tetrasulfoftalocianinas metálicas en óxidos de silicio por el método sol-gel.

El punto clave en estos dos trabajos fue el uso de la hidroxi-tetrasulfoftalocianina de aluminio, $(O H) A l T S P c$ (Figura 1.2) como una sonda para determinar las condiciones requeridas para la síntesis de xerogeles monolíticos y transparentes de sílice por el método sol-gel. Esta misma especie ha sido usada recientemente en nuestra investigación para determinar las condiciones de inserción de moléculas macrocíclicas en matrices de sílice órgano sustituidas [16].

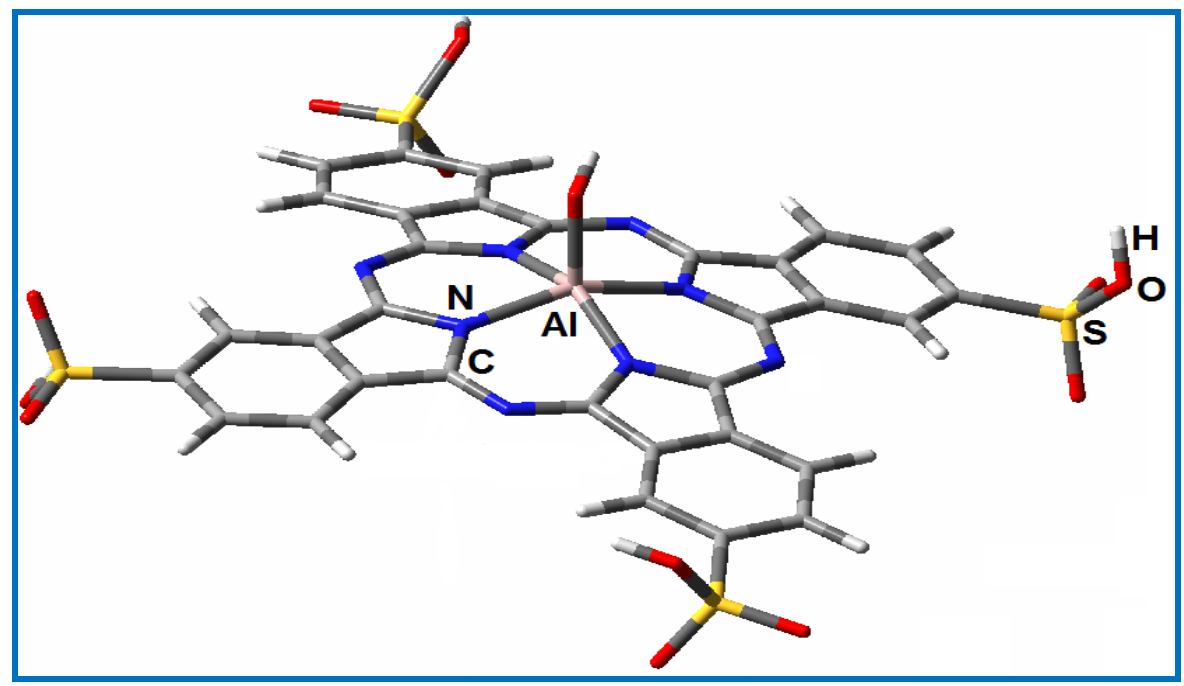

Figura 1.2 Estructura de la $\mu$-hidro xio-tetrasulfoftalocianina de alu min io, $(\mathrm{OH}) \mathrm{AITSPc}$, usada como mo lécula sonda atrapada en xerogeles de $\mathrm{ZrO}_{2}$ y $\mathrm{TiO}_{2}$.

La especie (OH)AITSPc se eligió como sonda debido a sus notables propiedades espectroscópicas y a su baja tendencia a formar agregados. A diferencia de otras 
tetrasulfoftalocianinas, la de aluminio, presenta una baja tendencia a la agregación debido a la presencia del grupo hidroxilo unido al aluminio de forma axial, lo cual inhibe la posibilidad de acercamiento e interacción en el plano del macrociclo. Aunque en alta concentración puede ocurrir la formación de dímeros cofaciales.

En disolución acuosa de la especie $(\mathrm{OH})$ AITSPc exhibe una fuerte emisión fluorescente roja al ser irradiada con luz UV $\left(\lambda_{\mathrm{c}}=370 \mathrm{~nm}\right)$, la cual, al igual que las principales bandas en el espectro UV-Vis, son detectables a concentraciones muy bajas y resultan muy sensibles a los cambios de polaridad del medio ambiente químico circundante. Finalmente, la especie (OH)AlTSPc se eligió como sonda en este tipo de trabajos debido a su notable estabilidad química y térmica, ya que al igual que la mayoría de las ftalocianinas, solo se degrada en condiciones extremas de acidez $\left(\mathrm{H}_{2} \mathrm{SO}_{4} 16 \mathrm{M}\right)$ o térmicas (por arriba de $\operatorname{los} 450{ }^{\circ} \mathrm{C}$ ). Como García-Sánchez et al. $[15,16]$ informaron puede ocurrir la formación de dímeros vía puente oxo (TSPc-Al-O-AITSPc) por la acción de la piridina (py) sobre los grupos hidroxilo de la especie $(\mathrm{OH})$ AlTSPc atrapada en xerogeles de sílice. Sin embargo, con la adición de dimetilformamida (DMF) como agente inhibidor de la agregación, logra conservar la especie $(\mathrm{OH}) \mathrm{AlTSPc}$ y otras similares, en forma monomérica $[15,16]$

\subsection{Geles translúcidos de $\mathrm{ZrO}_{2}$ y de $\mathrm{TiO}_{2}$.}

\section{a) Caracte rísticas, propiedades y aplicaciones del óxido de zirconio}

El óxido de zirconio $\left(\mathrm{ZrO}_{2}\right)$ es un material que presenta gran dureza y alto punto de fusión. En estado natural, tiene una estructura cristalina monoclínica (Figura 1.3 a) que se conserva desde temperatura ambiente hasta $1150^{\circ} \mathrm{C}$, conocida como $\left(\mathrm{ZrO}_{2}\right)$ no estabilizado. A esta temperatura se presenta una transformación a una estructura tetragonal. Por encima de $2370^{\circ} \mathrm{C}$, el óxido presenta una estructura cristalina cúbica estable has ta su fusión que ocurre a $2650^{\circ} \mathrm{C}$; el óxido de zirconio también puede presentar una estructura ortorrómbica a altas presiones. Estas tres formas cristalinas del $\mathrm{ZrO}_{2}$ mantienen una estrecha relación con la estructura fluorita. Debido a sus propiedades físicas y químicas, entre las que se destacan la resistencia química, refractancia y baja absorción de neutrones, el óxido de zirconio se utiliza como para recubrimientos en motores de reactores nucleares, ya que resiste las elevadas temperaturas que 
se producen en su interior, y para recubrir superficies que trabajen en medios ácidos o alcalinos. Siendo el $\mathrm{ZrO}_{2}$ un material biocompatible, desde hace varios años se viene utilizando para fabricar prótesis de rodilla y cadera por su alta resistencia al desgaste. Dada la conductividad iónica que puede presentar, se utiliza en sensores de oxígeno y como electrodo en pilas de combustión. Debido a la importancia tecnológica del $\mathrm{ZrO}_{2}$ y a los requerimientos de nuevas tecnologías, se pretende desarrollar métodos alternativos de síntesis de $\mathrm{ZrO}_{2}$ con tamaño y la morfología de partícula controlados. Los métodos que más utilizados son: el hidrotérmico a partir de soles de cloruros metálicos y urea, soluciones acuosas de cloruro de zirconilo a diferentes concentraciones y condiciones hidrotérmicas, o sometiendo la solución a microondas, síntesis a partir de alcóxidos, síntesis en fase gaseosa, síntesis con kerosén caliente y peróxidos y aquel en el que el agua se reemplaza por acetona antes del secado, entre otros [17].

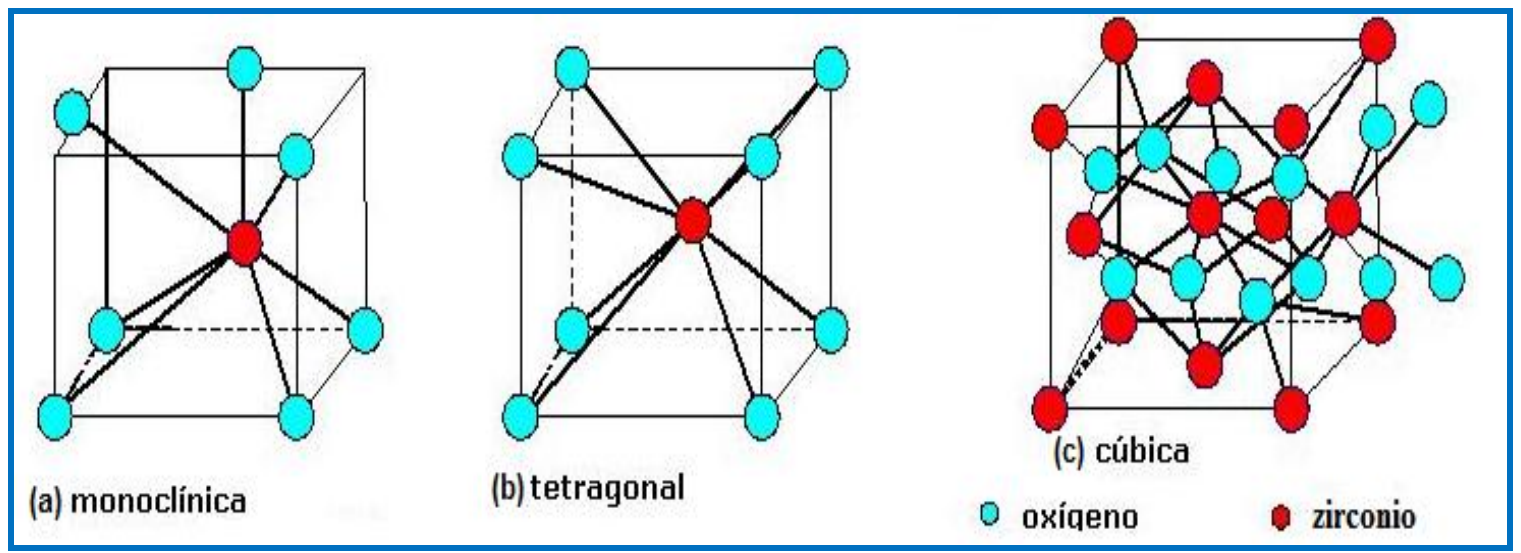

Figura 1.3 Representación gráfica de los polimorfis mos del óxido de zirconio, (a) fase monoclín ica, (b) fase tetragonal y (c) fase cúbica [18].

Las películas de óxido de zirconio $\left(\mathrm{ZrO}_{2}\right)$ tienen un gran interés en aplicaciones, como barreras de protección [19], las que se basan en la interesante combinación de propiedades mecánicas, químicas y físicas que exhibe el óxido de zirconio. Su elevado coeficiente de expansión térmico $\left(10^{-5} \mathrm{~K}^{-1}\right)$, próximo al de muchos materiales metálicos, junto con su conductividad térmica (2.09 $\mathrm{W} \mathrm{m}^{-1} \mathrm{~s} \mathrm{~K}$ ) que es dos órdenes de magnitud inferior a la de los metales, la convierte en una excelente barrera de protección térmica. También se pueden desarrollar películas delgadas de $\mathrm{ZrO}_{2}$ anisotrópicas de rugosidad nanométrica que pueden ser usadas como partes activas en sensores. Existen diversas técnicas para desarrollar películas delgadas de $\mathrm{ZrO}_{2}$, entre ellas vía 
sol-gel, evaporación por haz de electrones, deposición química de vapor (CVD) [20], entre otras. Las películas delgadas de óxido de zirconio sintetizadas por sol-gel han sido utilizadas para soportar nanopartículas de plata y monitorear su crecimiento al someterse a tratamiento térmico [21].

\section{b) Características, propiedades y aplicaciones del óxido de titanio.}

El óxido de titanio $\left(\mathrm{TiO}_{2}\right)$ es un material, útil por sus aplicaciones en catálisis, como material de recubrimiento y como sensor químico, además tiene aplicaciones en fotocatálisis, en celdas solares y filtros ópticos de películas delgadas, también presenta buena resistencia mecánica y estabilidad en ambientes corrosivos. De las formas cristalinas en que se puede encontrar al $\mathrm{TiO}_{2}$, la más estable es la rutilo, que presenta una celda unitaria tetragonal con los átomos de Ti ocupando las posiciones de las esquinas y la central (Figura 1.4). Cada átomo de titanio está coordinado con seis átomos de oxígeno vecinos y en los vértices de un octaedro distorsionado [22]. El óxido de titanio ha sido sintetizado por diferentes métodos como: fusión de flama de Verneuil, oxidación del $\mathrm{TiCl}_{4}$ en fase vapor y sol-gel [23]. El óxido de titanio es usado a escala industrial como adsorbente y pigmento, así mismo, se ha estudiado en reacciones de descomposición foto catalítica de contaminantes en corrientes liquidas y también gaseosas [24].

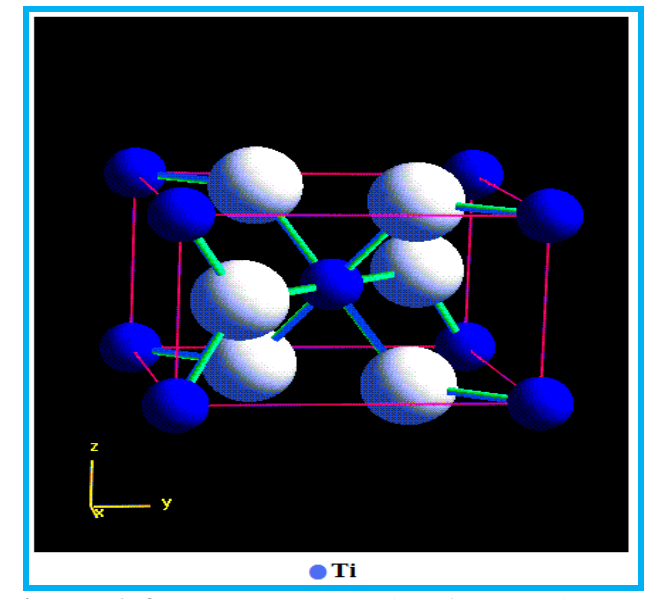

Figura 1.4 Estructura del $\mathrm{TiO}_{2}$ fase Rutilo [25]

La síntesis de películas delgadas y transparentes de $\mathrm{TiO}_{2}$ ha sido intensamente estudiada debido a sus potenciales aplicaciones, por ejemplo, en la depuración foto catalítica del agua y aire 
[26]. Para mejorar sus propiedades mecánicas y catalíticas, las películas del óxido de titanio se han impregnado con metales como $\mathrm{Sn}, \mathrm{Cu}$ [27] y Ag, vía sol-gel, demostrándose que se presentan una mayor actividad fotocatalítica. Estas películas han sido modificadas con $\mathrm{SiO}_{2}$ y polidimetilsiloxano (PDMS) para degradar estereato de metilo con buenos resultados. En lo referente a la síntesis de los xerogeles monolíticos transparentes de $\mathrm{TiO}_{2}$ por el método sol-gel hay poca información, porque no es fácil y común su obtención, la cual presenta dos problemas bien conocidos: uno de ellos es la rápida hidrólisis de los precursores de titanio y el otro la desestructuración del alcogel durante el procesos de envejecimiento y secado, este problema puede ser resuelto mediante la adición de agentes quelantes con la finalidad de reducir la velocidad de reacción de los alcóxidos de titanio usados como precursores. Algunos autores han logrado controlar la fase de hidrólisis proporcionando lentamente el agua necesaria para la hidrólisis, a partir de la esterificación del ácido acético con alcohol butílico [28]. Otro grupo de investigadores [29] han reportado la síntesis de películas delgadas de $\mathrm{TiO}_{2}$ transparentes por el método sol-gel, utilizando como precursores tetra-isopropóxido de titanio $\left(\operatorname{Ti}\left(\mathrm{OPr}^{\mathrm{i}}\right)_{4}\right)$, etanol, agua, ácido clorhídrico y polietilenglicol (PEG) con objeto de mejorar la resistencia y estabilidad térmica de las películas formadas y estudiar la fotoxidacion de yoduro de metilo. L. El Mir [30] reporta la síntesis de monolitos transparentes de $\mathrm{TiO}_{2}$ vía sol-gel y dopados con praseodimio para aplicaciones en luminiscencia, utilizando como precursores Isopropóxido de titanio, ácido acético, ácido clorhídrico, alcohol butílico y metanol. Controlando la hidrólisis mediante la esterificación lenta del ácido acético con alcohol isobutilico, es posible la formación de xerogeles monolíticos (Fig. 1.5).

En este trabajo se utilizan como precursores isopropóxido de titanio, tetraetoxisilano, isopropanol, ácido clorhídrico y acetilacetona ( $a c a c$ ) para controlar la reactividad del isopropóxido de titanio [31]. 


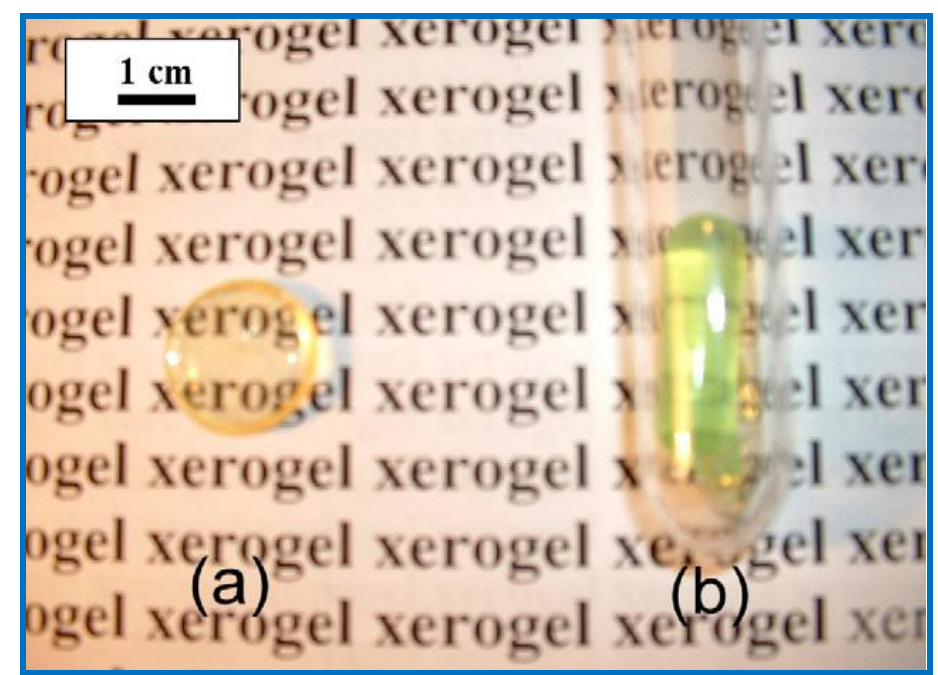

Figura1.5 Xerogeles monolíticos transparentes de $\mathrm{TiO}_{2}$ a) Sin dopar b) Dopados con Praseodimio [30]

Cabe mencionar que las técnicas descritas hasta aquí, para la síntesis de películas y monolitos translúcidos utilizan catálisis ácida, lo que no es conveniente en nuestro caso ya que las porfirinas son sensibles al ambiente químico que las rodea, por tanto la técnica de síntesis de nuestros monolitos tendría que ser distinta y se ha desarrollado.

\subsection{El proceso Sol-gel.}

El proceso sol-gel es un método de preparación de diversos tipos de materiales (cerámicos, semiconductores, vidrios, entre otros). Por med io de este proceso pueden producirse a bajas temperaturas, óxidos inorgánicos homogéneos con propiedades deseables de resistencia, transparencia óptica, durabilidad química, porosidad diseñada y resistencia térmica, en contraste con las elevadas temperaturas de fusión requeridas en la producción de vidrios inorgánicos convencionales. Muchas aplicaciones de estos materiales incluyen, películas protectoras y porosas, capas ópticas, capas dieléctricas y electrónicas, superconductores, semiconductores, refuerzo de fibras, biomateriales y catalizadores. Por este método, se pueden obtener nuevos materiales que por otros métodos de fabricación son muy difíciles de lograr, como por ejemplo, óxidos mixtos $\left(\mathrm{SiO}_{2}-\mathrm{TiO}_{2}, \mathrm{TiO}_{2}-\mathrm{ZrO}_{2}\right.$, etc. $)$; además de poder introducir impurezas con iones de cualquier elemento de la tabla periódica, moléculas inorgánicas complejas, orgánicas, bioquímicas e incluso células y bacterias [32-35]. 
Los precursores empleados en el proceso sol-gel son de dos tipos:

a) Compuestos inorgánicos en soluciones acuosas.

b) Compuestos órgano metálicos del tipo de los alcóxidos metálicos (Tabla 1.1)

\begin{tabular}{|c|c|}
\hline Nombre & Formula \\
\hline Tetraetóxisilano (TEOS) & $\mathbf{S i}\left(\mathbf{O C}_{2} \mathbf{H}_{5}\right)_{4}$ \\
\hline Trimetóxiborato & $\mathbf{B}\left(\mathbf{O C H}_{3}\right)_{3}$ \\
\hline Trietóxido de Aluminio & $\mathbf{A l}\left(\mathbf{O C}_{4} \mathbf{H}_{9}\right)_{3}$ \\
\hline Tetraisopropóxido de titanio & $\mathbf{T i}\left(\mathbf{O C}_{5} \mathbf{H}_{7}\right)_{4}$ \\
\hline Tetraisopropóxido de zirconio & $\mathbf{Z r}\left(\mathbf{O C}_{5} \mathbf{H}_{7}\right)_{4}$ \\
\hline
\end{tabular}

Tabla 1.1 Alcóxidos más importantes en el proceso Sol-Gel.

Al inicio del proceso Sol-Gel ocurren dos importantes procesos:

1) Hidrólisis: En esta etapa los precursores, comúnmente alcóxidos metálicos, $M(O R) n$, sufren un ataque nucleofílico del agua, con la consecuente sustitución de grupos alcoxilo, -OR, por grupos hidróxido, -OH. La hidrólisis ocurre desde el momento en que el alcóxido y el agua son mezclados, la reacción general se puede escribir:

$$
\mathrm{M}(\mathrm{OR})_{\mathrm{n}}+\mathrm{H}_{2} \mathrm{O} \longrightarrow \mathrm{OH}-\mathrm{M}(\mathrm{OR})_{\mathrm{n}-1}+\mathrm{ROH}
$$

donde $\mathrm{M}=\mathrm{Si}$, $\mathrm{Al}$, Ti o $\mathrm{Zr}$, etc.

$\mathrm{R}=$ un grupo alquilo $\mathrm{o}$ arilo.

2) Condensación: Durante la reacción de condensación los grupos intermediarios formados en la reacción de hidrólisis reaccionan entre sí, para generar redes poliméricas basadas en el establecimiento de enlaces metaloxano. $-M-O-M$-. Las dos alternativas para la formación de dichos enlaces proceden vía liberación de agua (oxolación) o de alcohol (alcoxolación), de acuerdo con las siguientes reacciones: 
$-\mathrm{M}-\mathrm{OH}+-\mathrm{M}-\mathrm{OH}$

(oxolación)

$-\mathrm{M}-\mathrm{OR}+-\mathrm{M}-\mathrm{OH}$

(alcoxolación)
$-\mathrm{M}-\mathrm{O}-\mathrm{M}-\quad+\mathrm{HOH}$

- $\mathrm{M}-\mathrm{O}-\mathrm{M}+\mathrm{ROH}$

El establecimiento de más enlaces $\mathrm{O}-\mathrm{M}-\mathrm{O}$ genera el surgimiento de un polímero tridimensional y que aumenta en rigidez y tamaño al progresar la policondensación. En primera instancia, cuando tal matriz polimérica alcanza un tamaño micrométrico se dice que ha formado un sol. Sin embargo, dado que las reacciones de hidrólisis y condensación prosiguen, las partículas del sol o bien, fragmentos separados de polímero se unen, aumentando continuamente el tamaño de las partículas promedio, su peso molecular, su rigidez y por tanto, la viscosidad de la mezcla gelificante. Cuando la matriz polimérica se vuelve demasiado rígida como para permitir su crecimiento ulterior ocurre la gelificación, redundando en la formación de una red tridimensional intrincada y compleja en la que la mezcla líquida remanente queda atrapada en las cavidades de tal matriz. Así se forma un gel a partir de cadenas poliméricas cuyo monómero es un óxido, que a su vez conducirá a la formación de un sólido.

Una de las principales complicaciones que se presentan al utilizar alcóxidos para generar monolitos transparentes y resistentes vía sol- gel es que suelen ser muy reactivos, lo cual hace muy complicado su manejo, por ejemplo, para los fines que en lo particular pretendemos. El modelo de cargas parciales (MCP) permite hacer comparaciones aproximadas de la reactividad de especies, describir reacciones químicas involucradas en el proceso sol-gel y resulta ser una guía útil para describir reacciones de polimerización inorgánica. Para un análisis cuantitativo del modelo se considera que en las reacciones de sustitución nucleofilica $\left(\mathrm{S}_{\mathrm{N}}\right)$ el sustituyente con la carga parcial negativa más grande $\delta(-)$ es el nucleófilo, y el sustituyente con la carga parcial positiva más grande, $\delta(+)$ es el electrólifo. Las reacciones nucleofilicas proceden de tal forma que el nucleófilo más fuerte se une al, o los núcleos, más deficientes en electrones (con $\delta(+)$ mayor) y el producto resultante presenta cargas parciales menos grandes. El proceso concluye cuando el nucleófilo se vuelve deficiente en electrones o bien con carga parcial igual a cero, $\delta \geq$ $\mathrm{O}[38]$. 
Los alcóxidos de los metales de transición son mucho más reactivos que los de silicio y reaccionan más violentamente y rápidamente con el agua. Así por ejemplo, la carga parcial calculada para los etóxidos de varios alcóxidos metálicos permite prever su reactividad y compararla con aquella observada para el tetraetóxido de silicio (TEOS). Para disminuir la reactividad de muchos alcóxidos, se recurre a diferentes métodos de atenuación de la misma, como intercambio de grupo alcóxido, intercambio de solvente, uso de agentes acomplejantes y el uso de diversos aditivos. Por ejemplo, las cargas parciales calculadas para el silicio y los grupos metóxi del TMOS permiten deducir que sustancias como la formamida reducen la reactividad del núcleo metálico [39]. Debido a que los metales de transición son más electropositivos que el silicio, en sus respectivos alcóxidos las cargas parciales suelen ser mayores que las del TEOS (Tabla 1.2). En consecuencia la hidrólisis de alcóxidos de metales de transición ocurre más fácil y rápidamente que la de los alcóxidos de silicio [40]. Por ejemplo, las constantes de velocidad de hidrólisis y de condensación del Ti(OEt $)_{4}$ a pH 7 son $10^{-3} \mathrm{M}^{-1} \mathrm{~s}^{-1} \mathrm{y}$ $30 \mathrm{M}^{-1} \mathrm{~s}^{-1}$, respectivamente, mientras que para el TEOS valen $5 \times 10^{-9} \mathrm{M}^{-1} \mathrm{~s}^{-1}$ y $10^{-4} \mathrm{M}^{-1} \mathrm{~s}^{-1}$ respectivamente, es decir alrededor de 6 órdenes de magnitud [41]. Por eso el Ti(OEt) $)_{4}$, como muchos alcóxidos de metales de transición es inestables en presencia de agua [42-43] y reacciona rápida y exotérmicamente con ella, lo que obliga a manipularlo en ambiente controlado y libre de humedad. Esto se debe a que la mayoría de los metales de transición pueden aumentar su número de coordinación a diferencia del silicio que lo mantiene en 4. Es por ello que este tipo de alcóxidos deben usarse con cuidado y de ser necesario atenuar su reactividad.

\begin{tabular}{|c|c|c|c|}
\hline Alcóxido & $\delta M$ & Alcóxido & $\delta M$ \\
\hline $\mathrm{Zr}(\mathrm{OEt})_{4}$ & +0.65 & $\mathrm{VO}(\mathrm{OEt})_{4}$ & +0.46 \\
\hline $\mathrm{Ti}(\mathrm{OEt})_{4}$ & +0.63 & WOEt $)_{4}$ & +0.43 \\
\hline $\mathrm{Nb}(\mathrm{OEt})_{4}$ & +0.53 & $\mathrm{Si}(\mathrm{OEt})_{4}$ & +0.32 \\
\hline $\mathrm{Ta}(\mathrm{OEt})_{4}$ & +0.49 & & \\
\hline
\end{tabular}

Tabla 1.2 Cargas parciales sobre los núcleos metálicos de algunos etóxidos. [44] 
Todo lo antes expuesto lleva a considerar la combinación de las interesantes y útiles propiedades fisicoquímicas de los macrociclos tetrapirrólicos con las también valiosas propiedades de los sustratos inorgánicos obtenibles vía proceso sol-gel. Como se ha mencionado, García-Sánchez et al. [15, 16] han explorado la inclusión de macrociclos tetrapirrólicos en xerogeles de sílice, pero sus resultados no descartan la posibilidad de aplicar la metodología a muy diversas especies químicas, no solo en matrices de sílice, sino de otros óxidos. De la misma forma, los mismos autores han planteado alternativas tendientes a optimizar las propiedades de tales macrociclos vía la incorporación de alcóxidos funcionalizados ú organosustituidos [45]. Por todo lo anterior, en la presente investigación se analiza la alternativa de sintetizar nuevos materiales a base de macrociclos tetrapirrólicos atrapados física o químicamente en los poros de xerogel de óxido de zirconio y óxido de titanio normal u organo-modificado con alcóxidos de silicio, por el método sol-gel.

\subsection{Encapsulamiento de moléculas diversas en geles.}

El método sol-gel ha permitido atrapar diversas moléculas con importantes propiedades con el objeto de obtener materiales mixtos con propiedades especiales. Estas moléculas generalmente se adicionan desde el inicio o cuando la mezcla gelificante se encuentra en la etapa de sol. La influencia de la proximidad de las paredes de los poros sobre las propiedades del material mixto es la principal interferencia a considerar, ya que las moléculas disueltas en el líquido contenido en el interior de los poros pueden interaccionar fuertemente con los grupos de las paredes del sólido. Estas interacciones incluyen las frecuentes colisiones, efectos de la región contraída y adhesiones vía interacciones electrostáticas, covalentes o puente de hidrógeno. Además, eldisolvente mismo puede ser perturbado por las paredes del poro y las moléculas más cercanas a las paredes pueden encontrarse más ordenadas. Si el poro se seca parcialmente, la molécula puede encontrarse en fase gaseosa, o adherida a las paredes y si la molécula está en la región constreñida del poro, se encontrará rodeada de un ambiente más rígido o bien auténticamente atrapada en fase sólida. El método sol-gel ha permitido atrapar especies químicas diversas que van desde iones de metales, no metales, compuestos orgánicos, metalorgánicos, proteínas y enzimas [46], células vivas y anticuerpos en matrices sólidas amorfas de óxidos metálicos, lo cual no es posible de lograr por difusión térmica o por los métodos 
tradicionales de impregnación que producen sistemas poco homogéneos y con baja concentración de especie atrapada. El éxito del método sol- gel se debe a que parte de precursores, generalmente metal -orgánicos, como los alcóxidos, cuya hidrólisis y condensación inicia en fase líquida y transcurre generalmente a baja temperatura, lo que ofrece ventajas como:

- Libre difusión del sustrato o nutrientes al sitio activo o molécula atrapada y fácil liberación de productos o desechos a través de la matriz porosa.

- Cuando no se establecen enlaces covalentes entre molécula atrapada y la matriz del gel se evitan modificaciones estructurales que alteran sus propiedades fisicoquímicas.

\subsection{Unión covalente de moléculas diversas en geles.}

Es conocido que las propiedades de los macrociclos como la absorción y emisión, entre otras, se ven afectadas de manera significativa al ser atrapadas en redes de diferentes óxidos, estas alteraciones son atribuidos a las interacciones con los grupos - MOH de la matriz del gel, la cuales son responsable de la polaridad dentro de los poros de los geles. Con objeto de disminuir las interacciones con la matriz se ha propuesto: separar los macrociclos de las paredes de los poros mediante enlaces creados por la unión covalente de estos, con alcoxidos funcionalizados (APTE, IPTES, NAEPTMES etc.). Con base en las relaciones $\mathrm{R}=\mathrm{n}_{\mathrm{H} 2 \mathrm{O}} / \mathrm{n}_{\mathrm{TEOS}}=$ 19.6 encontradas por García Sánchez et al $[15,16]$ para generar monolitos transparentes y translúcidos de $\mathrm{SiO}_{2}$ de la Luz Tapia Tlapaya [47], demostró que es posible la unión de la especie 5,10,15,20-tetra- (p-hidroxi) fenilporfirina, $\quad\left(\mathrm{H}_{2} \mathrm{~T} \quad(p-\mathrm{OH}) \quad \mathrm{PP}\right) \quad$ con 3 isocianatopropiltrietóxisilano, (IPTES) y las paredes de los poros, este último actúa como puente manteniendo alejada la molécula de las paredes, permitiendo que la molécula muestre algunas propiedades que presenta en solución. Más tarde R.I.Y. Quiroz-Segoviano muestra la unión de otra porfirina [48], la Tetrakis para carboxifenilporfirina de coblato , CoT (p - COOH) PP unida mediante 3-aminopropiltrietóxisilano, APTES también a las paredes de los poros de $\mathrm{SiO}_{2}$. Esta metodología será utilizada en la presente investigación para unir de manera covalente especies macrociclicas naturales o sintetizadas a las paredes de $\mathrm{ZrO}_{2}$ y $\mathrm{TiO}_{2}$, también se hará uso de alcóxidos órgano Sustituidos con objeto de alejar en la medida de lo posible las 
moléculas de las paredes de los poros en los dos óxidos, para comparar con sistemas similares de $\mathrm{SiO}_{2}$. 


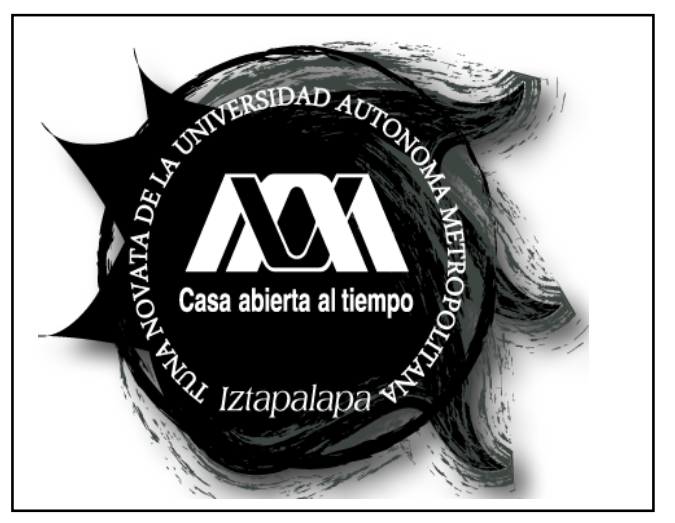

\section{UAM-I}

\section{CAPITULO II}

\section{Condiciones de Inserción de}

\section{MTSPc en xerogeles de $\mathrm{ZrO}_{2}$ y TiO$_{2}$.}

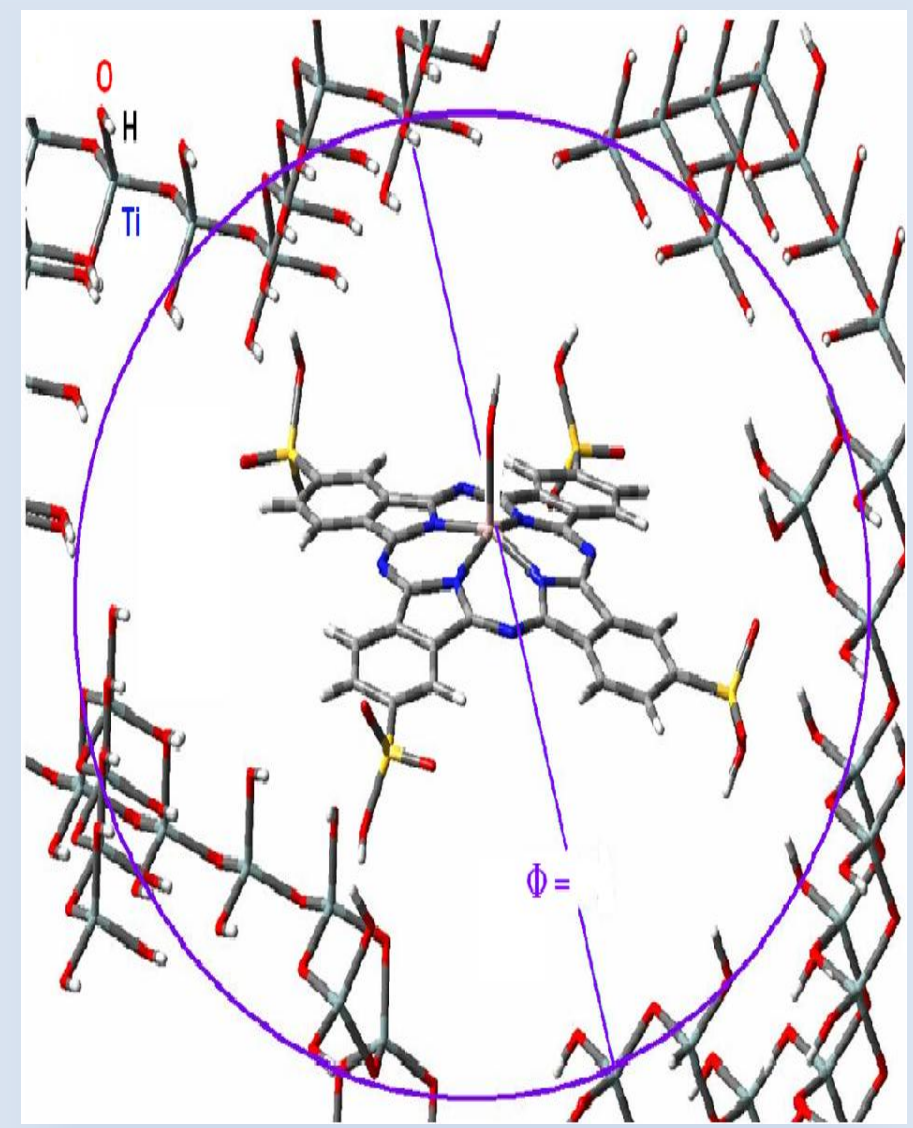

Situación Hi potética de la $(\mathrm{OH}) \mathrm{AI}$ TSPc Atrapada físicamente. 


\subsection{Determinación de las condiciones de síntesis de xerogeles translúcidos de $\mathrm{ZrO}_{2} \mathrm{y} \mathrm{TiO}_{2}$.}

En la búsqueda de las condiciones para la inserción de macrociclos en xerogeles monolíticos transparentes y resistentes de óxido de zirconio $\left(\mathrm{ZrO}_{2}\right)$ y óxido titanio $\left(\mathrm{TiO}_{2}\right)$, se prepararon mezclas gelantes a partir de volúmenes diferentes de sustancias precursoras y aditivos que permitieron generar materiales de diversas características.

Se recurrió al uso de acetilacetona $(\mathrm{AcacH})$ con objeto de disminuir la reactividad del propóxido utilizado $\left.\left[\left(\mathrm{Zr}_{(}\left(\mathrm{OPr}^{\mathrm{n}}\right)_{4}\right), \operatorname{Ti}\left(\mathrm{OPr}^{\mathrm{n}}\right)_{4}\right)\right]$. Con base en las observaciones hechas durante el proceso de gelado de las muestras sintetizadas y las características de los xerogeles finalmente obtenidos a partir de las mezclas indicadas en la tabla 2.1 para el $\mathrm{ZrO}_{2}$.

Se observó que una mayor cantidad de alcohol isopropílico genera xerogeles opacos o quebradizos, mientras que una cantidad mayor de agua promueve la aparición de un precipitado que probablemente contiene óxido de zirconio. De las muestras preparadas, aquella generadas a partir de la mezcla 2: 4: 8: 1 de $\left(\mathrm{Zr}_{(}\left(\mathrm{OPr}^{\mathrm{n}}\right)_{4}\right): \mathrm{H}_{2} \mathrm{O}: \mathrm{Pr}^{\mathrm{n}} \mathrm{OH}$ : AcacH), permite obtener xerogeles transparentes y monolíticos, aunque muy frágiles. También se observó que las muestras que presentan un mejor resultado fueron aquellas en que primero se mezclaron el propóxido de zirconio con acetilacetona en alcohol propílico. Con la finalidad de evitar la fractura de los sistemas, se agrega dimetilformamida (DMF) como agente controlador del secado a la mezcla gelante, lo cual permite obtener xerogeles de mayor resistencia (gel e, Figura 2.1)

Las observaciones anteriores nos indican que la muestra e sintetizada a partir de la relación molar 3:3:4:1 de $\mathrm{Zr}\left(\mathrm{OPr}^{\mathrm{n}}\right)_{4}: \mathrm{H}_{2} \mathrm{O}: \mathrm{Pr}^{\mathrm{n}} \mathrm{OH}: \mathrm{AcacH}$ respectivamente (más $0.1 \mathrm{ml}$ de DMF), da mejores resultados para la síntesis de xerogeles de óxido de zirconio monolítico y translúcidos [49]. 
Tabla: 2.1 Relaciones molares exploradas para la obtención de xerogeles monolíticos translúcidos de $\mathrm{ZrO}_{2}$.

\begin{tabular}{|c|c|c|c|c|c|}
\hline Mirestra & $\operatorname{Zn}\left(\mathrm{O} \mathrm{Pr}^{\mathrm{n}}\right)_{4}$ & $: \mathrm{H}_{2} \mathrm{O}$ & $: P_{1} 01$ & : Acac/ mol & Aspecto del xerogel \\
\hline A & 1 & 2 & 17 & 1 & Opaco y que bradizo \\
\hline B & 1 & 4 & 17 & 1 & $\begin{array}{l}\text { Mate rial que presenta dos } \\
\text { fases }\end{array}$ \\
\hline $\mathrm{C}$ & 1 & 5 & 17 & 1 & $\begin{array}{l}\text { Cristalino, Transpare nte con } \\
\text { Precipitado }\end{array}$ \\
\hline D & 2 & 4 & 8 & 1 & Cristalino y transpare nte \\
\hline $\mathbf{E}$ & 3 & 3 & 4 & $1^{*}$ & $\begin{array}{l}\text { Cris talino trans pare nte y } \\
\text { resistente }\end{array}$ \\
\hline
\end{tabular}

* Se adiciona $0.1 \mathrm{~mL}$. de dimetilformamida para evitar la contracción brusca del monolito y éste sea más resistente.

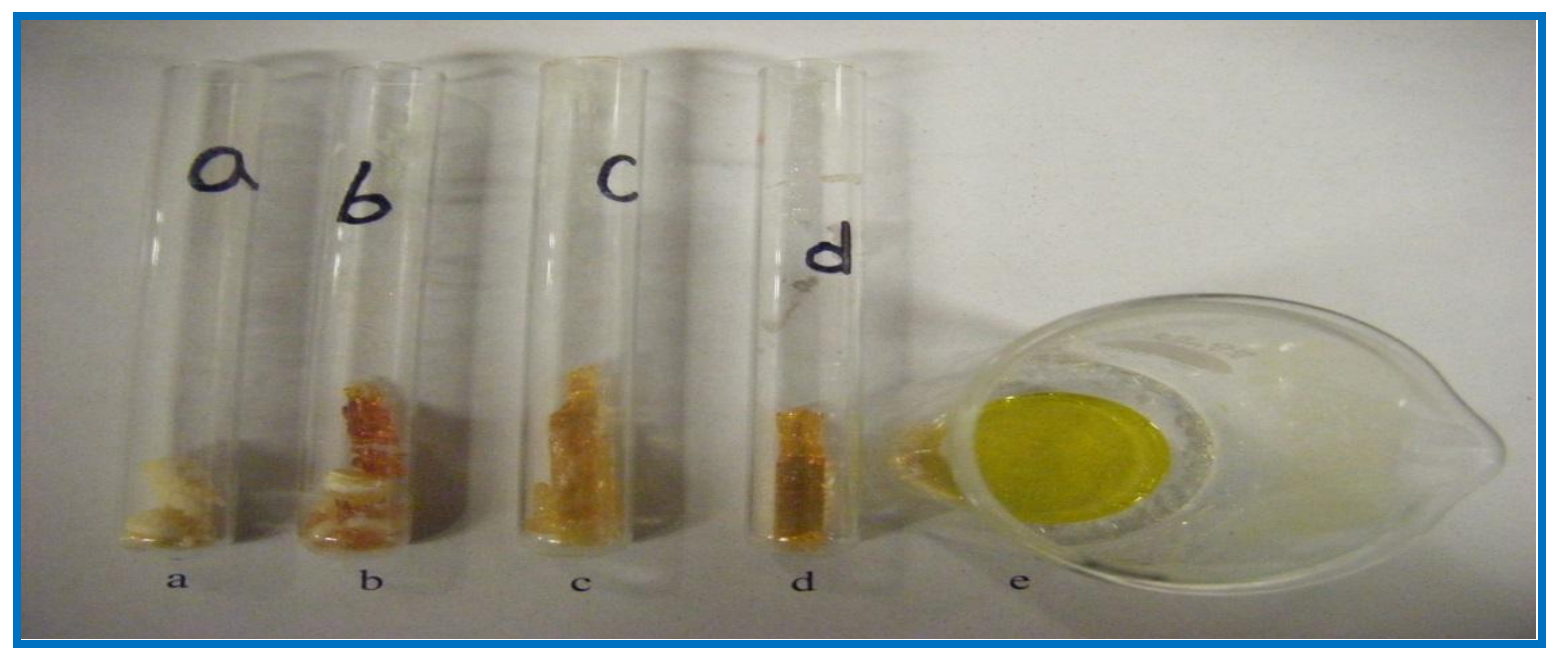

Figura 2.1 Aspecto de geles de óxido de zirconio de acuerdo con las re laciones presentadas en tabla 2.1.

Para determinar las condiciones de síntesis de monolitos traslúcidos de $\mathrm{TiO}_{2}$, se procedió de manera similar que como con el óxido de zirconio, es decir que se prepararon mezclas gelantes a partir de volúmenes diferentes de precursores y aditivos que permitieron generar también materiales con diversas características. En la tabla 2.2 se muestran las relaciones molares de los precursores utilizados en la síntesis de monolitos y el aspecto de algunos de los materiales más representativos sintetizados. Los xerogeles menos quebradizos y opacos son aquellos marcados como D a G (Figura 2.2). Es decir que los mejores resultados se obtienen con aquellas mezclas que requieren a un menor volumen de agua y de alcohol isopropílico, ya que una mayor cantidad genera xerogeles más opacos y quebradizos. 
Tabla: 2.2 Re laciones molares exploradas para la obtención de xerogeles monolíticos translúcidos de $\mathrm{TiO}_{2}$.

\begin{tabular}{|c|c|c|c|c|c|}
\hline Muestira & $\mathrm{TH}(\mathrm{OPr})_{4}$ & $\mathrm{H}_{2} \mathrm{O}$ & :PrOH & :Acac/mol & Aspecto del xerogel \\
\hline A & 4 & 17 & 14 & 1 & $\begin{array}{l}\text { Blanco con tono amarillo en un } \\
\text { extre mo, frágil y que bradizo. }\end{array}$ \\
\hline B & 13 & 14 & 36 & 1 & $\begin{array}{c}\text { Hete rogéneo, blanco con amarillo en } \\
\text { un extre mo. }\end{array}$ \\
\hline $\mathrm{C}$ & 4 & 17 & 12 & 1 & Homogéneo, amarillo con opacidad. \\
\hline D & 7 & 28 & 24 & 1 & $\begin{array}{l}\text { Amarillo translucido en la parte } \\
\text { inferior y opaco en la supe rior. }\end{array}$ \\
\hline $\mathbf{E}$ & 4 & 20 & 12 & 1 & $\begin{array}{l}\text { Amarillo, translucido homogéneo } \\
\text { frágil y fracturas }\end{array}$ \\
\hline $\mathbf{F}$ & 3 & 3 & 7 & 1 & Trans lúcido, homogéneo con grie tas \\
\hline G & 5 & 5 & 7 & $1^{*}$ & $\begin{array}{l}\text { Translúcido, amarillo homogéneo, } \\
\text { resistente y sin fracturas. }\end{array}$ \\
\hline
\end{tabular}

*se adiciona $0.3 \mathrm{ml}$ de dimetilforma mida con objeto de evitar la contracción brusca del monolito y esta sea más resistente.

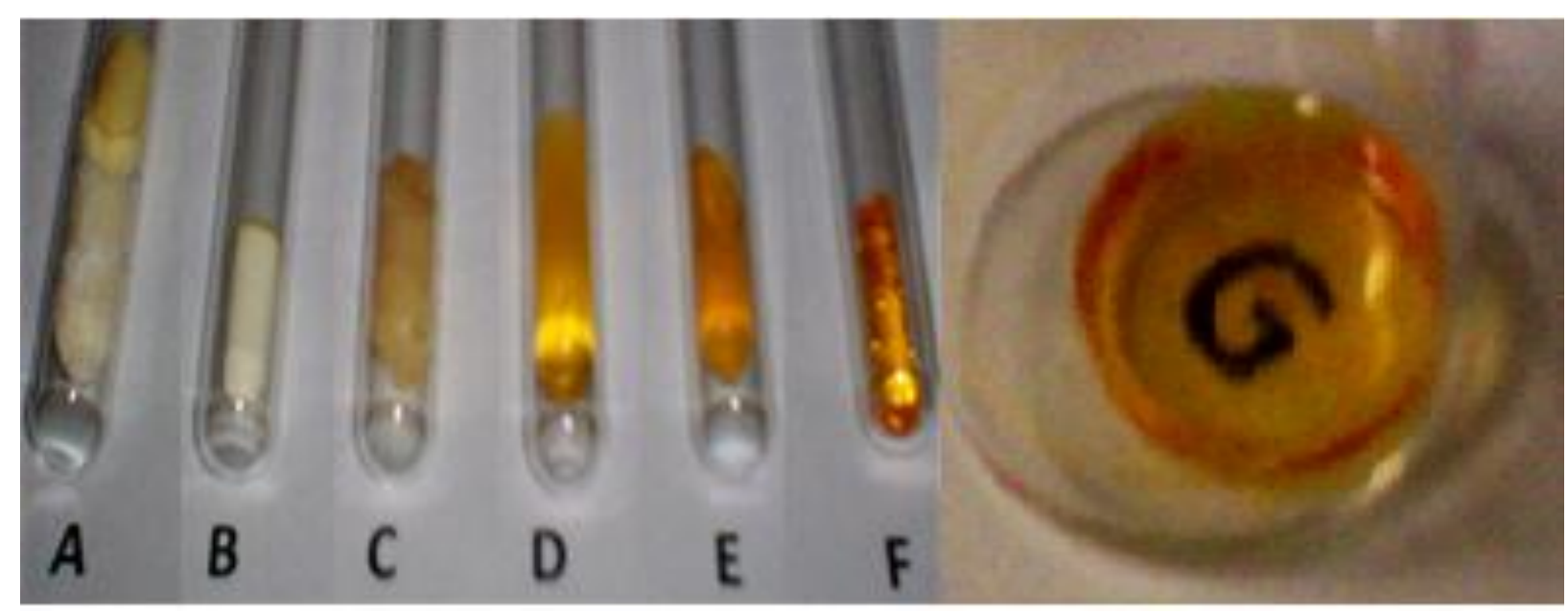

Figura 2.2 Aspecto de algunos materiales sintetizado de $\mathrm{TiO}_{2}$. 


\subsection{Caracterización de xerogeles translúcidos de $\mathrm{ZrO}_{2} \mathrm{y} \mathrm{TiO}_{2}$.}

\subsubsection{UV-Vis de xerogeles.}

En ambos casos, los xerogeles monolíticos finales son de color amarillo, atribuido a la formación de complejos con la acetilacetona, en sus respectivos espectros UV-Vis se observa una banda intensa por debajo de los 400nm que no permite mayor análisis en dicha región.

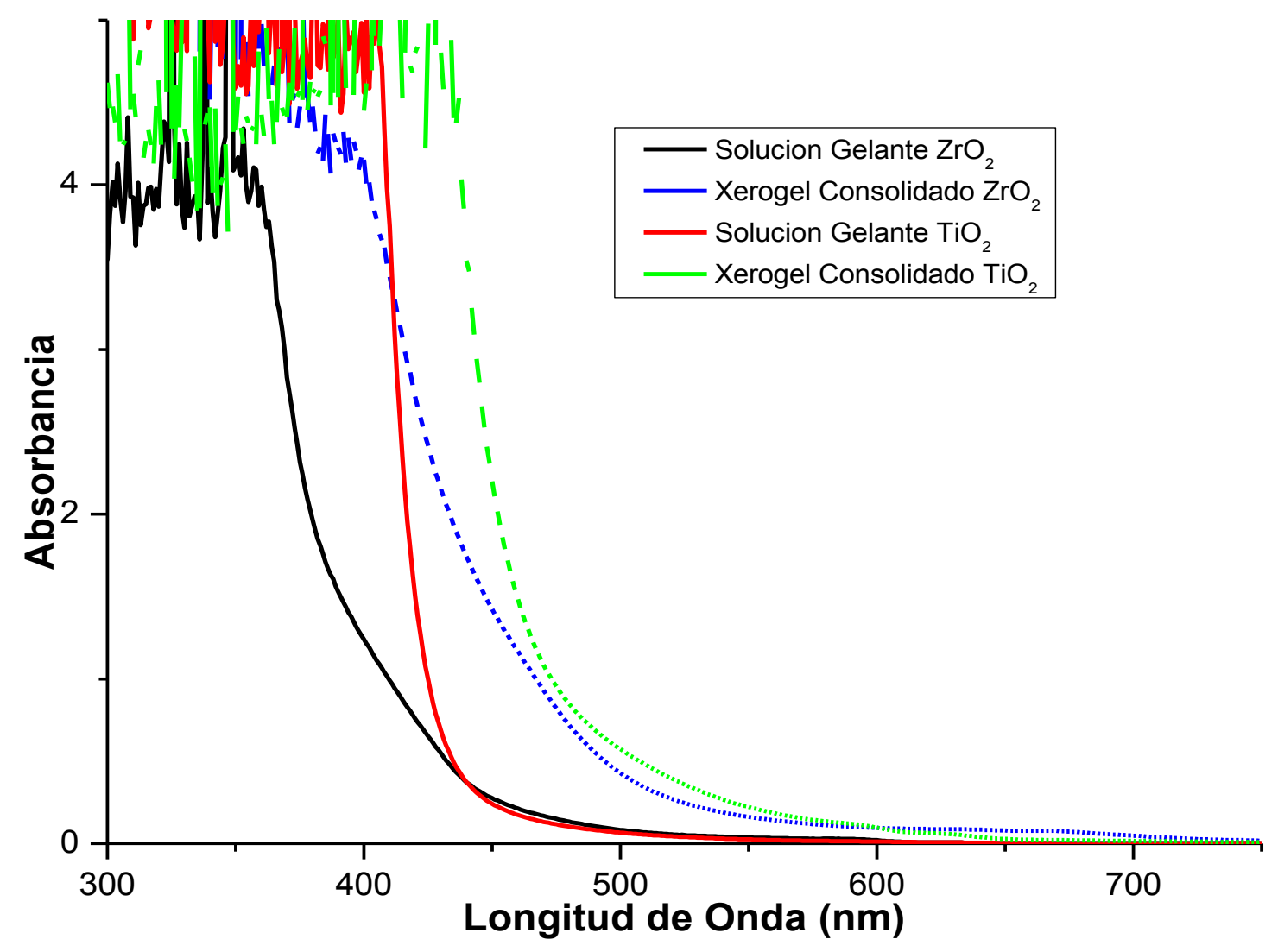

Figura 2.3 Espectros UV-Vis de mezcla gelante y xerogeles consolidaos $\mathrm{ZrO}_{2}$ y de $\mathrm{TiO}_{2}$.

\subsubsection{DRX Monolito de $\mathrm{ZrO}_{2}$ y $\mathrm{TiO}_{2}$}

Se obtuvieron los difractogramas de los materiales sintetizados y secados a temperatura ambiente a 80 y $100{ }^{\circ} \mathrm{C}$ de los dos óxidos. En estos se puede apreciar para el caso de las muestras de $\mathrm{ZrO}_{2}$ que son amorfas, lo cual era de esperarse ya que el $\mathrm{ZrO}_{2}$ presenta estructuras definidas sólo cuando se le realiza tratamiento térmico a más de $700{ }^{\circ} \mathrm{C}$ además de presentar un 
hombro característico para el $\mathrm{ZrO}_{2}$ amorfo en $2 \Theta=30$ [50], para el caso del $\mathrm{TiO}_{2}$ sucede algo similar cuando se sintetiza por el método sol-gel utilizando AcacH como acomplejante, por debajo de $450{ }^{0} \mathrm{C}$ los materiales sintetizados son amorfos [51], aunque sus bandas más prominentes coinciden con las principales de $\mathrm{ZrO}_{2}$ y $\mathrm{TiO}_{2}$ tratados térmicamente.

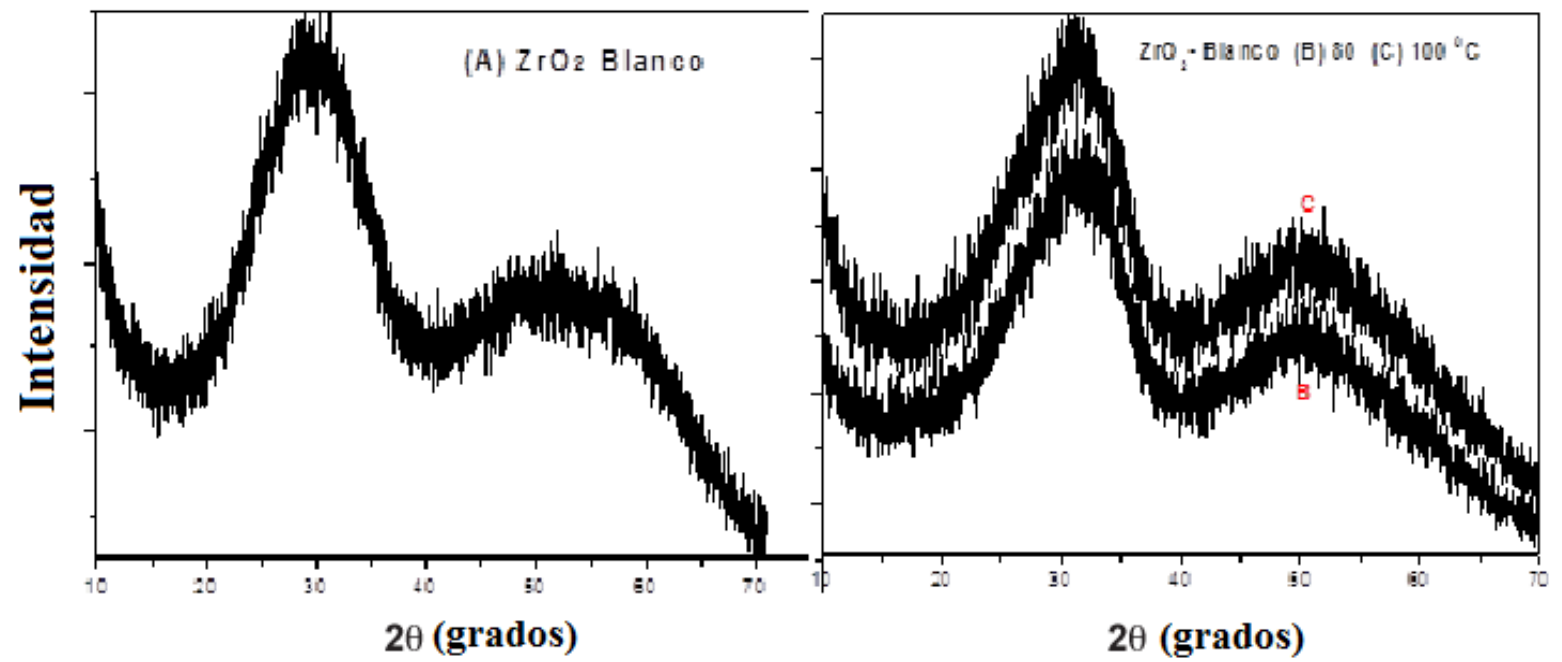

Figura 2.4 DRX de monolitos transparentes de $\mathrm{ZrO}_{2}$ (A) Temperatura $\mathrm{A}$ mb iente (B) $80^{\circ} \mathrm{C}$ y (C) $100^{\circ} \mathrm{C}$

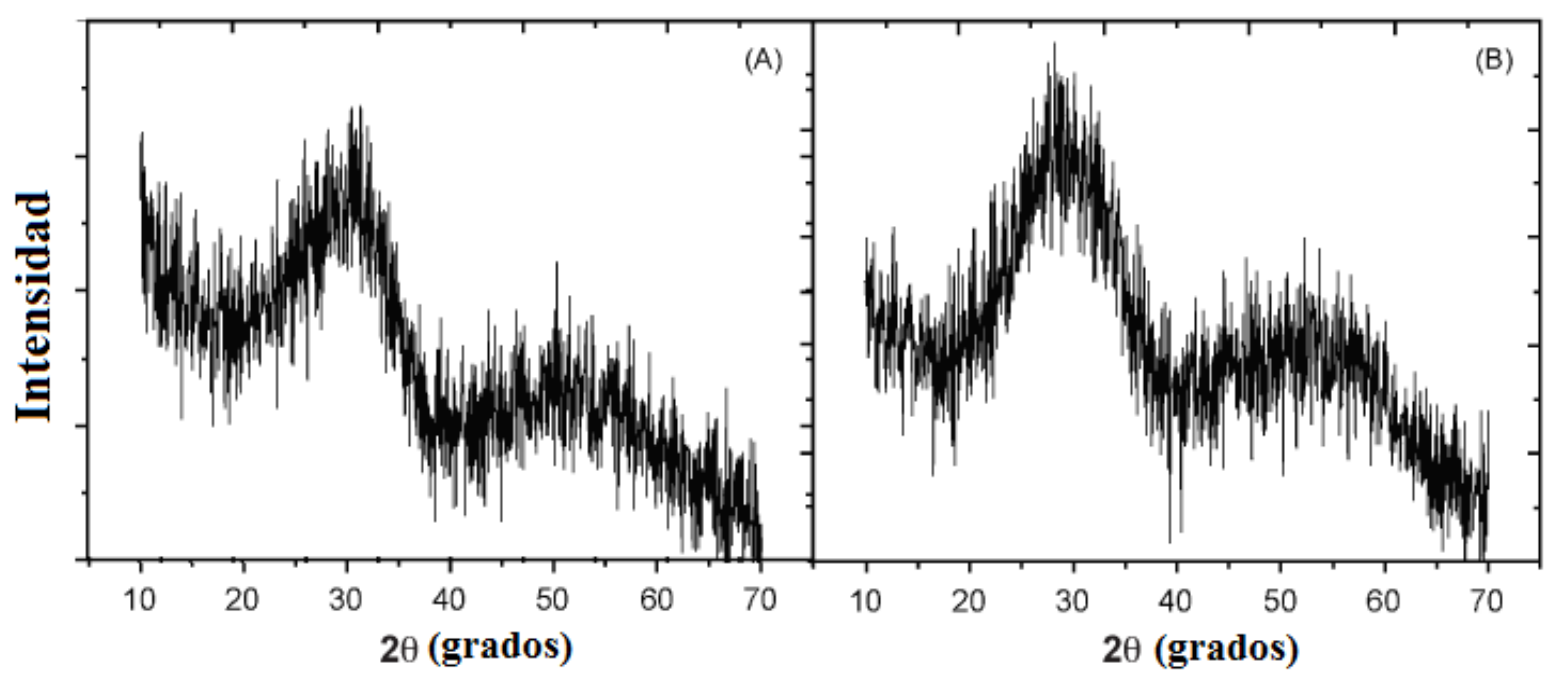

Figura 2.5 DRX de óxido de zirconio hidratado preparado por los métodos de precipitación a) convencional b) en solución homogénea. [50]. 


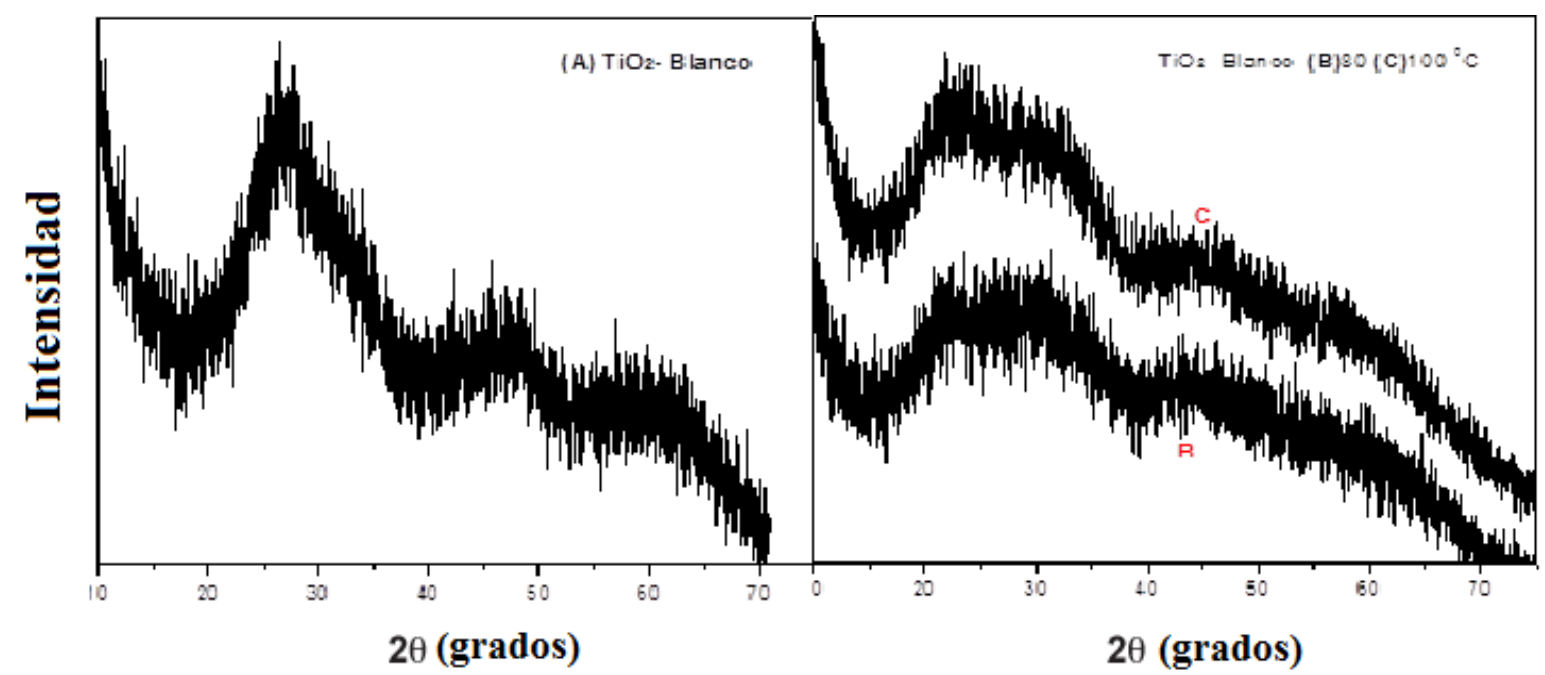

Figura 2.6 DRX de monolitos transparentes de $\mathrm{TiO}_{2}$ (A) Temperatura A mb iente (B) $80^{\circ} \mathrm{C}$ y (C) $100^{\circ} \mathrm{C}$

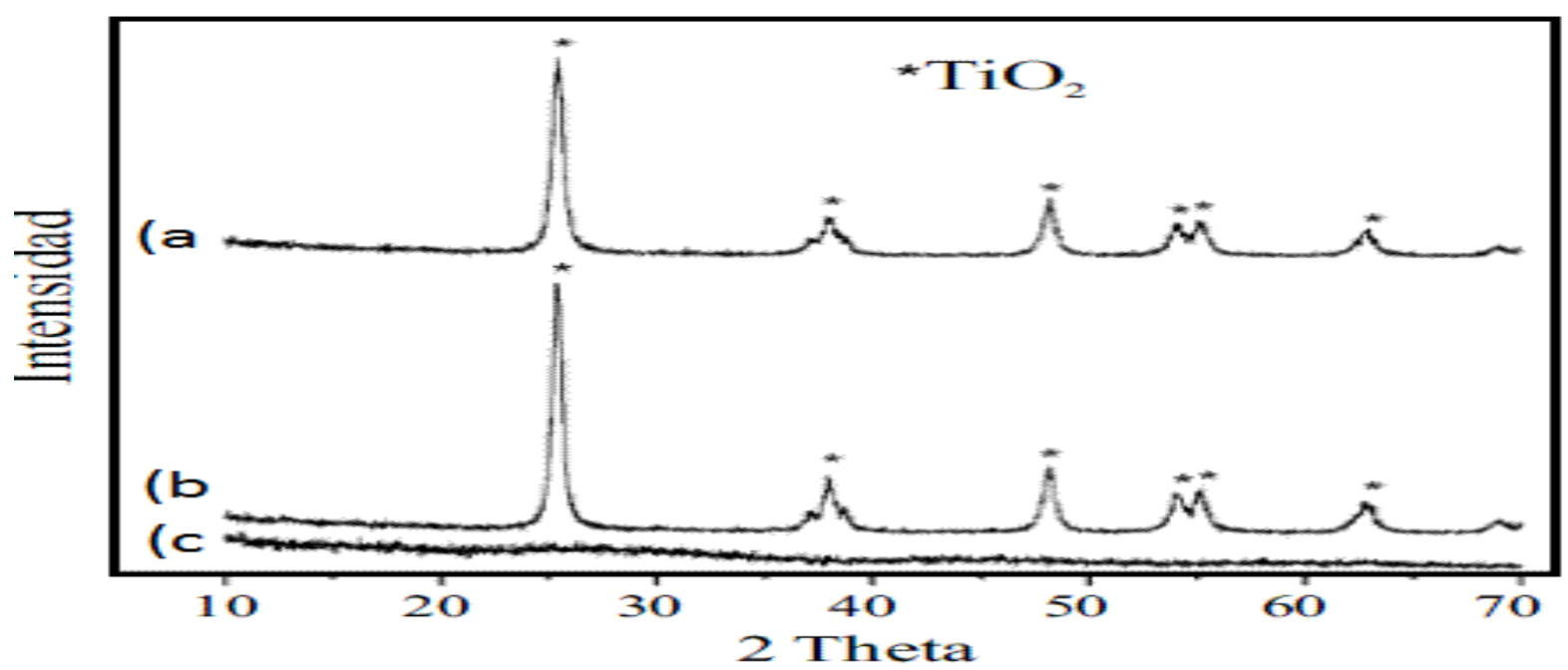

Figura 2.7 DRX de monolitos transparentes de $\mathrm{TiO}_{2}$ a) $500{ }^{\circ} \mathrm{C}$ b) $450^{\circ} \mathrm{C}$ y c) $350^{\circ} \mathrm{C}[51]$.

\subsubsection{Diámetro de poro y área superficial}

Se obtuvieron las isotermas de sorción -desorción de $\mathrm{N}_{2}$ a $76 \mathrm{~K}$ de los xerogeles puros sintetizados de $\mathrm{SiO}_{2}, \mathrm{ZrO}_{2}$ y $\mathrm{TiO}_{2}$. Las isotermas de adsorción de $\mathrm{N}_{2}$ que se muestran en la Figura 2.8 corresponden, según la clasificación de la IUPAC Tipo I con ciclo de Histéresis H3 [52], para el $\mathrm{ZrO}_{2}$, que es representativas de los materiales microporosos. Como puede verse en la figura $2.8 \mathrm{C}$ ) el ciclo de histéresis es muy estrecho lo cual sugiere que la difusión de las moléculas de absorbato se lleva a cabo con relativa facilidad de una cavidad a otra, por otro lado la figura 2.8 B) muestra una isoterma tipo II con histéresis H3 la cual es característica de un 
sólido macroporoso o no poroso. El ciclo de histéresis en la anterior isoterma, es relativamente grande lo cual sugiere que la difusión de las moléculas de absorbato se dificulta de una cavidad a otra, posiblemente por la existencia de interconexiones peque ñas entre los poros la figura 2.8 A) muestras una isoterma tipo I con Histéresis H2, que son características de los materiales con microporos anchos o mesoporos estrechos.

El diámetro de poro evaluado en el xerogel de $\mathrm{ZrO}_{2}$ fue de $2.2 \mathrm{~nm}$ y un área superficial específica de $28.1 \mathrm{~m}^{2} / \mathrm{g}$. En contraste, el diámetro de poro promedio y el área superficial determinados en el xerogel de $\mathrm{TiO}_{2}$ fueron de $2.5 \mathrm{~nm}$ y $308 \mathrm{~m}^{2} / \mathrm{g}$.

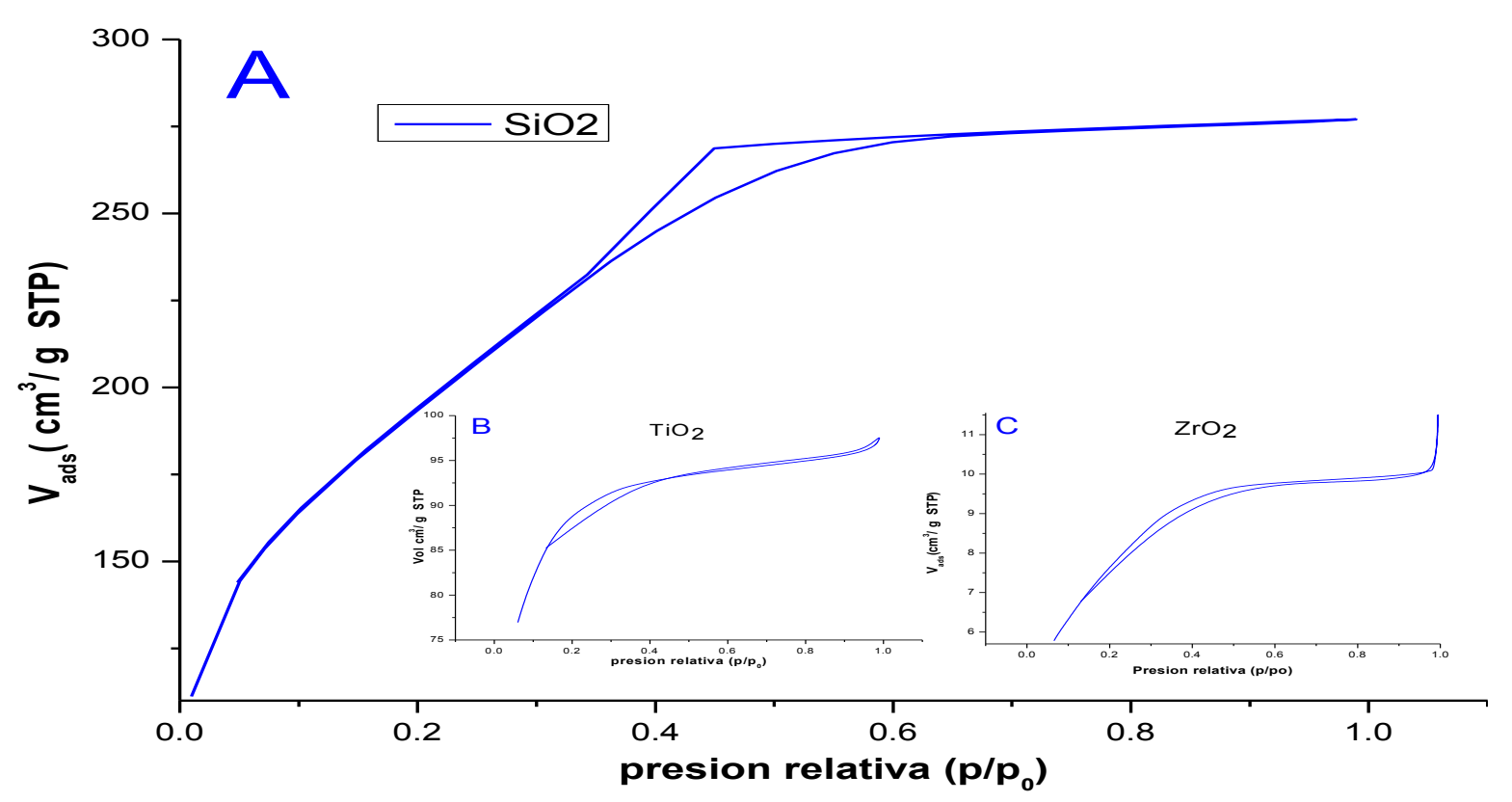

Figura 2.8 Isoterma de adsorción de $\mathrm{N}_{2}$ de xerogel de A) $\mathrm{SiO}_{2}$, $\mathrm{TiO}_{2}$ y C) $\mathrm{ZrO}_{2}$. 


\begin{tabular}{|c|c|c|c|c|}
\hline Especies & A trapamiento & Matriz & $\begin{array}{l}\text { Diáme tino de } \\
\text { Poro (nm) }\end{array}$ & Superficie ( $\mathrm{m} / \mathrm{g}$ ) \\
\hline B lanco & Fís ico & $\mathrm{ZrO}_{2}$ & 2.2 & 28.1 \\
\hline Blanco & Fís ico & $\mathrm{TiO}_{2}$ & 2.5 & 308 \\
\hline B lanco & Fís ico & $\mathrm{SiO}_{2}$ & 3.4 & 729 \\
\hline
\end{tabular}

Tabla 2.3 Área específica de los tres óxidos.

Los resultados descritos en la tabla 2.3 nos hacen sugerir que la discrepancia en el tamaño de poro entre el material de $\mathrm{ZrO}_{2}, \mathrm{TiO}_{2}$ y $\mathrm{SiO}_{2}$ se debe a la diferencia de reactividad de cada uno de los alcóxidos utilizados en la síntesis de los materiales, Así por ejemplo, una menor reactividad y por tanto, menor velocidad en las reacciones de hidrólisis y policondensación permite que se generen partículas de mayor volumen y en consecuencia poros de mayor tamaño y área superficial específica, que suelen retener un mayor volumen de líquido remanente en su interior con cuyos componentes no atacan tan fácilmente a aquellos núcleos con cargas parciales menos electropositivas.

\subsubsection{NIR. Rehidratación de xerogeles monolíticos y transparentes de $\mathrm{ZrO}_{2}, \mathrm{TiO}_{2}$ y $\mathrm{SiO}_{2}$.}

Los xerogeles de $\mathrm{TiO}_{2}$ y $\mathrm{ZrO}_{2}$ sintetizados son tratados térmicamente a $125^{\circ} \mathrm{C}$, con objeto de eliminar el agua fisisorbida y posteriormente seguir mediante, espectroscopia en la región del infrarojo cercano (NIR) el proceso de rehidratación que la humead del ambiente genera en los monolitos. Estos resultados nos permitirán establecer algunas diferencias con respecto a los monolitos de $\mathrm{SiO}_{2}$ reportados por García Sánchez [48], los cuales se tomaran como referencia ya que no se ha encontrado en la literatura fuentes que contengan información sobre rehidratación de monolitos de $\mathrm{TiO}_{2}$ y $\mathrm{ZrO}_{2}$. 


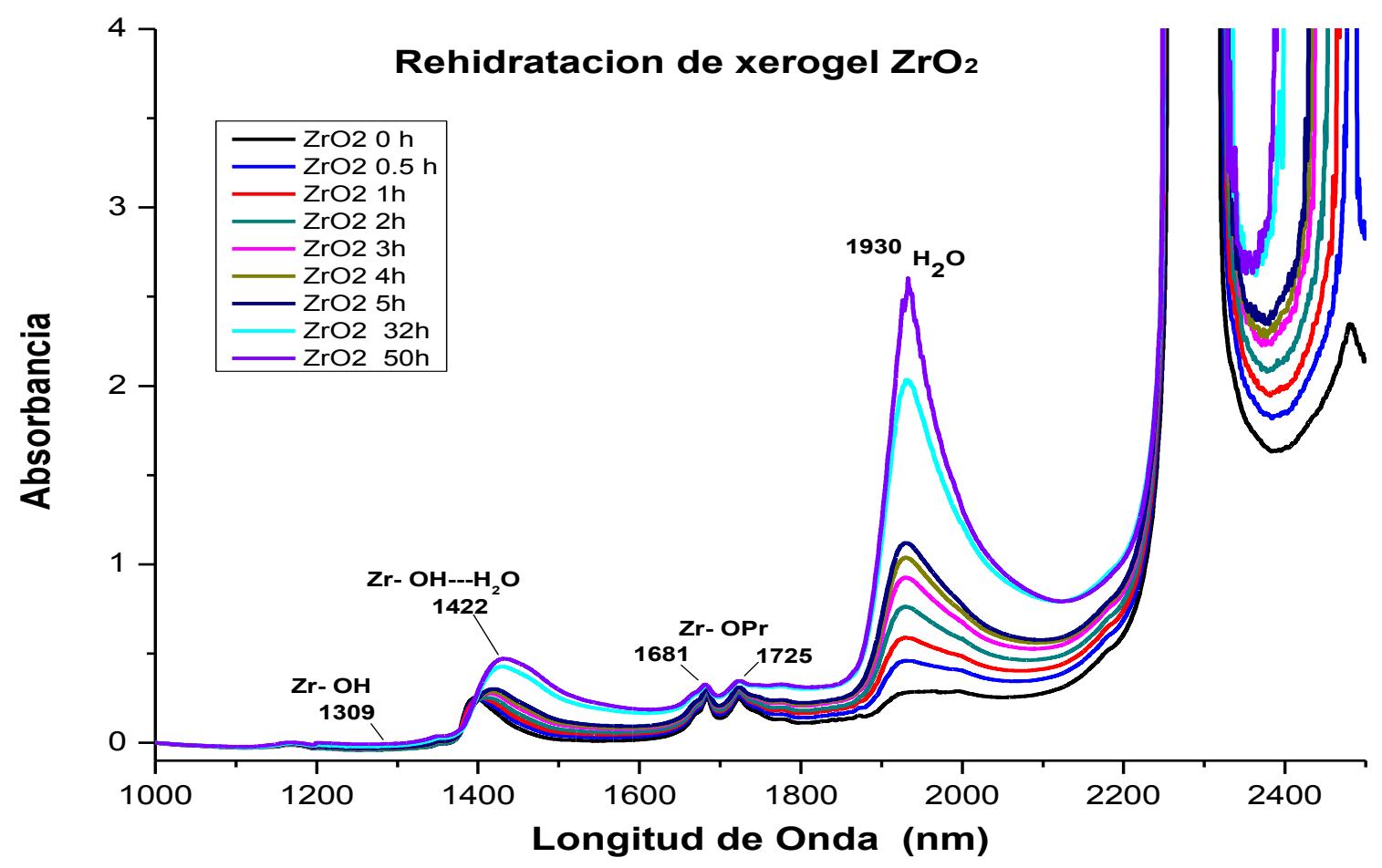

Fi

gura 2.9 Espectroscopia NIR del proceso de rehidratación del xerogel de $\mathrm{ZrO}_{2}$

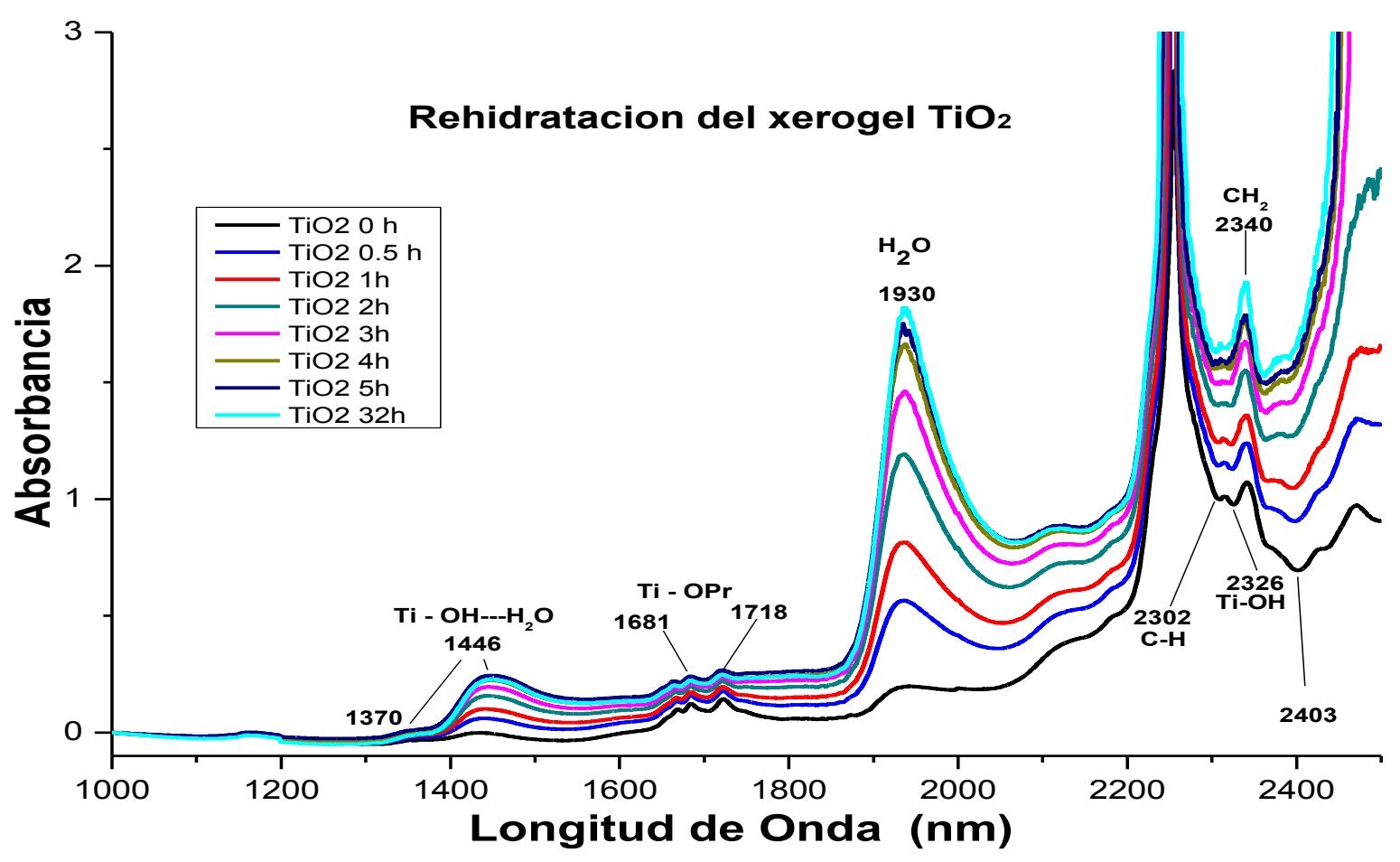

Figura 2.10 Espectroscopia NIR del proceso de rehidratación del xerogel de $\mathrm{TiO}_{2}$. 


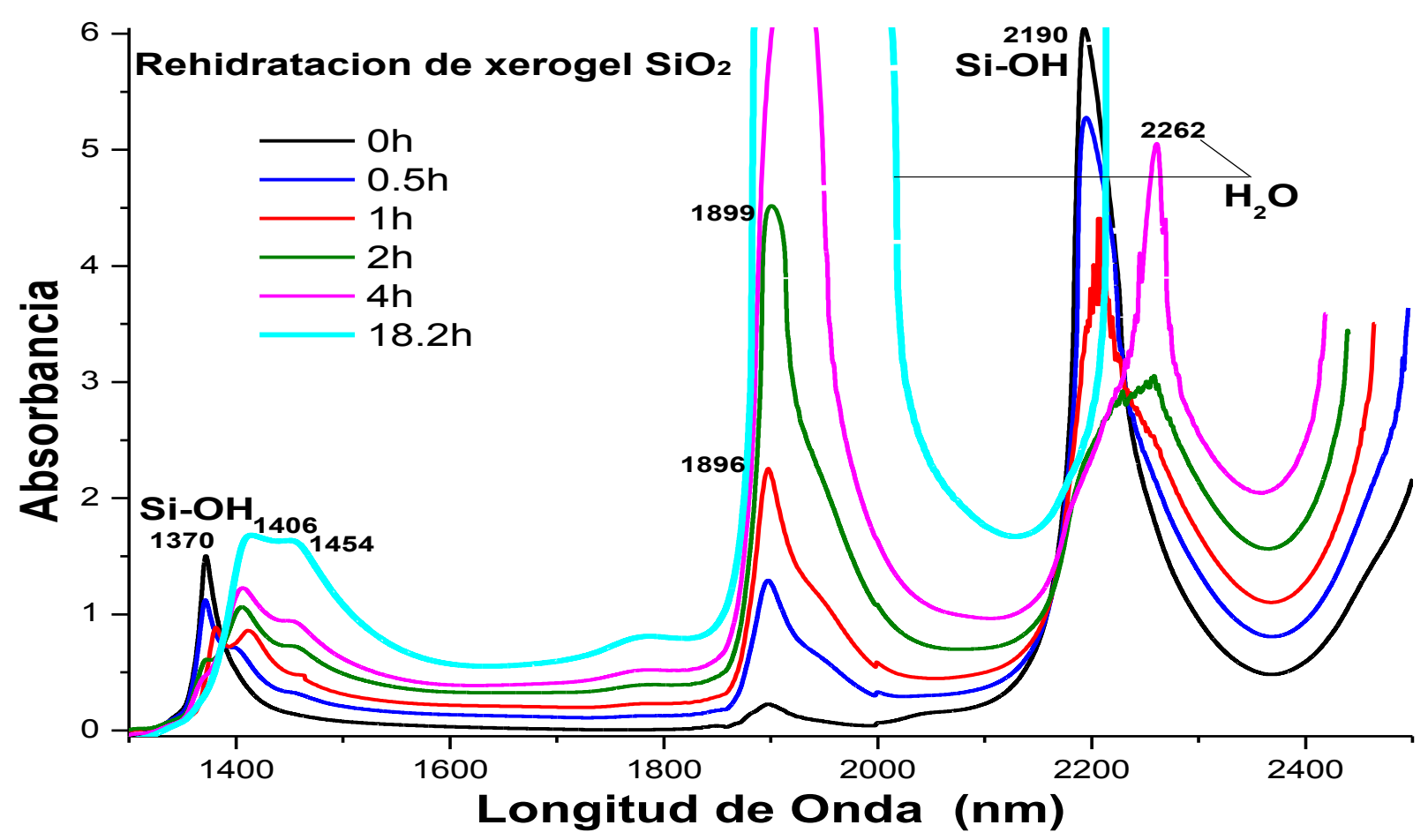

Figura 2.11 Espectroscopia NIR del proceso de rehidratación del Xerogel de $\mathrm{SiO}_{2 .}$. [48].

La figura 2.9 nos muestra el análisis NIR de la hidratación del Xerogel de $\mathrm{ZrO}_{2}$ en él es posible observar que después de $50 \mathrm{~h}$ de rehidratación el xerogel aún no llega a saturarse completamente, de hecho se sabe que el tiempo de saturación ronda las 96 h [49], En el espectro NIR del gel recién secado ( $\mathrm{t}=0$ hrs.) se observa que la banda en alrededor de 1930 asignada al agua fisisorbida es pequeña al inicio del proceso, pero que aumenta de intensidad por efecto de la rehidratación. Algo similar ocurre durante el proceso de rehidratación de la muestra de $\mathrm{TiO}_{2}$, ya que la banda observada a $1930 \mathrm{~nm}$ aumenta de intensidad al transcurrir el tiempo, aunque su aumento oc urre a un ritmo menor (Figura 2.10). Las bandas observadas cerca de 1400 y $2270 \mathrm{~nm}$, en el espectro del xerogel seco de $\mathrm{ZrO}_{2}$, se asocian a grupos $\mathrm{Zr}$-OH libres. Estas señales son muy semejantes a las bandas observadas a 1370 y $2190 \mathrm{~nm}$ en el xerogel seco de $\mathrm{SiO}_{2}$ (Figura 2.11). Sin embargo, no existe una banda notoria a $1370 \mathrm{~nm}$ en el espectro del xerogel seco de $\mathrm{TiO}_{2}$ seco, aunque si se observa una banda intensa cercana a $2270 \mathrm{~nm}$.

Así mismo, la presencia de agua provoca la existencia de una banda a 1422, asociada con grupos $\mathrm{Zr}$-OH interaccionando con agua vía puentes de hidrógeno y que también aumenta a medida que transcurre el tiempo. Algo similar sucede en el proceso de rehidratación del xerogel de $\mathrm{TiO}_{2}$ (Figura 2.10), observándose la aparición de una banda centrada en los $1446 \mathrm{~nm}$. Las 
anteriores diferencias sugieren la existencia de un menor número de grupos $\mathrm{M}-\mathrm{OH}$ en la matriz de $\mathrm{TiO}_{2}$ que en la de $\mathrm{ZrO}_{2}$, lo cual, asociado a poros de mayor tamaño en aquel sustrato, sugiere un carácter menos hidrofílico que dificulta la adsorción total de agua.

Las bandas observadas entre 1682 y $1725 \mathrm{~nm}$, en ambas muestras de $\mathrm{ZrO}_{2}$ y $\mathrm{TiO}_{2}$, se asignan a los grupos alquil provenientes de los alcóxidos utilizados o de la acetilacetona; como lo muestra el patrón de cambios no son afectadas por la presencia de agua.

El anterior análisis se asemeja como ya lo mencionamos con anterioridad al descrito por García Sánchez [48] para la asignación de las bandas de los espectros NIR de sílice obtenida por el método sol-gel, como lo muestra la figura 2.11, en la cual las bandas $\mathrm{Si}-\mathrm{OH}$ son ocultadas por la interacción con el agua que paulatinamente se readsorbe.

La figura 2.12 muestra el gráfico que representa la tasa de rehidratación de cada uno de los xerogeles comparados, se tomó como referencia la diferencia de absorbancia de la banda a 1930 nm, la cual se asocia al agua fisisorbida. Esta gráfica revela diferencias sustanciales de hidrofilicidad entre las matrices de $\mathrm{ZrO}_{2}$ y $\mathrm{TiO}_{2}$ respecto de la de $\mathrm{SiO}_{2}$, pero sobre todo hace evidente la ocurrencia de procesos dinámicamente diferentes debidos a caracter ísticas texturales muy distintas respecto de la matriz de sílice.

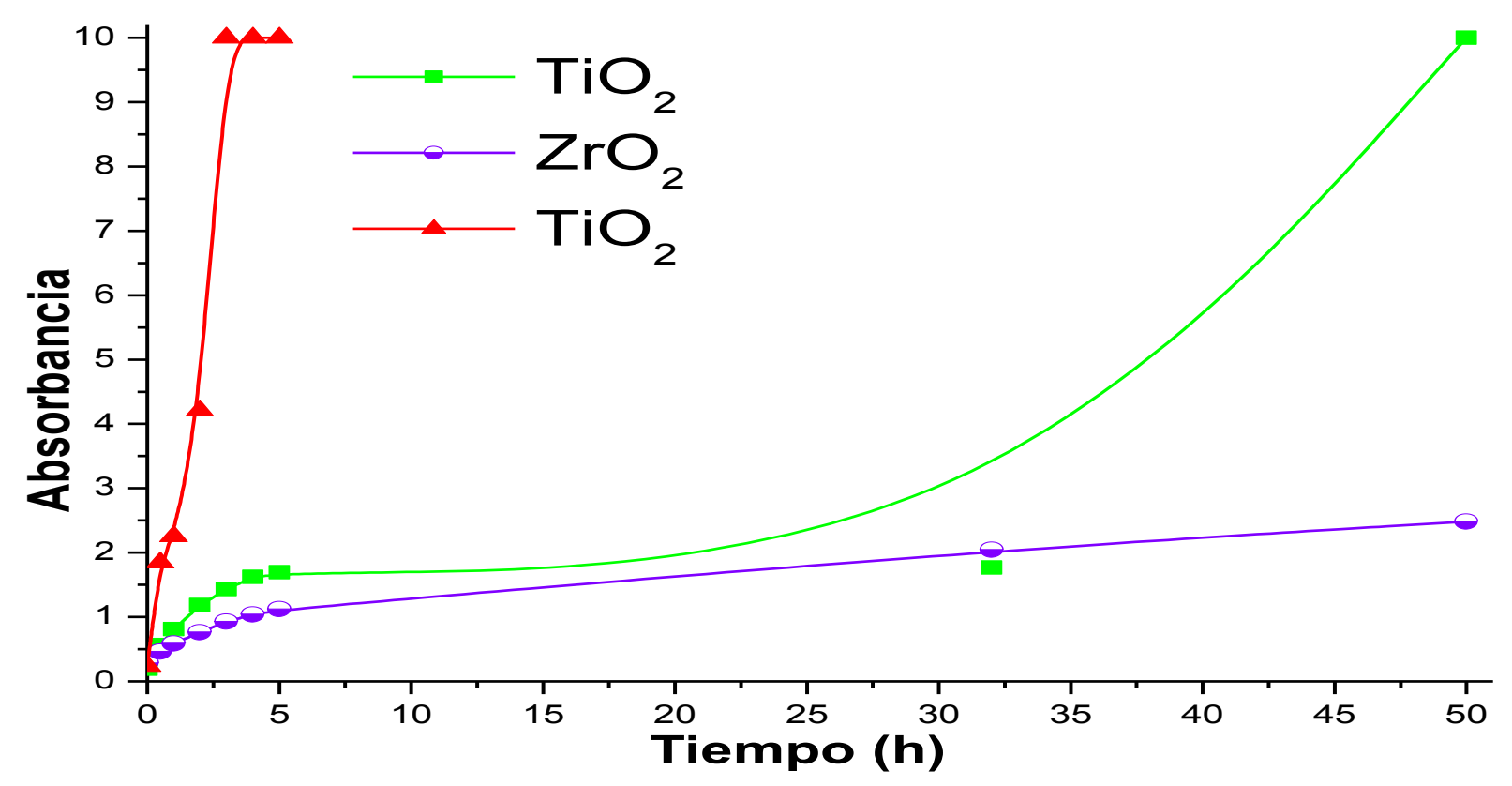

Figura 2.12 Tas a de rehidratación de xerogeles. 


\subsection{Síntesis de xerogeles translúcidos de $\mathrm{ZrO}_{2}$ y $\mathrm{TiO}_{2}$ con la especie (OH)AITSPc atrapada.}

Una vez encontradas las relaciones en volumen que permitieron la síntesis de monolitos translúcidos de mediana resistencia, se procede a la síntesis de materiales que contienen atrapada a la molécula zonda $(\mathrm{OH})$ AlTSPc en la red de zirconio y titanio.

Se realizan muestras gelantes utilizando las relaciones en volumen indicadas en la tabla 2.4 y 2.5 .

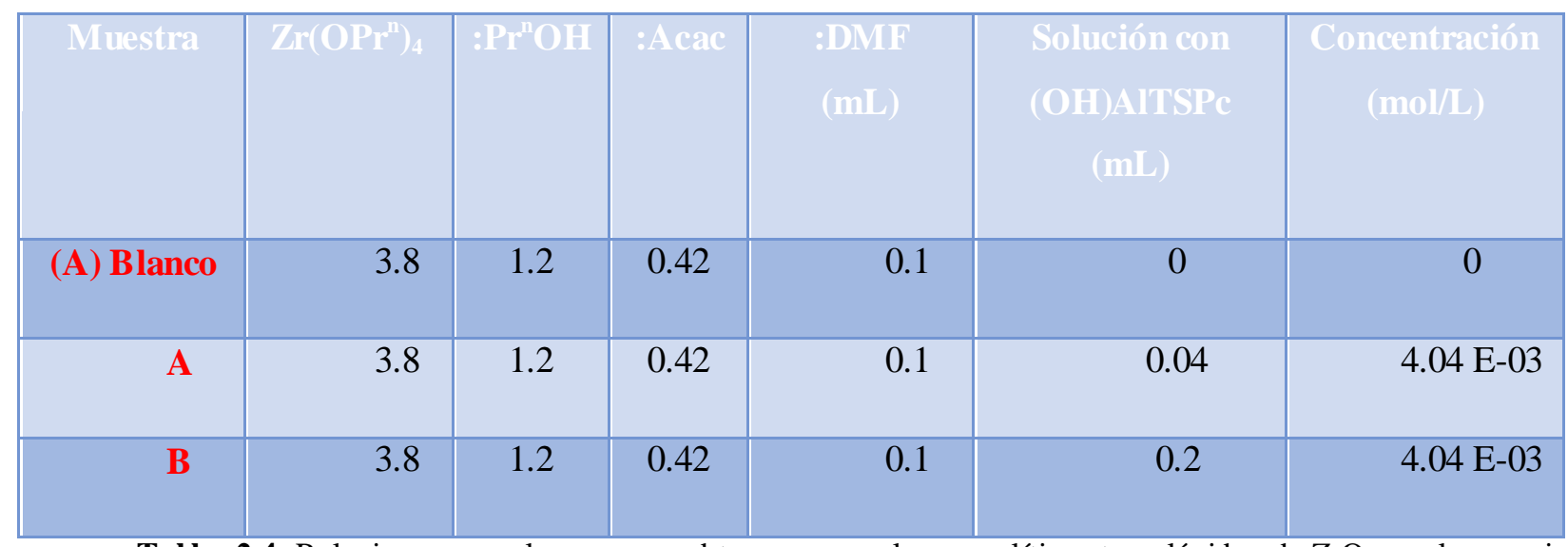

Tabla: 2.4 Relaciones en volumen para obtener xerogeles monolíticos translúcidos de $\mathrm{ZrO}_{2}$ con la especie (OH)AlTSPc .

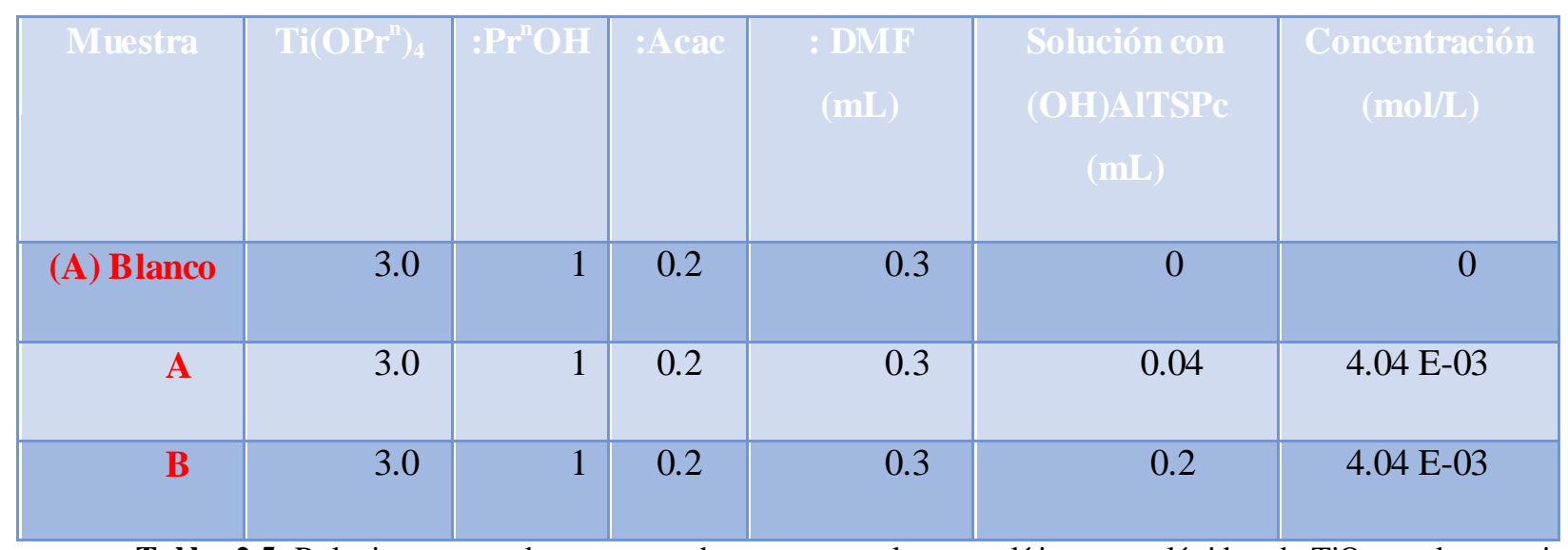

Tabla: 2.5 Relaciones en volumen para obtener xerogeles monolíticos translúcidos de $\mathrm{TiO}_{2}$ con la especie (OH)AlTSPc . 


\subsection{Caracterización de xerogeles translúcido de $\mathrm{ZrO}_{2}$ y $\mathrm{TiO}_{2}$ con la especie (OH)AITSPc atrapada.}

\subsubsection{UV-Vis de xerogeles}

El espectro UV-Vis de la especie $(\mathrm{OH}) \mathrm{AlTSPc}$ monomérica en solución (figura 2.13) presenta una banda de Soret en $347 \mathrm{~nm}$, una intensa banda $\mathrm{Q}_{\mathrm{II}}$ en $679 \mathrm{~nm}$ y dos bandas de menor intensidad en $647\left(\mathrm{Q}_{\mathrm{III}}\right)$ y $612 \mathrm{~nm}\left(\mathrm{Q}_{\mathrm{IV}}\right)$, todas estas asociadas a transiciones electrónicas atribuidas a transiciones $\pi-\pi *$ del macrociclo. Los espectros UV-Vis de las muestras gelantes $\mathbf{B}$ y $\mathbf{C}$ de la figura 2.14 presentan bandas máximas en 680 y $685 \mathrm{~nm}\left(\mathrm{Q}_{\mathrm{II}}\right)$ en $\mathrm{ZrO}_{2}$ y $\mathrm{TiO}_{2}$ respectivamente y bandas $Q_{\text {III }}$ en 647 y 654 nm y bandas QIV de menor intensidad en 613 y 617 $\mathrm{nm}$, respectivamente. Si bien lo anterior sugiere la existencia de la especie (OH)AlTSPc en forma monomérica y estable en el interior de la poros de ambos sustratos, resulta evidente que la banda $\mathrm{Q}_{\text {II }}$ es más notoria cuando la especie $(\mathrm{OH}) \mathrm{AlTSPc}$ se encuentra atrapada en $\mathrm{TiO}_{2}$ que cuando se encuentra en $\mathrm{ZrO}_{2}$.

Esta banda suele asociarse a la formación de dímeros cofaciales o vía puente $\mu$-oxo de la ftalocianina, es decir que al parecer, el ambiente fisicoquímico de la mezcla gelificante con $\mathrm{TiO}_{2}$ es menos polar y propicia la aproximación de las moléculas de $(\mathrm{OH}) \mathrm{AlTSPc}$. En todo caso, esta sutil diferencia corrobora la diferencia de polaridad en las mezclas gelantes que originan las matrices de $\mathrm{TiO}_{2}$ y $\mathrm{ZrO}_{2}$.

Sin embargo, al final del proceso, los espectros de la $(\mathrm{OH})$ AlTSPc en las figuras 2.14 y 2.15 son más parecidos: en ellos las bandas $\mathrm{Q}_{\mathrm{III}}$ son insignificantes o difíciles de observar, sin embargo, las bandas $Q_{\text {IV }}$ se localizan cerca de $616 \mathrm{~nm}$ y $602 \mathrm{~nm}$ y las bandas $\mathrm{Q}_{\mathrm{II}}$ en $667 \mathrm{~nm}$ y $680 \mathrm{~nm}$ y para los xerogeles de $\mathrm{ZrO}_{2}$ y $\mathrm{TiO}_{2}$, respectivamente. Lo más importante es que ambos espectros son característicos del macrociclo de $(\mathrm{OH}) \mathrm{AlTSPc}$ en forma estable y monomérica. El desplazamiento en la posición de la banda más intensa sugiere, nuevamente, la existencia de un ambiente fisicoquímico de diferente polaridad en torno al macrociclo atrapado al interior de los poros. Esta diferencia puede deberse a una diferente población de grupos $\mathrm{M}-\mathrm{OH}$ superficiales o a diferente distribución de densidad electrónica en los enlaces M-O debido a la identidad del núcleo metálico. En todo caso tales diferencias son capaces de inhibir el despliegue o disipar 
propiedades espectroscópicas como la de fluorescencia de la especie $(\mathrm{OH})$ AITSPc atrapada al interior de los poros.

Sin embargo, todo ello sugiere que la molécula ha sido atrapada dentro de la matriz de óxido de zirconio y óxido de titanio en forma monomérica.

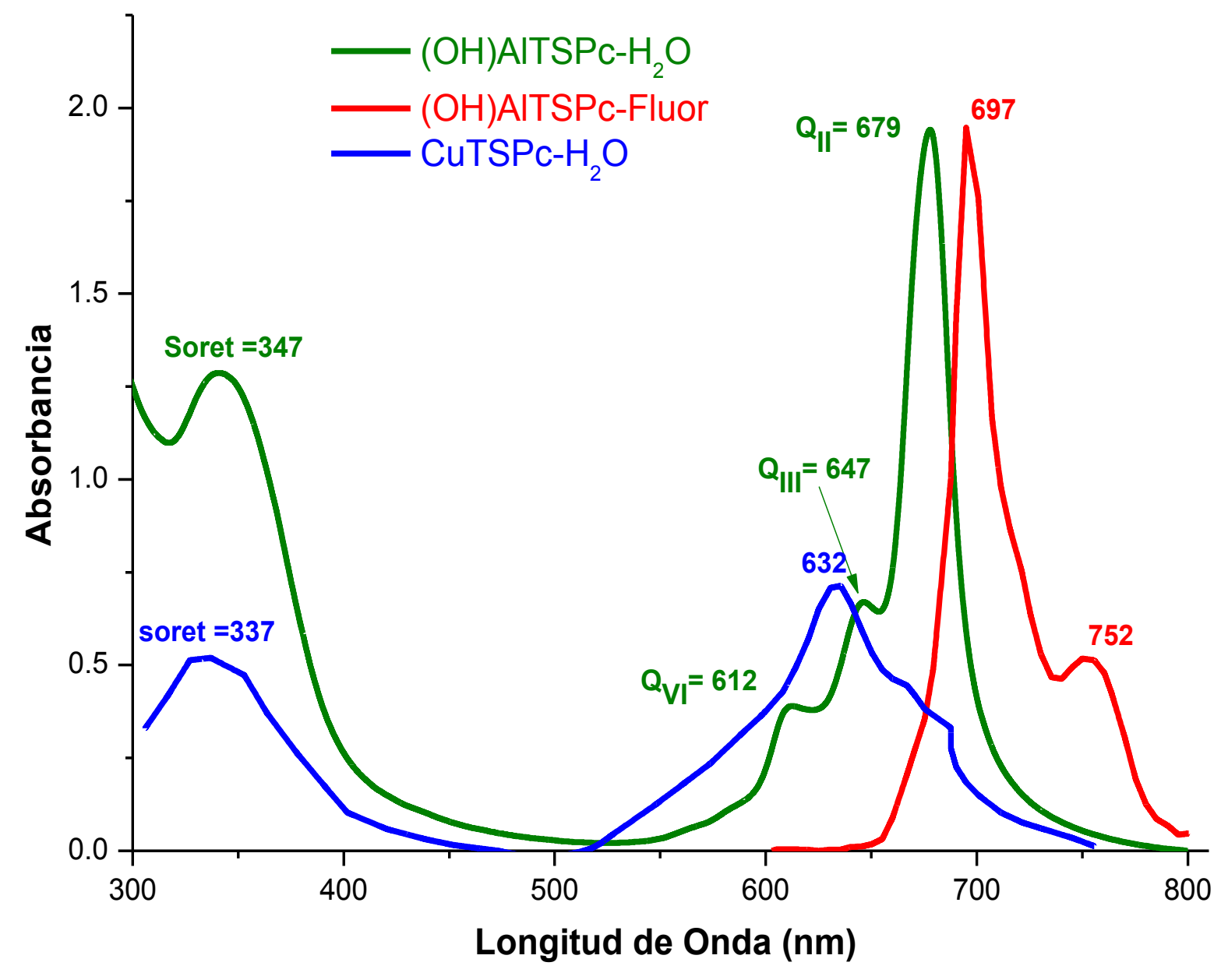

gura 2.13 Espectros UV-Vis de la especie (OH)AlTSPc en solución [48] 

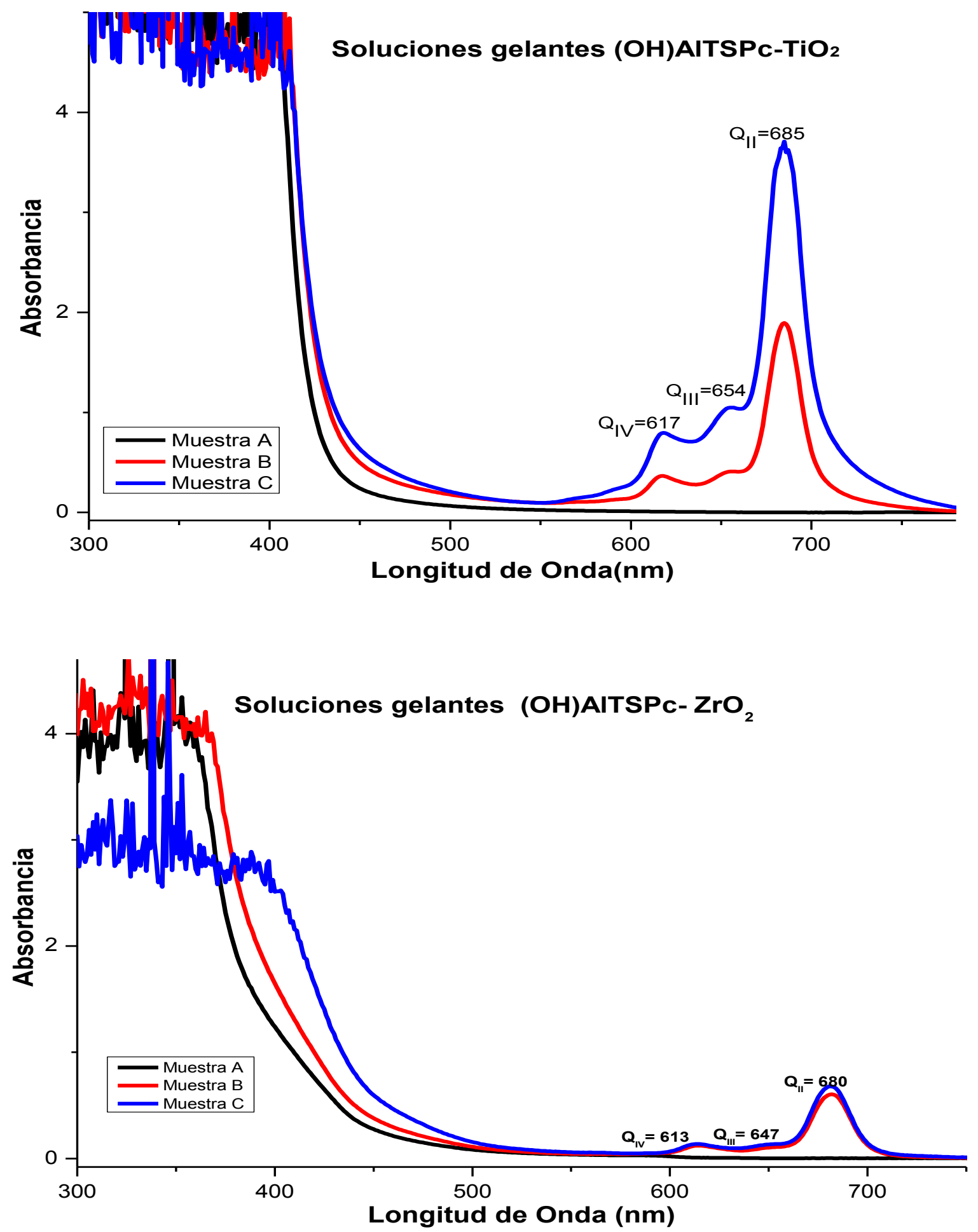

Figura 2.14 Espectros UV-Vis de me zclas gelantes de $\mathrm{TiO}_{2}$ y $\mathrm{ZrO}_{2} \sin$ (Espectro A) y con la especie (OH)AlTSPc (Espectros B y C) 


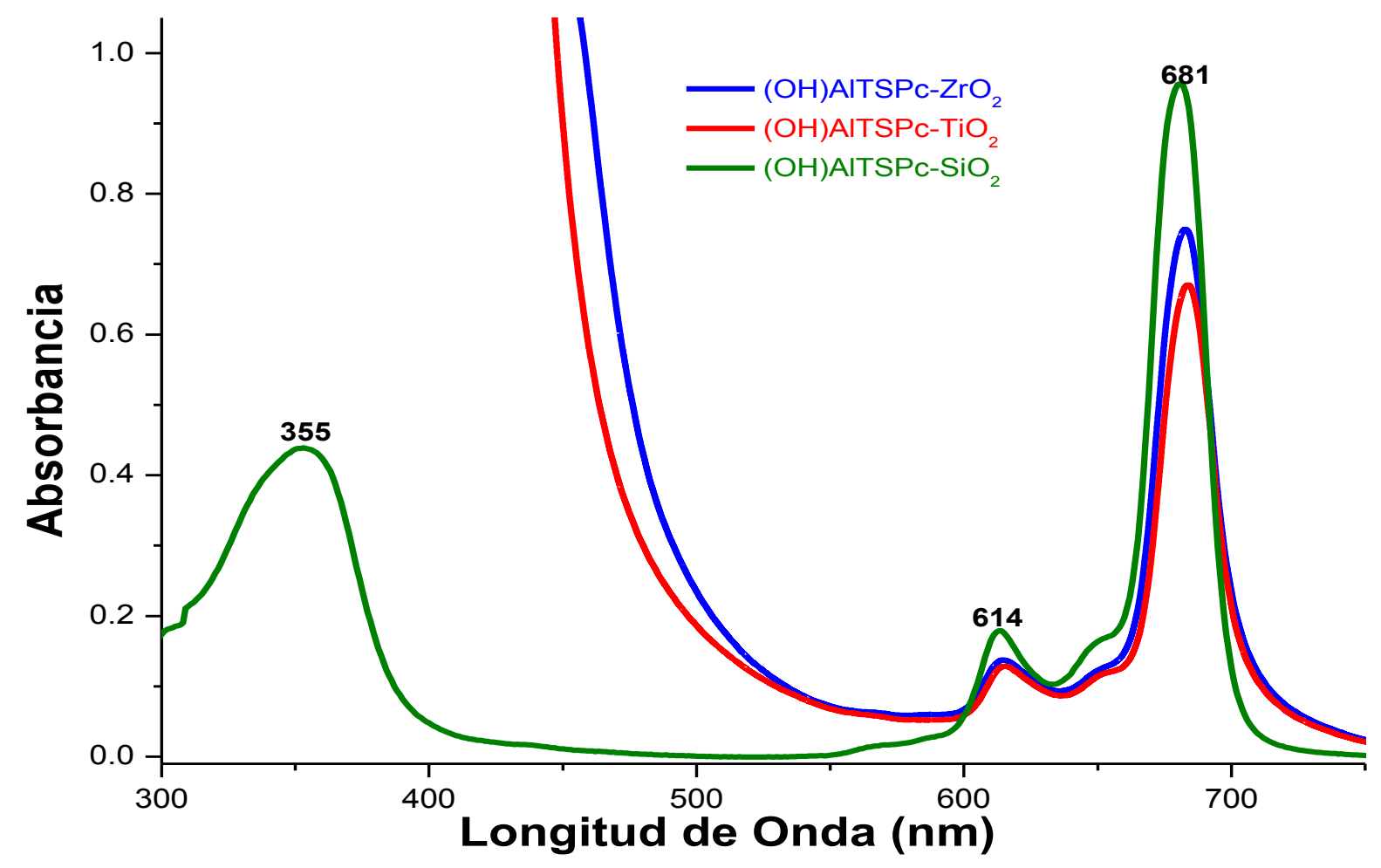

Figura 2.15 Espectros UV-Vis de los xerogeles finales con la especie $(\mathrm{OH}) \mathrm{AlTSPc}$ en $\mathrm{TiO}_{2}, \mathrm{ZrO}_{2}$ y $\mathrm{SiO}_{2}$.

\subsubsection{Diámetro de poro y área superficial en los dos óxidos.}

Se obtuvieron las isotermas de adsorción de $\mathrm{N}_{2}$ de los xerogeles sintetizados de $\mathrm{ZrO}_{2}$ y $\mathrm{TiO}_{2}$ con la especie (OH)AITSPc atrapada en los poros. La isotermas de adsorción de $\mathrm{N}_{2}$ que se muestran en la figura 2.16 corresponde a una isoterma Tipo III con ciclo de histéresis H3 para el $\mathrm{TiO}_{2}$ [52], característica de los sólidos no porosos o macro porosos. Como puede verse en la figura el ciclo de histéresis es pequeño, lo cual sugiere que la difusión de las moléculas de absorbato se lleva a cabo con relativa facilidad de una cavidad a otra, para el $\mathrm{ZrO}_{2}$ se presenta una isoterma Tipo I (b) con ciclo de histéresis H3 [52], que es representativa de los materiales micro porosos que tienen superficies externas relativamente pequeñas, micro poros más anchos con la posibilidad de presentar meso poros estrechos. El ciclo de histéresis en esta isoterma, es poco más grande que en la de $\mathrm{TiO}_{2}$ lo cual sugiere que la difusión de las moléculas de absorbato 
se dificulta de una cavidad a otra, posiblemente por la existencia de interconexiones pequeñas entre los poros.

Se reportan diámetros de poro de $2.2 \mathrm{mn}$ y áreas superficiales de $28.1 \mathrm{~m}^{2} / \mathrm{g}$ para el $\mathrm{ZrO}_{2}$ en contraste para el $\mathrm{TiO}_{2}$ son reportados valores de $2.5 \mathrm{~nm}$ y $308 \mathrm{~m}^{2} / \mathrm{g}$ de diámetro y área respectivamente.

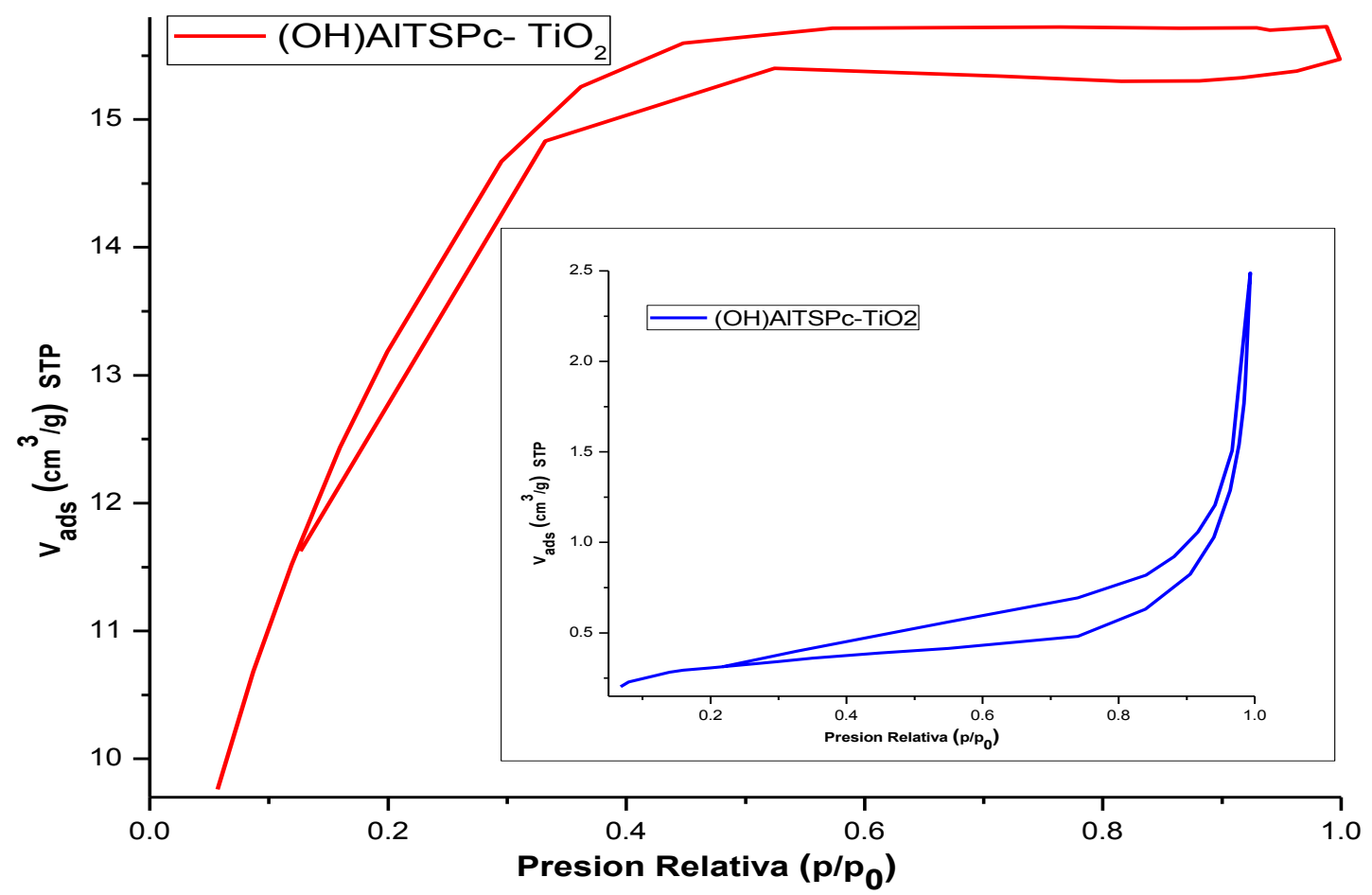

Figura 2.16 Isotermas de xerogeles finales con la especie (OH)AITSPc atrapada en $\mathrm{TiO}_{2}, \mathrm{ZrO}_{2}$.

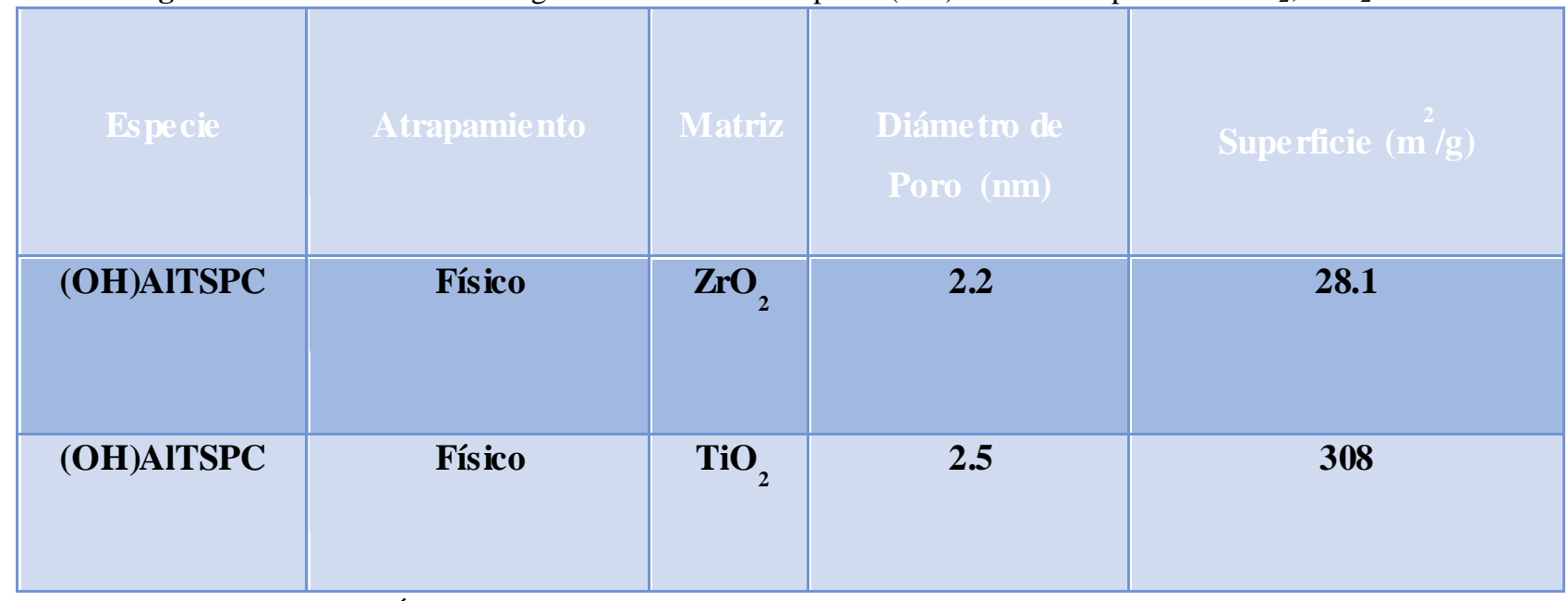

Tabla 2.6 Área específica y diámetro de poro de los dos óxidos con la especie atrapada . 
Se determinó también la distribución de diámetro de poro utilizando las isotermas y aplicando la teoría del funcional de la densidad no lineal (NLDFT) utilizando la curva de desorción y suponiendo poros esféricos (Figuras 2.17 y 2.18). Los resultados indican para los dos óxidos un aumento en la cantidad de tamaño de poros específicos, para el caso del $\mathrm{ZrO}_{2}$ al ser atrapada la especie $(\mathrm{OH})$ AITSPc el tamaño de poro predominante resulta ser $2.6 \mathrm{~nm}$ desapareciendo prácticamente los poros de mayor dimensión, para el caso del $\mathrm{TiO}_{2}$ el tamaño de poro que se presenta con mayor frecuencia es el de $28 \mathrm{~nm}$, El ligero aumento de diámetro de poro en los dos óxidos, así como la formación de un tamaño preferente puede atribuirse a la especie $(\mathrm{OH})$ AlTSPc que se encuentra atrapada en los poros del material.

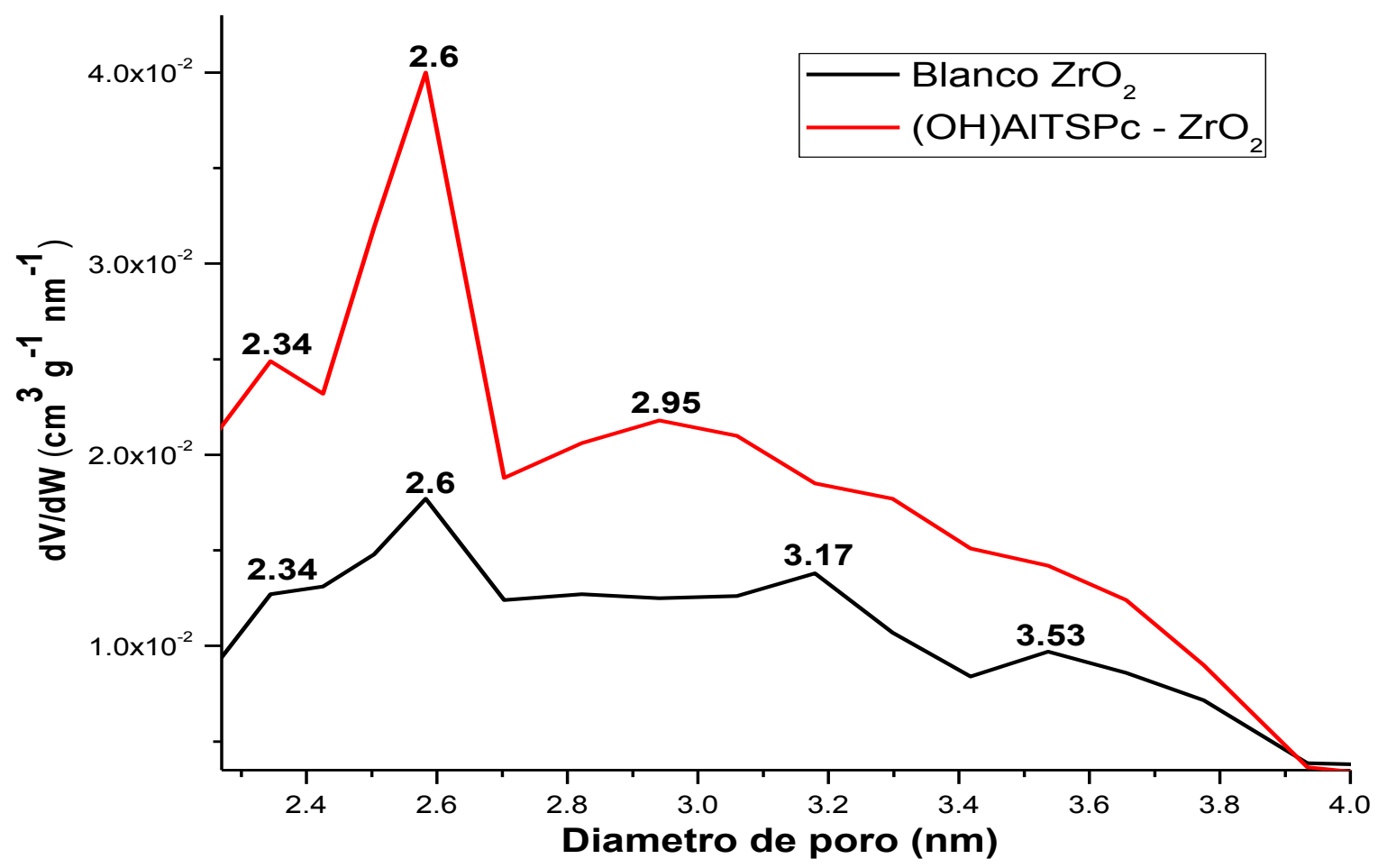

Figura 2.17 Distribución de diámetro de poro de xerogeles con y sin (OH)AIT SPc en $\mathrm{ZrO}_{2}$. 


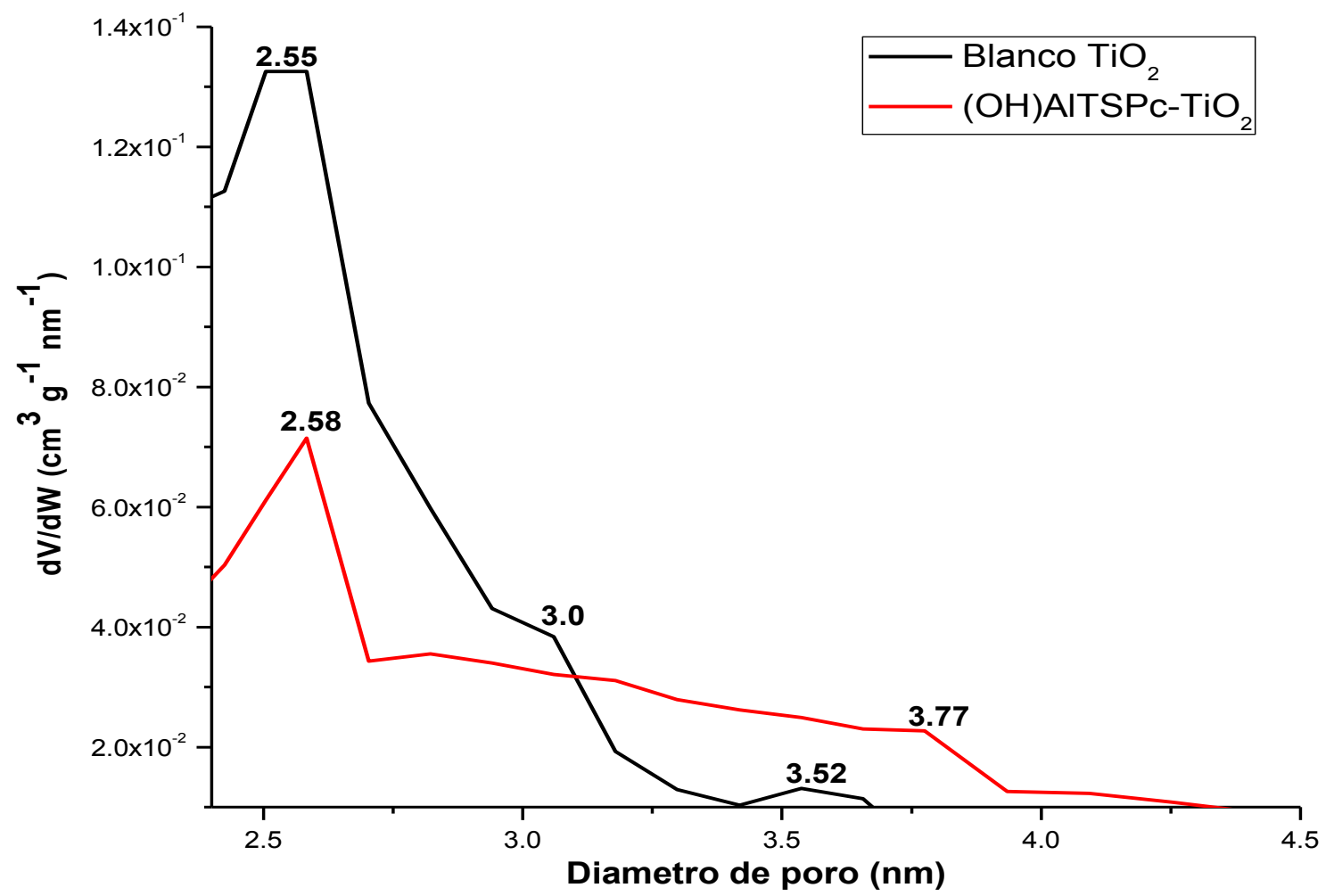

Figura 2.18 Distribución de diámetro de poro de xerogeles con y $\sin (\mathrm{OH}) \mathrm{AITSP}$ en $\mathrm{TiO}_{2}$. 


\subsubsection{Microscopía de Barrido (SEM), Análisis EDS Y TEM.}

En las imágenes TEM de los Xerogeles de $\mathrm{ZrO}_{2}$ y $\mathrm{TiO}_{2}$ en las que se encuentra físicamente atrapada la especie $(\mathrm{OH})$ AlTSPc es posible distinguir partículas translúcidas con una superficie relativamente lisa, sin cavidades o fracturas evidentes ( Fig. 2.19 a y 2.19 b). Sin embargo con un aumento mayor (Fig. 2.19 c y 2.19 d), es posible observar una morfología diferente. Estas diferencias podrían atribuirse a la porosidad interna de las redes, lo que sugiere la existencia de cavidades más pequeñas en el $\mathrm{TiO}_{2}$ comparadas con la red de $\mathrm{ZrO}_{2}$. Dado que ambas muestras fueron sintetizadas a partir de la misma concentración de la especie $(\mathrm{OH})$ AITSPc , las diferencias de textura sólo se pueden explicar en términos de las reactividades de los alcóxidos empleados y a la identidad del catión metálico presente en la estructura de las redes inorgánicas.

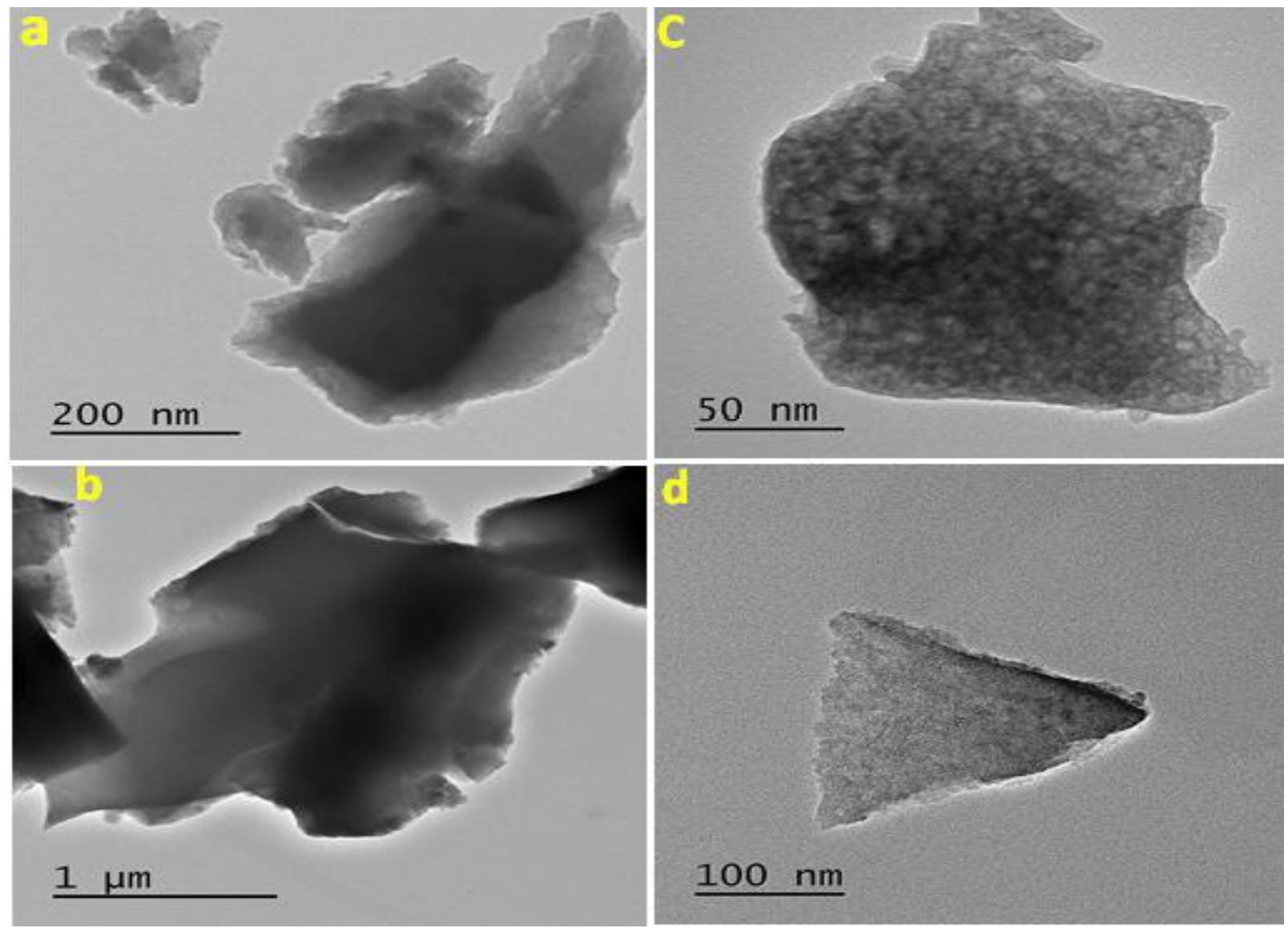

Fig. 2.19 imagen TEM de un xerogel con las especies (OH) AIT SPc at rapadas dentro de los poros de $\mathrm{ZrO} 2$ (a y c) y $\mathrm{TiO} 2$ (b y d) redes 
Se obtuvieron imágenes de microscopía de barrido (SEM) y análisis por EDS de carbono, zirconio y aluminio presente en el material sintetizado con precursores de Zirconio.

Los monolitos resultantes son de color verde, por la presencia de la especie $(\mathrm{OH}) \mathrm{AlTSPc}$. La imagen de SEM (Figura 2.20) indica que el material presenta algunas, irregularidades y fisuras, lo que sugiere cierta fragilidad. La distribución de carbono, zirconio y aluminio en el material indica la homogeneidad en la distribución de estos elementos en el material. Cabe destacar la presencia de aluminio que sólo se puede atribuir al complejo macrocíclico utilizado como sonda.

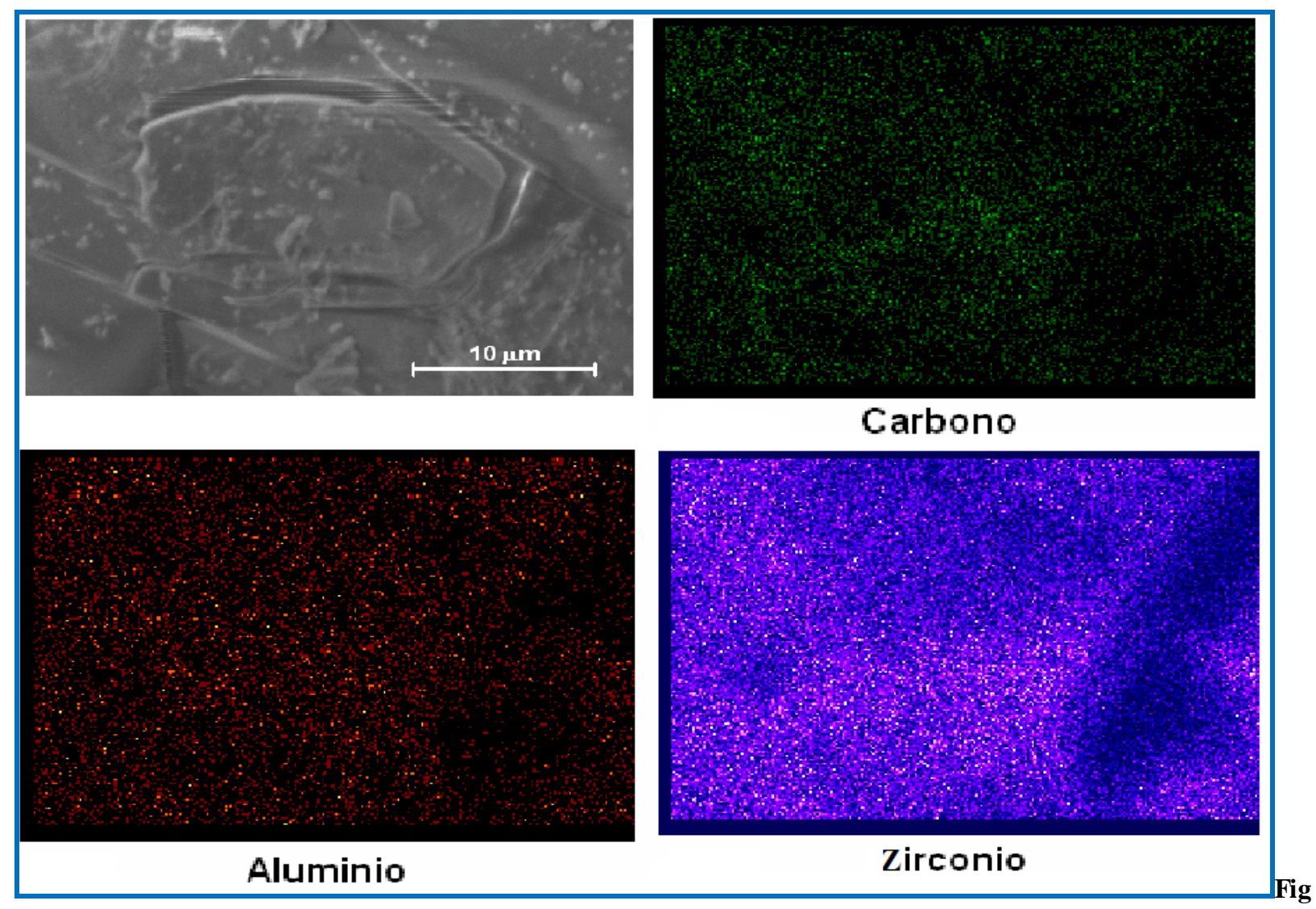

ura 2.20 Imagen de microscopía de barrido (SEM) e imágenes de EDS para carbono, zirconio y alu min io presente en la muestra. 


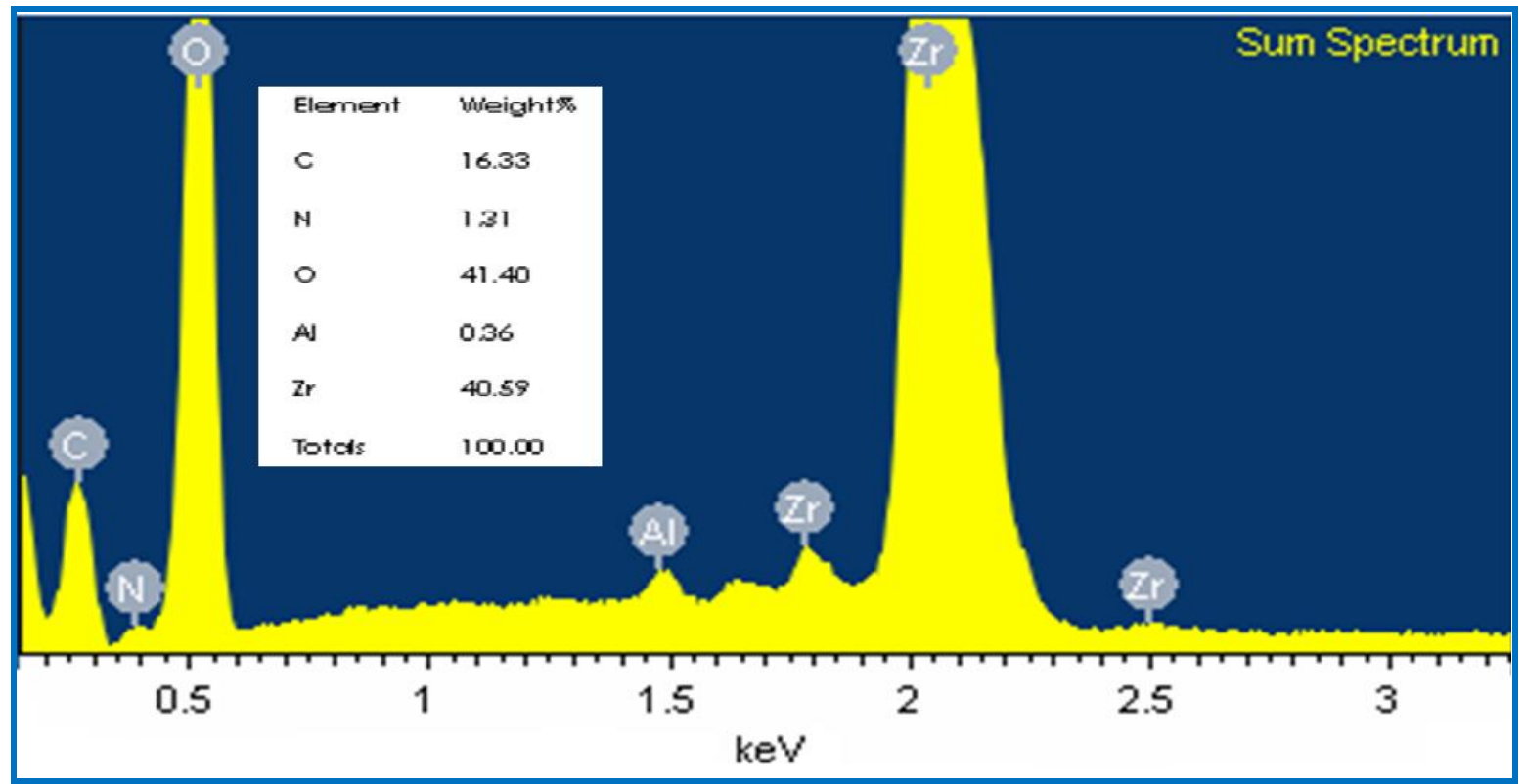

Figura 2.21. Porcentaje de elementos detectados por EDS en la muestra.

El mapeo EDS (Figura 2.21) de una de las muestras con la especies (OH)AlTSPc atrapada físicamente revela una distribución homogénea de los elementos $\mathrm{Zr}, \mathrm{Al}$, y $\mathrm{C}$. También son detectados los siguientes porcentajes en peso \%: 0,37 de Al (1,00 mol), 1,31 de $\mathrm{N}(6,82$ mol), 16,33 de C (99,14 mol), 41,4 (188,7 mol) de O, y 40,59 de Zr (32,45 mol). El porcentaje de Al y $\mathrm{N}$ sólo se puede asociar a la presencia de ftalocianina de aluminio, con la fórmula molecular $\mathrm{AlN}_{8} \mathrm{C}_{32} \mathrm{~S}_{4} \mathrm{O}_{13} \mathrm{H}_{13} \mathrm{Na}_{4}$. Los excesos de carbono y oxígeno pueden estar relacionados con el mismo complejo de ftalocianina, sin embargo también podrían atribuirse a la existencia de acetilacetona remanente $(\mathrm{AcacH})$, dimetilformamida $(\mathrm{DMF})$ o grupos propoxi $\left(\mathrm{OC}_{3} \mathrm{H}_{7}\right)$. Con esta información es posible calcular la relación molar $\mathrm{O} / \mathrm{Zr}$ la cual es de aproximadamente 5.5 y atribuirla a la presencia de grupos $\mathrm{Zr}-\mathrm{OH}$ en la red. Además el análisis del porcentaje en peso revela que en la superficie de las muestras existen 32 átomos de zirconio por cada molécula de $(\mathrm{OH})$ AlTSPc; la mayoría de estos últimos átomos están formando parte de las cavidades de poros que rodean las especies macrocíclicas atrapadas. Para el caso de xerogeles de $\mathrm{TiO}_{2}$, que incluye a la especie $(\mathrm{OH})$ AlTSPc atrapada. 


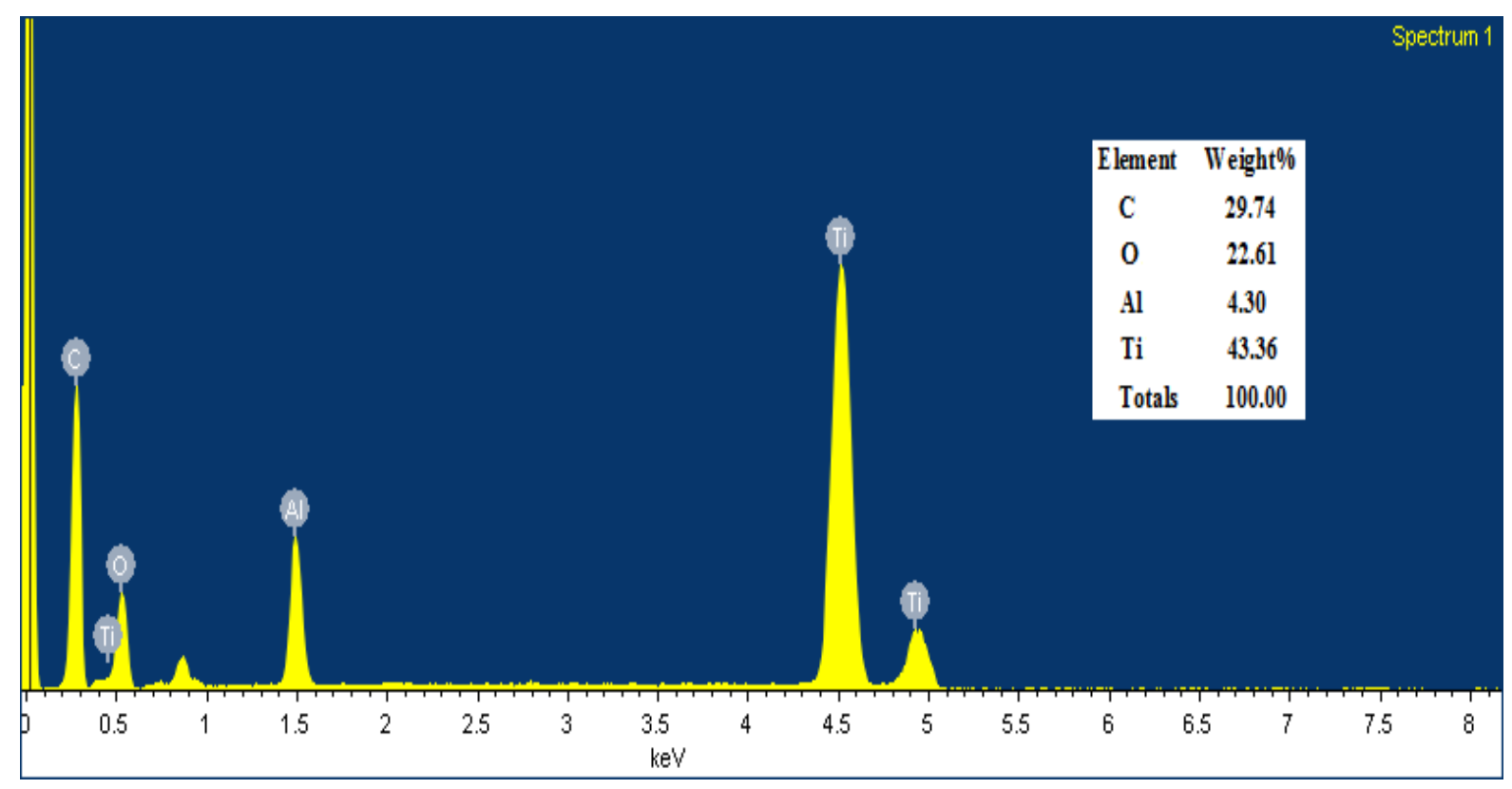

Figura 2.22 Porcentaje de elementos detectados por EDS en la muestra.

Para el caso del material sintetizado con $\mathrm{TiO}_{2}$ el mapeo EDS de una de las muestras con la especies $(\mathrm{OH}) \mathrm{AlTSPc}$ atrapada son detectados los siguientes porcentajes en peso \%:0.8 de $\mathrm{Al}$ (1,00 mol), $3.46 \mathrm{de} \mathrm{N}$ (8.3 mol), 29.74 de C ( $83.64 \mathrm{~mol}), 22.61$ (47.69 mol) de O, y 43,36 de Ti (30.61 mol). El porcentaje de Nitrógeno se obtuvo considerando que por cada átomo de Aluminio existen 8 de Nitrógeno los cuales se encuentran ligados a la molécula (OH)AlTSPc, como en el caso del $\mathrm{ZrO}_{2}$ el carbono se puede asociar a la especie atrapada y a los compuestos remanentes de acetilacetona $(\mathrm{AcacH}), \mathrm{N}, \mathrm{N}$-dimetilformamida (DMF) o grupos propoxi $\left(\mathrm{OC}_{3} \mathrm{H}_{7}\right)$. La relación molar O/Ti es de aproximadamente 1.5 y se puede atribuir a la presencia de grupos Ti-OH remanentes en la red. La relación de moléculas de átomos de Ti con respecto a las de la especie $(\mathrm{OH})$ AlTSPc es de 30, muy similar a la presentada con $\mathrm{ZrO}_{2}$. 

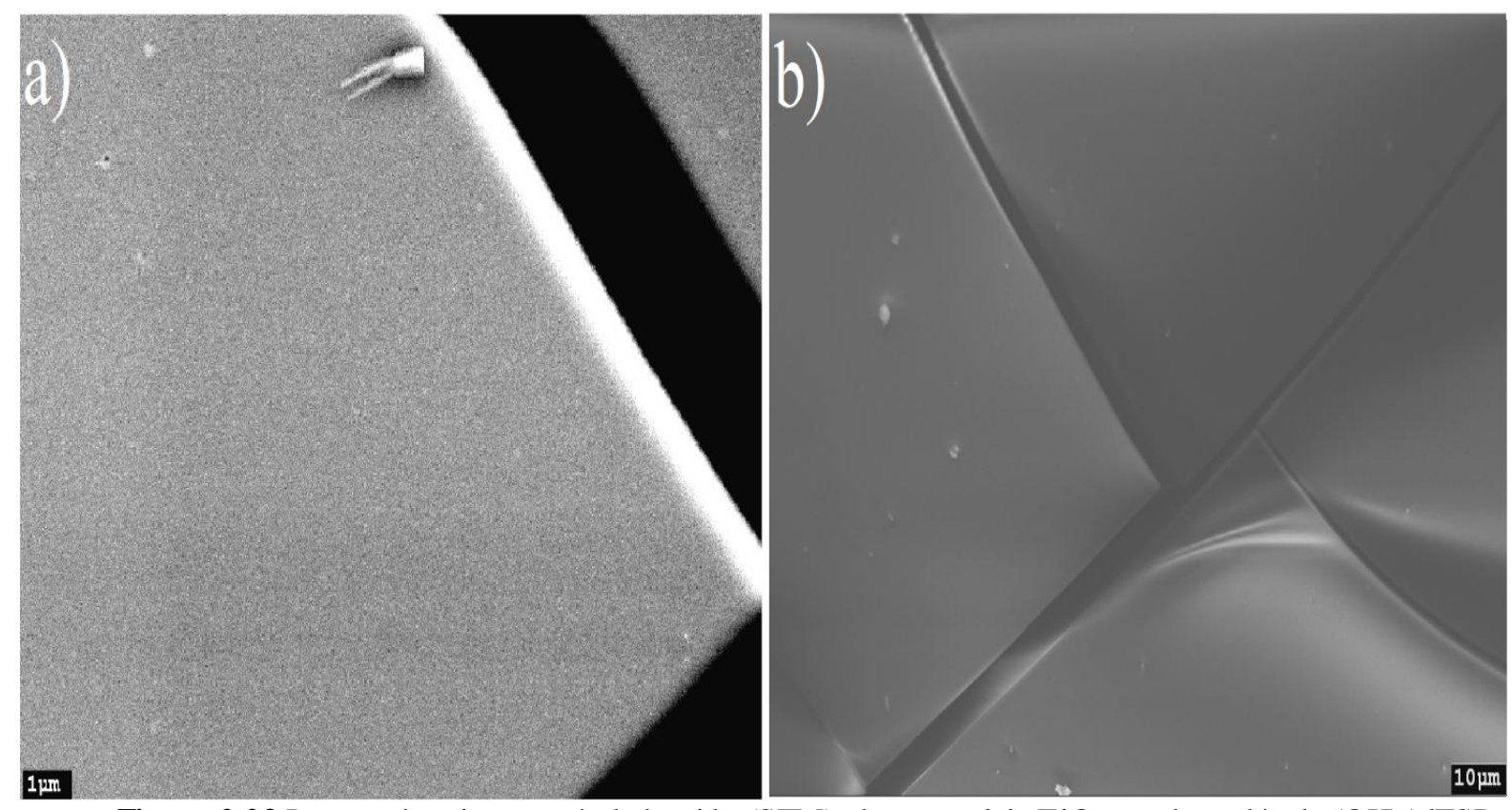

Figura 2.23 Imagen de microscopía de barrido (SEM) de xerogel de $\mathrm{TiO}_{2}$ con la mo lécula $(\mathrm{OH}) \mathrm{A}$ ITSPc atrapada a) $1 \mathrm{~m} \mu$ b) $10 \mu$

Los monolitos resultantes son de color verde, en la imagen de SEM, Figura 2.23 a) se puede apreciar una superficie lisa con fracturas y ciertas irregularidades, la figura 2.23b) muestra un material homogéneo que hace suponer que las sustancias presentes están distribuidas uniformemente.

\subsection{Atrapamiento de especies MTSPc (M=Co, $\mathrm{Cu}, \mathrm{Fe}, \mathrm{Zn}$ y Al ) en xerogeles de $\mathrm{ZrO}_{2}$ y $\mathrm{TiO}_{2}$.}

Con base en las observaciones hechas con la molécula sonda utilizada y después de determinar la factibilidad de atrapar a la especie $(\mathrm{OH})$ AlTSPc en forma estable y monomérica en el interior de los poros de los xerogeles de $\mathrm{ZrO}_{2}$ y $\mathrm{TiO}_{2}$ monolítico y transparente, se sintetizaron monolitos equivalentes, utilizando las relaciones de las tablas 8 y 9 , ahora agregando a la mezcla gelificante una solución $4.4 \times 10^{-3} \mathrm{M}$. de los complejos de tetrasulfoftalocianina de $\mathrm{Co}, \mathrm{Cu}, \mathrm{Fe}, \mathrm{Ni}$ y Al, (MTSPc) con objeto de atrapar dichas especies de manera física en los óxidos. (Tabla 2.7 y 2.8 ). 
Tabla: 2.7 Relaciones en volumen de mezclas gelantes para obtener xerogeles monolíticos translúcidos de $\mathrm{ZrO}_{2}$ con especies MTSPc.

\begin{tabular}{|c|c|c|c|c|c|c|}
\hline Muestra & $\operatorname{Zr}\left(\mathrm{OPr}^{\mathrm{n}}\right)_{4}$ & $: \mathrm{Pr}^{\mathrm{n} O \mathrm{OH}}$ & Acac & DNIF (ml) & $\begin{array}{c}\text { Solución con } \\
(\mathrm{OH}) \mathrm{AlTSP}_{\mathrm{H}} \mathrm{H} \mathrm{H}_{2} \mathrm{O} \\
(\mathrm{ml})\end{array}$ & $\begin{array}{l}\text { Concentración } \\
\text { (mol/L) }\end{array}$ \\
\hline (OH)AITSPc & 3.8 & 1.2 & 0.42 & 0.1 & 0.2 & 4.04 E-03 \\
\hline CoTSPe & 3.8 & 1.2 & 0.42 & 0.1 & 0.2 & 4.04 E-03 \\
\hline CuTSPc & 3.8 & 1.2 & 0.42 & 0.1 & 0.2 & 4.04 E-03 \\
\hline$(\mathrm{OH}) \mathrm{Fe}$ TSPc & 3.8 & 1.2 & 0.42 & 0.1 & 0.2 & 4.04 E-03 \\
\hline NiTSPc & 3.8 & 1.2 & 0.42 & 0.1 & 0.2 & $4.04 \mathrm{E}-03$ \\
\hline
\end{tabular}

Tabla: 2.8 Relaciones en volumen de mezclas gelantes para obtener xerogeles monolíticos translúcidos de $\mathrm{TiO}_{2}$ con especies MTSPc.

\begin{tabular}{|c|c|c|c|c|c|c|}
\hline Muestra & $\mathrm{Ti}\left(\mathrm{OPr}^{\mathrm{n}}\right)_{4}$ & $: \mathrm{Pr}^{\mathrm{n} O H}$ & :Acac & : DMIF (ml) & $\begin{array}{l}\text { Solución con } \\
(\mathrm{OH}) \mathrm{A} \text { AISSPc/ } \mathrm{H}_{2} \mathrm{O} \\
(\mathrm{ml})\end{array}$ & $\begin{array}{l}\text { Concentración } \\
\text { (mol/lu) }\end{array}$ \\
\hline (OH)AITSPc & 3.0 & 1 & 0.2 & 0.3 & 0.2 & 4.04 E-03 \\
\hline CoISPe & 3.0 & 1 & 0.2 & 0.3 & 0.2 & 4.04 E-03 \\
\hline CuTSPc & 3.0 & 1 & 0.2 & 0.3 & 0.2 & 4.04 E-03 \\
\hline (OHI) FeTSPc & 3.0 & 1 & 0.2 & 0.3 & 0.2 & 4.04 E-03 \\
\hline NiTSPc & 3.0 & 1 & 0.2 & 0.3 & 0.2 & 4.04 E-03 \\
\hline
\end{tabular}




\subsection{Caracterización de xerogeles translúcidos de $\mathrm{ZrO}_{2}$ y $\mathrm{TiO}_{2}$ con especies (MTSPc) atrapadas.}

\subsubsection{UV-Vis}

Se obtienen los espectros UV-Vis de cada una de las muestras y de los xerogeles finales.

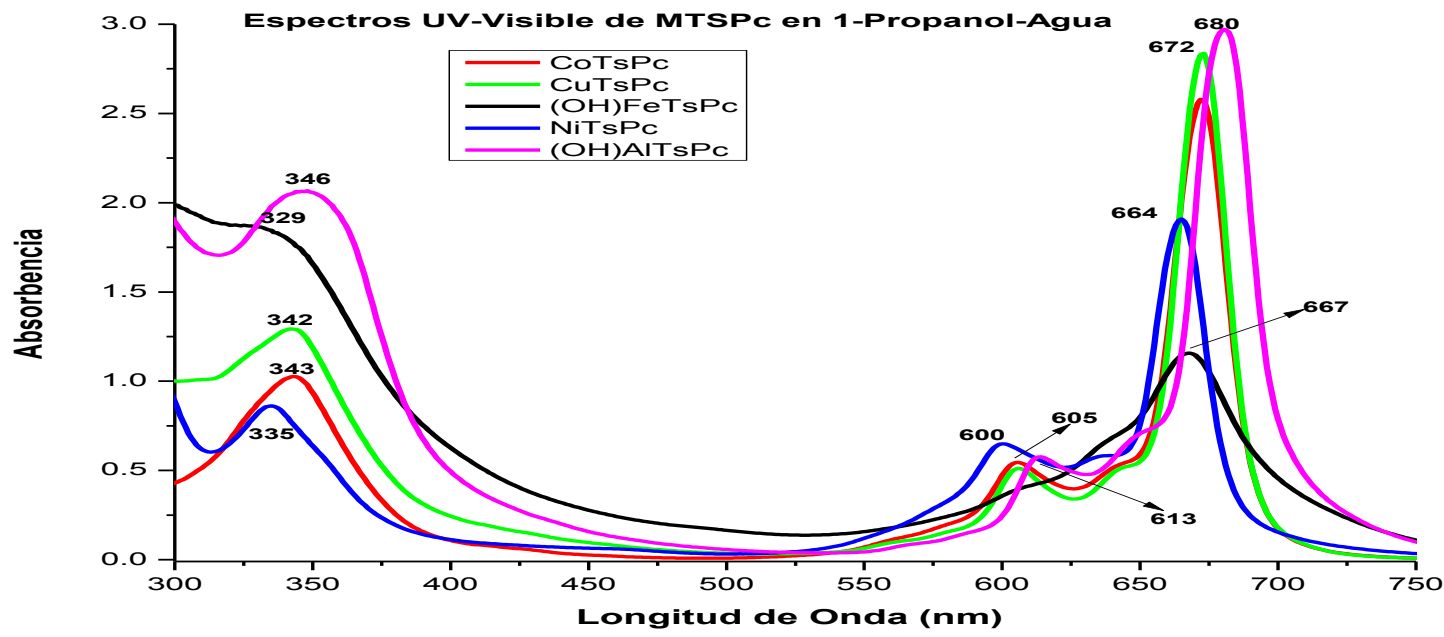

Los espectros UV-Visible de las MTSPc en solución 1-propanol- agua (Figura 2.24) se

obtienen con objeto de compararlos con los espectros en solución gelante y los monolitos consolidados, nótese que los espectros de las moléculas son espectros de moléculas como monómeros.

Figura 2.24 Espectros UV-Vis de especies MTSPc en 1 Propanol-Agua 

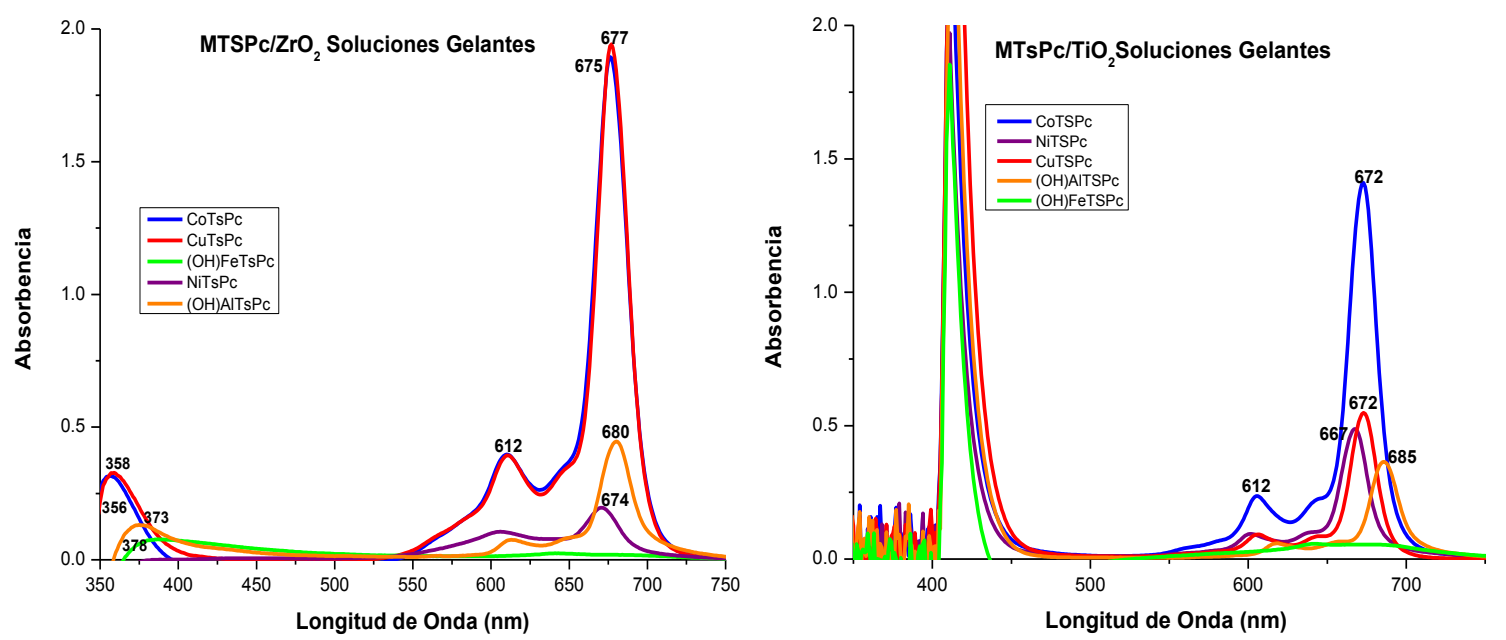

Figura 2.25 Espectros UV-Vis de las soluciones gelantes con las especies $\mathrm{MTSPc}_{\mathrm{e}} \mathrm{TiO}_{2}$ y $\mathrm{ZrO}_{2}$

En la figura 2.25 se puede apreciar que la especie $(\mathrm{OH}) \mathrm{FeTSPc}$ forma agregados en las soluciones gelantes de los dos óxidos y que las bandas características de las otras moléculas se encuentran presentes en los óxidos lo cual nos indica que se encue ntran atrapadas en la solución.
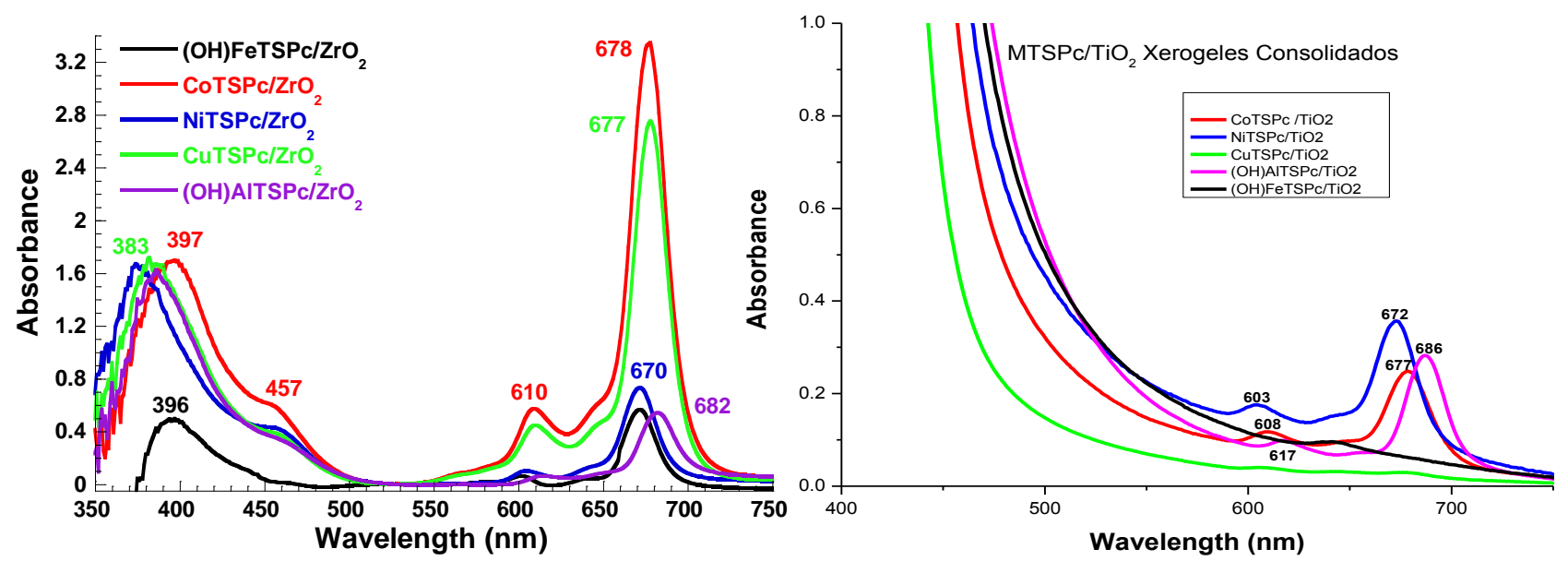

Figura 2.6 Espectros UV-Vis de Xerogeles consolidados en $\mathrm{ZrO}_{2}$ y $\mathrm{TiO}_{2}$ respectivamente

Por el patrón de bandas observado en la figura 2.6 puede inferirse que la mayoría de los complejos tipo MTSPc permanecen atrapados en forma monomérica, $s$ in embargo las especies $(\mathrm{OH}) \mathrm{Fe}$ TSPc y CuTSPc tienden a formar agregados al ser atrapada en la red de óxido de titanio, al parecer el ambiente químico dentro del poro determina el estado de cada molécula, esto resulta relevante ya que para que algunas de estas moléculas despliegan propiedades importantes requieren ser soportadas en materiales adecuados. Como en el caso del complejo (OH)AITSPc, las bandas $\mathrm{Q}_{\mathrm{II}}$ se observan menos intensas y desplazadas al rojo al ser atrapadas en $\mathrm{TiO}_{2}$, lo que 
sugiere la existencia de ambientes fisicoquímicos diferentes al interior de los poros de $\mathrm{TiO}_{2}$ y de $\mathrm{ZrO}_{2}$.

\subsubsection{Diámetro de poro y área superficial}

Se obtuvieron las isotermas de adsorción de $\mathrm{N}_{2}$ de los xerogeles sintetizados de $\mathrm{ZrO}_{2}$ y $\mathrm{TiO}_{2}$ con las moléculas CoTSPc, FeTSPc, NiTSPc, CuTSPc y (OH)AITSPc , Las isotermas de adsorción de $\mathrm{N}_{2}$ que se muestran en las figuras 2.27 y 2.28 presentan isotermas que pueden clasificarse como isotermas IUPAC de tipo I con ciclos de histéresis H3 [52], que son representativas de materiales con forma de hendidura. En estos tipos de redes, la condensación y la evaporación de las moléculas de $\mathrm{N}_{2}$ debe realizarse de forma relativamente fácil y sin la irrupción de fenómenos cooperativos o efectos de bloqueo de poros. En el conjunto de muestras de TiO2, los ciclos de histéresis fueron más estrechos que los correspondientes a las muestras de $\mathrm{ZrO} 2$; Adicionalmente, las capacidades de adsorción de $\mathrm{N}_{2}$ de las muestras de $\mathrm{TiO}_{2}$ resultaron ser mayores que las de las muestras de $\mathrm{ZrO}_{2}$. Tambien resulta evidente que la capacidad de sorción de cada muestra depende de la identidad del compuesto MTSPc atrapado dentro de la red porosa.

Resulta interesante también observar que al parecer la presencia de las especies macrociclicas afecta las dimensiones promedio de las cavidades en la matriz de $\mathrm{ZrO}_{2}$ finalmente obtenida. En la figura 2.27 se observa también que la matriz de $\mathrm{ZrO}_{2}$ pura presenta menor capacidad adsorbente de $\mathrm{N}_{2}$, la cual aumenta en el orden CoTSPc $<$ NiTSPc $<$ FeTSPc $<$ CuTSPc, hasta su máximo con la especie $(\mathrm{OH})$ AITSPc a diferencia de lo que sucede en la matriz de $\mathrm{TiO}_{2}$ en la cual la matriz pura tiene la capacidad de adsorber más $\mathrm{N}_{2}$ que casi todos los otros materiales, en esta serie la tendencia es $(\mathrm{OH})$ AlTSPc $<$ NiTSPc $<$ FeTSPc $<$ CoTSPc $<$ CuTSPc .Efecto que puede asociarse a la diferente capacidad absorbente de $\mathrm{H}_{2} \mathrm{O}$. 


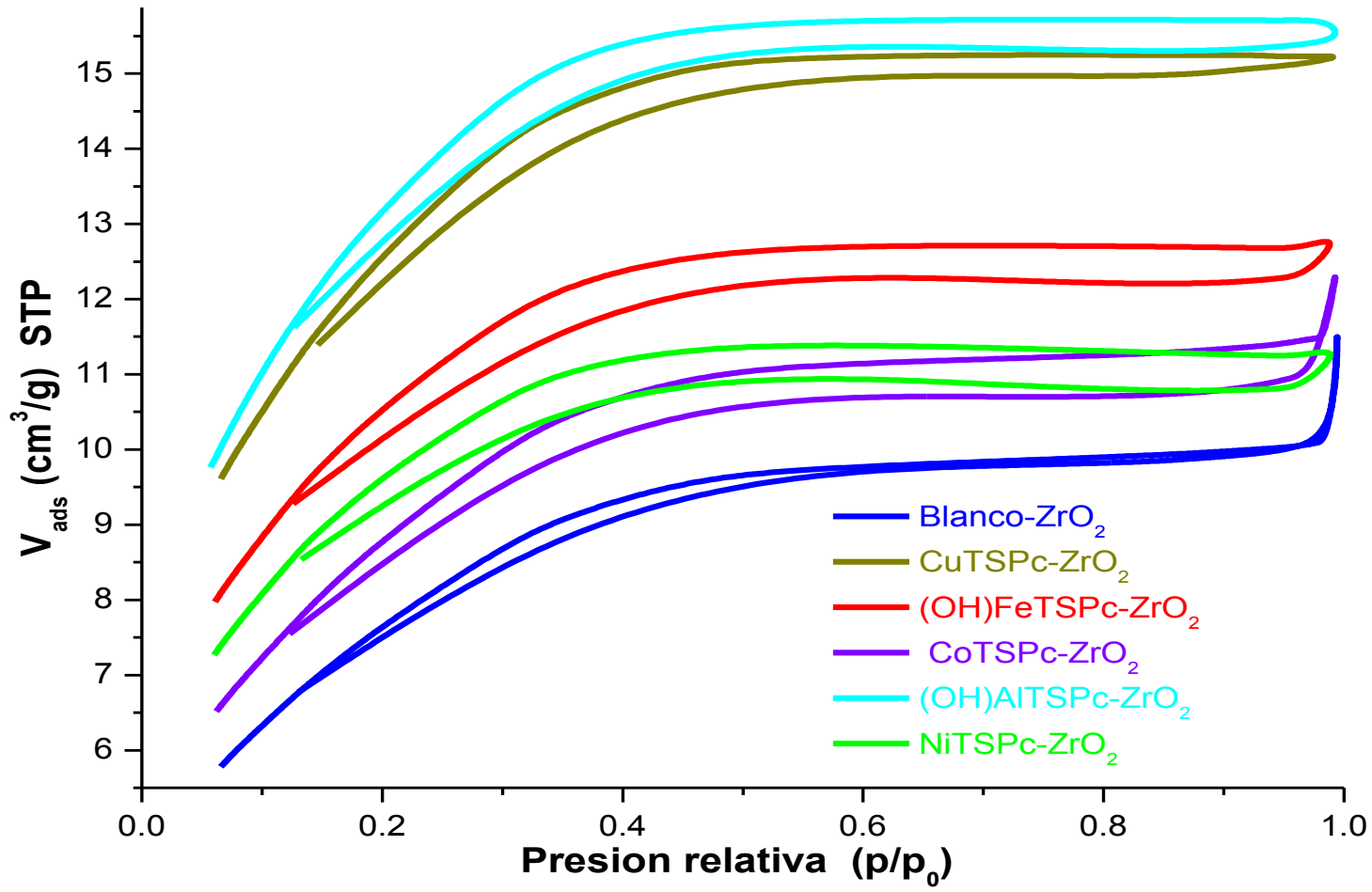

Figura 2.27 Isotermas de Adsorción de $\mathrm{N}_{2}$ de los xerogeles de $\mathrm{ZrO}_{2}$ y TiO con las especies MTSPc atrapadas

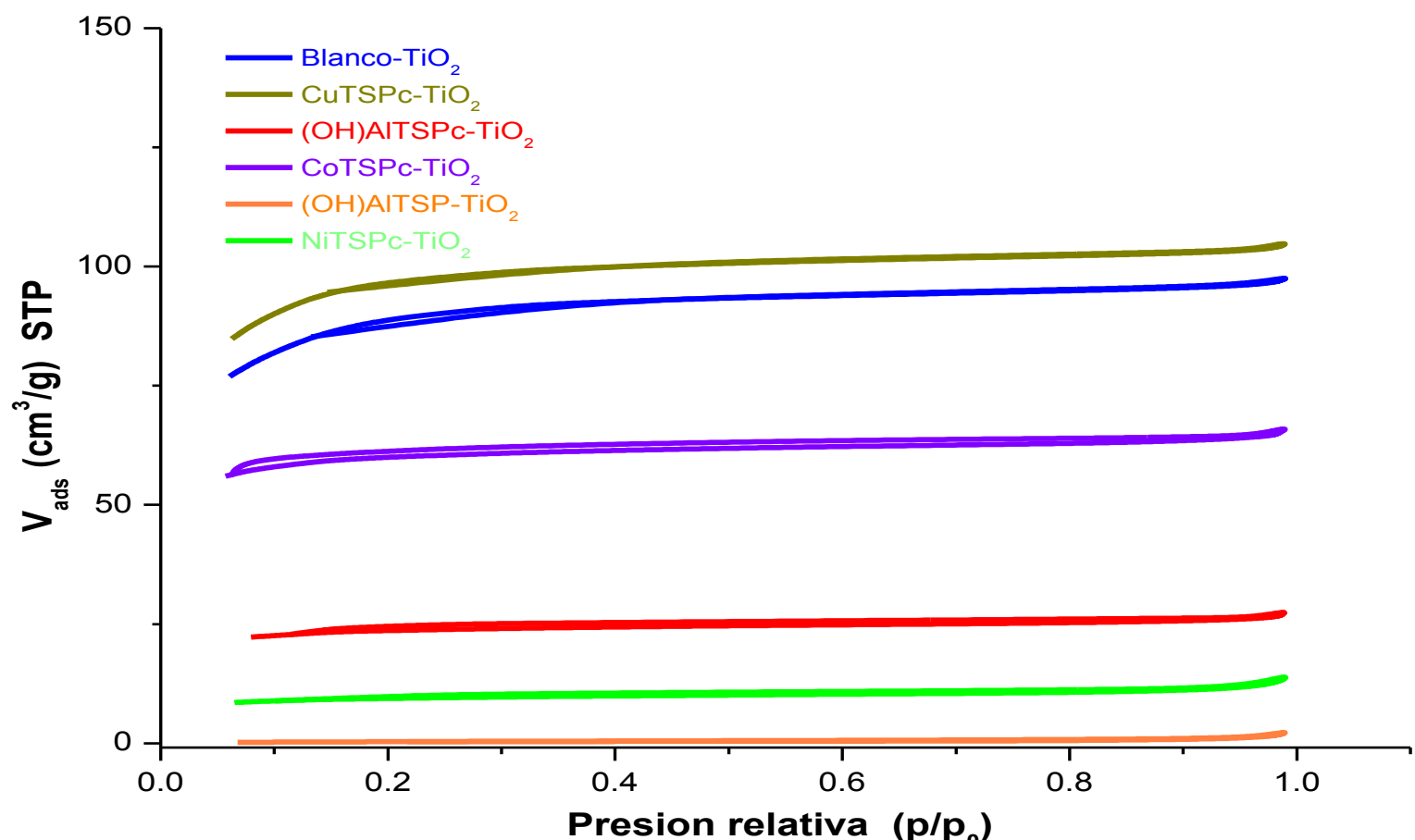

Figura 2.18 Isotermas de Adsorción de $\mathrm{N}_{2}$ de los xerogeles de $\mathrm{ZrO}_{2}$ y TiO con las especies MTSPc atrapadas 
A partir de las isotermas $\mathrm{N}_{2}$, se calcularon las superficies especificas y los diámetros medios de poro $(\Phi)$ de cada sustrato (Figura 2.29 y 2.30). Este último parámetro se obtuvo a partir de la aplicación del enfoque funcional de densidad no local a la curva límite de desorción del bucle de histéresis de la isoterma, asumiendo cavidades esféricas. En el caso de las muestras de $\mathrm{ZrO}_{2}$ para el blanco y las que contenían las especies MTSPc atrapadas en el interior, los diámetros de poro $(\Phi)$ y las superficies oscilaban en un pequeño intervalo de 2,2 a 2,4 nm y el área de superficie oscilaba entre 28,1 y 48,3 $\mathrm{m}^{2}$ / g. En contraste con las muestras de TiO2, los diámetros medios de poro $(\Phi)$ y el área superficial determinada variaron a lo largo de un rango más amplio de valores que van desde 2,5 a $8,3 \mathrm{~nm}$ y 32 a $334 \mathrm{~m}^{2} / \mathrm{g}$, respectivamente. Para la muestra de sílice sin molécula (blanco- $\mathrm{SiO}_{2}$ ), el diámetro promedio de los poros fue de $3,4 \mathrm{~nm}$ y el área superficial representó 729 m² / g [53-55].

\begin{tabular}{|c|c|c|c|}
\hline Matriz & Muestra & $\begin{array}{l}\text { Diámetro de poro } \\
\text { promedio }(\Phi)(\mathrm{nm})\end{array}$ & $\begin{array}{l}\text { Área superficial } \\
\qquad\left(\mathrm{m}^{2} / \mathrm{g}\right)\end{array}$ \\
\hline $\mathrm{ZrO}_{2}$ & MTSPc (M = Fe, Co, Ni, Cu, Al) & 2.2 a 2.4 & 28.1 a 48.3 \\
\hline Blanco $\mathrm{ZrO}_{2}$ & & 2.2 & 28.1 \\
\hline $\mathrm{TiO}_{2}$ & $\operatorname{MTSPc}(\mathrm{M}=\mathrm{Fe}, \mathrm{Co}, \mathrm{Ni}, \mathrm{Cu}, \mathrm{Al})$ & 2.5 a 8.3 & 32.0 a 334.0 \\
\hline Blanco- $\mathrm{TiO}_{2}$ & & 2.5 & 308.0 \\
\hline $\mathrm{SiO}_{2}$ & $\operatorname{MTSPc}(\mathrm{M}=\mathrm{Fe}, \mathrm{Co}, \mathrm{Ni}, \mathrm{Cu}, \mathrm{Al})$ & 2.2 to $2.4^{*}$ & 540.0 a $631.0^{*}$ \\
\hline Blanco-SiO ${ }_{2}$ & & $3.4^{*}$ & $729.0 *$ \\
\hline
\end{tabular}

Tabla 2.9. Parámetros Textura les evaluados a partir de las isotermas de sorción de $\mathrm{N}_{2}$ de los materiales sintetizados de $\mathrm{ZrO}_{2}$ y TiO 2 con y sin las especies MTSPc, *Parámetros de sistemas similares de $\mathrm{SiO}_{2}$ obtenidos de [53-55]. 


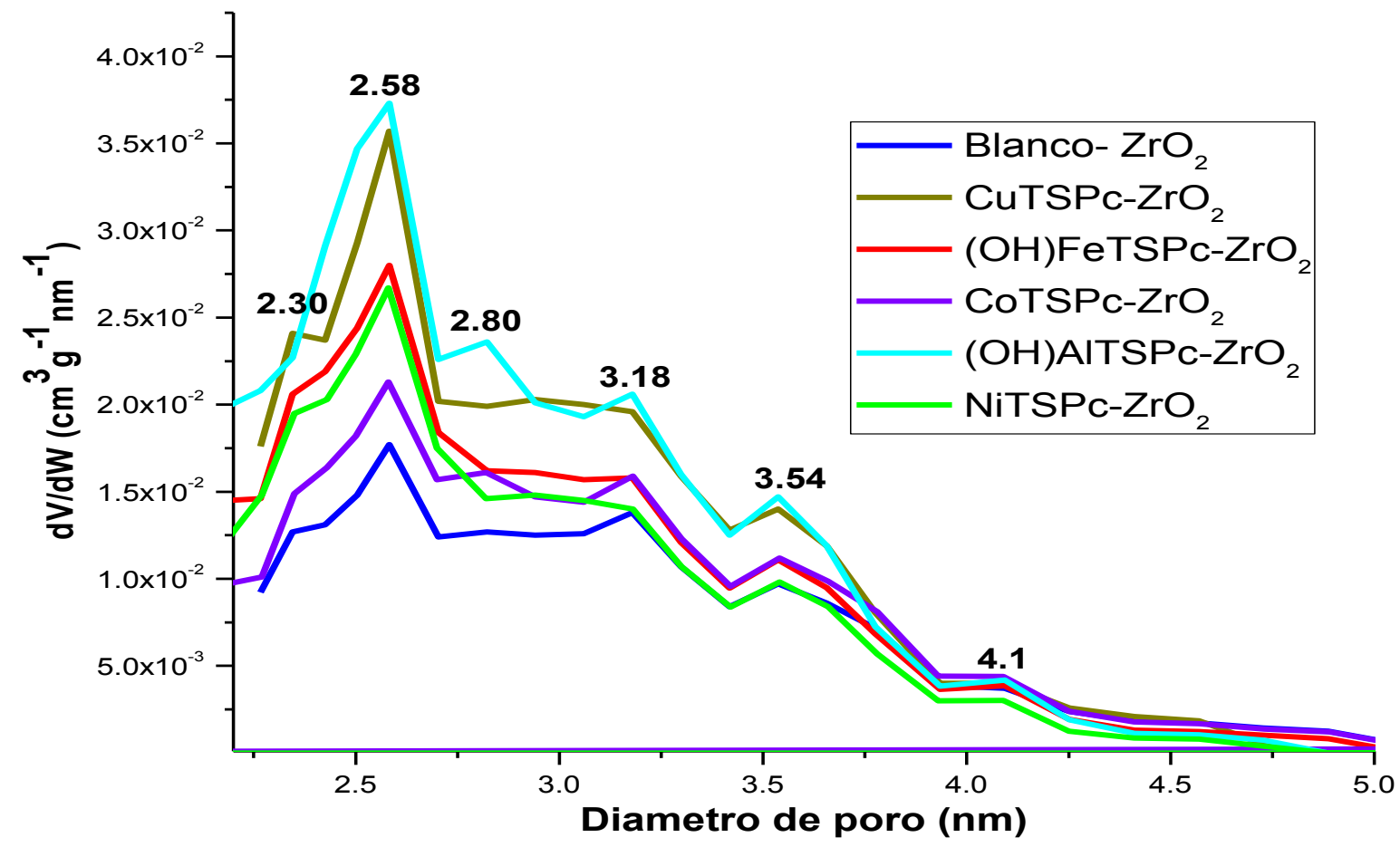

Figura 2.29. Distribución de ta maño de poro de los materiales de $\mathrm{ZrO}_{2}$ calculadas por Aplicación del enfoque de NLDFT a la isoterma de la frontera de la desorción asumiendo poro esférico.

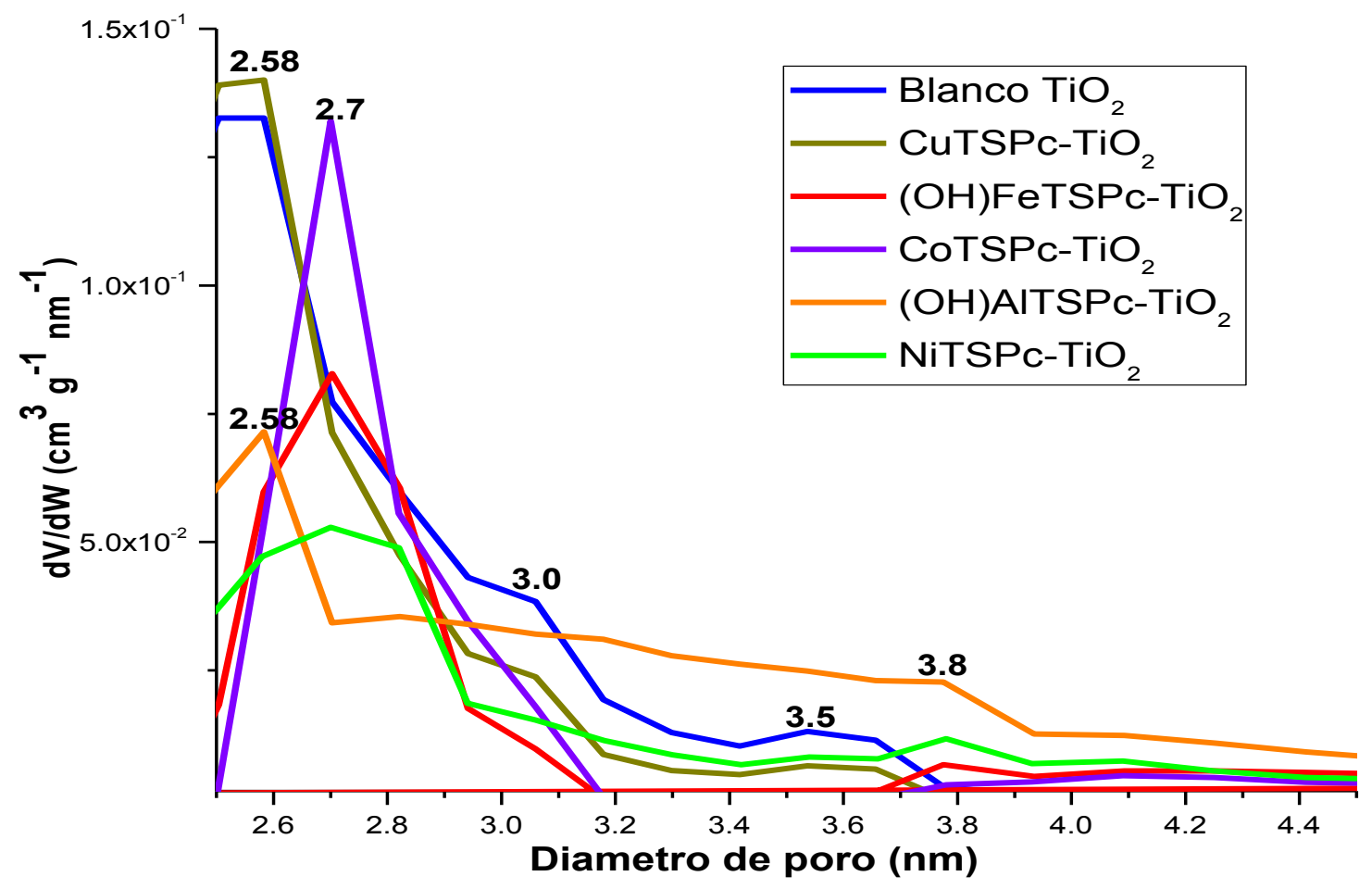

Figura 2.30 Distribución de tamaño de poro de los materiales de $\mathrm{TiO}_{2}$ calculadas por Aplicación del enfoque de NLDFT a la isoterma de la frontera de la desorción asumiendo poro esférico 
Al determinarse el diámetro de poro promedio y el área superficial específica resulta más evidente que estos parámetros dependen de la identidad del catión en la especie MTSPc. Así mismo estos tamaños de poro en los xerogeles de $\mathrm{ZrO}_{2}$ obtenidos, resultan ser de dimensiones (Tabla 2.9) similares a los generados con $\mathrm{SiO}_{2}$ alrededor de la molécula de (OH)AITSPc (tabla 11) [53-55] lo que sugiere que las MTSPc se encuentran atrapadas dentro de cavidades de la red de $\mathrm{ZrO}_{2}$ que se han formado en torno a las especies MTSPc y en última instancia, que las dimensiones de dichas cavidades dependen de la identidad del catión presente en tales complejos. Se supone dicho efecto porque los complejos macrocíclico tipo MTSPc tienen un tamaño aproximado de 1.8 a $2.0 \mathrm{~nm}$, que son dimensiones muy próximas a las determinadas en las muestras sintetizadas. En lo que respecta a las áreas superficiales, resulta evidente que las diferencias son atribuibles a la naturaleza misma de la matriz de $\mathrm{ZrO}_{2}$, ya que se sabe que éste genera áreas superficiales muy pequeñas y del orden de $100 \mathrm{~m}^{2} / \mathrm{g}$ [56] al sintetizarse por el método sol gel y secarse a temperatura ambiente y de alrededor de $74 \mathrm{~m}^{2} / \mathrm{g}$ si se realiza tratamiento térmico de alrededor de $400{ }^{0} \mathrm{C}$ [57]. Sin embargo, la presencia de las especies MTSPc parece inducir la formación de cavidades menores, acorde con las dimensiones del macrociclo atrapado con un tamaño aproximado de $1.8 \mathrm{~nm}$ entre los grupos sulfo periféricos. 


\subsubsection{Microscopia de Barrido (SEM), Análisis EDS Y TEM}

Se obtuvieron imágenes TEM de los Xerogeles que contienen la especie CoTSPc (Figura 2.31), en esta es posible observar que la red está constituida por la agregación de partículas, cuyas redes son mayores en el $\mathrm{ZrO}_{2}$ que en la matriz $\mathrm{TiO}_{2}$ (Figuras $2.31 \mathrm{a}, \mathrm{b}$ ). De manera similar, en las imágenes TEM de xerogeles de $\mathrm{TiO}_{2}$ dopados con las especies NiTSPc y CuTSPc (Figuras $2.31 \mathrm{c}, \mathrm{d}$ ), se puede observar una red formada por la agregación de partículas de tamaños más pequeños. Al aumentar la resolución de las imágenes (Figura 2.31 a, b, d), es posible observar diferencias en los tamaños de las partículas que forman la red, que dependen aparentemente de la identidad del catión central de la especie MTSPc. Además, a una amplificación relativamente alta, las diferentes regiones de opacidad sugieren la existencia de cavidades y cuellos muy pequeños que las conectan, como se muestra en la imagen del xerogel de $\mathrm{TiO}_{2}$ con las especies de CuTSPc atrapadas dentro.
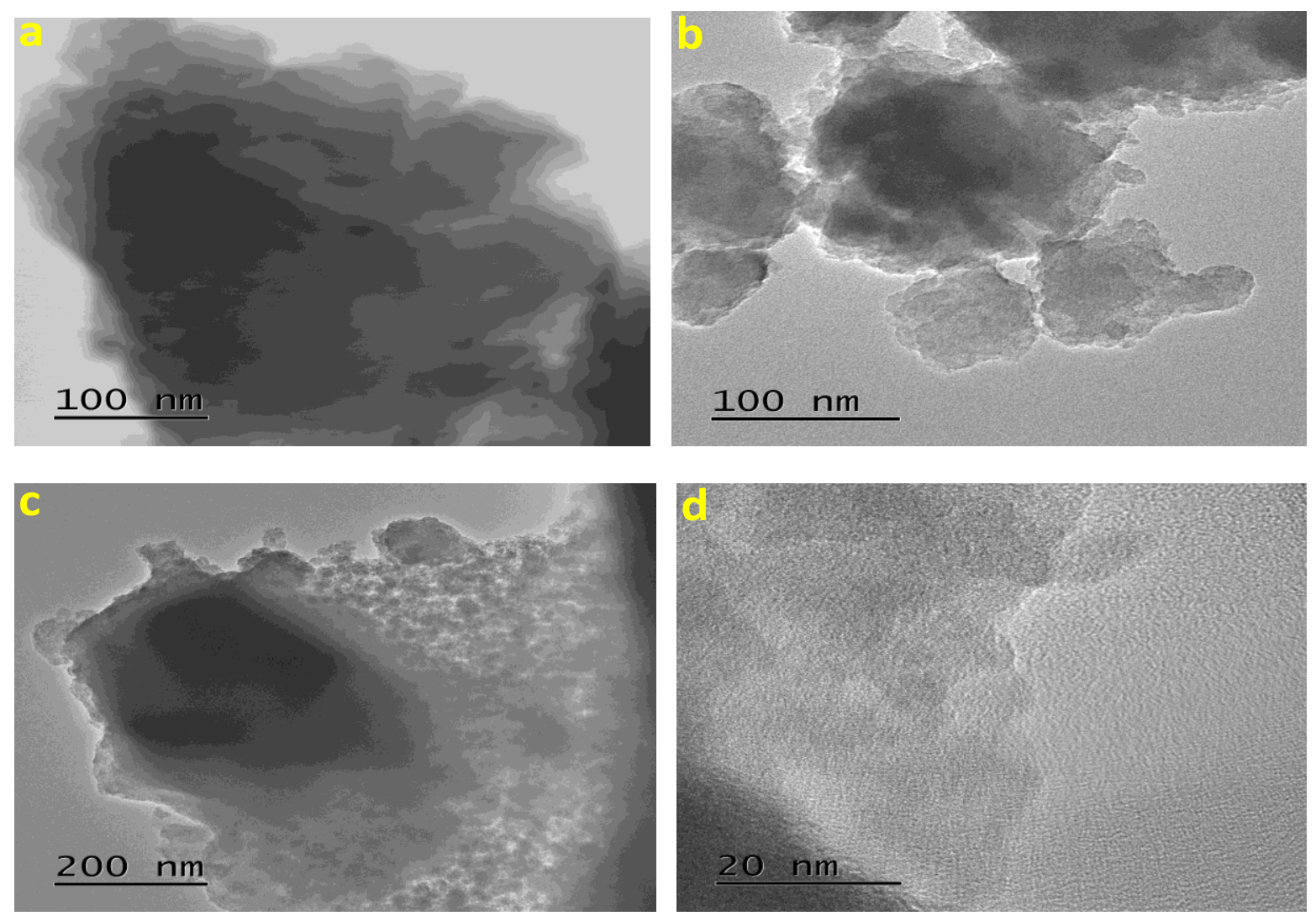

Figure 2.31. Imágenes TEM de las muestras que contienen atrapada la especie CoTSPc en los poros de: (a) $\mathrm{ZrO}_{2}$ y (b) $\mathrm{TiO}_{2}$ e imágenes TEM de muestras que contienen atrapada a las especies (c) NiTSPc y (d) CuTSPc en $\mathrm{TiO}_{2}$. 

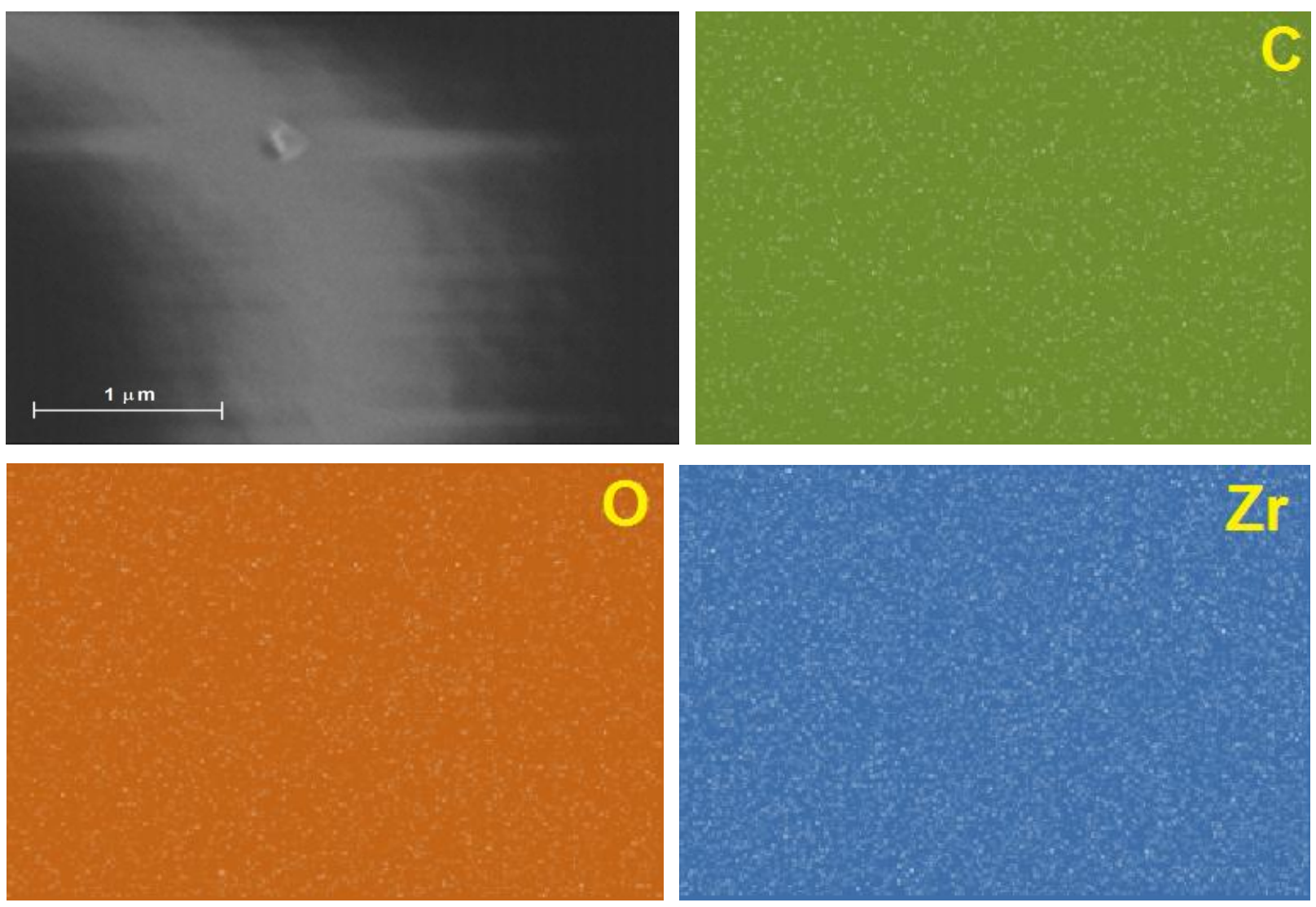

Figura 2.32 Imágenes SEM y mapeo EDS del xerogel de $\mathrm{ZrO}_{2}$ con la especie CoTSPc atrapada dentro de los poros.

La imagen SEM del xerogel de $\mathrm{ZrO}_{2}$, encapsulando la especie CoTSPc, revela una superficie lisa sin cavidades evidentes (Figura 2.32), sin embargo, debido a la resolución del microscopio no pueden apreciarse, si las hubiera, pequeñas cavidades nanometricas, En contraste, la cartografía de EDS indica una distribución homogénea de carbono, oxígeno y zirconio, cuyos porcentajes en peso correspondieron al 27,47\%, 53,31\% y 18,17\%, respectivamente. Estos datos revelan la presencia de materiales orgánicos relacionados con la estructura de macrociclo atrapado, así como restos de grupos propoxi y / o restos de acetilacetona. El exceso de oxígeno puede estar asociado a la presencia de numerosos grupos superficiales de $\mathrm{Zr}-\mathrm{OH}$, que proporcionan un cierto carácter hidrofílico a la red. Para el caso de los xerogeles de $\mathrm{TiO}_{2}$ con moléculas MTSPc atrapadas, los resultados de SEM y EDS fueron similares a los obtenidos para $\mathrm{ZrO}_{2}$. 
Con base en los resultados obtenidos utilizado las técnicas de caracterización en los materiales sintetizados se puede determinar lo siguiente: los xerogeles de $\mathrm{ZrO}_{2}$ suelen en general ser más resistentes que los de titanio, esta característica sugiere que pueden utilizarse en aplicaciones ópticas con mejores resultados, que la especie $(\mathrm{OH}) \mathrm{AlTSp}$ se encuentra atrapada en los monolitos transparentes de los dos óxidos de manera monomérica y estable interaccionando con los grupos $\mathrm{M}-\mathrm{OH}$ superficiales, que existen diferencias de polaridad entre los sistemas sintetizados de $\mathrm{ZrO}_{2}$ y TiO 2 , que la especie CuTSPc se mantiene monomérica en $\mathrm{ZrO}_{2}$, no así en $\mathrm{SiO}_{2}$ y $\mathrm{TiO}_{2}$ debido a la diferencia de polaridades, que los tamaños de poro promedio en los dos óxidos son similares a los generados con $\mathrm{SiO}_{2}$ alrededor de la molécula de $(\mathrm{OH})$ AITSPc lo que sugiere que las MTSPc se encuentran atrapadas dentro de cavidades de la red que se han formado en torno a las especies MTSPc, que las dimensiones de dichas cavidades dependen de la identidad del catión presente en tales complejos y por último que existen diferencias en el área superficial de los materiales efecto que se atribuye a la naturaleza de cada una de las matrices las cuales presentan el siguiente orden en magnitud. $\mathrm{SiO}_{2}>\mathrm{TiO}_{2}>$ $\mathrm{ZrO}_{2}$. 


\section{UAM-I}

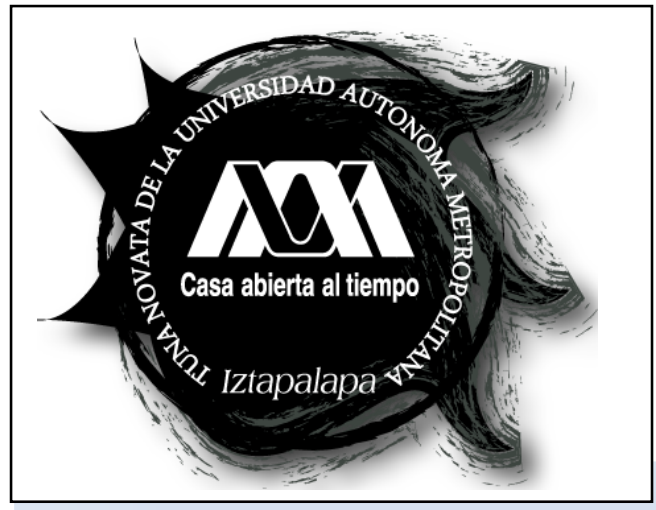

\section{CAPITULO III}

\section{UNIÓN COVALENTE DE ESPECIES}

\section{MACROCÍCLICAS EN XEROGELES DE $\mathrm{ZrO}_{2} \mathrm{Y}$ $\mathrm{TiO}_{2}$.}

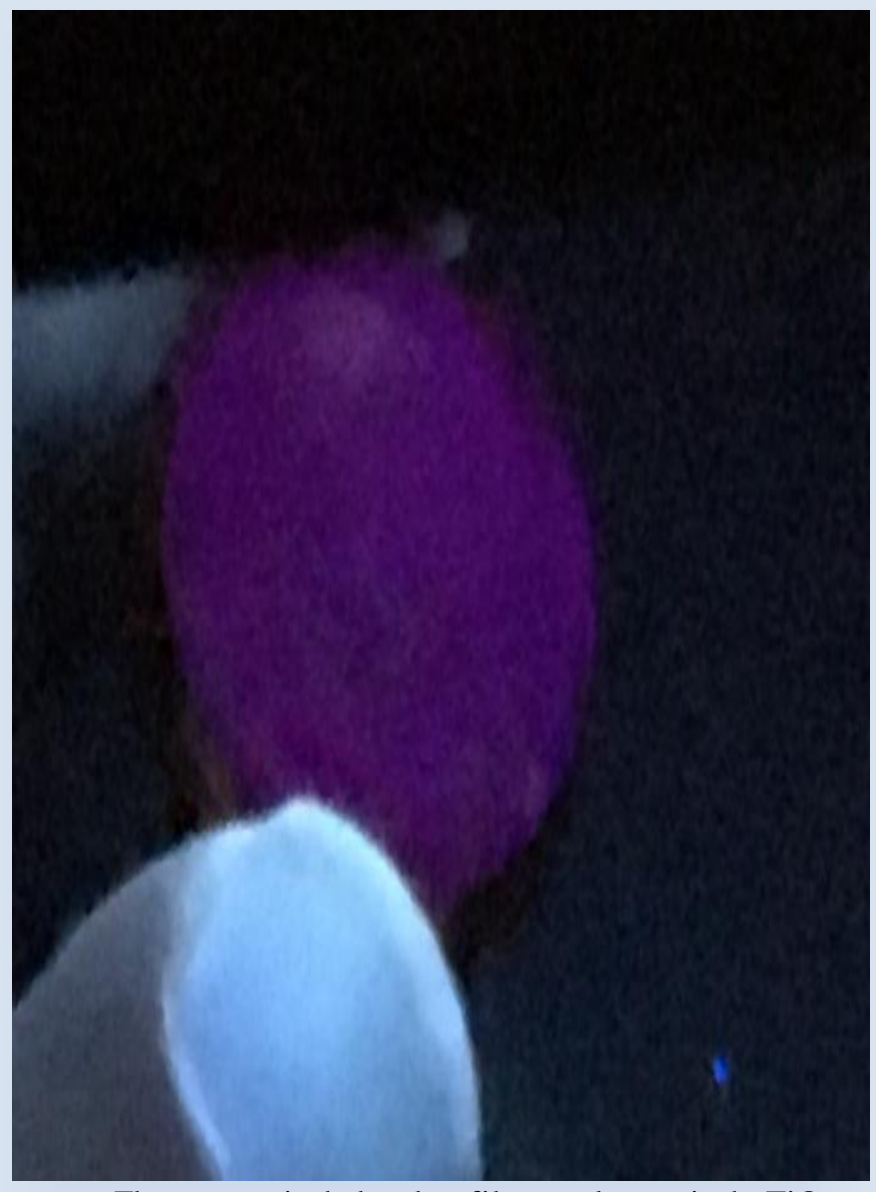

Fluorescencia de la clorofila $a$ en la matriz de $\mathrm{TiO}_{2}$. 


\subsection{Unión covalente de la especie $\mathrm{H}_{2} \mathrm{~T}(p-\mathrm{COOH}) \mathrm{PP}$ con APTES en $\mathrm{ZrO}_{2}$ y $\mathrm{TiO}_{2}$.}

Una vez que se han atrapado de manera física especies MTSPc en los óxidos de zirconio y titanio se procede a explorar la posibilidad de unir de manera covalente especies macrociclicas, esto con el objeto de disminuir en lo posible las interacciones que de manera natural se dan entre las moléculas atrapadas y los grupos remanentes, como los M-OH y M-OR, de la matriz inorgánica las cuales suelen afectar de manera significativa el despliegue eficiente de las propiedades fisicoquímicas de la especie atrapada para ello en un principio se propone sintetizar la especie $\left(\mathrm{H}_{2} \mathrm{~T}(p-\mathrm{COOH}) \mathrm{PP}\right)$-APTES y la extracción de la clorofila $a$ para su posterior unión covalente vía el uso de APTES.

La Clorofila $a$ es un colorante pirrolico con importantes propiedades ópticas que requiere ser soportado en matrices diversas con objeto de mantener sus propiedades, cabe mencionar que la clorofila $a$ presenta usos variados por tanto requiere ser soportada en algún sustrato para posteriormente recuperar el material., la especie $\left(\mathrm{H}_{2} \mathrm{~T}(p-\mathrm{COOH}) \mathrm{PP}\right)$ posee también propiedades ópticas interesante que se desean conservar en sólidos.

\subsubsection{Síntesis de precursor $\mathrm{H}_{2} \mathrm{~T}(p-\mathrm{COOH}) \mathrm{PP}$-APTES.}

La especie $\mathrm{H}_{2} \mathrm{~T}(p-\mathrm{COOH}) \mathrm{PP}-\mathrm{APTES}$ fue sintetizada utilizando la metodología reportada por Quiroz [58] . Se disuelven 0.09g $\left(1.2 \times 10^{-4} \mathrm{~mol}\right)$ de $\mathrm{H}_{2} \mathrm{~T}(p-\mathrm{COOH}) \mathrm{PP}$ en $20 \mathrm{ml}$ de etanol anhidro, la mezcla se calienta a $80^{\circ} \mathrm{C}$ por 1 hora con agitación constante en atmosfera de $\mathrm{N}_{2}$ y reflujo, como la reacción es 1:4 se agregan $0.12 \mathrm{ml}$ de 3-amino-propil-trietóxisilano (APTES) $\left(1.2 \times 10^{-4} \mathrm{~mol}\right)$, con objeto de establecer uniones amida entre los grupos amino de los alcóxidos y los grupos carboxilo de la porfirina, el tiempo de reacción fue de 6h. El esquema de reacción se presenta en la figura 3.1. 


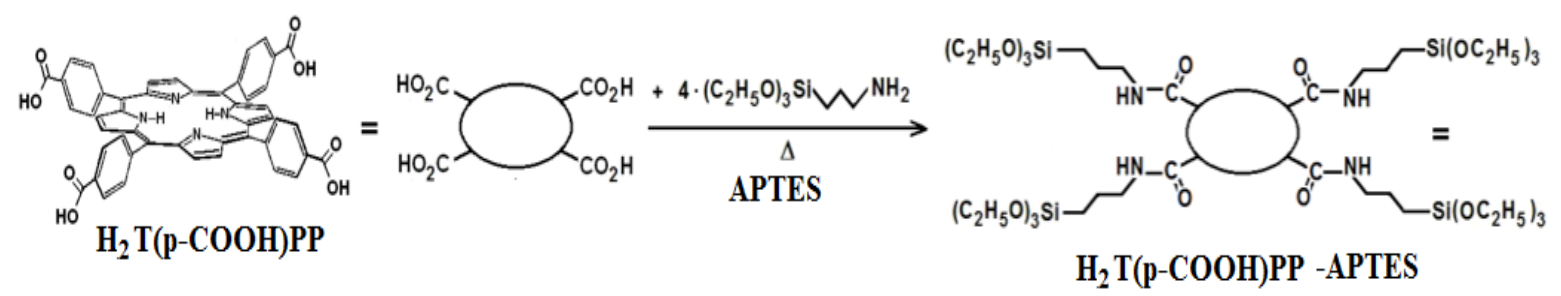

Figura 3.1. Ruta de síntes is para obtener los precursores (a) $\mathrm{H}_{2} \mathrm{P}-\mathrm{F}$, a partir de la especie y $\mathrm{H}_{2} \mathrm{~T}(p$ $\mathrm{COOH}) \mathrm{PP}$ y el alcó xido funcionalizado APTES.

\subsection{Síntesis de Xerogeles de $\mathrm{ZrO}_{2} \mathrm{H}_{2} \mathrm{~T}(p$-COOH $)$ PP-APTES y $\mathrm{TiO}_{2}-\mathrm{H}_{2} \mathrm{~T}(p$ - COOH)PP-APTES}

Se sintetizaron xerogeles de $\mathrm{ZrO}_{2}$ y $\mathrm{TiO}_{2}$ utilizando el precursor $\mathrm{H}_{2} \mathrm{~T}(p-C O O H) \mathrm{PP}$ APTES siguiendo las relaciones molares que generan materiales transparentes de acuerdo con la siguientes tablas.

Tabla 3.1 Relaciones para sintetizar xerogeles con $\mathrm{ZrO}_{2}$ y la especie $\mathrm{H}_{2} \mathrm{~T}(p-\mathrm{COOH}) \mathrm{PP}-\mathrm{APTES}$

\begin{tabular}{|c|c|c|c|c|c|c|}
\hline Muestra & $\mathrm{Zr}\left(\mathrm{OPr}^{\mathrm{n}}\right)_{4}$ & $\begin{array}{l}\text { Solución } \\
\text { Carboxi- APTES } \\
\text { en Pr }{ }^{n} \mathrm{OH}(\mathrm{ml})\end{array}$ & : Acac & $\begin{array}{l}\text { : DVIF } \\
(\mathrm{ml})\end{array}$ & Concentración & $\begin{array}{l}\mathrm{H}_{2} \mathrm{O} \\
(\mathrm{ml})\end{array}$ \\
\hline Blanco & 3.8 & 1.2 & 0.42 & 0.1 & & 0.2 \\
\hline $\mathrm{ZrO}_{2}$ & 3.8 & 1.2 & 0.42 & 0.1 & $1.6 \mathrm{E}-2$ & 0.2 \\
\hline
\end{tabular}

Tabla 3.2. Re laciones para sintetizar xerogeles con $\mathrm{TiO}_{2}$ y la especie $\mathrm{H}_{2} \mathrm{~T}(p-C O O H) \mathrm{PP}-\mathrm{APTES}$

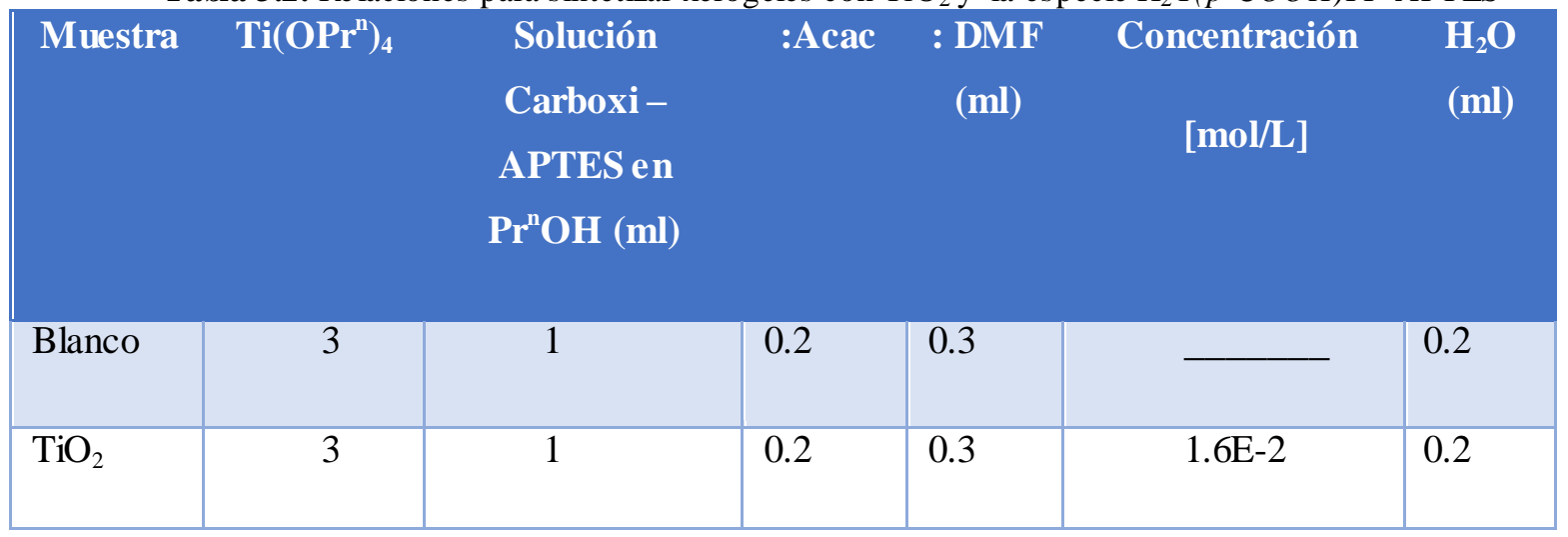




\subsubsection{UV-Vis de Xerogeles.}

Es conocido que los compuestos porfirinicos son susceptibles al ambiente químico en el que se encuentran inmersos, el disolvente utilizado y también que ha concentraciones entre $4 \mathrm{X}$ $10^{-4}$ y $1 \times 10^{-3}$ [59] , estos tienden a formar dímeros y agregados, la figura 3.2 muestra el espectro UV-Vis de la especie $\mathrm{H}_{2} \mathrm{~T}(p-C O O H) \mathrm{PP}$ monomérica en 1-propanol el cual presenta una banda de Soret en $416 \mathrm{~nm}$, y cuatro bandas Q a 512, 547, 590 y 645nm, en la misma grafica se presenta el espectro del dímero de la especie $\mathrm{H}_{2} \mathrm{~T}(p-C O O H) \mathrm{PP}$, en este se presentan un efecto batocrómico, la banda soret se posiciona en $426 \mathrm{~nm}$ y las cuatro bandas Q aparece n en 526, 567, 605 y $664 \mathrm{~nm}$. Todas estas como ya se ha mencionado asociadas a transiciones electrónicas $\pi-\pi^{*}$ del macrociclo.

Al mezclar la $\mathrm{H}_{2} \mathrm{~T}(p-C O O H) P P-A P T E S$ a la solución gelante de $\mathrm{ZrO}_{2}$ (figura 3.3 a) la especie despliega un espectro como si se encontrara en solución de 1-propanol es decir como monómero, esta condición se mantiene hasta la etapa de consolidación del xerogel (figura 3.3 c) lo cual indica que el ambiente menos polar de la red de zirconio mantiene a la molécula en forma monómerica y estable dentro del poro, en lo que se refiere al comportamiento de la especie porfirinica en el $\mathrm{TiO}_{2}$ cabe destacar que en la muestra gelante figura $3.3 \mathrm{~b}$ y hasta la consolidación del xerogle las bandas de soret y las bandas Q se desplazan en ambos casos (soluciones gelantes y xerogeles consolidados ) a longitudes de onda mayores por efecto nuevamente del ambiente químico más polar de la red de titanio, sin embargo la posición de las bandas soret a 514 y $517 \mathrm{~nm}$ en la solución gelante y xerogeles consolidados respectivamente y las bandas Q (soluciones gelantes 519,569,605 y 664nm y xerogeles consolidados 517,551,646 y $667 \mathrm{~nm})$ nos indica que la $\mathrm{H}_{2} \mathrm{~T}(p-C O O H)$ PP-APTES se encuentra de forma monómerica y estable dentro de los poros de titanio, cabe mencionar que en los materiales consolidados de ambos óxidos la banda de soret de la porfirina libre se traslapa con la de las redes de los óxidos ya que esto absorben energía a longitudes de onda menores a 500nm. Sin embargo las bandas Q nos indican la presencia de la especie dentro de los poros en las condiciones antes señaladas. 


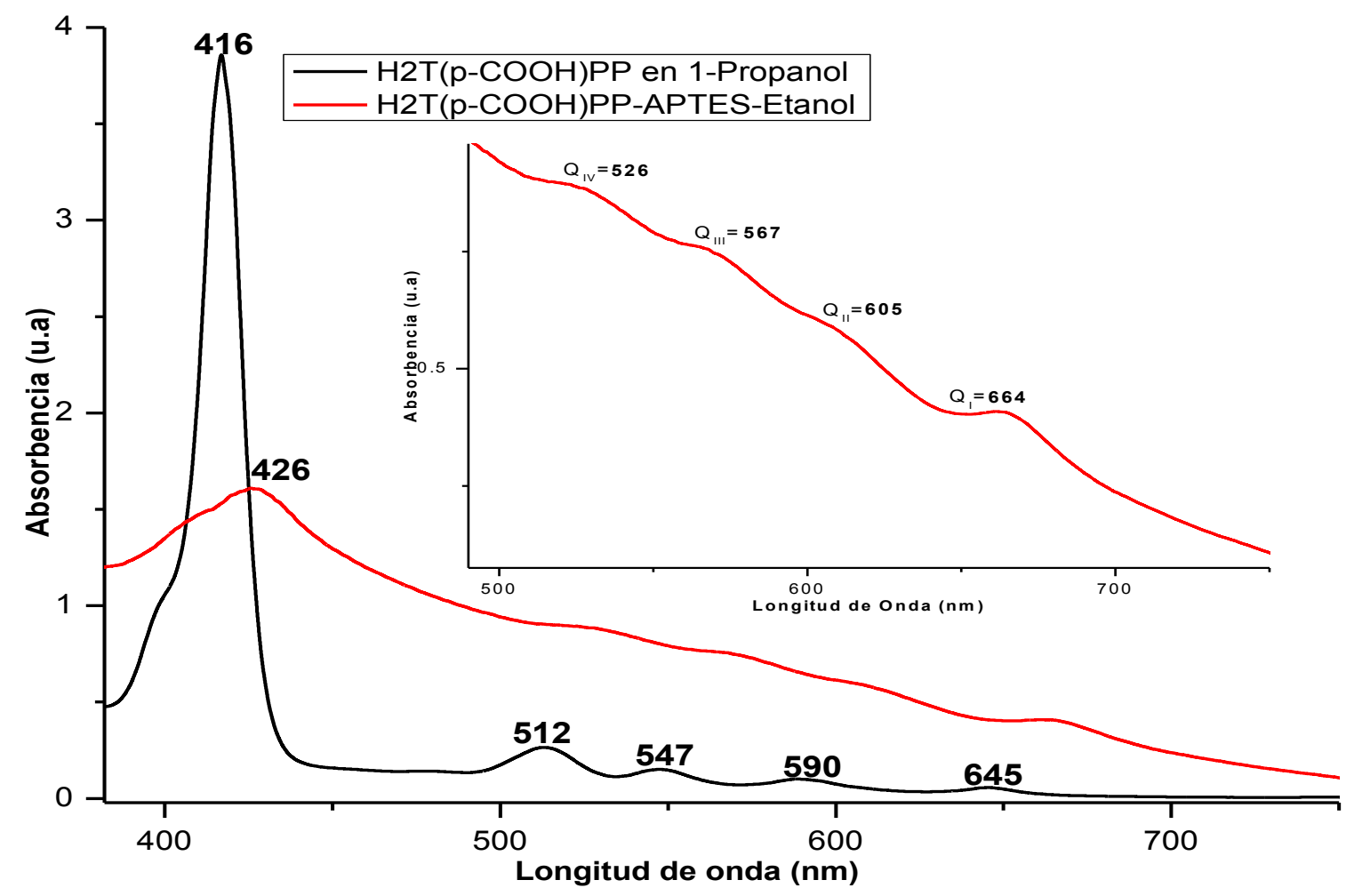

Figura 3.2 Monómero de la Especie $\mathrm{H}_{2} \mathrm{~T}(\mathrm{p}-\mathrm{COOH}) \mathrm{PP}$ en 1-prpopanol y dímero de $\mathrm{H}_{2} \mathrm{~T}(\mathrm{p}-\mathrm{COOH}) \mathrm{PP}$ APTES en etanol.
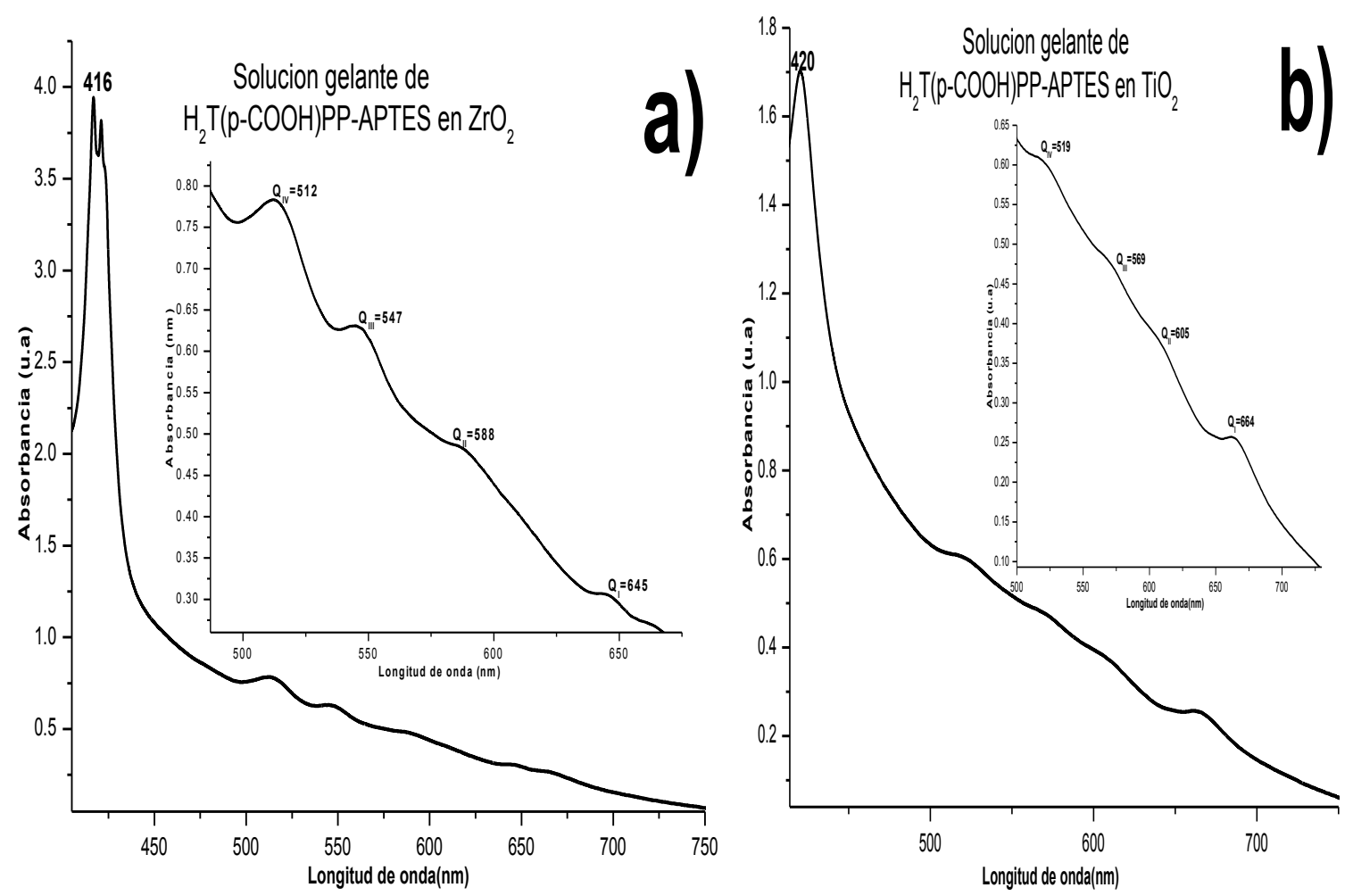

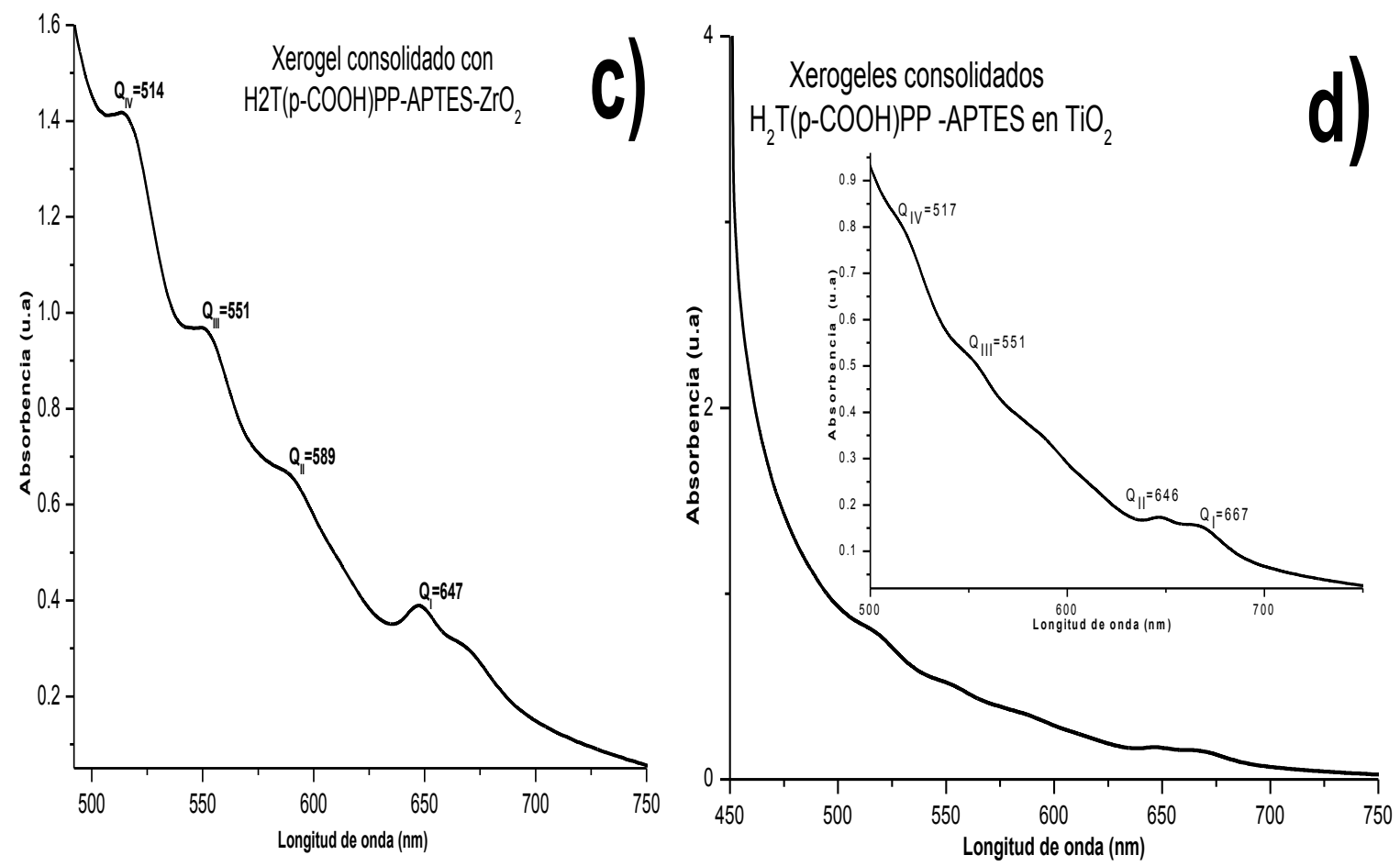

Figura 3.3 Espectros UV-Vis de la especie $\mathrm{H}_{2} \mathrm{~T}(\mathrm{p}-\mathrm{COOH}) \mathrm{PP}-\mathrm{APTES}$ a) solución gelante de $\mathrm{ZrO}_{2}$ b) solución gelante de $\mathrm{TiO}_{2}$ c) xerogel consolidado de $\mathrm{ZrO}_{2}$ d) xerogel consolidado de $\mathrm{TiO}_{2}$.

\subsubsection{Fluorescencia de Xerogeles.}

La especie $\mathrm{H}_{2} \mathrm{~T}(p-\mathrm{COOH}) \mathrm{PP}$ en solución muestra fluorescencia roja al ser irradiado con luz ultravioleta, como ya se ha reportado [58] el espectro de emisión también depende del disolvente en el que se encuentra inmerso, sin embargo de manera general presenta dos bandas principales localizadas a alrededor de 641 y 706nm, en la región del naranja y el rojo asociada con la emisiones $\pi$ - $\pi^{*}$ del macrociclo.

Se obtuvieron espectros de fluorescencia de los xerogeles sintetizados con $\mathrm{H}_{2} \mathrm{~T}(p$ COOH)PP-APTES y $\mathrm{ZrO}_{2}$ figura 3.4 a diferentes longitudes de onda de excitación $\lambda_{\text {exc }}=370 \mathrm{~nm}$ (Figura 3.4 a), en este caso aparece una banda ancha en el rango de 400 a $600 \mathrm{~nm}$ con una señal intensas a $460 \mathrm{~nm}$ asociada a la matriz de $\mathrm{ZrO}_{2}$ que resulta ser menos intensa una de las bandas que aparece de 654 y mayor que la que aparece a $717 \mathrm{~nm}$ ambas atribuidas al macrociclo presente en la porfirina. En el caso de las muestras exitadas a $\lambda_{\text {exc }}=420 \mathrm{~nm}$ (Figura $3.4 \mathrm{~b}$ ) destaca el hecho de que la banda atribuida a la matriz de zirconio reduce un poco su emisión 
mientas que las bandas asociadas con el macrociclo la aumentan de manera considerable y se mantienen en la misma longitud de onda, lo que sugiere que esta señal está asociada a la banda de Soret (400 nm-420 nm).

Se obtuvieron también espectros de fluorescencia de los xerogeles sintetizados con la especie $\mathrm{H}_{2} \mathrm{~T}\left(\mathrm{p}\right.$-COOH)PP-APTES y $\mathrm{TiO}_{2}$ figura 3.5 a diferentes longitudes de excitación Cuando se utiliza $\lambda_{\text {exc }}=370 \mathrm{~nm}$ (Figura 3.5 a) se observa que aparece una banda ancha de poca intensidad en el rango de 400 a $600 \mathrm{~nm}$ asociada a la matriz de $\mathrm{TiO}_{2}$, aparecen también dos bandas asociadas con el macrociclo en 650 y $714 \mathrm{~nm}$ respectivamente. Este resultado indica que la interacción de la porfirina con la matriz de $\mathrm{TiO}_{2}$ resulta ser menor que la que se presenta con el $\mathrm{ZrO}_{2}$ y pudiera asociarse a menor interacción de la porfirina con las paredes de la matriz de TiO2 o a un medioambiente fisicoquímico más adecuado para la ocurrencia de las transiciones de la porfirina en la matriz de $\mathrm{TiO}_{2}$. Así mismo, a simple vista se observa que al ser irradiado con luz UV-Vis el xerogel este presenta un color rojizo, este efecto desaparece en la matriz de $\mathrm{ZrO}_{2}$. Al excitar las muestras con una $\lambda_{\text {exc }}=420 \mathrm{~nm}$ (Figura $3.5 \mathrm{~b}$ ) la intensidad de la señales del macrociclo son de mayor intensidad, sin embargo permanecen en la misma longitud de onda hecho que como en el caso anterior sugiere que esta señal está asociada a la banda de Soret (400 nm-420 nm) y explica como ya se mencionó el color rojo del xerogel al ser excitado con luz UV-Vis.

Resulta evidente que ambas matrices permiten la ocurrencia de los procesos de absorción de radiación y emisión de luz en la región del rojo e infrarrojo, asociadas al macrociclo de porfirina, sin embargo, la baja intensidad de las señales a menos de $600 \mathrm{~nm}$ en el caso de los sistemas de $\mathrm{TiO}_{2}$ sugieren que tales transiciones ocurren de forma más eficiente o con menor interferencia en dicha matriz. 


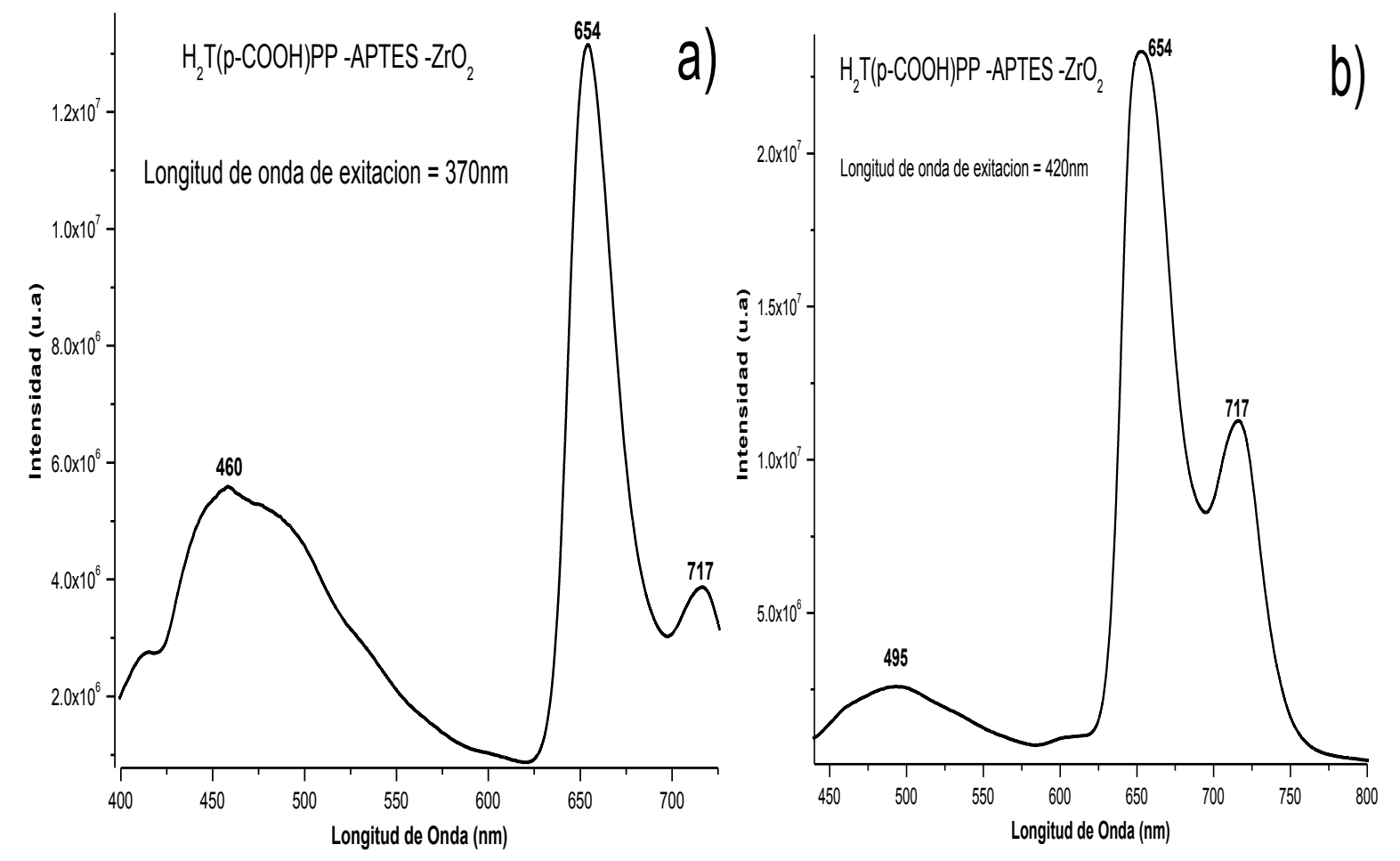

Figura 3.4 Espectros de excitación de xerogeles consolidados de $\mathrm{ZrO}_{2} \quad\left(a \quad \lambda_{\text {exc }}=370 \mathrm{nmb}\right) \lambda_{\text {exc }}=420 \mathrm{~nm}$ $\mathrm{H}_{2} \mathrm{~T}(\mathrm{p}-\mathrm{COOH}) \mathrm{PP}-\mathrm{APTES}$.
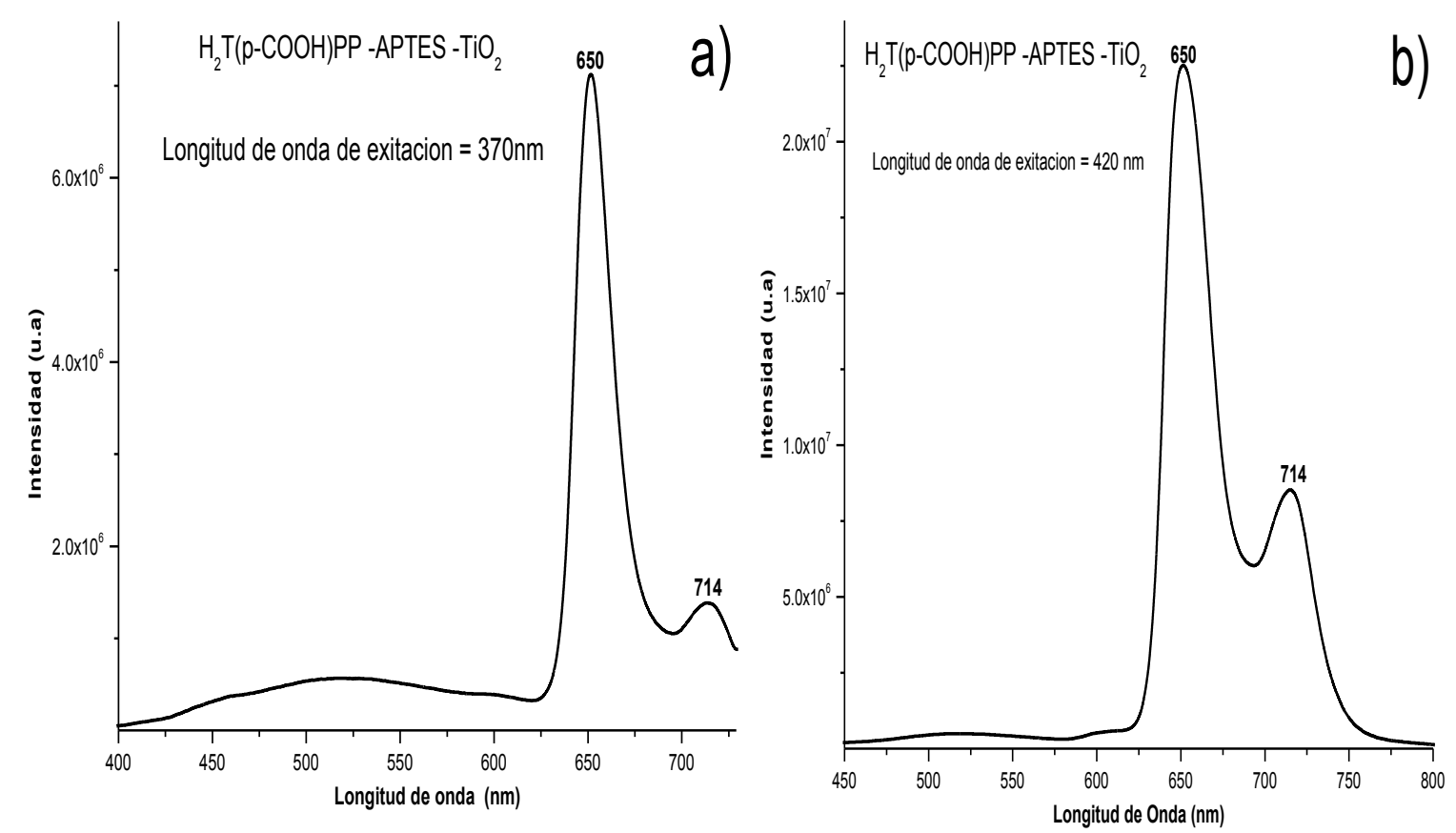

Figura 3.5 Espectros de excitación de xerogeles consolidados de $\mathrm{TiO}_{2} \quad\left(\mathrm{a} \quad \lambda_{\text {exc }}=370 \mathrm{nmb}\right) \lambda_{\text {exc }}=420 \mathrm{~nm}$ $\mathrm{H}_{2} \mathrm{~T}(\mathrm{p}-\mathrm{COOH}) \mathrm{PP}$-APTES. 


\subsubsection{Diámetro de poro y área superficial en los dos óxidos.}

Se obtuvieron las isotermas de sorción -desorción de $\mathrm{N}_{2}$ a $76 \mathrm{~K}$ de los xerogeles consolidados sintetizados de $\mathrm{ZrO}_{2}$ y $\mathrm{TiO}_{2}$ con la especie $\mathrm{H}_{2} \mathrm{~T}(p-C O O H) \mathrm{PP}-\mathrm{APTES}$ unidas a la matriz de los óxidos, Las isotermas que se muestran en las figura 3.6 a)y b) corresponden, según la clasificación de la IUPAC a las Tipo I con ciclo de Histéresis H3 [52],es evidente que los ciclos de histéresis de ambos óxidos son mucho más pronunciados que los que presentan los óxidos prístinos (la discusión de las isotermas de los blancos aparece en el capítulo 2) esto puede atribuirse a la presencia de la porfirina en el material, probablemente al formarse la red de óxido sobre la especie macrociclica se forman pequeñas interconexiones entre los poros los cuales obstruyen la difusión del $\mathrm{N}_{2}$, el ciclo de histéresis más ancho en el óxido de $\mathrm{TiO}_{2}$ sugiere que este efecto es mayor que en el de zirconio.

Los diámetros de poro evaluados en los xerogeles de $\mathrm{ZrO}_{2}$ y $\mathrm{TiO}_{2}$ fue de 2.3 y $2.0 \mathrm{~nm}$ respectivamente, la disminución del diámetro de poro con respecto a la red prístina de los dos óxidos se encuentran en concordancia con sistemas similares de $\mathrm{SiO}_{2}[58]$ la diferencia entre el tamaño de poro las áreas en los tres óxidos pudiera asociarse con la velocidad de reacción entre los mismos.

Cabe mencionar que uno de los resultados más importantes en esta etapa es el hecho de que el área en los materiales de $\mathrm{ZrO}_{2}$ sintetizados con la porfirina funcionalizada unida aumenta de manera considerable lo cual resulta positivo por ejemplo en el área de catálisis.

Los resultados del diámetro de poro y área superficial se reportan en la tabla 3.3. 

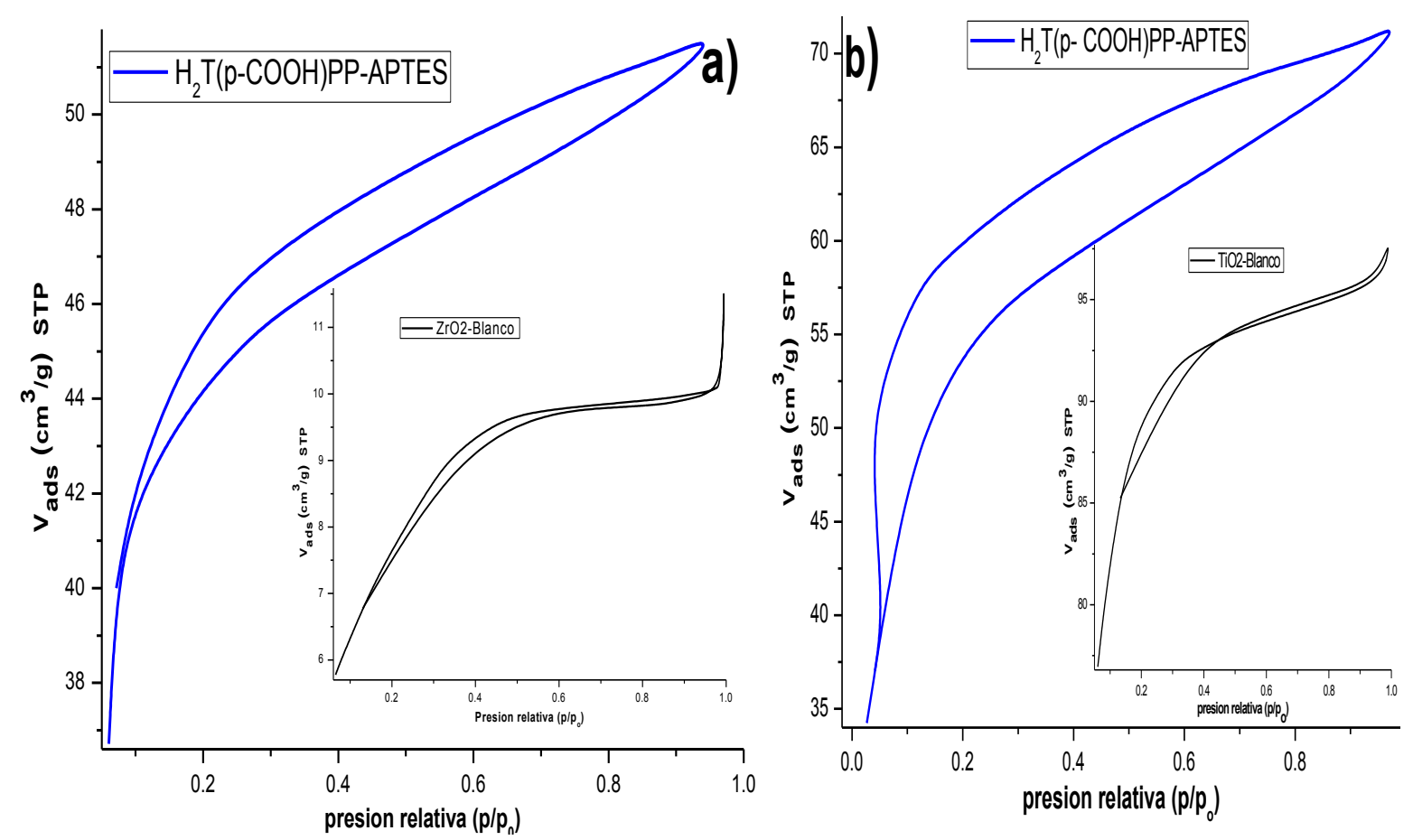

Fig. 3.6 Isotermas de Adsorción $\mathrm{H}_{2} \mathrm{~T}(\mathrm{p}-\mathrm{COOH}) \mathrm{PP}-\mathrm{APTES}$ a) $\mathrm{ZrO}_{2}$ y b) $\mathrm{TiO}_{2}$

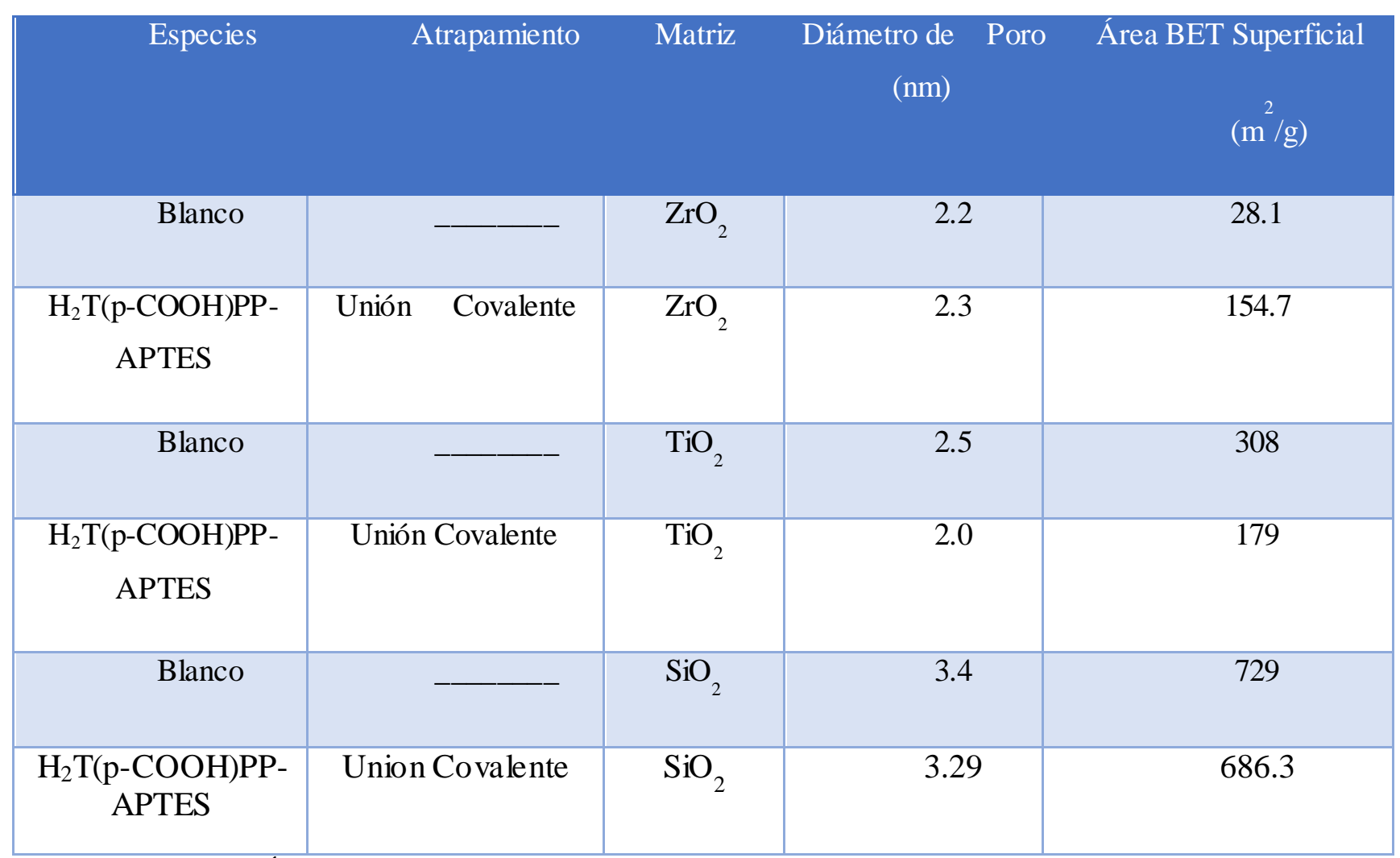

Tabla 3.3. Áreas superficiales específicas y diámetros de poro $(\Phi)$ de xerogeles de $\mathrm{SiO}_{2}, \mathrm{TiO}_{2}$ y $\mathrm{ZrO}_{2}$ en los cuales las especies $\mathrm{H}_{2} \mathrm{~T}(p$-COOH$) \mathrm{PP}$-APTES se encuentra covalentemente unida. 
El diámetro medio de poro $(\Phi)$ se calculó a través de las isotermas de $\mathrm{N}_{2}$, este parámetro se obtuvo a partir de la aplicación del enfoque funcional de densidad no local (NLDFT) a la curva límite de desorción del bucle de histéresis de la isoterma, asumiendo cavidades esféricas. Para el caso de las muestras de $\mathrm{ZrO}_{2}$ figura 3.7 (a) el diámetro de poro promedio en la matriz prístina presenta valores de 2.6 a $3.5 \mathrm{~nm}$, al unir la molécula de $\mathrm{H}_{2} \mathrm{~T}(p-C O O H) \mathrm{PP}-\mathrm{F}$ a la red los poros de más de $3 \mathrm{~nm}$ desaparecen privilegiándose la formación de poros de 2.26nm.

Para el caso de los materiales con de $\mathrm{TiO}_{2}$ sucede algo similar al disminuir de manera significativa los poros de más de $3 \mathrm{~nm}$. Incrementándose los de 2.03 y $2.53 \mathrm{~nm}$.
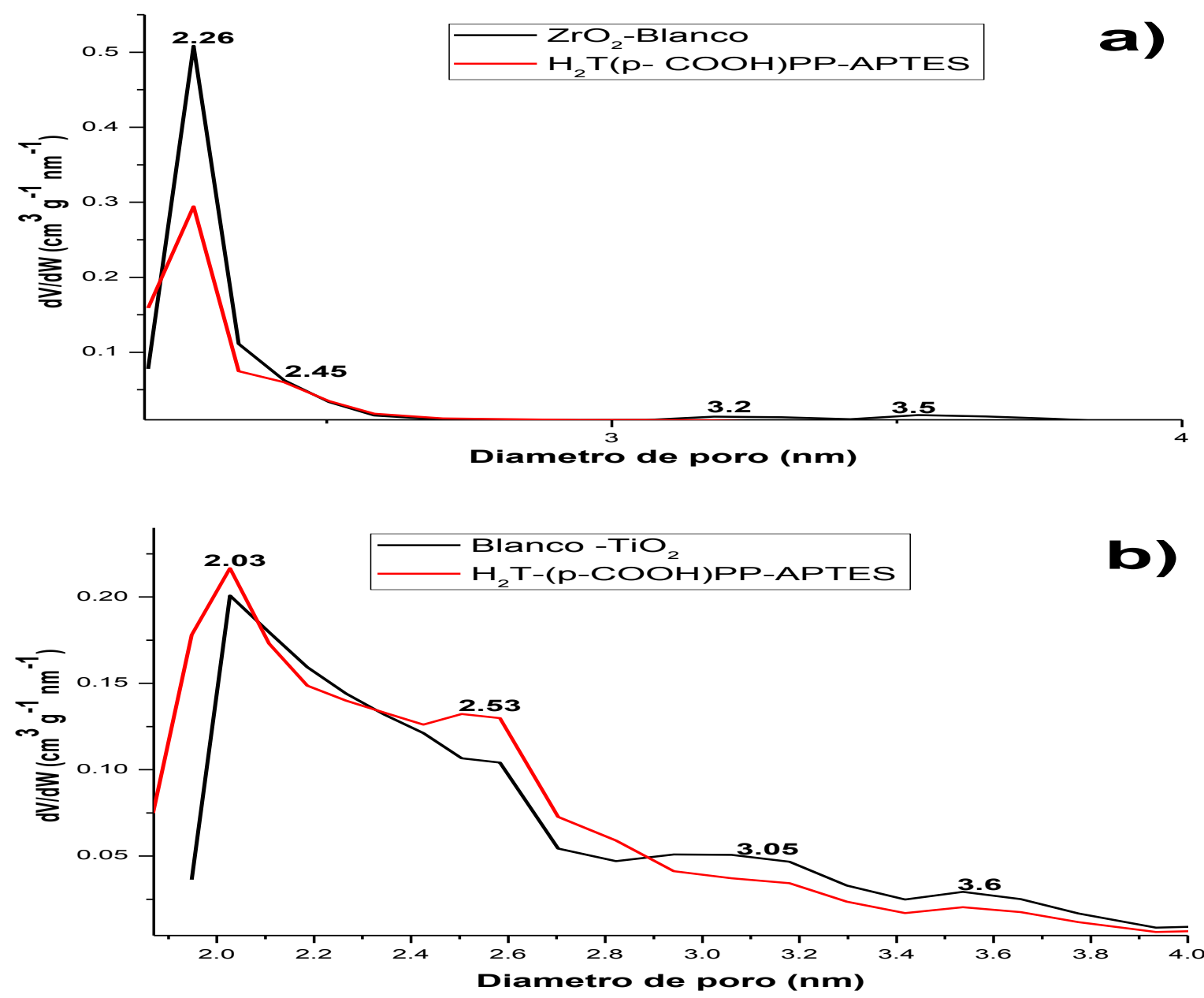

ura 3.7 Distribución de diámetros de poro promedio calculados por NLDFT a) $\mathrm{ZrO}_{2}$ blanco y con la especie porfirinica y b) $\mathrm{TiO}_{2}$ blanco y con la especie porfirinica. 


\subsubsection{Microscopía Electrónica de Barrido (SEM) y Análisis EDS}

Los monolitos consolidados de $\mathrm{ZrO}_{2}$ y $\mathrm{TiO}_{2}$ presentan una coloración café, debido a la presencia de la especie $\mathrm{H}_{2} \mathrm{~T}(p-\mathrm{COOH}) \mathrm{PP}-\mathrm{F}$. La imagen de SEM de la Figura 3.8 a) y b) indica para los materiales de $\mathrm{ZrO}_{2}$ que el material es liso con algunas irregularidades y sin presencia evidente de porosidad, para el caso de los xerogeles de $\mathrm{TiO}_{2}$ las figuras c) y d) se observa que los materiales son más frágiles que los de zirconio, con mayores irregularidades y fracturados.

En el análisis EDS fueron detectados los siguientes porcentajes en peso para los xerogeles de $\mathrm{TiO}_{2} \%$ : 086 de $\mathrm{Si}(1.00 \mathrm{~mol}), 46.75 \mathrm{de} \mathrm{O}(95.47 \mathrm{~mol}), 16.94 \mathrm{de} \mathrm{C}(46.05 \mathrm{~mol})$ y $35.46 \mathrm{de} \mathrm{Ti}$ (20.80mol). Puede establecerse que el silicio y el exceso de oxígeno en el muestra se debe a la molécula de APTES que se encuentra unida a la especie porfirinica libre. Parte del carbono puede asociarse nuevamente a la porfirina, pero también a acetilacetona remanente $(\mathrm{acacH})$, $\mathrm{N}, \mathrm{N}$-dimetilformamida (DMF) y grupos propoxi $\left(\mathrm{OC}_{3} \mathrm{H}_{7}\right)$ y trietoxifelsilano. La relación molar de $\mathrm{O} / \mathrm{Ti}$ es de 4.5 y se atribute a presencia de grupo $\mathrm{Zr}-\mathrm{OH}$ que forman la red. Para el caso de xerogeles de $\mathrm{ZrO}_{2}$ se presentan valores similares en lo referente al análisis EDS.

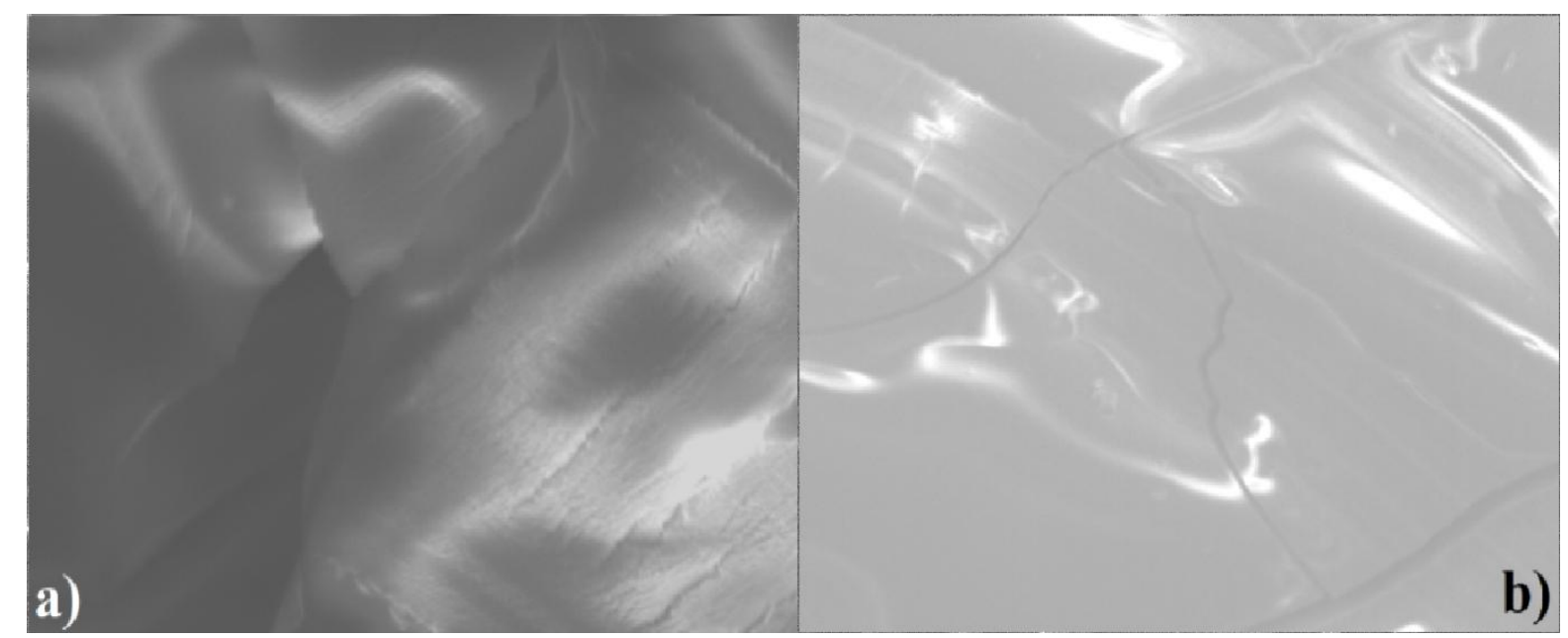

Figura 3.8 Imagen de microscopía de barrido (SEM) de xerogel de $\mathrm{ZrO}_{2}$ con la especie $\mathrm{H}_{2} \mathrm{~T}(\mathrm{p}-\mathrm{COOH}) \mathrm{PP}$ unida a) $1 \mathrm{m \mu}$ b) $10 \mu \mathrm{m}$ 


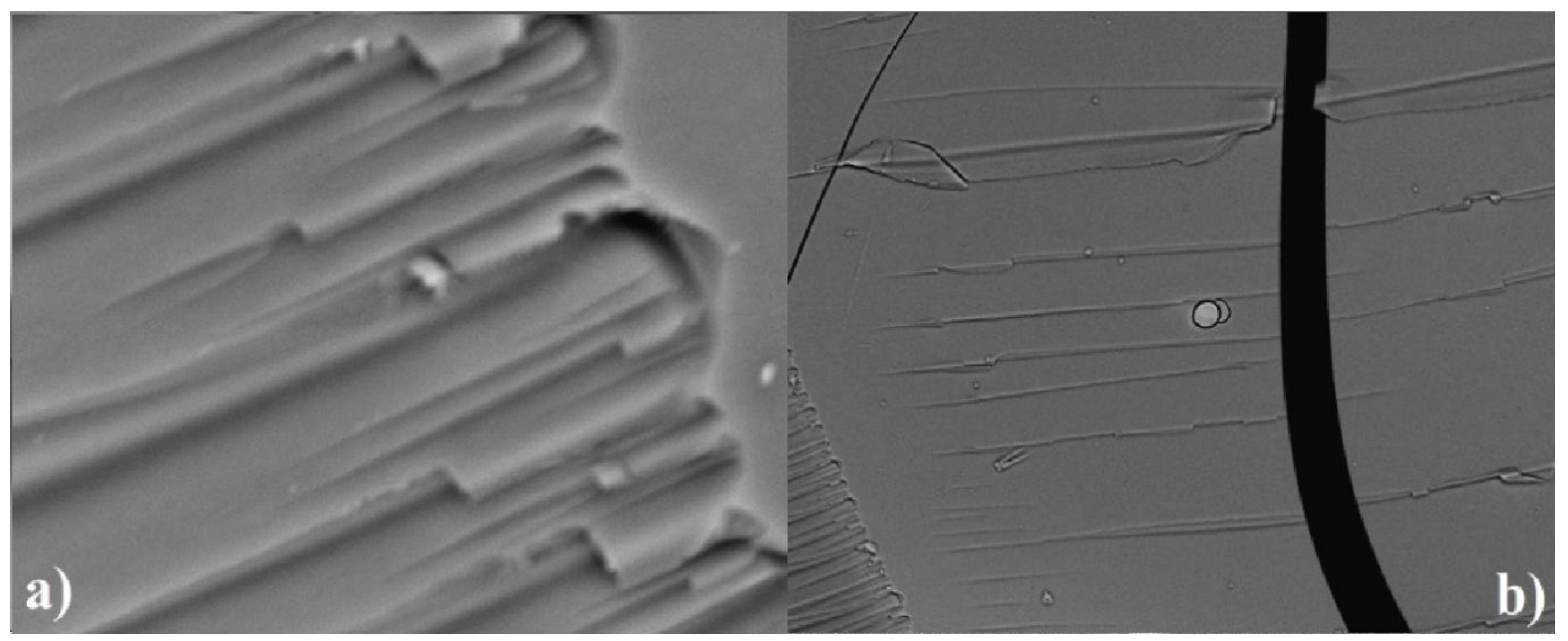

Figura 3.9 Imagen de microscopía de barrido ( $\mathrm{SEM}$ ) de xerogel de $\mathrm{TiO}_{2}$ con la especie $\mathrm{H}_{2} \mathrm{~T}(\mathrm{p}-\mathrm{COOH}) \mathrm{PP}$ unida a) $1 \mathrm{~m} \mu \mathrm{b}) 10 \mu \mathrm{m}$

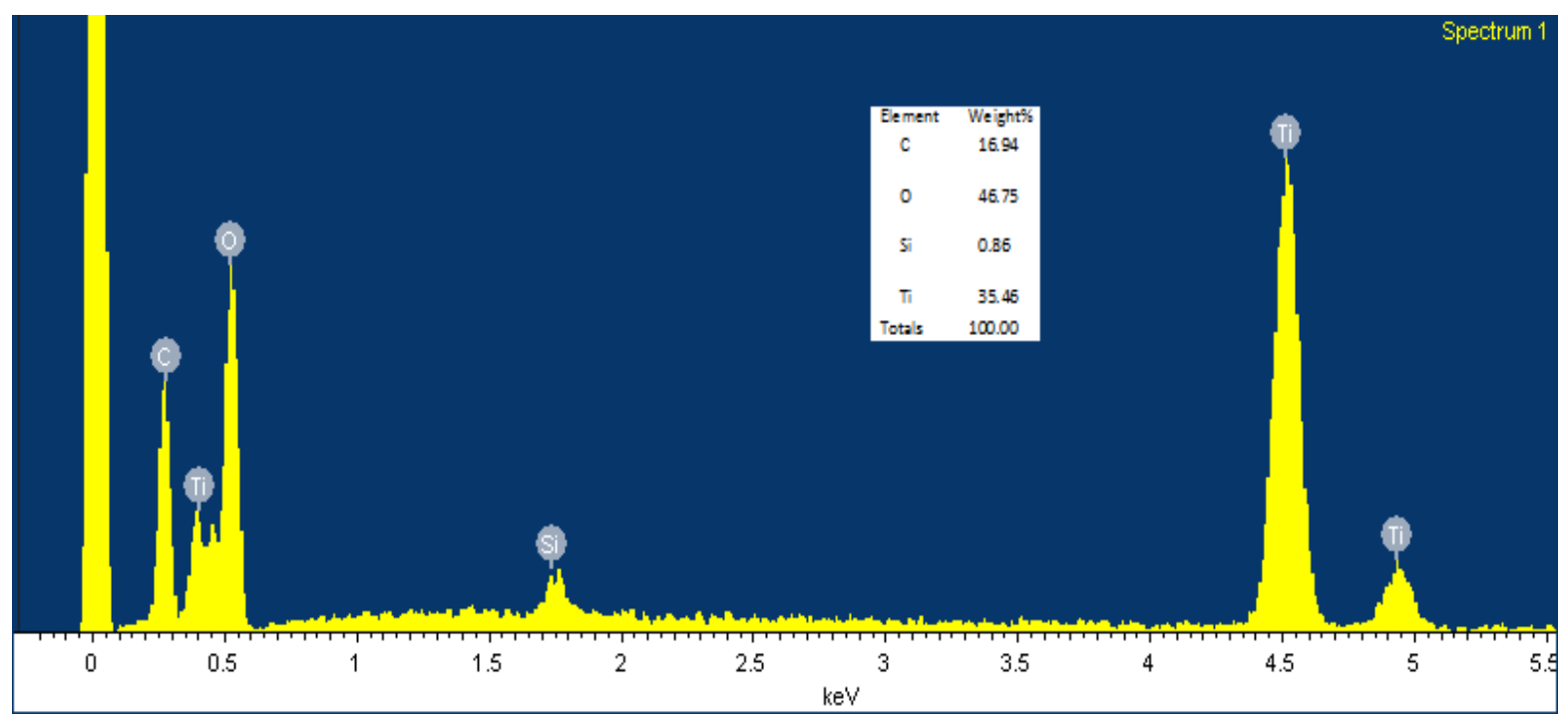

Figura 3.10 Porcentaje de elementos detectados por EDS en la muestra $\mathrm{TiO}_{2}$ con la especie $\mathrm{H}_{2} \mathrm{~T}(\mathrm{p}-$ $\mathrm{COOH}) \mathrm{PP}$

De acuerdo con la evidencia que arrojan las técnicas de caracterización se puede decir que la molécula $\mathrm{H}_{2} \mathrm{~T}\left(p\right.$-COOH)PP-APTES se mantiene dentro de los xerogeles de $\mathrm{TiO}_{2}$ y $\mathrm{ZrO}_{2}$ estable y forma monómerica, la fluorescencia roja de la especie porfirinica es evidente en los xerogeles de $\mathrm{TiO}_{2}$, sin embargo es posible mediante el uso de AOS alejar la molécula de las paredes de los poros y así optimar la fluorescencia de esta en los xerogeles. 


\subsection{Unión covalente de la Clorofila $a$-APTES en $\mathrm{ZrO}_{2}$ y $\mathrm{TiO}_{2}$.}

La clorofila $a$ presenta importantes propiedades ópticas, recientemente ha sido utilizada para sintetizar materiales luminiscentes, sistemas de sensores hibridos y dispositivos en la llamada terapia fotodinámica (TFD) [58] es por ello que es deseable preservar estas propiedades en matrices solidas de óxidos no convencionales como los de $\mathrm{TiO}_{2}$ y $\mathrm{ZrO}_{2}$ el método sol gel ha sido utilizado ya para unir de manera covalente la clorofila a xerogeles de $\mathrm{SiO}_{2}$ y SBA-15, en este proceso se utiliza el 3-amino-propil-trietóxisilano (APTES) para funcionalizar la clorofila y posteriormente unirla a las paredes de los materiales [61] esta metodología es utilizada para sintetizar xerogeles de $\mathrm{TiO}_{2}$ y $\mathrm{ZrO}_{2}$ añadiendo a la mezcla gelificante un alcóxido sustituido como lo es el $\Phi$-TEOS que se unirá a la red de los óxidos y alejara a la clorofila de las paredes de los poros disminuyendo las interacciones matrizmolécula y posteriormente compararlos con materiales similares de $\mathrm{SiO}_{2}$ reportados en la literatura [60].

\subsubsection{Síntesis de precursor Clorofila $a$-APTES}

En primera instancia se extrae la clorofila $a$ utilizando el método descrito por M.A. García Sánchez [61] a partir de pasto común y utilizando acetona como disolvente; La mezcla resultante se almacena en refrigeración a $4^{\circ} \mathrm{C}$, protegiéndola de la incidencia de luz. La mayor parte de acetona se destila a presión reducida con objeto de concentrar la clorofila $a$. Posteriormente se purifica el extracto haciéndolo pasar a través de una columna cromatografíca de sílice empleando acetona y 1-propanol como eluyentes. La fracción fluorescente roja que contiene la clorofila $a$ y el disolvente se destiló hasta que se detectó la aparición de un

precipitado y la solución saliente se almacenó de nuevo a $4^{\circ} \mathrm{C}$ en condiciones de oscuridad. Finalmente, la clorofila $a$ se concentró a partir de una alícuota de $15 \mathrm{ml}$ de la última disolución, cuyo disolvente se evaporó. El compuesto restante se disolvió en $20 \mathrm{ml}$ de 1-Propanol, con el fin de realizar una mezcla de concentración aproximada a $200 \mathrm{mg} / \mathrm{ml}$ y se obtiene el espectro UVVis de la solución. 

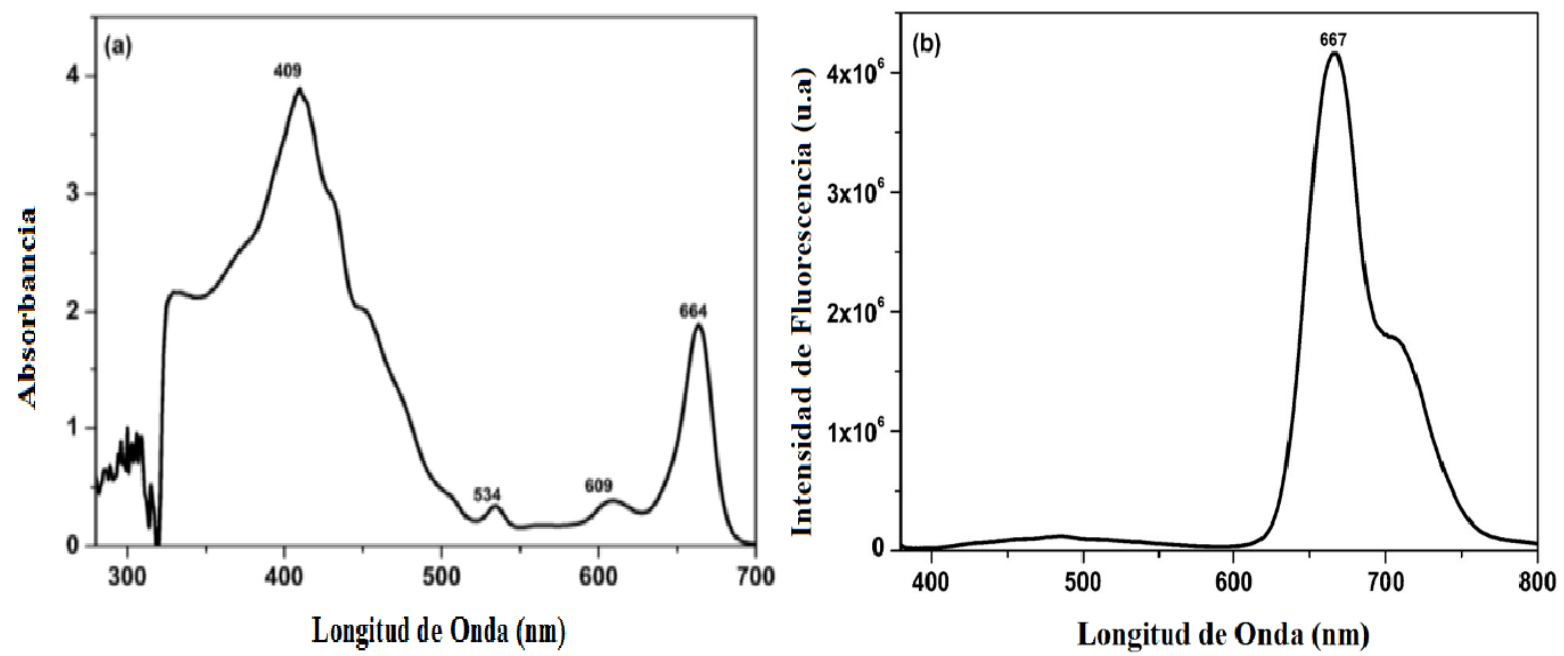

Figura 3.11 Espectro a) UV-Vis y b) de fluorescência de clorofila a extraída [59]

El espectro de absorción UV-Visible de una solución de clorofila a (Fig. 3.11 ) Muestra una banda de Soret en torno a $409 \mathrm{~nm}$ junto con tres bandas a 534, 609 y $664 \mathrm{~nm}$, respectivamente, que son características de esta sustancia [62-64]. Estas transiciones electrónicas del macrociclo tetrapirrolico de la clorofila pueden ser asignadas a transiciones electrónicas $\pi$ - $\pi^{*}$ en porfirinas y compuestos similares, el espectro de fluorescencia en la misma figura muestra una banda intensa a $667 \mathrm{~nm}$ y una más pequeña alrededor de $710 \mathrm{~nm}$ ambas características también de la clorofila $a$.

Después de la extracción de la clorofila se procede a funcionalizarla utilizando el 3amino-propil-trietóxisilano (APTES), para ello se utilizó la metodología reportada por M.A García Sánchez [61]. Se prepara una solución madre a partir de $20 \mathrm{mg}$ de la clorofila extraída en $50 \mathrm{ml}$ de 1-Propanol. Para la unión covalente se mezclan $10 \mathrm{ml}$ de la solución madre y se le agregan $0.20 \mathrm{ml}$ de APTES manteniendo agitación constante y una temperatura de $70{ }^{0} \mathrm{C}$ durante 24 horas. Esta solución se utilizó para sintetizar los xerogeles de $\mathrm{ZrO}_{2}$ y $\mathrm{TiO}_{2}$. 


\subsection{Síntesis de Xerogeles de $\mathrm{ZrO}_{2}$-Clorofila a -APTES y $\mathrm{TiO}_{2}-$ Clorofila $a$ - APTES con $\Phi$-TEOS (trietoxifelsilano).}

Para sintetizar materiales con la especie Clorofila a -APTES unida de manera covalente a las paredes de los óxidos funcionalizados se utilizaron relaciones molares similares a las reportadas para atrapar los macrociclos tetrapirrólicos sintéticos.

Tabla 3.4 Relaciones para sintetizar xerogeles con $\mathrm{ZrO}_{2}$ y la especie Clorofila-APTES.

\begin{tabular}{|c|c|c|c|c|c|c|c|c|}
\hline Muestra & $\mathrm{Zr}\left(\mathrm{OPr}^{\mathrm{n}}\right)_{4}$ & $\mathrm{Pr}^{\mathrm{n}} \mathrm{OH}$ & :Acac & $\begin{array}{l}\text { : DMF } \\
(\mathrm{ml})\end{array}$ & $\begin{array}{l}\text { Solución } \\
\text { con } \\
\text { Clorofila } \\
\text { - APTES } \\
\text { en } \operatorname{Pr}^{\mathrm{n}} \mathrm{OH} \\
\quad(\mathrm{ml})\end{array}$ & $\begin{array}{c}\text { Concentración } \\
(\mathrm{mol} / \mathrm{l})\end{array}$ & $\begin{array}{l}\text { Pyridina } \\
(\mathrm{ml})\end{array}$ & $\begin{array}{c}\varnothing \text {-TEOS } \\
(\mathrm{ml})\end{array}$ \\
\hline Blanco & 3.8 & 1.2 & 0.42 & 0.1 & 0 & 0 & 0.05 & 0 \\
\hline A & 3.8 & 1.2 & 0.42 & 0.1 & 1 & 2.2E-1 & 0.05 & 0.1 \\
\hline B & 3.8 & 1.2 & 0.42 & 0.1 & 0.9 & $2.2 \mathrm{E}-1$ & 0.05 & 0.1 \\
\hline $\mathrm{C}$ & 3.8 & 1.2 & 0.42 & 0.1 & 0.5 & $2.2 \mathrm{E}-1$ & 0.05 & 0.1 \\
\hline $\mathrm{D}$ & 3.8 & 1.2 & 0.42 & 0.1 & 0.3 & $2.2 \mathrm{E}-1$ & 0.05 & 0.1 \\
\hline $\mathrm{E}$ & 3.8 & 1.2 & 0.42 & 0.1 & 0.1 & $2.2 \mathrm{E}-1$ & 0.05 & 0.1 \\
\hline
\end{tabular}

Tabla 3.5 Relaciones para sintetizar xerogeles con $\mathrm{TiO}_{2}$ y la especie Clorofila-APTES.

\begin{tabular}{|c|c|c|c|c|c|c|c|c|}
\hline Muestra & $\mathrm{Ti}\left(\mathrm{OPr}^{\mathrm{n}}\right)_{4}$ & $\mathrm{Pr}^{\mathrm{n}} \mathrm{OH}$ & :Acac & $\begin{array}{l}\text { :DMF } \\
(\mathrm{ml})\end{array}$ & $\begin{array}{c}\text { Solución } \\
\text { con } \\
\text { Clorofila } \\
\text {-APTES } \\
\text { (ml) }\end{array}$ & $\begin{array}{l}\text { Concentración } \\
\qquad(\mathrm{mol} / \mathrm{l})\end{array}$ & $\begin{array}{l}\text { Pyridina } \\
\text { (ml) }\end{array}$ & $\begin{array}{c}\varnothing \text {-TEOS } \\
(\mathrm{ml})\end{array}$ \\
\hline Blanco & 3.0 & 1.0 & 0.2 & 0.3 & 0 & 0 & 0.05 & 0 \\
\hline A & 3.0 & 1.0 & 0.2 & 0.3 & 1 & $2.2 \mathrm{E}-1$ & 0.05 & 0.1 \\
\hline B & 3.0 & 1.0 & 0.2 & 0.3 & 0.9 & $2.2 \mathrm{E}-1$ & 0.05 & 0.1 \\
\hline
\end{tabular}




\begin{tabular}{|c|c|c|c|c|c|c|c|c|}
\hline C & 3.0 & 1.0 & 0.2 & 0.3 & 0.5 & $2.2 \mathrm{E}-1$ & 0.05 & 0.1 \\
\hline $\mathrm{D}$ & 3.0 & 1.0 & 0.2 & 0.3 & 0.3 & $2.2 \mathrm{E}-1$ & 0.05 & 0.1 \\
\hline $\mathrm{E}$ & 3.0 & 1.0 & 0.2 & 0.3 & 0.1 & $2.2 \mathrm{E}-1$ & 0.05 & 0.1 \\
\hline
\end{tabular}

\subsubsection{UV-Vis de Xerogeles.}

El espectro UV-Vis de la especie Clorofila a-F monomérica en 1-propanol (figura 3.12) presenta una banda de Soret en $400 \mathrm{~nm}$, y tres bandas en 498, 607 y $663 \mathrm{~nm}$, respectivamente, todas estas asociadas a transiciones electrónicas $\pi-\pi^{*}$ del macrociclo presente en la clorofila. Los espectros UV-Vis de las muestras gelantes en $\mathrm{ZrO}_{2}$ a) y $\mathrm{TiO}_{2}$ b) de la figura 3.13 presentan espectros similares entre ellos, las bandas Q se encuentran en las mismas posiciones lo que sugiere que la clorofila se encuentra en forma monomérica y estable en el interior de la poros de ambos sustratos. Los espectros de los xerogeles consolidados presentados en la figura 3.14 muestran para el caso del $\mathrm{ZrO}_{2}$ a) que las banda de Soret y las bandas $\mathrm{Q}$ no tuvieron cambios en las posiciones con respecto a las soluciones gelantes cabe mencionar que se presenta una pequeña banda en $707 \mathrm{~nm}$ lo cual sugiere que la agregación de moléculas de clorofila [60]. Este fenómeno se puede atribuir a que en el proceso de hidrolisis y condensación en el xerogel la concentración de clorofila en la muestras aumenta, esta idea podría sustentarse en el hecho de que esta banda a $707 \mathrm{~nm}$ desaparece en las muestras D y E que son las que tienen las concentraciones más bajas de los materiales sintetizados $1.1 \mathrm{X}_{10}{ }^{-2}$ al inicio del proceso sol-gel, para el caso de los xerogeles de $\mathrm{TiO}_{2}$ b) al parecer ocurre un fenómeno similar, solo que ahora en las muestras etiquetadas con las letras D y E con menor concentración de clorofila la banda a $707 \mathrm{~nm}$ no desaparece, así, aunque las molécula de clorofila a permanecen como monómeros a concentraciones altas en disolventes comunes [65] al parecer el ambiente químico y la concentración de la clorofila en los materiales sintetizados favorece la aparición de agregados preferentemente en el $\mathrm{TiO}_{2}$. 


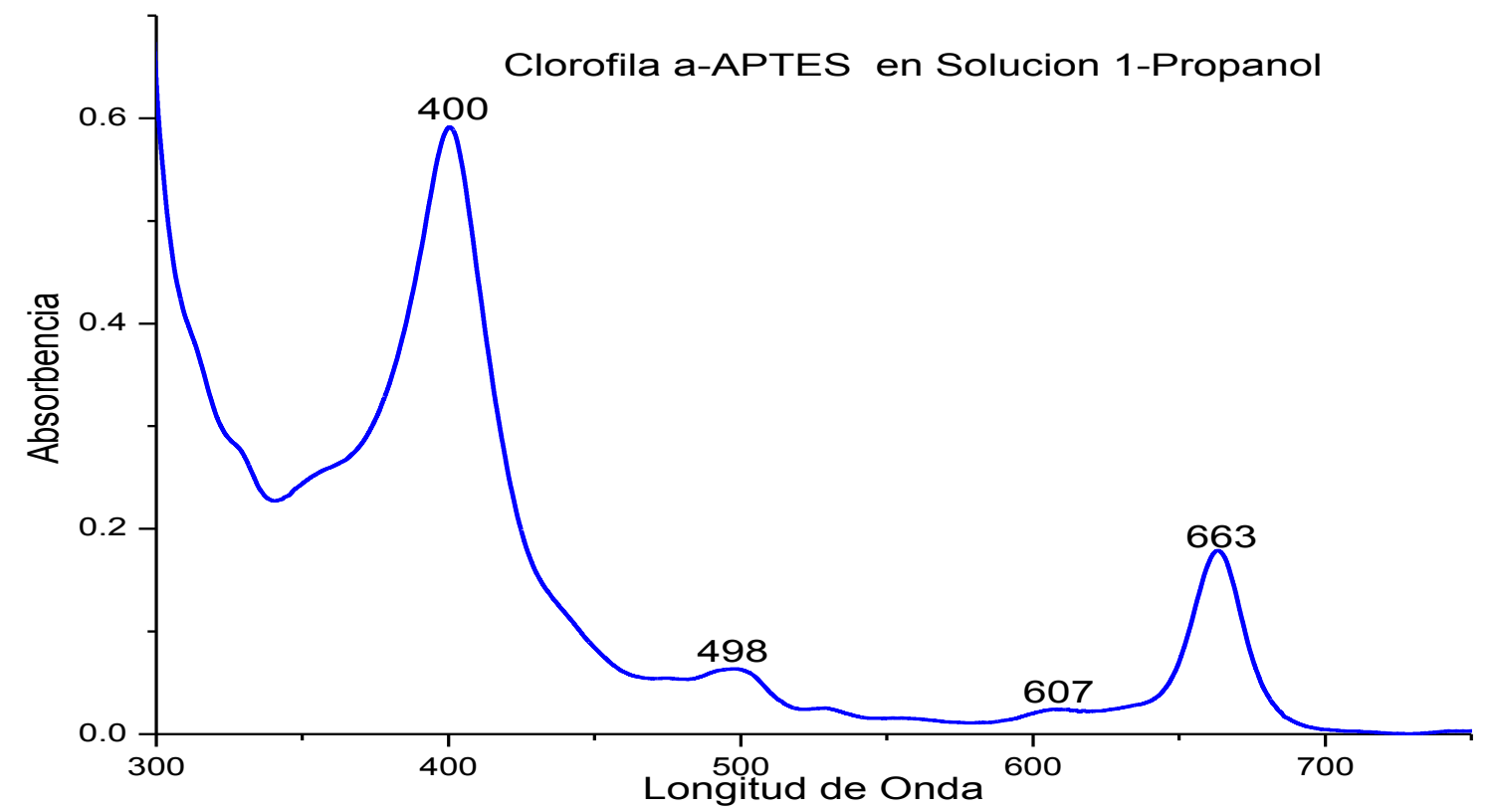

Figura 3.12 Espectro de Clorofila a-APTES en 1 propanol
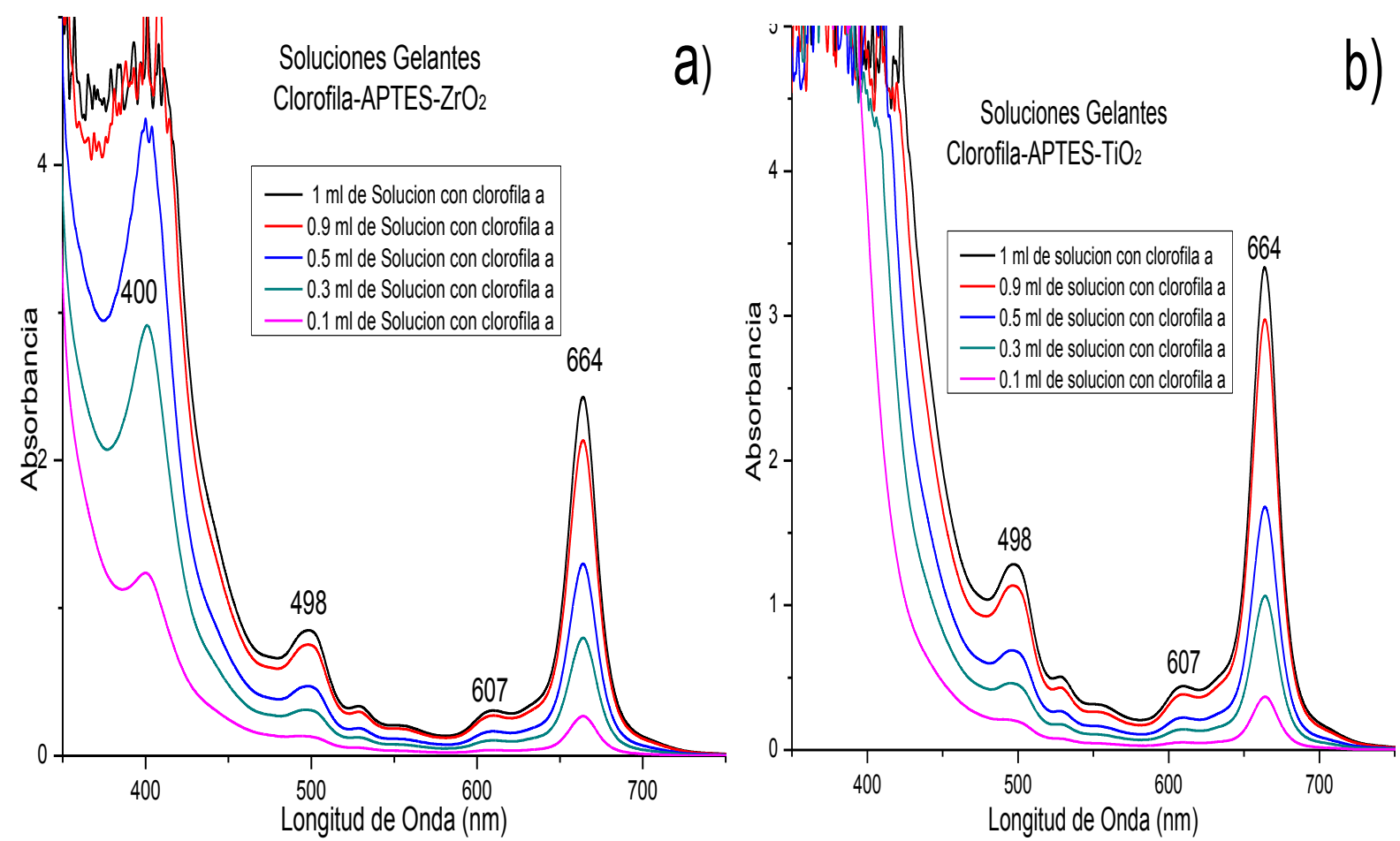

Figura 3.13 Espectros UV-Vis de mezclas gelantes sintetizadas de a) $\mathrm{ZrO}_{2}$ y b) $\mathrm{TiO}_{2}$ con Clorofila $a-$ APTES con diferentes volúmenes de solución patrón. 

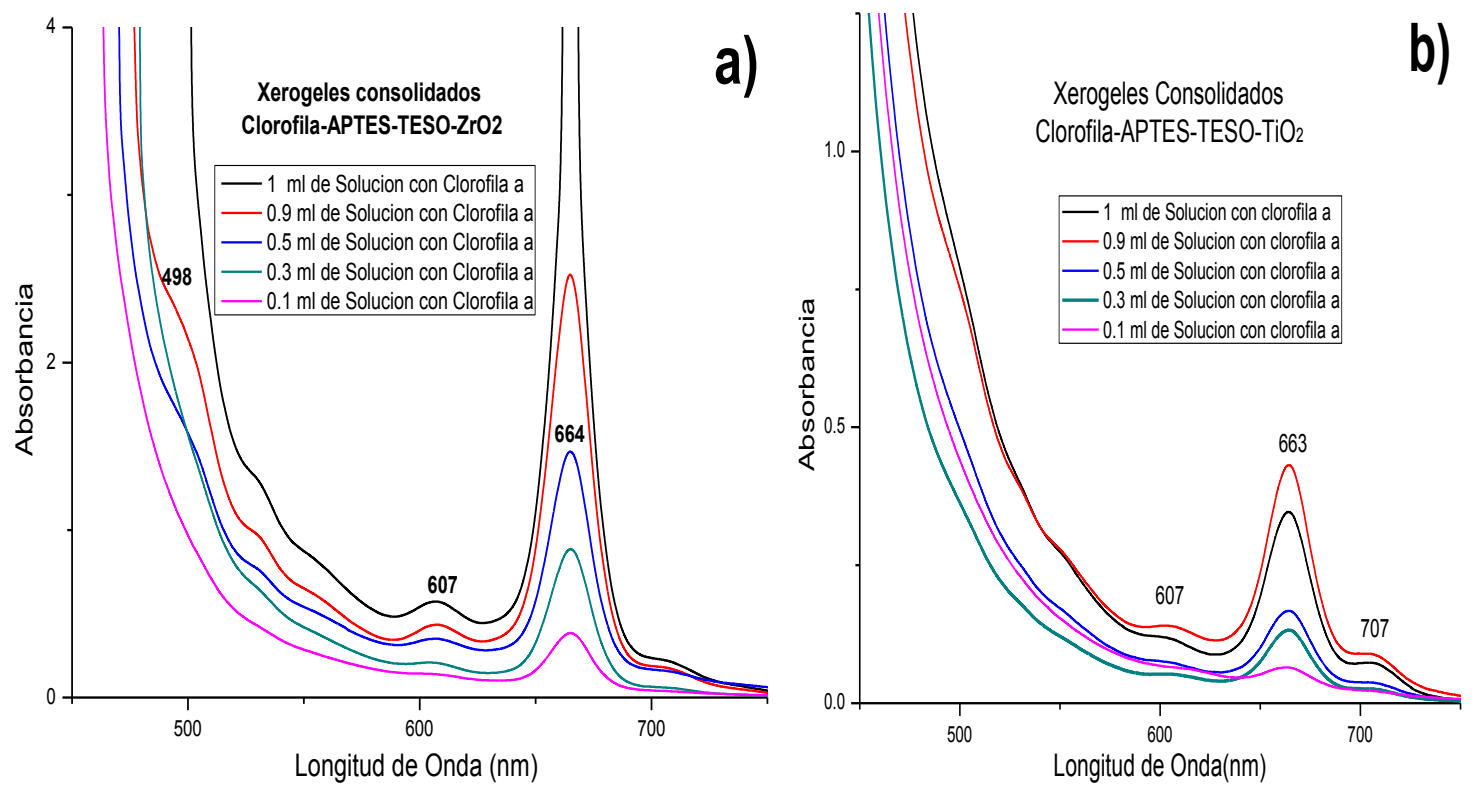

Figura 3.14 Espectros UV-Vis de Xerogeles sintetizados de a) $\mathrm{ZrO}_{2}$ y b) $\mathrm{TiO}_{2}$ con Clorofila $a$-APTES con diferentes volúmenes de solución patrón.

\subsubsection{Fluorescencia de Xerogeles.}

El macrociclo de la clorofila muestra fluorescencia roja al ser irradiado con luz ultravioleta, como ya se ha reportado [60] el espectro de emisión depende del disolvente en el que se encuentra inmerso, sin embargo de manera general se observa que aparecen dos bandas principales localizadas a alrededor de 668 y $700 \mathrm{~nm}$, en la región del rojo y la cercana al infrarrojo asociada con la emisiones $\pi$ - $\pi^{*}$ del macrociclo.

Con lo que respecta al espectro de fluorescencia del $\mathrm{ZrO}_{2}$ sintetizado por el método sol-gel se ha reportado [66] que presenta una banda anda ancha asociada a la emisión de la matriz del óxido que va desde 450 a $600 \mathrm{~nm}$ con picos más pronunciados en 460, 465 y $555 \mathrm{~nm}$ respectivamente al ser excitada con diferentes longitudes de onda del intervalo del ultra violeta,

El espectro de fluorescencia del $\mathrm{TiO}_{2}$ sintetizado utilizando el método sol-gel presenta de manera general una banda ancha que va de 400 a $600 \mathrm{~nm}$ con una emisión máxima a $455 \mathrm{~nm}$ al ser excitada con un luz ultravioleta [67]. 
Con base en esta información se obtuvieron espectros de fluorescencia de los xerogeles sintetizados con clorofila $a$ en $\mathrm{ZrO}_{2}$ figura 3.15 a diferentes longitudes de onda de excitación. Usando a $\lambda_{\text {exc }}=370 \mathrm{~nm}$, se observa que aparece una banda ancha en el rango de 400 a $600 \mathrm{~nm}$ con dos señales intensas a 399 y $560 \mathrm{~nm}$ asociadas a la matriz de $\mathrm{ZrO}_{2}$, solas o interaccionando con el macrociclo tetrapirrólico, que resultan ser tan intensas como la banda que aparece de 600 a $750 \mathrm{~nm}$ con un máximo de emisión en $688 \mathrm{~nm}$ y que se atribuye al macrociclo presente en la clorofila. Cabe destacar que como es de esperarse la intensidad de la banda asociada con el macrociclo disminuye de acuerdo con la concentración de clorofila en el material, mientras que las emisiones de la matriz de zirconio no muestran disminución significativa, este hecho explica la tonalidad azul-verdoso que presenta el xerogel al ser expuesto a luz UV-Vis. Este patrón se repite al excitar las muestras con una $\lambda_{\text {exc }}=420 \mathrm{~nm}$ (Figura $3.15 \mathrm{~b}$ ) salvo que en este caso la intensidad de las señales es un poco mayor, presentándose un corrimiento batocromico para el caso de las señales asociadas con la matriz de zirconio, mientras que la señal de la clorofila permanece sin cambio alguno, lo que sugiere que esta señal está asociada a la banda de Soret (400 nm-420 nm). Para el caso de los materiales excitados con $\lambda_{\text {exc }}=430 \mathrm{~nm}$ (Figura $3.15 \mathrm{c}$ ), ocurre algo similar a las anteriores. Cabe destacar que las muestras fueron excitadas con longitudes de onda de 500-550 nm y no se presentaron cambios significativos en los espectros obtenidos.

Se obtuvieron también espectros de fluorescencia de los xerogeles sintetizados con clorofila $a$ y $\mathrm{TiO}_{2}$ figura 3.16 a longitudes de excitación. Utilizando $\lambda_{\mathrm{exc}}=370 \mathrm{~nm}$ (Figura 3.16 a )se observa que aparece una banda ancha muy intensa en el rango de 400 a $600 \mathrm{~nm}$ con un máximo de intensidad en $440 \mathrm{~nm}$ asociadas a la matriz de $\mathrm{TiO}_{2}$, sola o interaccionando con el macrociclo tetrapirròlico, que resultan ser mucho más intensa que la que aparece de 650 a 800 nm con un máximo de emisión en $688 \mathrm{~nm}$ y que se atribuye al macrociclo presente en la clorofila, este fenómeno es parecido al que se suscita en la matriz del $\mathrm{SiO}_{2}$ [60] solo que aquí resulta mucho más drástica la diferencia de emisiones de la red y el macrociclo.

La intensidad de la banda asociada con el macrociclo de la clorina disminuye de acuerdo con la concentración de clorofila en el material, mientras que las emisiones de la matriz de titanio a diferencia del $\mathrm{ZrO}_{2}$ también muestra una disminución. Al excitar las muestras con una 
$\lambda_{\text {exc }}=420 \mathrm{~nm}$ (Figura $3.16 \mathrm{~b}$ ) la intensidad de las señales es contraria apareciendo una pequeña banda asociada a la matriz de $\mathrm{TiO}_{2}$ que va de 400 a 600nm con una emisión máxima en 505nm y una banda de 600 a $800 \mathrm{~nm}$ con un pico a $668 \mathrm{~nm}$ característico del macrociclo hecho que como en el caso anterior sugiere que esta señal está asociada a la banda de Soret $(400 \mathrm{~nm}$ $420 \mathrm{~nm}$ ) y explica el color rojo del xerogel al ser excitado con luz UV-Vis- Para el caso de los materiales excitados con $\lambda_{\text {exc }}=430 \mathrm{~nm}$ (Figura $3.16 \mathrm{c}$ ), la banda de la matriz crece y la del macrociclo sufre una ligera disminución, las muestras fueron excitadas también longitudes de onda de 500-550nm y no se presentaron cambios significativos en los espectros obtenidos.
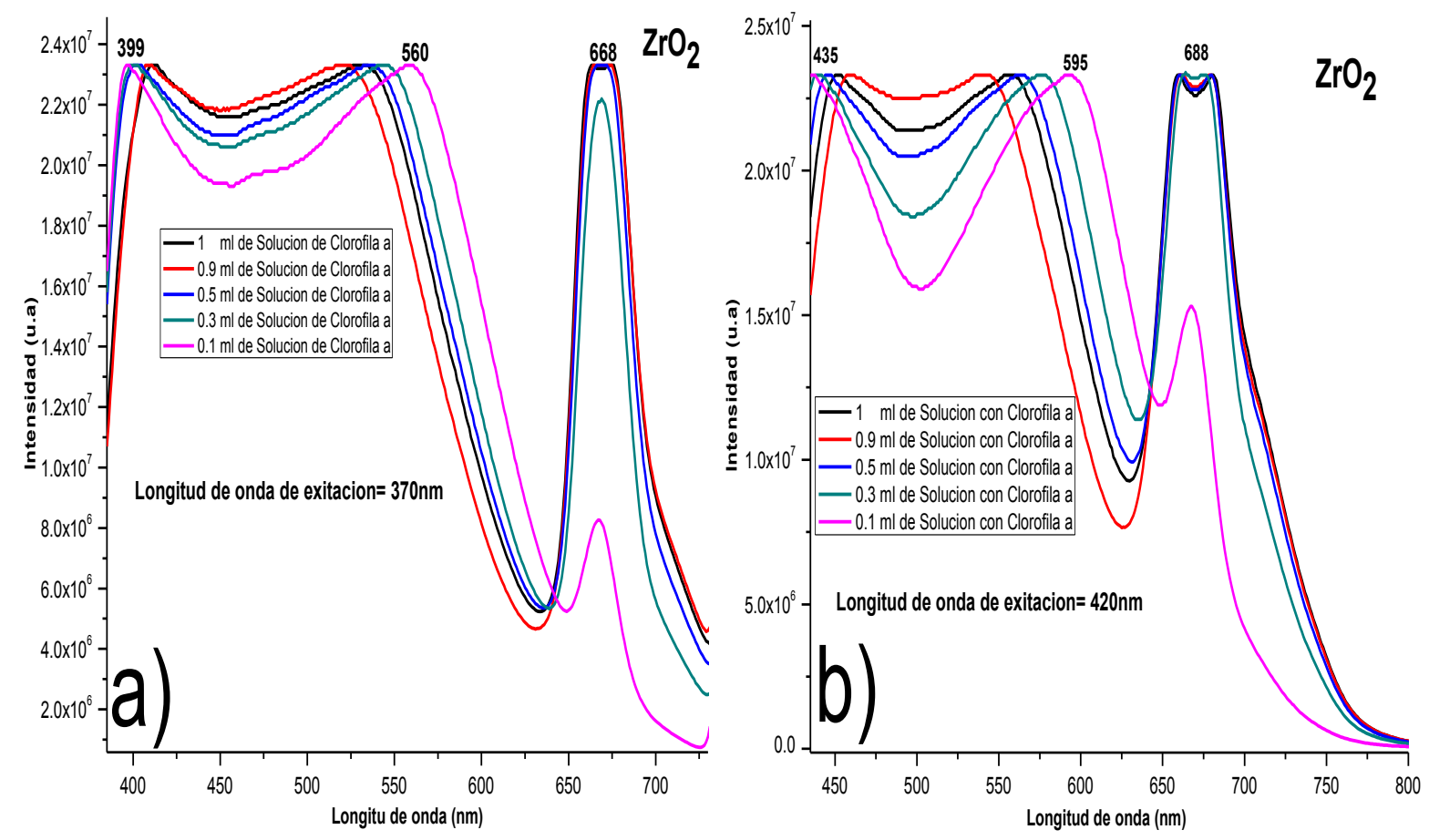


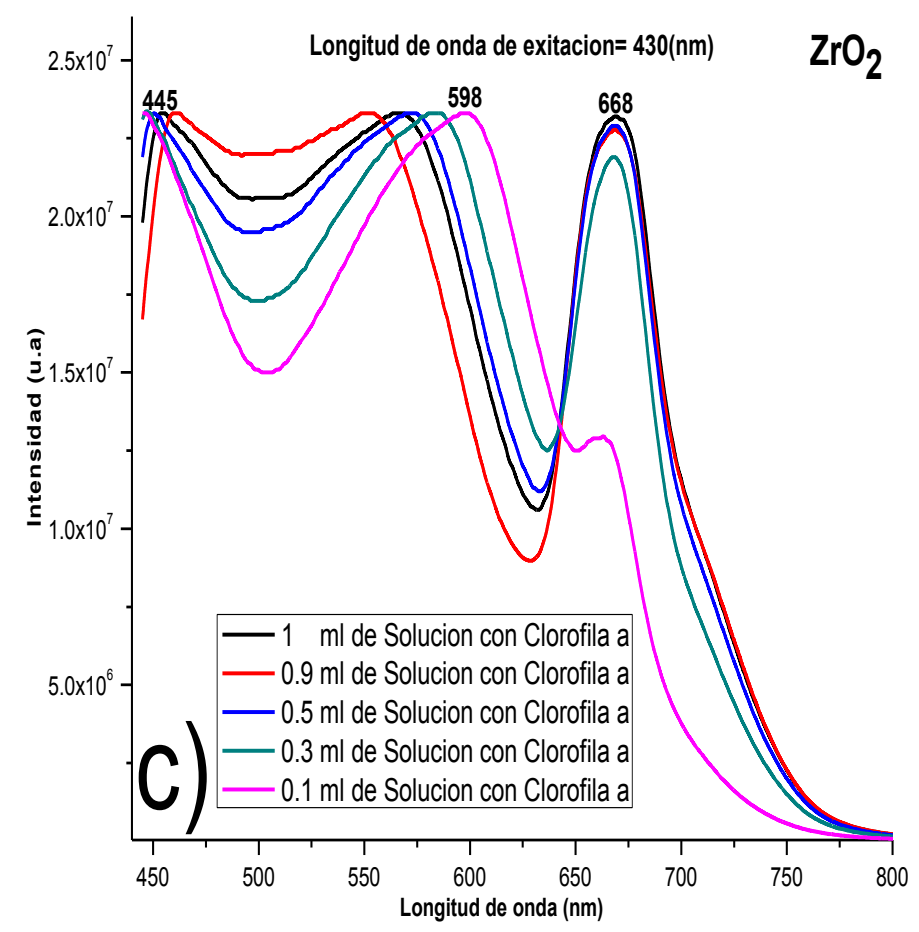

Figura 3.15. Espectros de excitación de xerogeles consolidados de $\mathrm{ZrO}_{2}$ (a $\lambda_{\text {exc }}=370 \mathrm{~nm}$ b) $\lambda_{\text {exc }}=420 \mathrm{~nm}$ c) $\lambda_{\text {exc }}=430 \mathrm{~nm}$ con Clorofila a - APTES y con diferentes volúmenes de solución patrón.
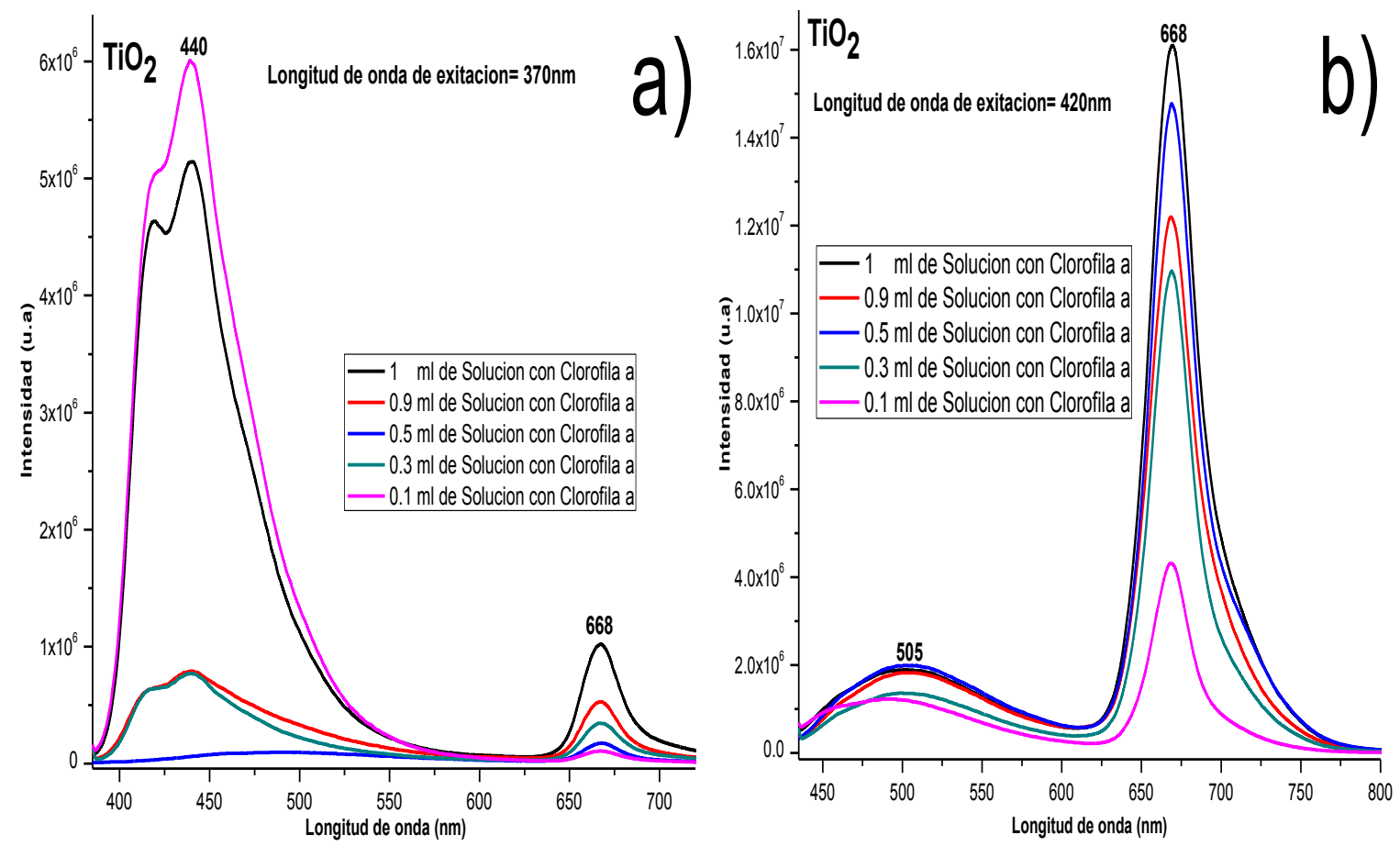


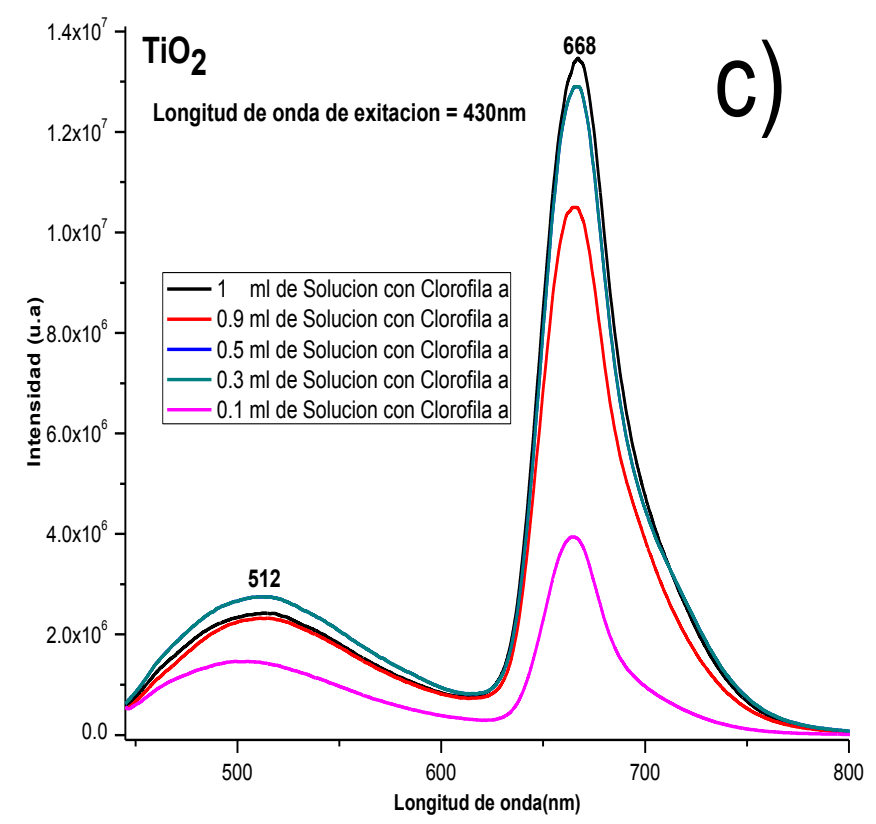

Figura 3.16 Espectros de excitación de xerogeles consolidados de $\mathrm{TiO}_{2} \quad\left(\right.$ a $\left.\lambda_{\text {exc }}=370 \mathrm{nmb}\right) \lambda_{\text {exc }}=420 \mathrm{~nm}$ c) $\lambda_{\text {exc }}=430 \mathrm{~nm}$ con Clorofila a - APTES y con diferentes volúmenes de Solución patrón.

\subsubsection{Diámetro de poro y área superficial en los dos óxidos}

Las isotermas de sorción-desorción de $\mathrm{N}_{2}$ a $76 \mathrm{~K}$ de xerogeles de $\mathrm{ZrO}_{2}$ y $\mathrm{TiO}_{2}$ figura 3.17 en los cuales se encuentra unida la Clorofila $a-\mathrm{F}$, son similares entre sí, corresponde según la IUPAC a una isoterma Tipo I con ciclo de histéresis $\mathrm{H} 3$ que son características de solidos micro porosos [52], con superficies externas relativamente pequeñas, microporos más anchos con la posibilidad de presentar mesoporos estrechos. El ciclo de histéresis de las isotermas de $\mathrm{TiO}_{2}$ es más acho que el que presentan los xerogeles de $\mathrm{ZrO}_{2}$, esto sugiere que la difusión de las moléculas de absorbato se dificulta de una cavidad a otra, posiblemente por la existencia de interconexiones pequeñas entre los poros.

Se reportan diámetros de poro de 1.2 a $1.13 \mathrm{mn}$ y áreas superficiales de 152.5 a 266.7 $\mathrm{m}^{2} / \mathrm{g}$ para el $\mathrm{ZrO}_{2}$, en contraste para el $\mathrm{TiO}_{2}$ son reportados valores de 1.44 a $1.28 \mathrm{~nm}$ y 102.6 a $296 \mathrm{a} \mathrm{m}^{2} / \mathrm{g}$ de diámetro y área respectivamente (Tabla 3.6). Resulta evidente que las los diámetros de poro y áreas superficiales depende de la concentración de clorofila a en los xerogeles. 

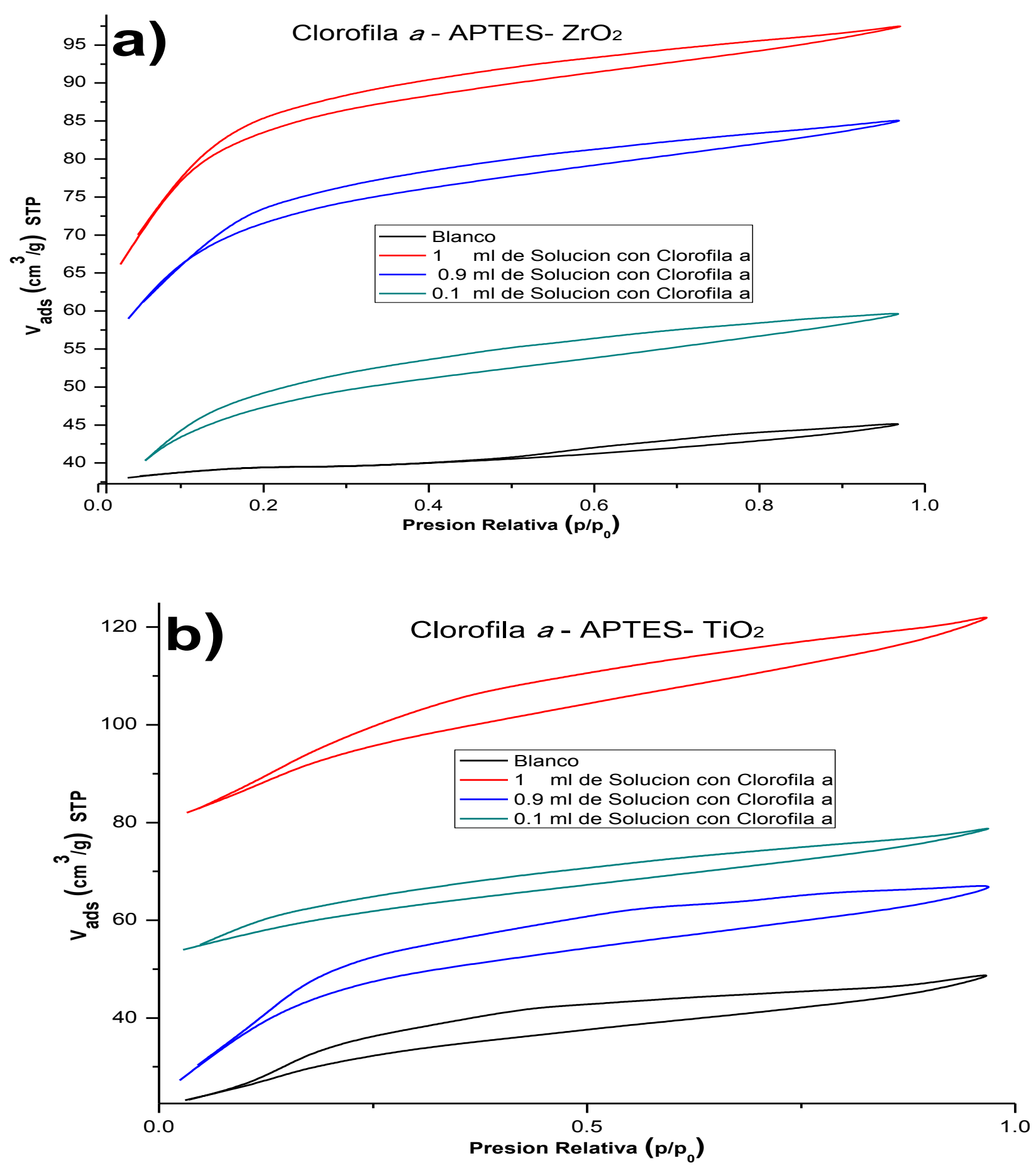

Fig. 3.17 Isotermas Adsorción Clorofila a -APTES a) $\mathrm{ZrO}_{2}$ y b) $\mathrm{TiO}_{2}$ 


\begin{tabular}{|c|c|c|}
\hline $\begin{array}{l}\text { Muestira } \\
\mathrm{ZrO}_{2}\end{array}$ & $\begin{array}{l}\text { Área BET Supericial } \\
\qquad \mathrm{m}^{2} / \mathrm{g}\end{array}$ & Diáme tro de poro $(\mathrm{nm})$ \\
\hline Blanco & 117.6 & 1.19 \\
\hline A & 266.7 & 1.13 \\
\hline B & 227.8 & 1.16 \\
\hline E & 152.5 & 1.2 \\
\hline
\end{tabular}

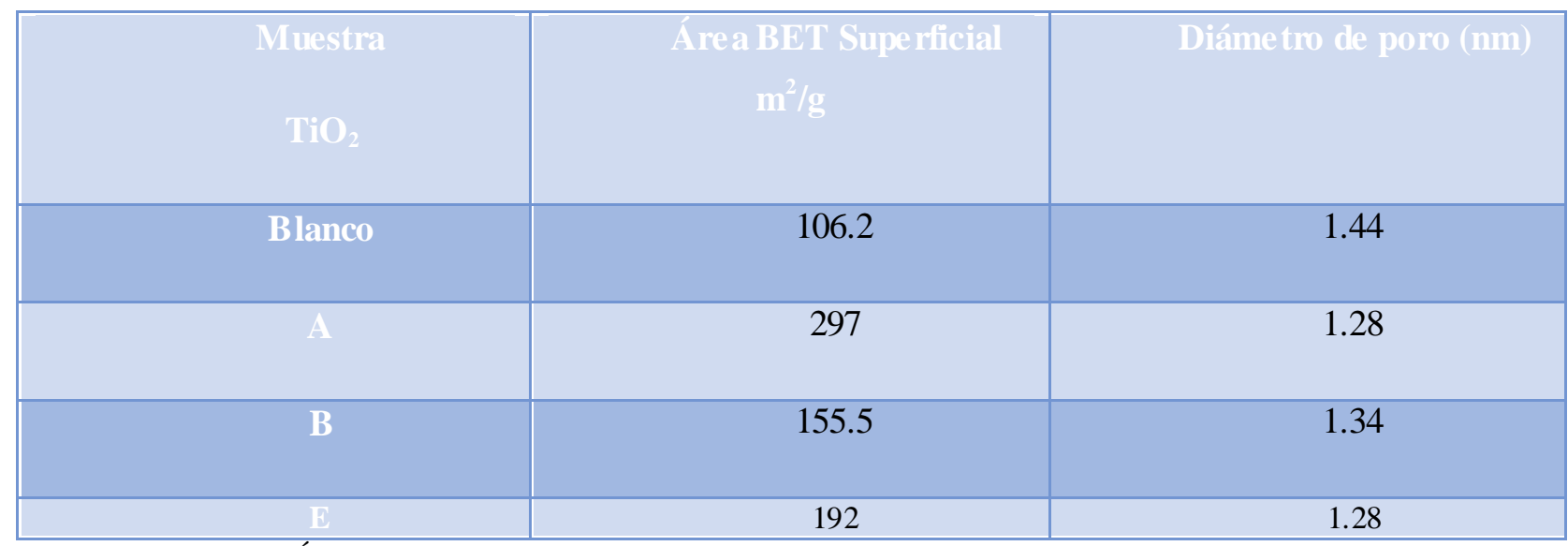

Tabla 3.6 Áreas y Diámetro de poro de xerogeles de $\mathrm{ZrO}_{2}$ y TiO 2 . Donde A, B y C para ambos sistemas corresponden a xerogeles sintetizados con $0.1,0.9$ y 0.1 de solución patrón.

El diámetro medio de poro $(\Phi)$ se calculó a través de las isotermas de $\mathrm{N}_{2}$, este parámetro se obtuvo a partir de la aplicación del enfoque funcional de densidad no local a la curva límite de desorción del bucle de histéresis de la isoterma, asumiendo cavidades esféricas. Los resultados arrojan que para el caso de las muestras de $\mathrm{ZrO}_{2}$ (figura 3.18 a) la molécula de clorofila $a$-F favorece la formación de diámetros de poro de 2.0 a $2.2 \mathrm{~nm}$. Mientras que la red de zirconio prístina muestra una distribución de 5 a $8 \mathrm{~nm}$. Para el caso de los xerogeles de $\mathrm{TiO}_{2}$ (Figura 3.18 b) el cambio en el diámetro de poro promedio entre la red prístina de titanio y los monolitos con clorofila $a-\mathrm{F}$ resulta ser menos drástico al variar de un diámetro de $2.7 \mathrm{~nm}$ para el blanco a 2.0 y $2.5 \mathrm{~nm}$ para los xerogeles con clorofila, estos diámetro de poro resultan 
consistentes con los reportados para sistemas análogos de $\mathrm{SiO}_{2}$ con clorofila [61] para los cuales se presentan resultados de $2.01 \mathrm{~nm}$.

Cabe señalar que en la misma figura aparece la formación de una pequeña cantidad de poros de $3.57 \mathrm{~nm}$, en los dos óxidos, esto puede deberse a que los poros se formaron en torno a la clorofila agregada o a dímeros de la misma.
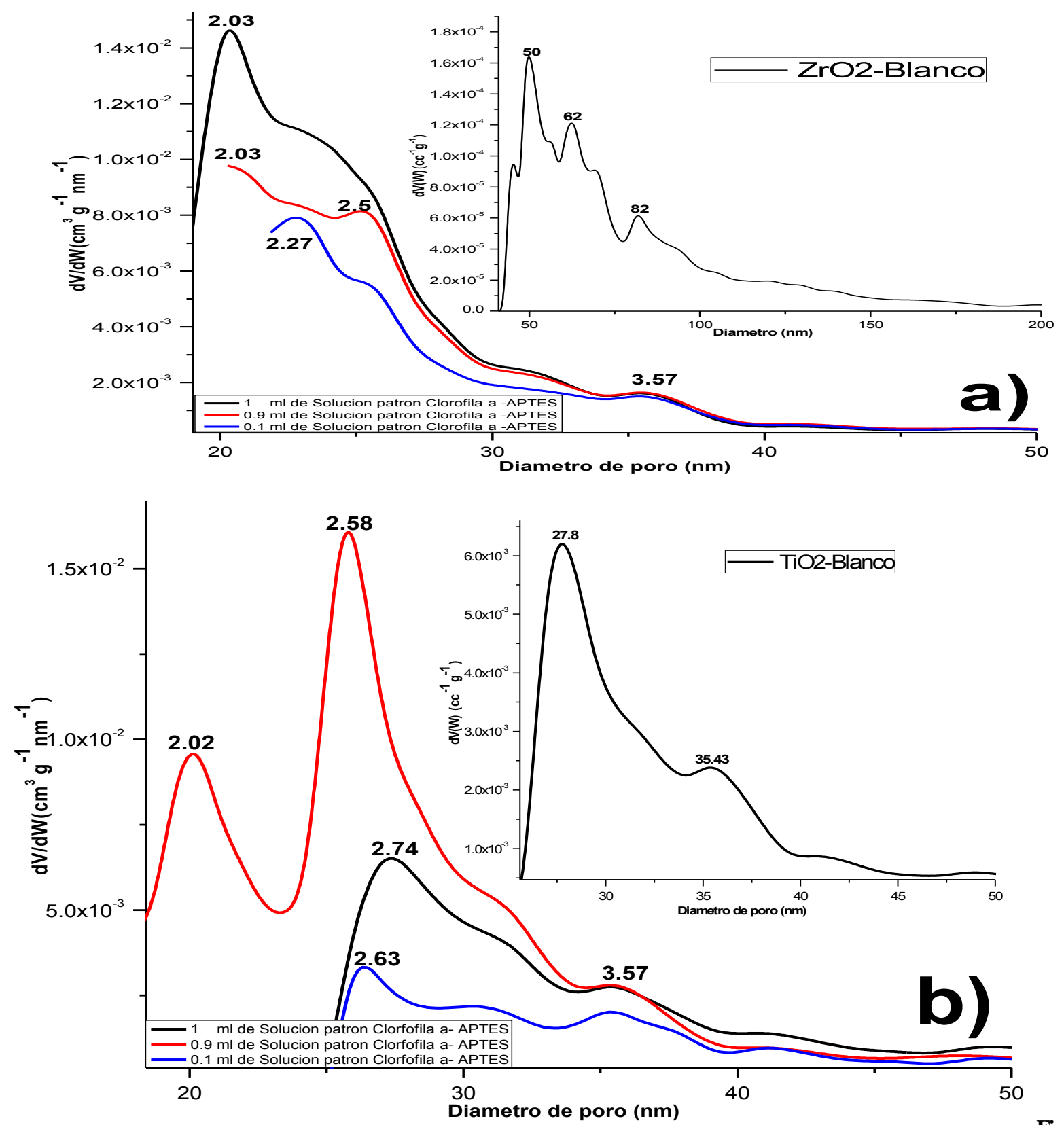

a 3.18 Distribución de diámetros de poro promed io calcu lados por NLDFT a) $\mathrm{ZrO}_{2}$ y b) $\mathrm{TiO}_{2}$

Figur 


\subsubsection{Microscopía Electrónica de Barrido (SEM) y Análisis EDS}

Los monolitos sintetizados y consolidados presentan una coloración verde, debido a la presencia de la clorofila a-F. La imagen de SEM (Figura 3.19) indica que el material es liso con algunas irregularidades y fracturas a) y b) para los materiales de $\mathrm{ZrO}_{2}$, para el caso de los xerogeles de $\mathrm{TiO}_{2}$ las figuras c) y d) se revela que los materiales son más frágiles que los de zirconio y con mayores irregularidades.

$\mathrm{El}$ análisis EDS para los xerogeles de $\mathrm{ZrO}_{2}$ detecta los siguientes porcentajes en peso \%: 0.21 de $\mathrm{Mg}$ (1.00 mol), 0.19 de $\mathrm{Si}(0.78 \mathrm{~mol}), 56.17 \mathrm{de} \mathrm{O}$ (406 mol), 34.77 de C (335.04 mol) y 8.67 de $\mathrm{Zr}$ (10.99 mol). Cabe señalar que el Mg solo se puede asociar a la presencia de clorofila y el silicio está relacionado con el APTES, los excesos del carbono y oxigeno podrían atribuirse a la existencia de acetilacetona remanentee $(\mathrm{acacH})$, dimetilformamida (DMF) y grupos propóxi $\left(\mathrm{OC}_{3} \mathrm{H}_{7}\right)$ y Trietoxifelsilano. Con esta información es posible calcular la relación molar $\mathrm{O} / \mathrm{Zr}$ la cual es de aproximadamente 37 y atribuirla a la presencia de grupos $\mathrm{Zr}-\mathrm{OH}$ remanentes en la red. El análisis del porcentaje en peso revela que en la superficie de las muestras existen 11 átomos de zirconio por cada molécula de clorofila suponemos que la mayoría de estos átomos están formando parte de las cavidades de poros que rodean a la clorofila unida. Para el caso de xerogeles de $\mathrm{TiO}_{2}$ se presentan valores similares en lo referente al análisis EDS.

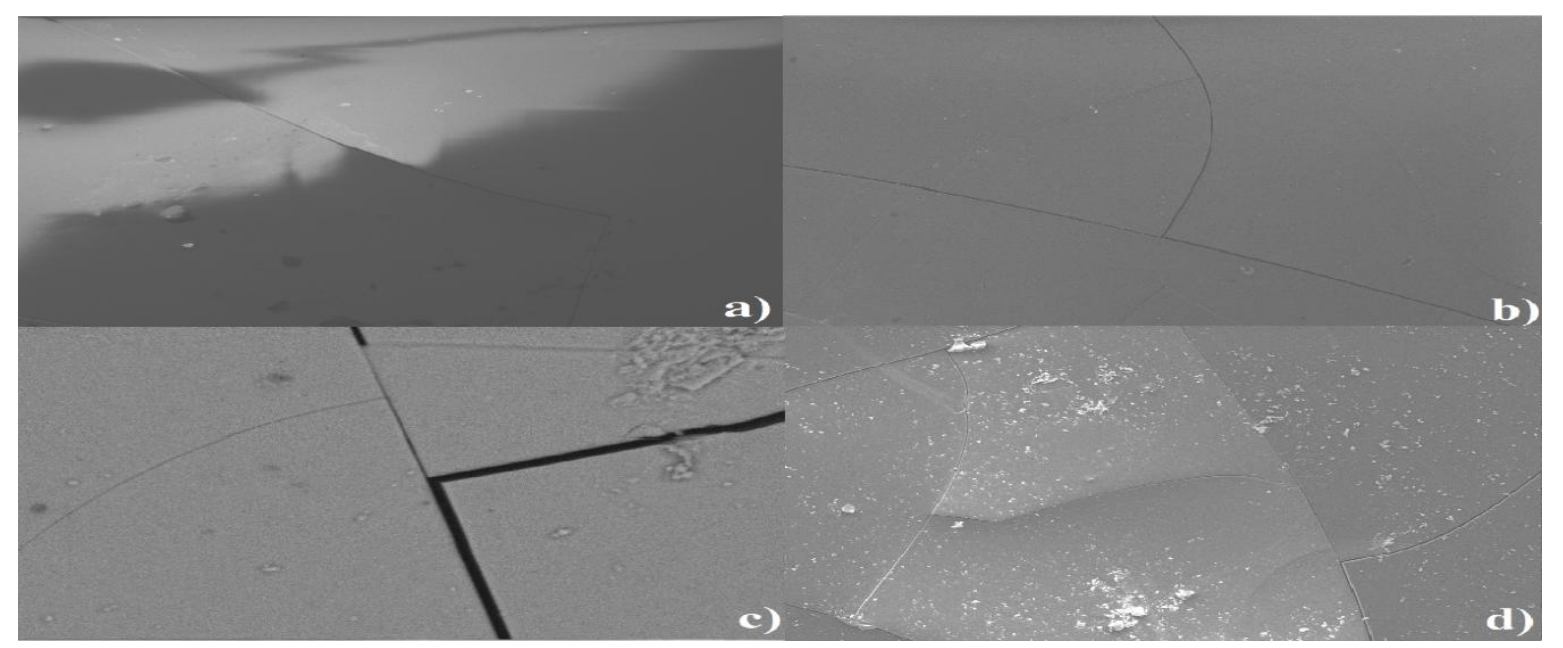

Figura 3.19 Imagen de microscopía de barrido (SEM) de xerogel de $\mathrm{ZrO}_{2}$ con la Clorofila a-APTES unida a) $10 \mathrm{~m} \mu$ b) $100 \mu \mathrm{m}$ y con $\mathrm{TiO}_{2}$ y Cloro fila a-APTES c) $10 \mathrm{~m} \mu \mathrm{d}$ ) $100 \mu \mathrm{m}$. 


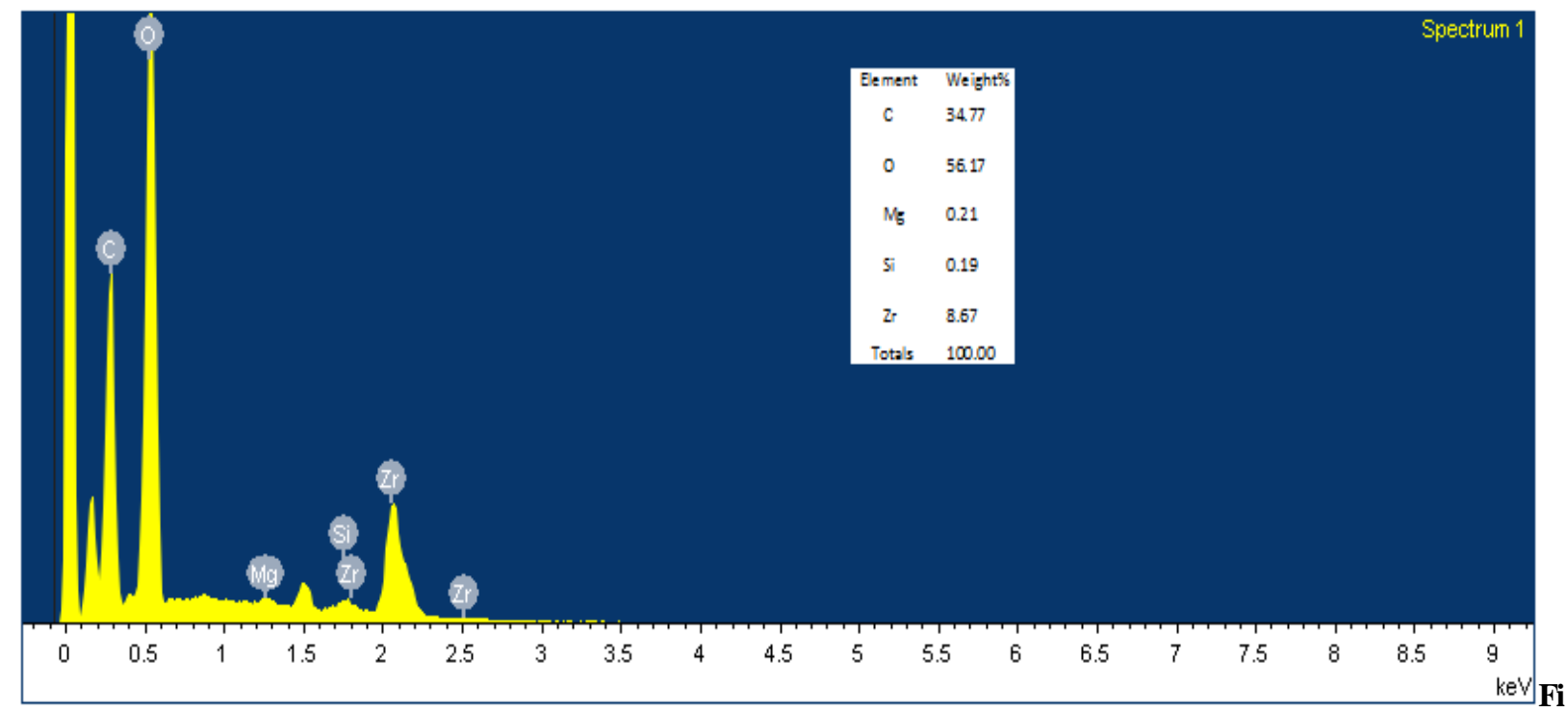

gura 3.20 Porcentaje de elementos detectados por EDS en la muestra.

Al final de la síntesis y caracterización de los materiales de $\mathrm{TiO}_{2} \mathrm{yZrO}_{2}$ podemos mencionar que: se sintetizaron materiales de $\mathrm{ZrO}_{2}$ y $\mathrm{TiO}_{2}$ que contienen a la especie $\mathrm{H}_{2} \mathrm{~T}(\mathrm{p}-\mathrm{COOH}) \mathrm{PP}-\mathrm{APTES}$ unida a las paredes de los poros, la especie porfirinica se mantiene como monómero y estable dentro de los óxidos, al parecer el ambiente químico menos polar del $\mathrm{ZrO}_{2}$ y la unión covalente con el APTES intervienen para que la molécula presente propiedades parecidas a las que presenta en solución, también se puede decir que la fluorescencia roja de la especie $\mathrm{H}_{2} \mathrm{~T}(\mathrm{COOH}) \mathrm{PP}-\mathrm{F}$ en los xerogeles de óxido de titanio se preservo, no así en los xerogeles de $\mathrm{ZrO}_{2}$ en donde predomino la de la matriz de óxido, que al unirse la especie en al $\mathrm{ZrO}_{2}$ se logra un aumento considerable en el área del material lo cual puede resultar interesante el catálisis y por último que los diámetros de poro promedio calculados por el método (NLDFT) muestran que ante la presencia de la porfirina en el material predominan los poros de 2 a $2.2 \mathrm{~nm}$ según el material y que los de más de $3 \mathrm{~nm}$ prácticamente desaparecen y que el diámetro de poro y el área superficial reportada para sistemas de $\mathrm{TiO}_{2}$ presentan semejanza con las tendencias reportadas en sistemas análogos de $\mathrm{SiO}_{2}$ por Quiroz y M.A.Garcia en contraste los sistemas de $\mathrm{ZrO}_{2}$ presentan una tendencia a la inversa. 


\title{
UAM-I
}

\section{CAPITULO IV}

\author{
$\mathrm{H}_{2} \mathrm{~T}$ (p-COOH)PP UNIDA
}

COVALENTEMENTE A MATRICES DE $\mathrm{ZrO}_{2}$ y

$\mathrm{TiO}_{2}$ ÓRgANO MODIFICADAS.

Xerogel consolidado de $\mathrm{ZrO}_{2}$ con la es pecie $\mathrm{H}_{2} \mathrm{~T}(\boldsymbol{p}-\mathrm{COOH}) \mathrm{PP}$-APTES unida a poros organomodificados. 


\subsection{Propiedades de la $\mathrm{H}_{2} \mathrm{~T}(\mathrm{p}-\mathrm{COOH}) \mathrm{PP}$-APTES.}

La síntesis de macrociclos tetrrapirrolicos en particular las ftalocianinas y porfirinas es uno de los campos de estudio de la química orgánica que más se ha desarrollados en la época actual, debido a los múltiples usos de esto compuestos en áreas como la catálisis, óptica y sensores, por ser estas especies muy sensibles al ambiente químico en el que encuentran inmersas. Con esto en mente se han sintetizado múltiples compuestos con base en estructuras porfirinicas y con el objeto encontrar aplicaciones y dar solución a diversas problemáticas en las áreas antes mencionadas, Un caso particular es el de las meso-porfirinas, derivados de la porfina en las cuales son sustituidos uno o varios de los hidrógenos metínicos por grupos arilo o alquilo (Figura 4.1).

Los métodos de síntesis de algunas meso-porfirinas, así como la variación de las propiedades físicas como la solubilidad y el punto de fusión asociable a las posiciones en las que se presentan los sustituyentes y el número de carbonos en ella, han sido reportadas [68]. Los anteriores resultan parámetros importantes a considerar a la hora de buscar aplicaciones de estas importantes moléculas, ya sean libre o coordinadas a diversos metales.

Además de las propiedades mencionadas, se sabe que algunas de las porfirinas libres muestran fluorescencia en el intervalo de 600 a 800nm [69-71] y que la luz roja o infraroja de longitud de onda de entra 600 y $1500 \mathrm{~nm}$ logra una mejor penetración en tejidos vivos [72]. Debido a esto y a que algunas porfirinas libre son adsorbidas de manera selectiva por bacterias [68] son utilizadas en la llamada terapia fotodinámica. Toda esta serie de interesantes propiedades se desean conservar en la medida de lo posible al insertarla en redes de óxidos no convencionales como los de zirconio y titanio, emulando lo realizado por Quiroz y García Sánchez [73] que sintetizaron y unieron a xerogeles de $\mathrm{SiO}_{2}$ la molécula 5, 10, 15, 20-tetrakismeso-paracarboxifenilporfirina $\left(\mathrm{H}_{2} \mathrm{~T}(p-\mathrm{COOH}) \mathrm{PP}\right)$, obteniendo resultados interesante. La síntesis de la molécula anterior y su funcionalización con APTES se describió en el capítulo anterior. 


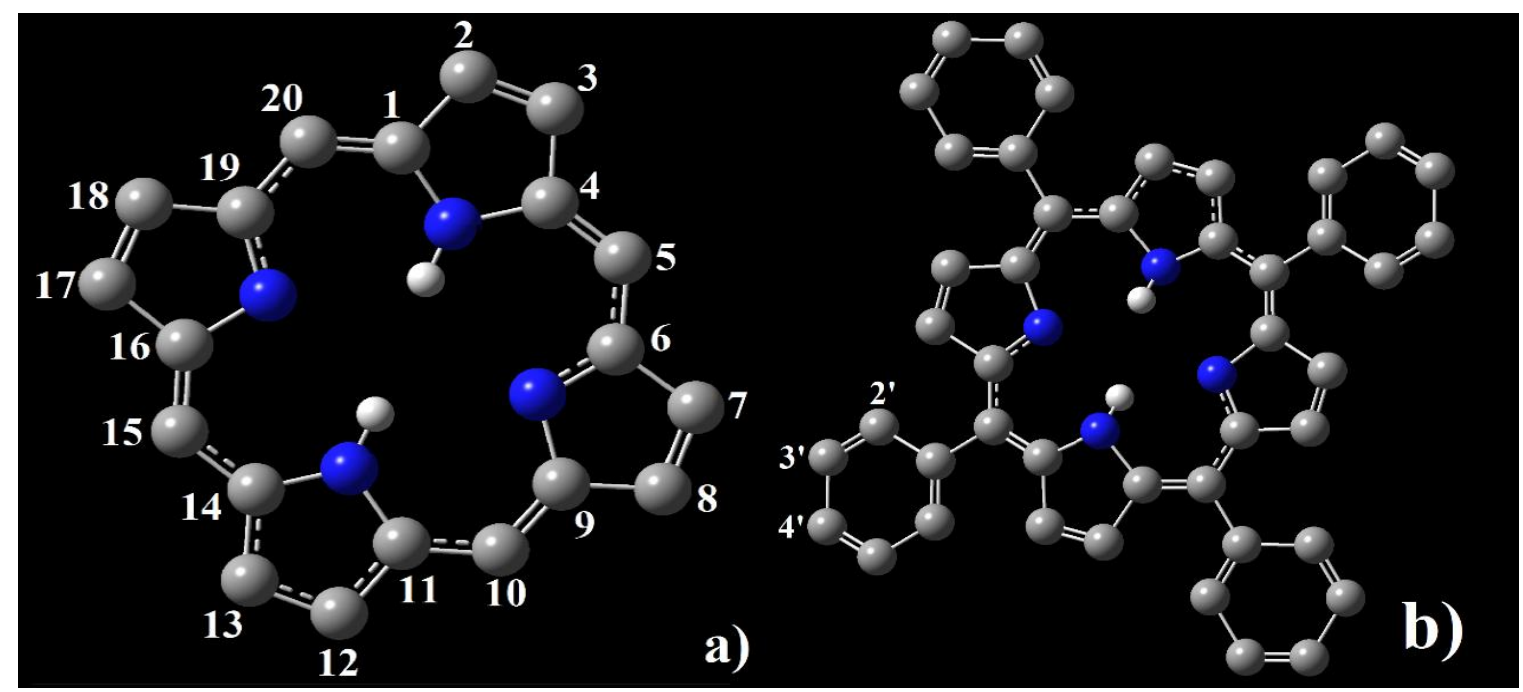

Figura 4.1. (a) Estructura y posiciones periféricas de los átomos del macrociclo de porfirina $\left(\mathrm{H}_{2} \mathrm{P}\right)$ y $(\mathrm{b})$ estructura química de la 5, 10, 15,20-tetrakis-meso-fenilporfirina ( $\left.\mathrm{H}_{2} \mathrm{TPP}\right)$. Los números primos (posiciones orto, meta y paras ) representan las posiciones en donde se pueden unir diversas moléculas orgánicas.

\subsection{Síntesis de Xerogeles de $\mathrm{ZrO}_{2}$ y $\mathrm{TiO}_{2}$ Órgano modificados con $\mathrm{H}_{2} \mathrm{~T}(\mathrm{p}$ - COOH)PP-APTES.}

Se sintetizaron xerogeles de $\mathrm{TiO}_{2}$ y $\mathrm{ZrO}_{2}$ utilizando alcóxidos órgano sustituidos y usando las relaciones molares que generan materiales transparentes, de acuerdo con la siguientes tablas 4.1 y 4.2. En todas las muestras, excepto en el blanco que carece de la especie porfirinica y alcóxido órgano sustituido, la piridina se agrega para evitar la protonación del macrociclo. 


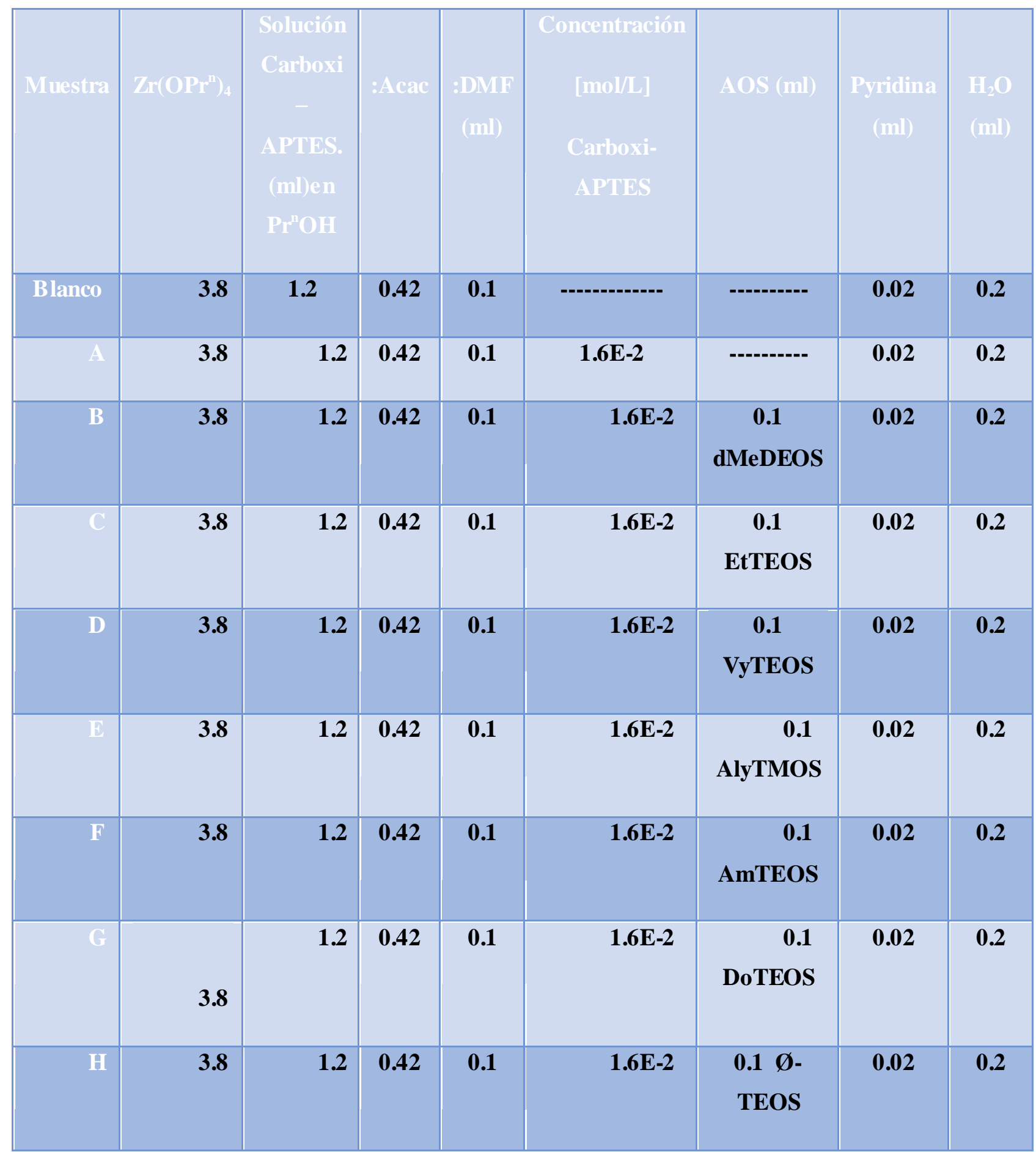

Tabla: 4.1 Relaciones en volumen de mezclas para obtener xerogeles monolíticos translúcidos de $\mathrm{ZrO}_{2}$ con la especie $\mathrm{H}_{2} \mathrm{~T}(p-\mathrm{COOH}) \mathrm{PP}-\mathrm{APTES}$ unida poros órgano modificados. 


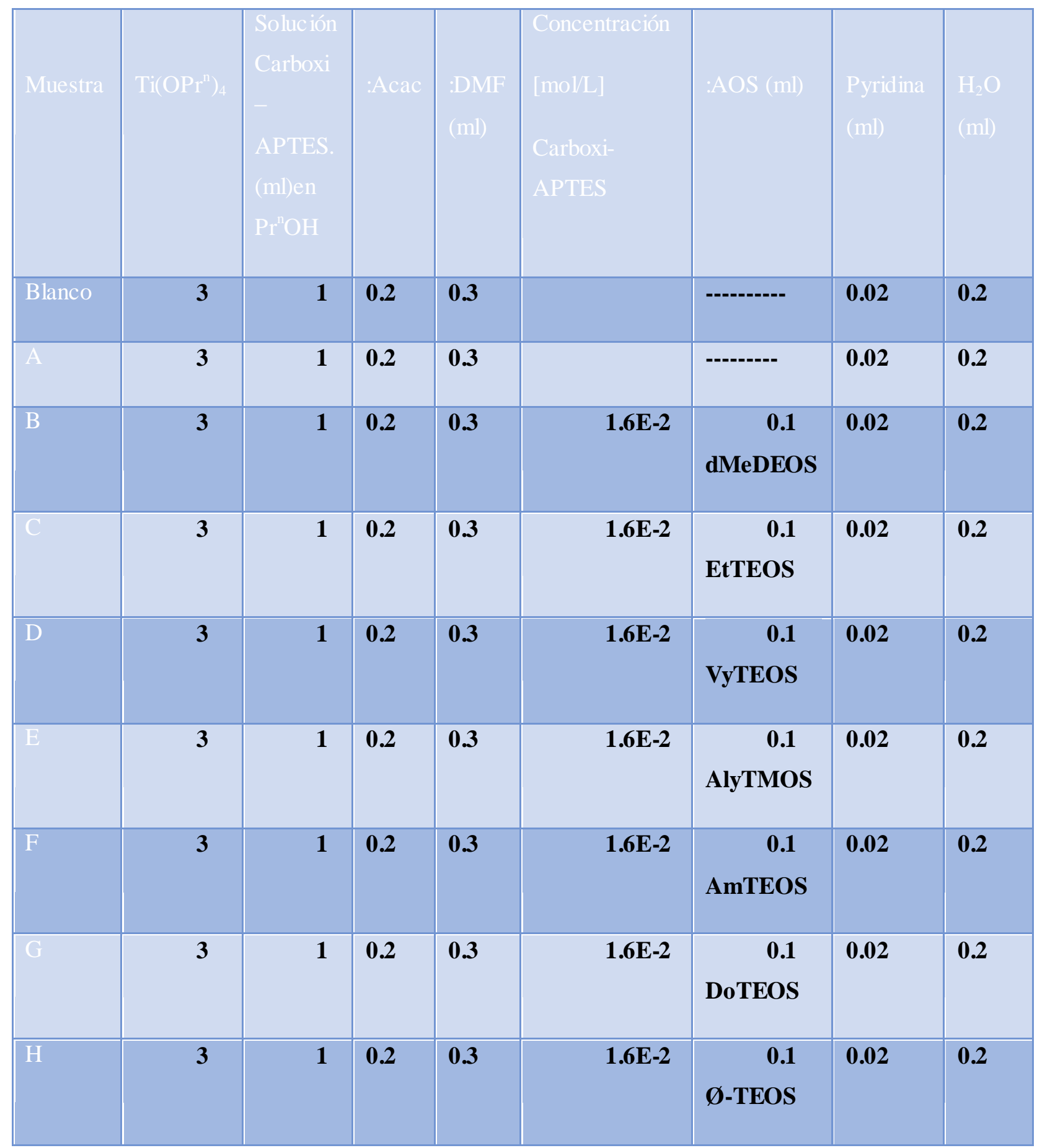

Tabla: 4.2 Relaciones en volumen de mezclas para obtener xerogeles monolíticos translúcidos de $\mathrm{TiO}_{2}$ con la especie $\mathrm{H}_{2} \mathrm{~T}(p-\mathrm{COOH}) \mathrm{PP}$-APTES unida poros órgano modificados. 

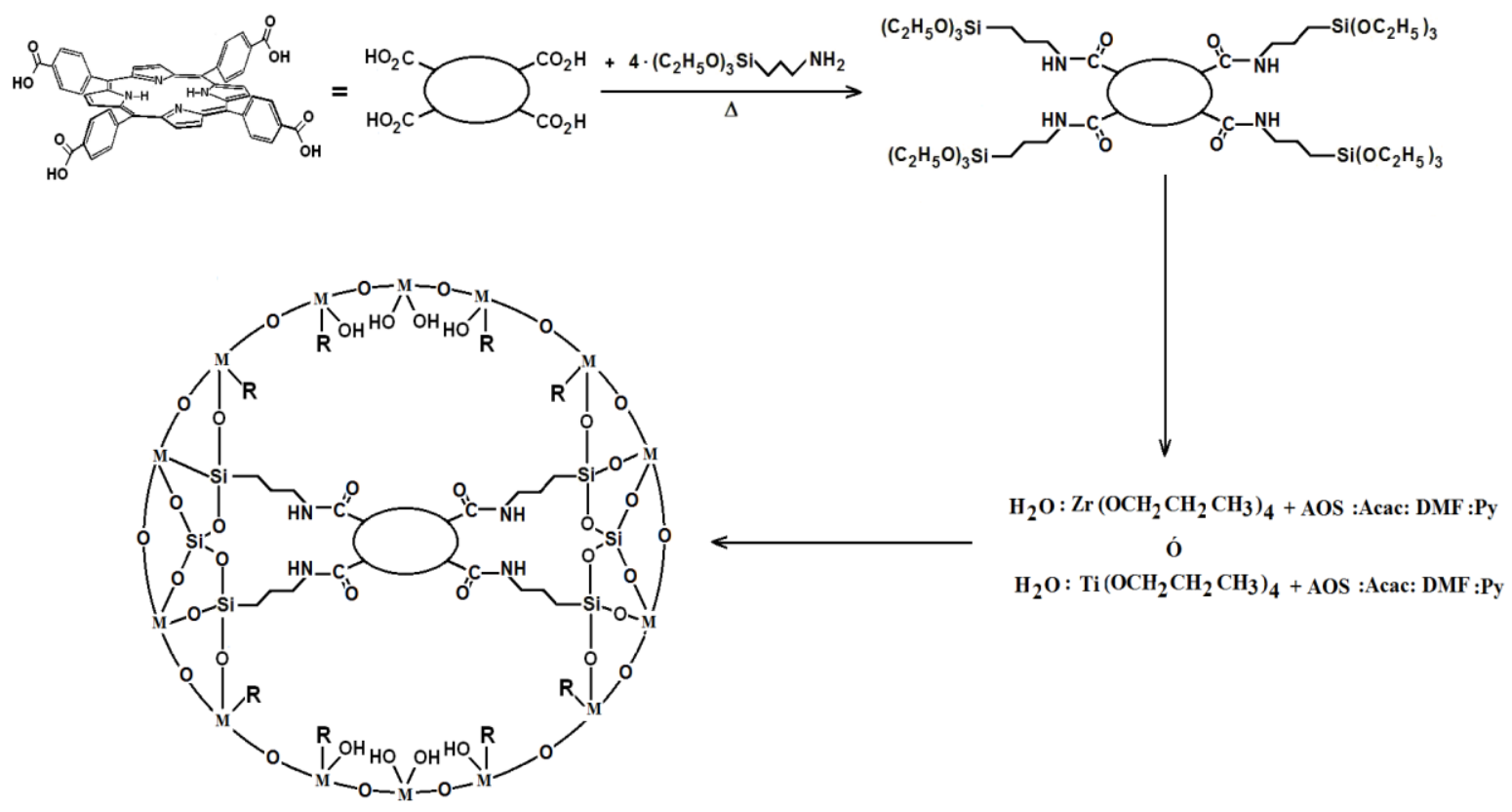

Figura 4.2 Ruta de síntesis de la unión covalente de la base libre $\mathrm{H}_{2} \mathrm{~T}(p-C O O H) \mathrm{PP}$ con la superficie porosa de matrices de xerogeles de zirconio y titanio órgano-modificada. $M$ representa el metalque forma la matriz zirconio ó titanio y a los grupos alquilo o arilo provenientes de los alcóxidos órgano-sustituidos. El esquema basado en el trabajo de R.I Qu iroz [58].

\subsection{UV-Vis de Xerogeles.}

Se obtuvieron espectro UV-Vis de las mezclas gelificantes de $\mathrm{TiO}_{2}$ y $\mathrm{ZrO}_{2}($ Figura 4.4 a y c ) con la porfirina funcionalizada considerando que el ambiente químico circundante y las modificaciones en su estructura afectan las transiciones electrónicas de los macrociclos [69-71], atribuidas a absorciones de tipo $\pi$ - $\pi^{*}$. Este análisis se realizó para tratar de determinar el ambiente físico- químico en el que la porfirina se encuentra al ser unida a las paredes de los poros de los óxidos. La banda de Soret en estos compuestos aparece en el intervalo de 410 a 440nm. Asignándosele una transición $\mathbf{a}_{2 \mathrm{u}}(\boldsymbol{\pi}) \rightarrow \mathbf{e}_{\mathrm{g}}\left(\boldsymbol{\pi}^{*}\right)$ con intervención de los pares libres de los átomos de nitrógeno pirrolicos, mientras que las transiciones $\mathbf{a}_{\mathbf{1 u}}, \mathbf{a}_{\mathbf{2}} \mathbf{u}(\boldsymbol{\pi}) \rightarrow \mathbf{e}_{\mathrm{g}}\left(\boldsymbol{\pi}^{*}\right)$ son asociadas a las bandas $\mathrm{Q}_{\mathrm{I}}$ a $\mathrm{Q}_{\mathrm{IV}}$, producto de la transferencia de carga de los carbonos de pirrol a los otros del macrociclo y al acoplamiento vibracional [74-75]. Estas bandas aparecen en el 
espectro entre los 500 y 700nm y son influenciadas débilmente por la presencia de grupos en la periferia del macrociclo.

Lo anterior sugiere que aquellas transiciones asociadas al macriociclo ocurren de forma más eficiente en presencia de los grupos alilo, etilo y dodecilo. Sobre todo en el caso de los primeros, se sospecha que tal efecto es favorecido por la cercanía y posible interacción de las regiones aromáticas con el doble enlace de tales grupos alilo $\left(-\mathrm{CH}_{2}-\mathrm{CH}=\mathrm{CH}_{2}\right)$. Para el caso de los xerogeles sintetizados con $\mathrm{TiO}_{2}$ y la especie $\mathrm{H}_{2} \mathrm{~T}(\mathrm{p}-\mathrm{COOH}) \mathrm{PP}-\mathrm{APTES}$, las señales de UVVis también están asociadas las especie unida en un medio sólido, las bandas $Q_{\text {I a }} Q_{\text {IV }}$ se encuentran en 647,588,550 y $515 \mathrm{~nm}$, respectivamente. Las secuencia de decreciente de la banda $\mathrm{Q}_{4}$ para los xerogeles finales sigue el orden: amilo $<\mathrm{S} / \mathrm{AOS}<$ fenilo $<$ alilo $<$ vinil $<$ metilo<etilo<dodecilo. Lo anterior sugiere que aquellas transiciones asociadas al macriociclo ocurren de forma más eficiente en presencia de los grupos dodecil, etilo y metilo. Curiosamente, en esta matriz de $\mathrm{TiO}_{2}$, los grupos que propician la mayor intensidad en las señales $\mathrm{Q}$, son aquellos sin dobles enlace, lo cual parece obedecer al medio generado por la matriz de $\mathrm{TiO}_{2}$.

Las bandas de Soret de la porfirina se ven eclipsadas por la absorción de los óxidos los cuales absorben a longitudes de onda menores a 500nm. En todos los casos las señales en los espectros de absorción reportadas para la especie $\mathrm{H}_{2} \mathrm{~T}(p-\mathrm{COOH}) \mathrm{PP}$ en los sistemas de óxidos están asociadas con la base libre. Aunque en ambos caso la banda $\mathrm{Q}_{\mathrm{I}}$ asociada con la porfirina no se observa de mayor intensidad que las otras [72] y no se presenta un corrimiento hipsocromico considerable asociada con las especie dicatiónica, $\mathrm{H}_{4} \mathrm{~T}(p-C O O H) \mathrm{PP}^{2+}$ [76], si se observa una ligera deformación de la banda $\mathrm{Q}_{\mathrm{I}}$ en el sistema de $\mathrm{TiO}_{2}$. Los xerogeles consolidados de ambos óxidos no presentan cambio en la tonalidad, permaneciendo de color marrón asociado al aspecto de la porfirina en solución Sin embargo, aquella ligera deformación de las bandas $\mathrm{Q}_{\mathrm{I}}$ en los sistemas de $\mathrm{TiO}_{2}$, bien puede deberse a una interacción diferente entre la porfirina y la matriz de $\mathrm{TiO}_{2}$ en comparación con las de $\mathrm{SiO}_{2} \mathrm{u} \mathrm{ZrO}_{2}$, o bien una ligera protonación del macrociclo en tales sistemas, lo que sugeriría un ambiente fisicoquímico más polar u ácido en la matriz de $\mathrm{TiO}_{2}$ y una mayor dificultad para regularlo mediante el uso de los grupos alquil o arilo colocados en las paredes de los poros de tales matrices. 


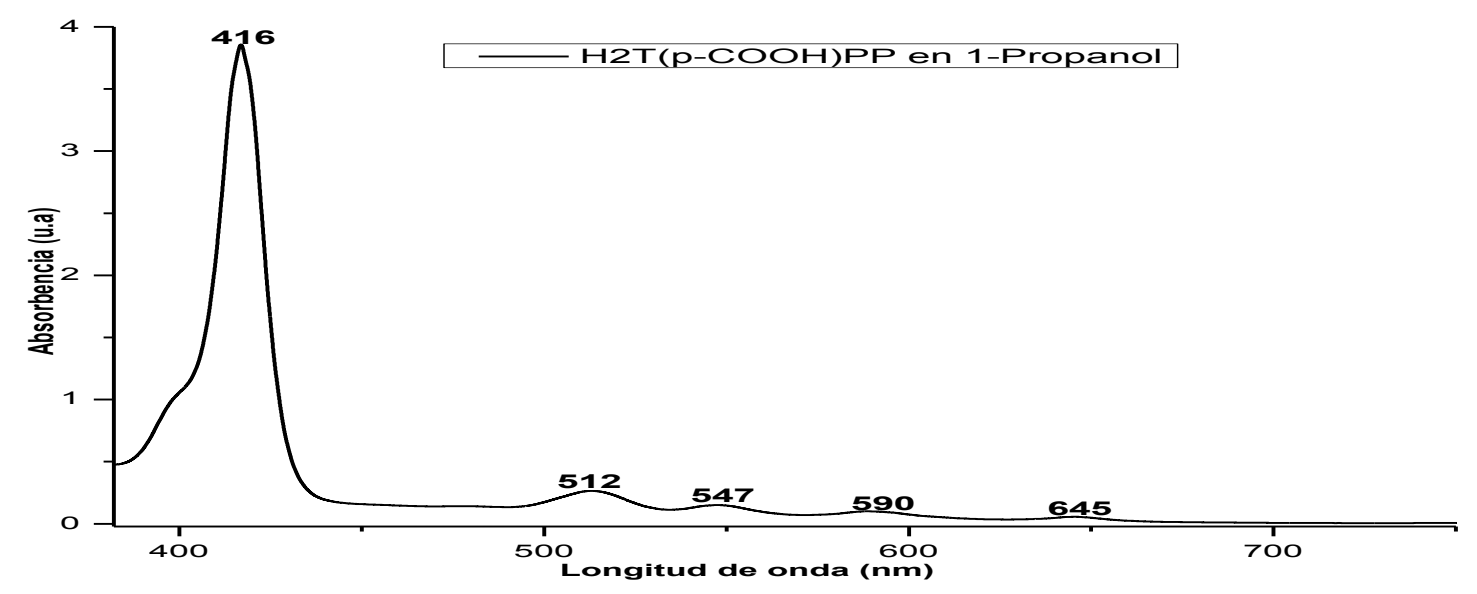

Figura 4.3 Espectro de UV-Vis de la especie $\mathrm{H}_{2} \mathrm{~T}(\mathrm{p}-\mathrm{COOH}) \mathrm{PP}$ en 1-Propanol.
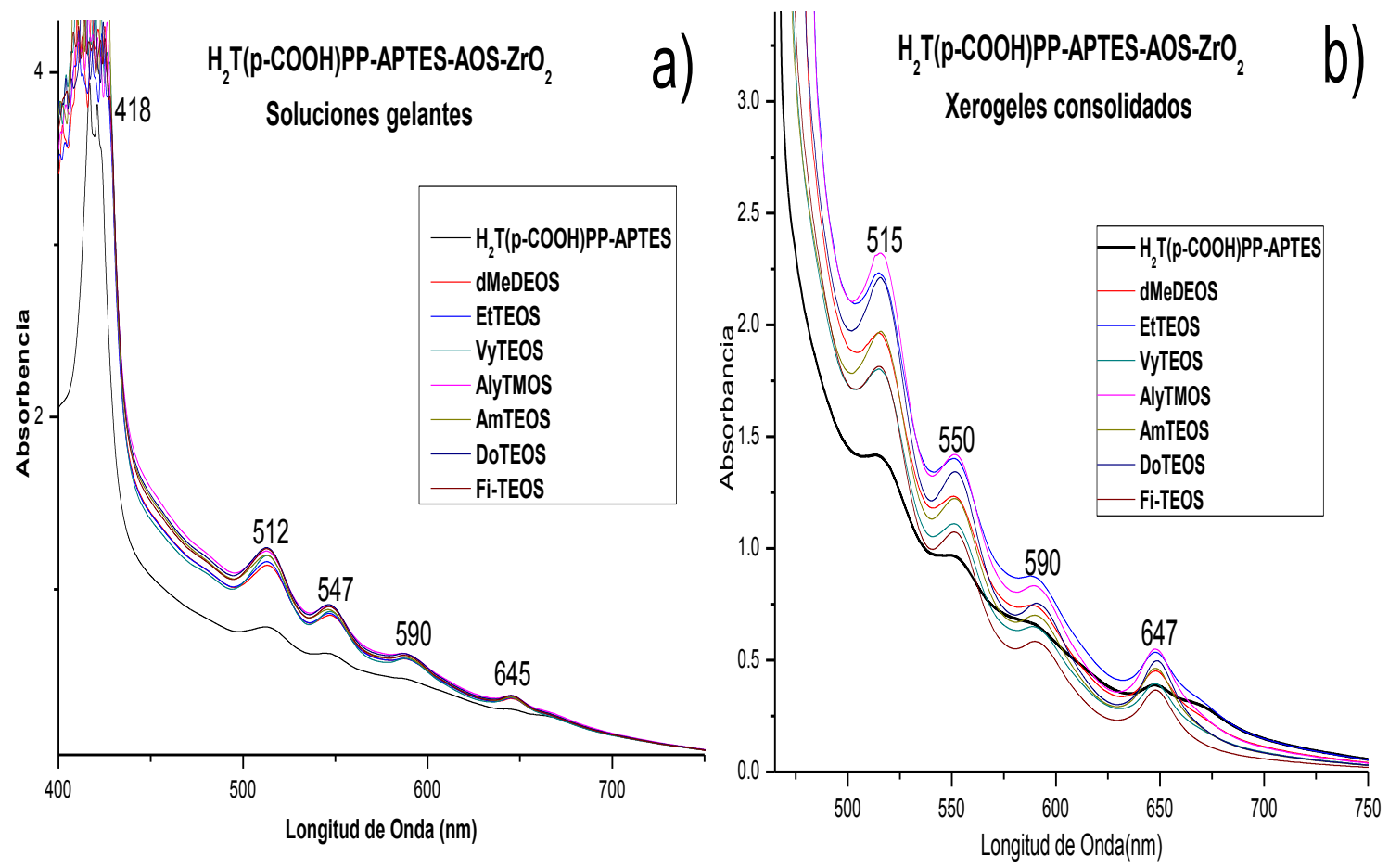

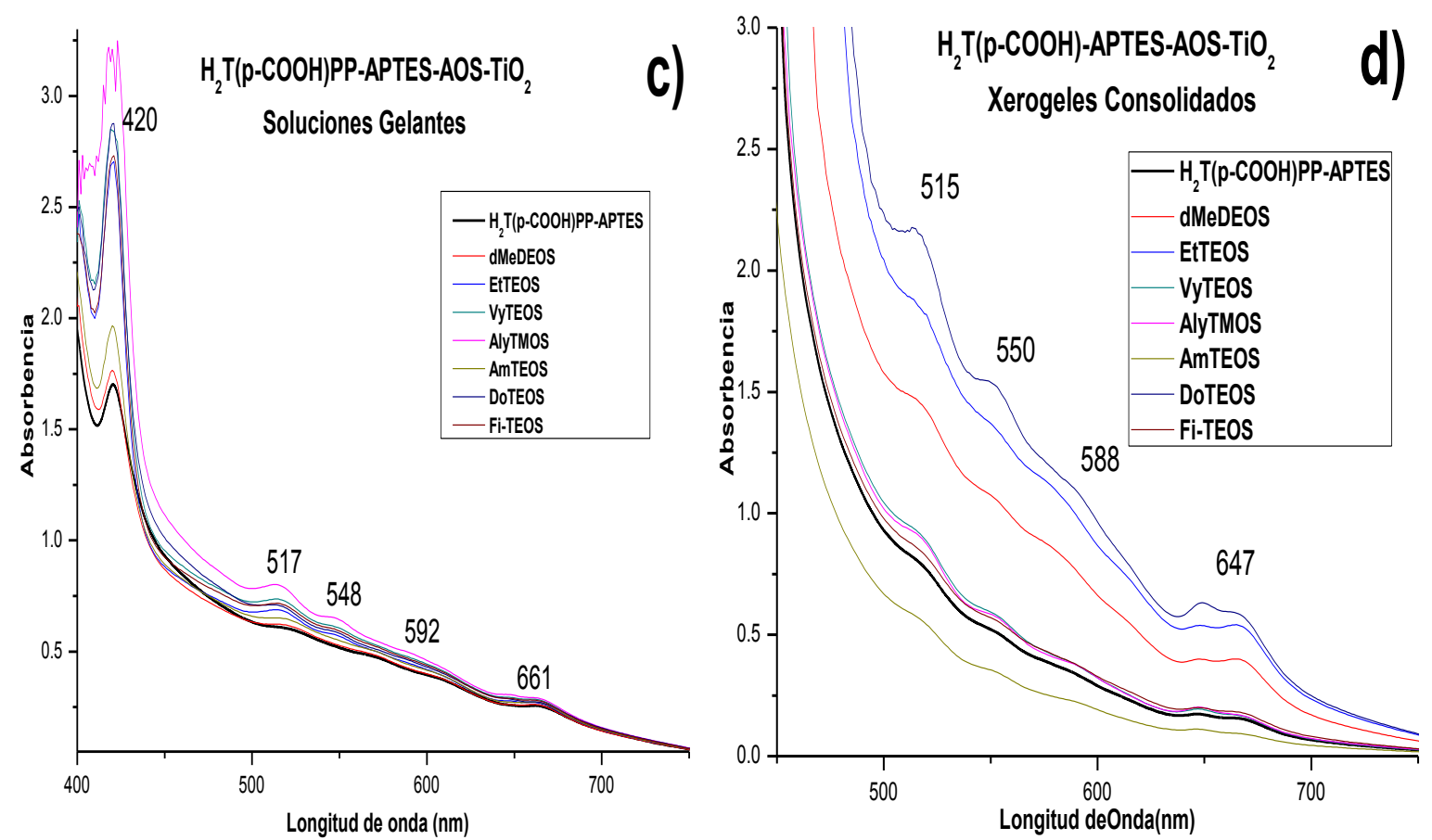

Figura 4.4 Espectros UV-Vis de Soluciones gelantes de a) $\mathrm{ZrO}_{2}$ y c) $\mathrm{TiO}_{2}$ y xerogeles consolidados b) $\mathrm{ZrO}_{2}$ y d) $\mathrm{TiO}_{2}$ de la especie $\mathrm{H}_{2} \mathrm{~T}$-(p-COOH)PP-APTES unida matrices modificadas con AOS.

\subsection{Espectros NIR}

Se obtuvieron los espectros de NIR (espectroscopia de infrarrojo cercano) con objeto de describir la presencia de grupos alquilo en matrices de $\mathrm{ZrO}_{2}$ y $\mathrm{TiO}_{2}$. En el espectro de la Figura 4.5 a), la banda que aparecen a $1392 \mathrm{~nm}$ se asigna a la vibración de los grupos - $\mathrm{ZrOH}$, los cuales interactúan vía puente de hidrogeno con el agua, la señala a $1880 \mathrm{~nm}$ (en la misma figura 4.5 a) se asocia a el agua fisisorbida. Las señales identificadas en el espectro a 1160,1681, 1723, 2267 y $2450 \mathrm{~nm}$ pueden estar relacionadas con armónicos y vibraciones combinadas de grupos funcionales orgánicos, tales como $\mathrm{C}-\mathrm{H}, \mathrm{C}=\mathrm{O} ; \mathrm{COOH}$. Tales señales aparecen al sintetizar $\mathrm{ZrO}_{2}$ transparente utilizando acetilacetona para controlar la reactividad del butóxido de zirconio, como reportó por Petkova et al [77], y asociadas todas estas con los grupos alquilo.

Por otro lado, las señales mostradas en la figura 4.5 b) de los xerogeles de $\mathrm{TiO}_{2}$ con la especie $\mathrm{H}_{2} \mathrm{~T}(p-\mathrm{COOH}) \mathrm{PP}$-APTES unida a las paredes de los poros, son más nítidas que las anteriores, las bandas ubicadas a 1392 y $2200 \mathrm{~nm}$ se asignan a vibraciones de los grupos TiOH, que interactúan vía puente de hidrogeno con agua. La señala a $1920 \mathrm{~nm}$ se asocia con 
agua fisisorbida y las bandas que aparecen a 1680,1720, 2304,2366, 2380 y 2400 se deben a las vibraciones de grupos alquilo que probablemente permanecieron, pese a que las muestras fueron sometidas a un tratamiento térmico a $150^{\circ} \mathrm{C}$ [78] por un lapso de tiempo de 24 horas.

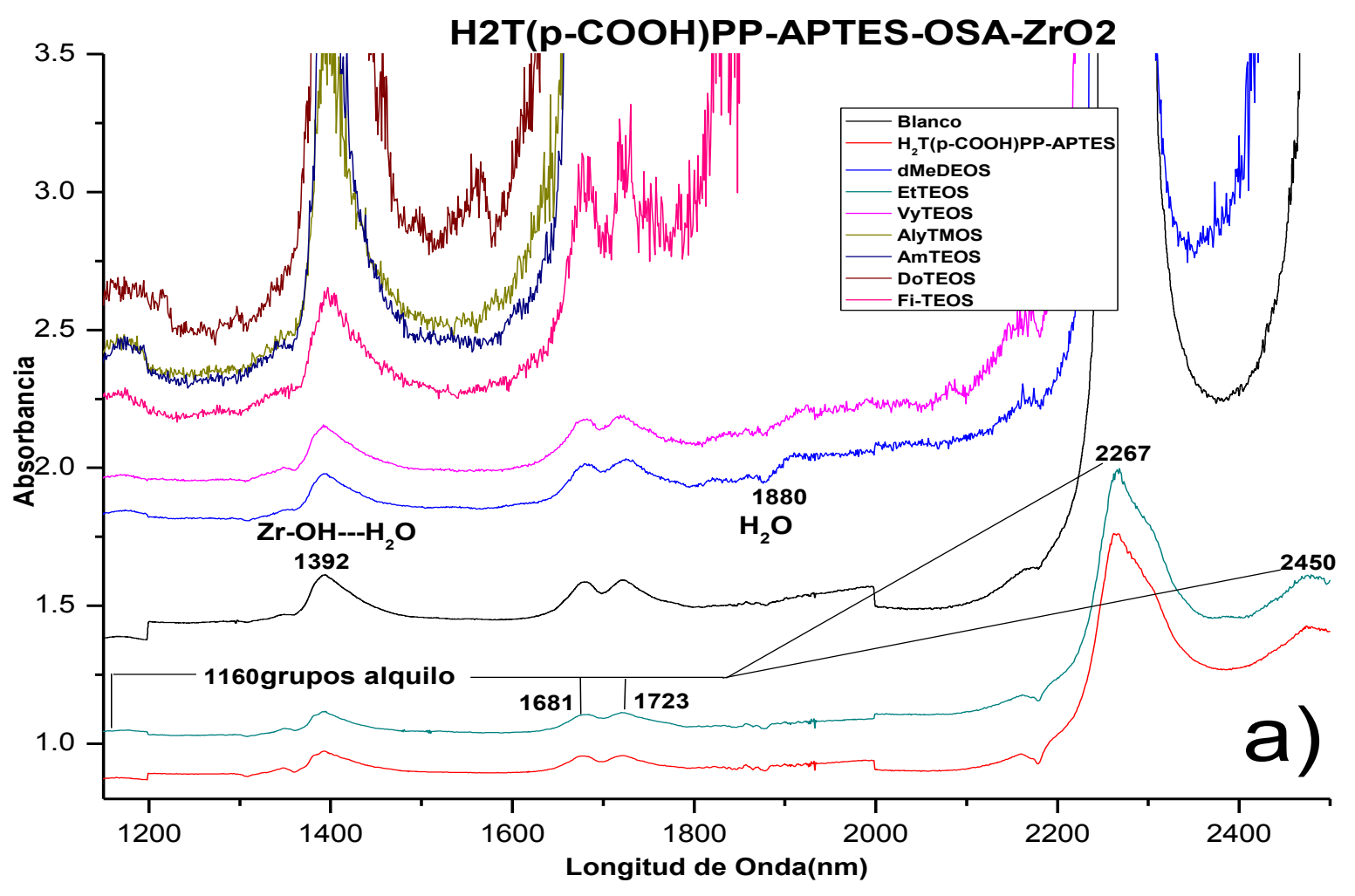




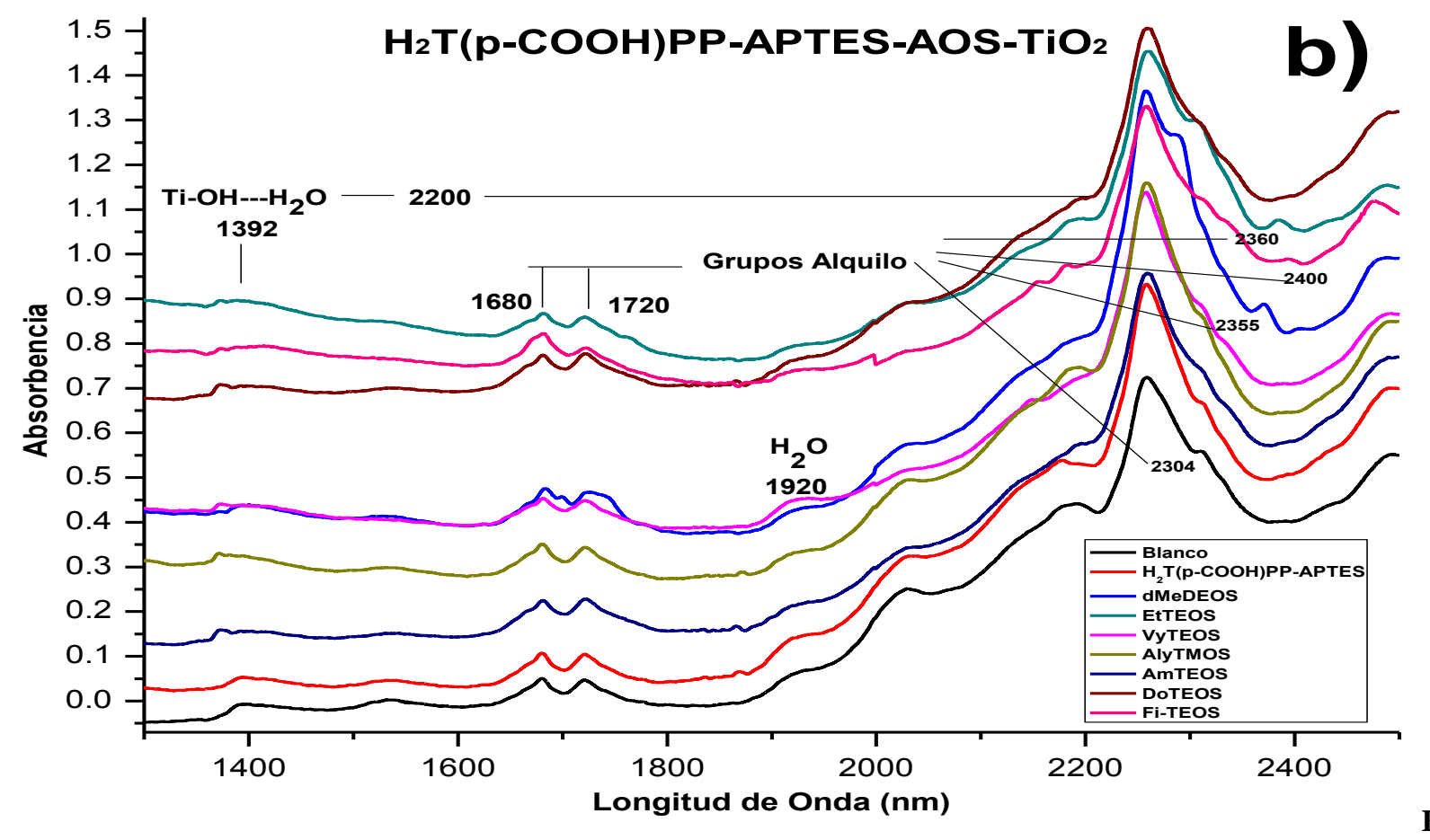

gura 4.5 Espectros de infrarrojo cercano (NIR) de los xerogeles órgano modificada a) $\mathrm{ZrO}_{2}$ y b) $\mathrm{TiO}_{2}$ de con la especie $\mathbf{H}_{2}$ T(p-COOH)PP-APTES covalentemente unida, tratadas térmicamente a $150^{\circ} \mathrm{C}$

\subsection{Fluorescencia de Xerogeles}

Se obtuvieron espectros de fluorescencia de xerogeles consolidados de $\mathrm{ZrO}_{2}$ y $\mathrm{TiO}_{2}$ a 516nm modificados orgánicamente que presentan unida covalentemente mediante APTES la especie $\mathrm{H}_{2} \mathrm{~T}(p-\mathrm{COOH}) \mathrm{PP}$. Para el caso del óxido de zirconio, aparecen dos bandas principales a 654 y $716 \mathrm{~nm}$, características de los espectros de emisión de las porfirinas y una serie de bandas de menor intensidad a aproximadamente 610,568 y $525 \mathrm{~nm}$, que podrían atribuirse a la matriz de $\mathrm{ZrO}_{2}$ sola o interactuando con la porfirina con la matriz (Figura 4.7 a). Se observa que las dos primeras se encuentran desplazadas al rojo con respecto a los observados en solución (643 y $706 \mathrm{~nm}$. Figura 4.6) este efecto puede asociarse con la diferente polaridad existente en el interior de los poros de Zirconio y las interacciones con los grupos que se encuentran en la superficie. Existe también una diferencia en las emisiones de la especie en los diferentes sistemas la cual se atribuye al ambiente en cada una de ellas responsabilidad de los grupos unidos a la matriz, así, en el espectro de emisión de los materiales sintetizados con $\mathrm{TiO}_{2}$ (Figura 4.7 b ) muestran dos bandas principales en 651 y $715 \mathrm{~nm}$. Es decir, también se observan las 
bandas características de la porfirina y un más ligero efecto batocromico, sin embargo a diferencia de los sistemas de zirconio en estos se presenta solo una banda de poca intensidad por debajo de los $600 \mathrm{~nm}$, asociable con la matriz de titanio sola o interactuando con el macrociclo, incluso a longitudes de onda de exitación de 420nm. Es decir las interacciones de la especie $\mathrm{H}_{2} \mathrm{~T}$ (p-COOH)PP con la matriz de $\mathrm{TiO}_{2}$ son mucho menores que las presentadas en sistemas de zirconio, esto se puede asociar con el hecho de que al someter los xerogeles de $\mathrm{TiO}_{2}$ con la especie porfirinica a luz UV-Vis estos emitan un color rojizo en contraste con lo de zirconio que presentan un color amarillo. Este hecho pudiera resultar contradictorio con lo observado por espectroscopia $\mathrm{UV}-\mathrm{V}$ is respecto de la menor inhibición de la protonación en el $\mathrm{TiO}_{2}$, pero pudiera reforzar la idea de un tipo diferente de interacción entre la porfirina y esta. Si la matriz de $\mathrm{TiO}_{2}$ interacciona menos con la porfirina, es posible que no inhiba la aproximación de las especies que la protonan o bien las paredes de los poros del $\mathrm{TiO}_{2}$ se encuentra a mayor distancia de aquel macrociclo.

La intensidad de fluorescencia de la especie $\mathrm{H}_{2} \mathrm{~T}(p-\mathrm{COOH}) \mathrm{PP}$ dentro de los xerogeles de $\mathrm{ZrO}_{2}$ presenta la siguiente tendencia en orden decreciente de acurdo con el AOS empleado AmTEOS $>\Phi$-TEOS $>$ dMeDEOS $>$ DoTEOS $>$ VyTEOS $>$ AlyTMOS $>$ EtTEOS $>\mathrm{H}_{2}$ T $(p-C O O H) P P-$ APTES, mientras que para la serie de materiales con $\mathrm{TiO}_{2}$ la tendencia resulta ser DoTEOS $>\Phi-$ TEOS $>\mathrm{H}_{2}$ T(p-COOH)PP-APTES > AmTEOS > EtTEOS>AlyTMOS>dMeDEOS>VyTEOS.

Este último resultado sugiere que la presencia de los grupos alquil de cadena larga, como los grupos amilo (de cinco carbonos), los dodecilo (de doce) y sobre todo la de los fenilo provoca una mayor eficiencia para la ocurrencia de las transiciones de la porfirina, seguramente porque aquellos grupos interaccionan fuertemente con las regiones aromáticas de tal macrociclo. 


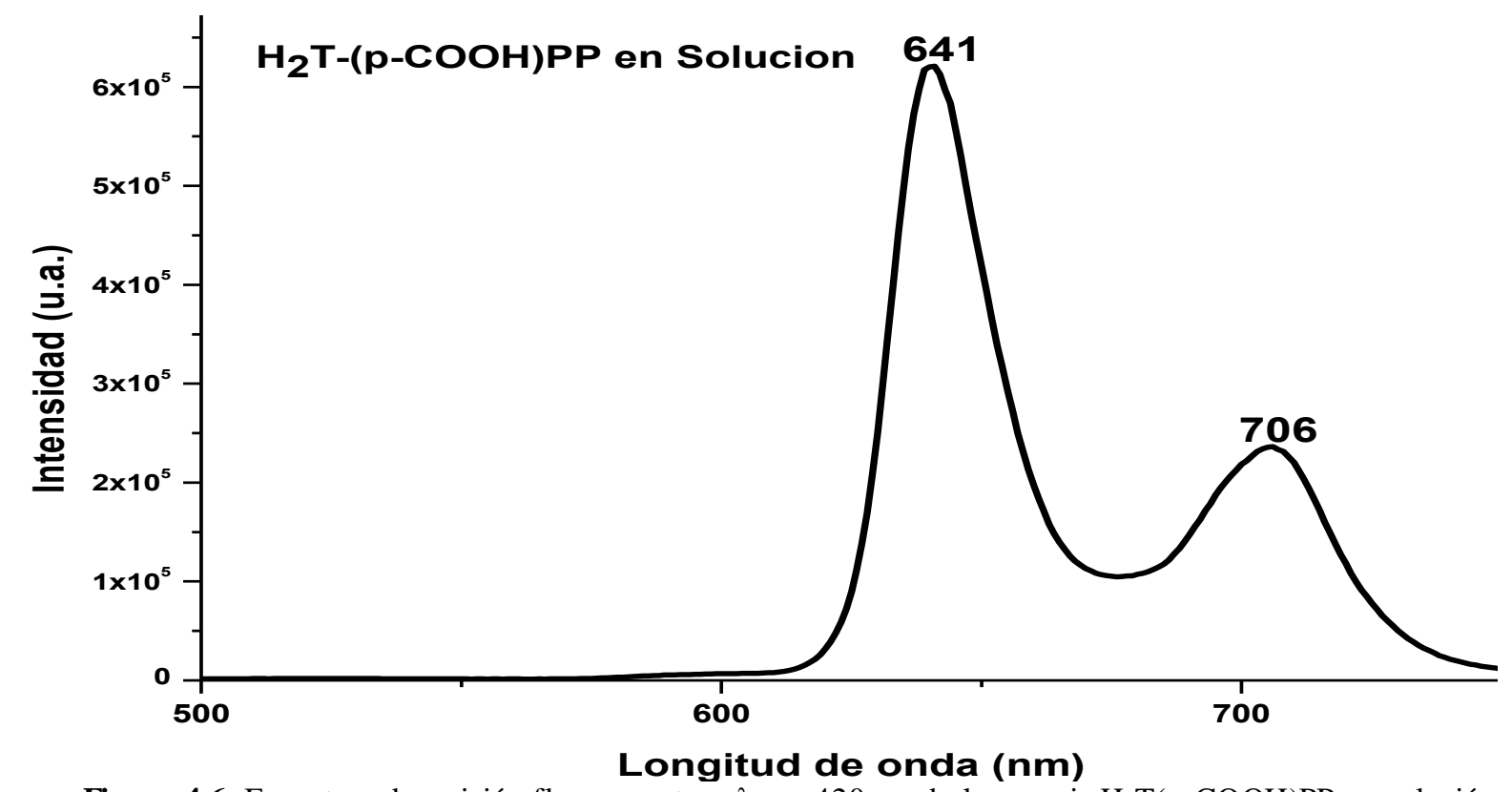

Figura 4.6 Espectros de emisión fluorescente a $\lambda_{\text {ecx. }}=420 \mathrm{n}$ m de la especie $\mathrm{H}_{2} \mathrm{~T}(\mathrm{p}-\mathrm{COOH}) \mathrm{PP}$ en solución.

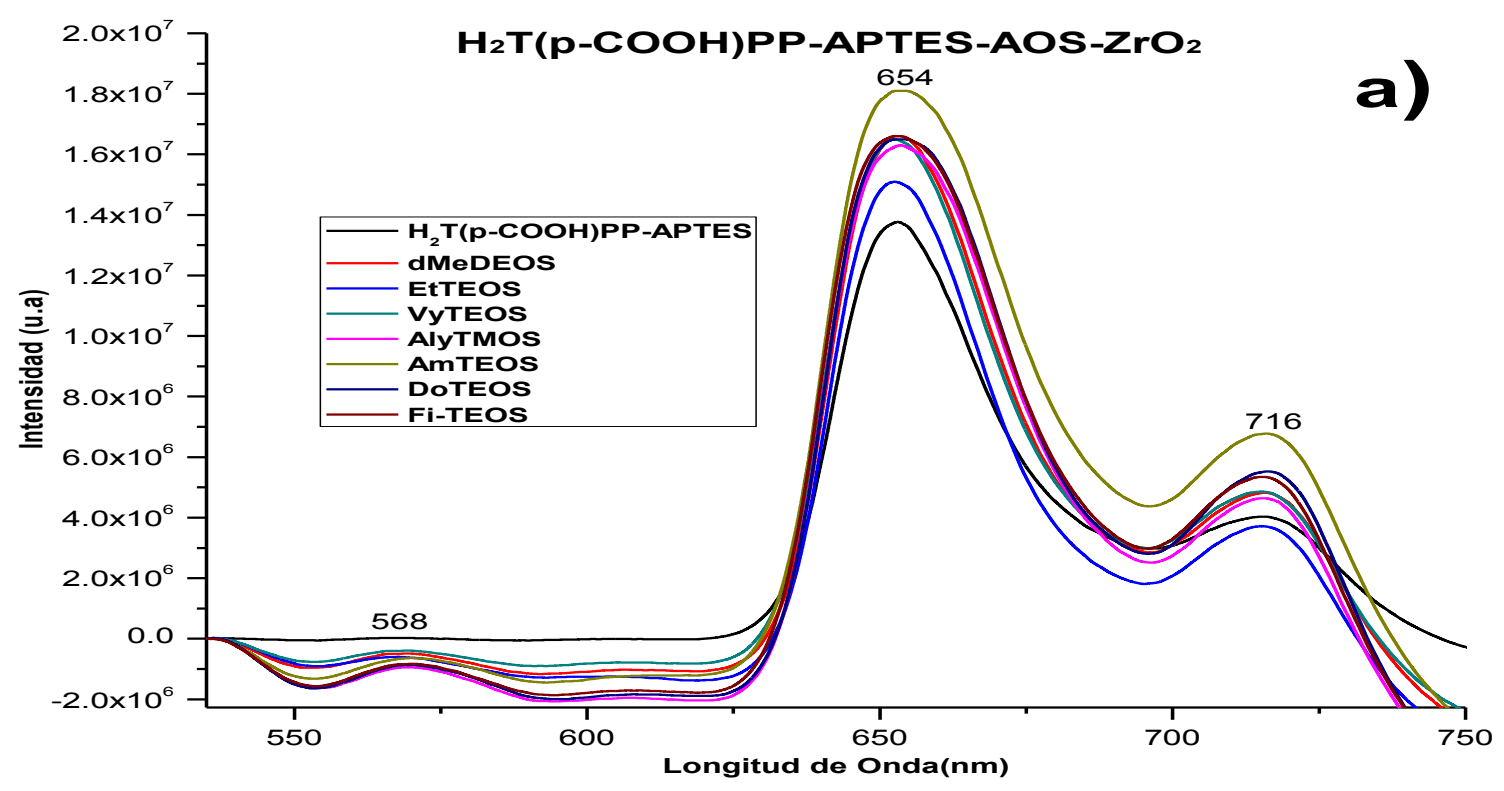




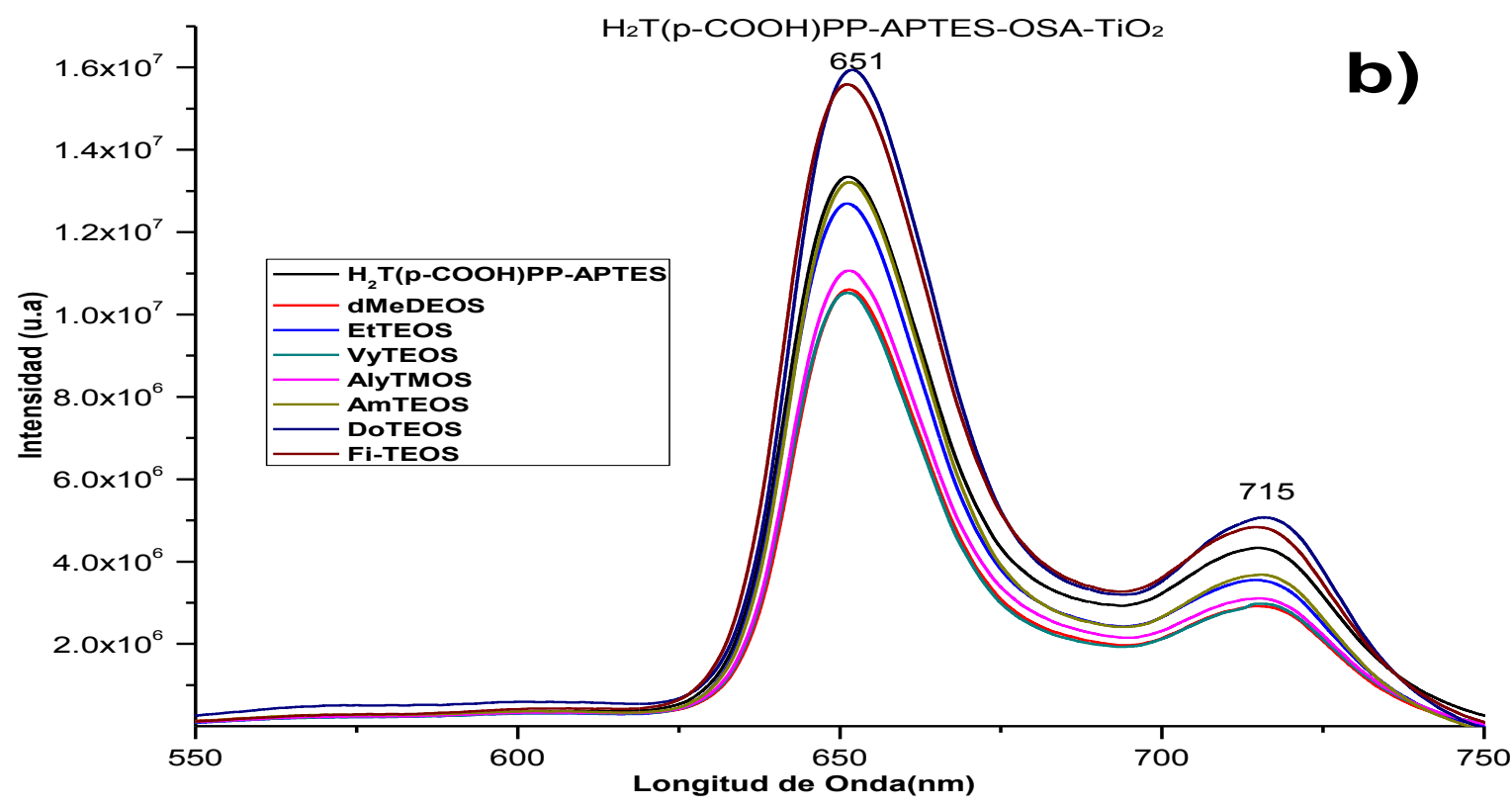

ura 4.7 Espectros de emisión fluorescente a $\lambda_{\text {ecx. }}=516 \mathrm{n}$ m de la especie $\mathbf{H}_{\mathbf{2}} \mathbf{T}(\mathbf{p}-\mathbf{C O O H}) \mathbf{P P}$-APTES unida covalentemente a la matriz de a) $\mathrm{ZrO}_{2}$ y b) $\mathrm{TiO}_{2}$ órgano modificada.

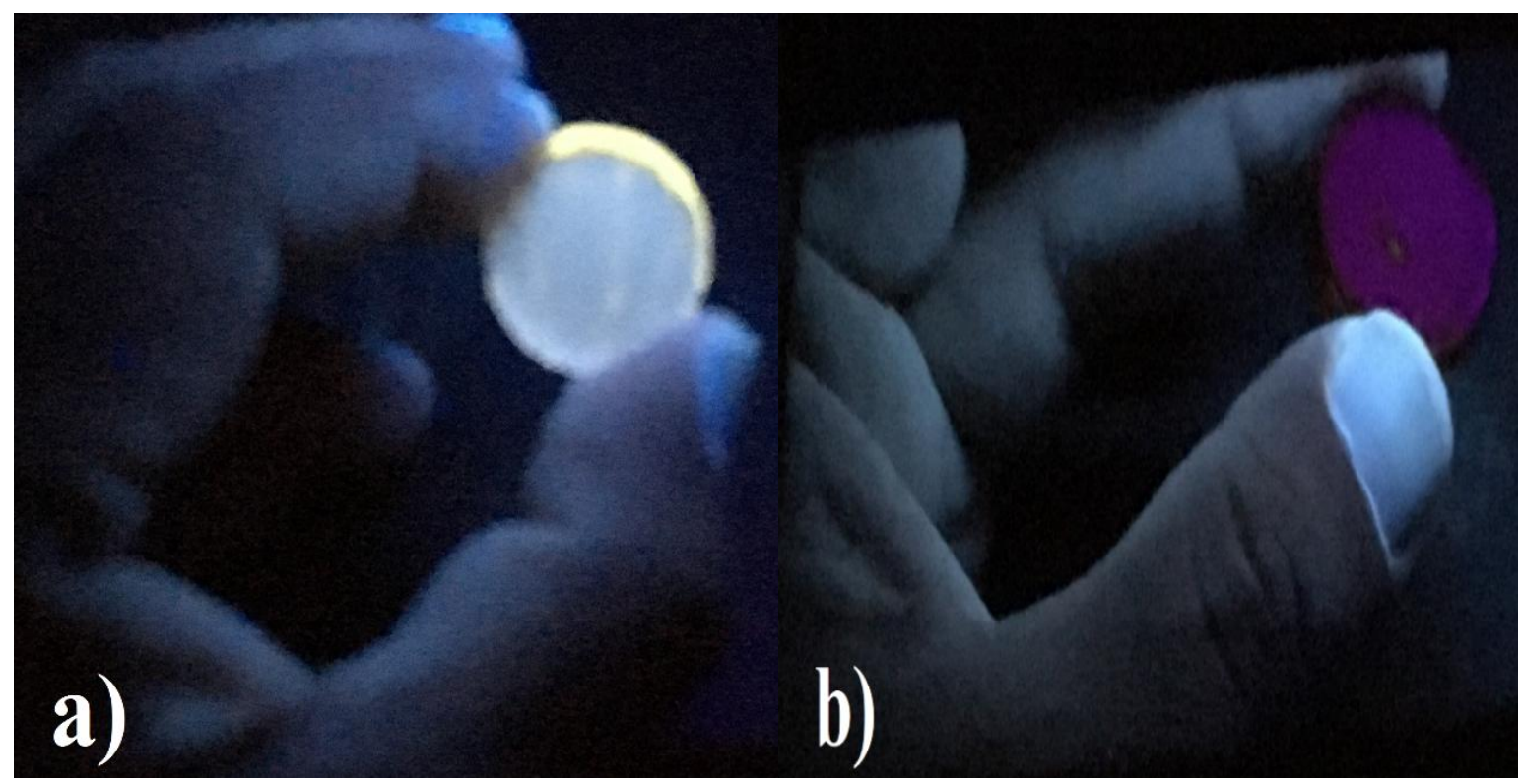

Figura 4.8 Fluorescencia de Xerogeles consolidados de a) $\mathrm{ZrO}_{2}$ y b) $\mathrm{TiO}_{2}$ con la especie $\mathrm{H}_{2} \mathrm{~T}(\mathrm{p}-\mathrm{COOH}) \mathrm{PP}$ APTES unida a poros órgano-modificados. 


\subsection{Diámetro de poro y área superficial en los dos óxidos.}

Se obtuvieron isotermas de sorción-desorción de $\mathrm{N}_{2}$ a $76 \mathrm{~K}$ de los xerogeles consolidados sintetizados de $\mathrm{ZrO}_{2}$ y $\mathrm{TiO}_{2}$ con la especie $\mathrm{H}_{2} \mathrm{~T}(p-C O O H) \mathrm{PP}-\mathrm{APTES}$ unidas a la matriz de los óxidos órgano sustituidos. Lo anterior para determinar las características texturales de las matrices de Zr y Ti órgano modificadas y hacer una eluscidación sobre la estructura en la cual se encuentra unida la porfirina libre en cuestión. Las isotermas que se muestran en la figura 4.10 a) y b) son similares y corresponden, según la clasificación de la IUPAC a las Tipo I con ciclo de Histéresis $\mathrm{H} 3$ [52]. Los ciclos de histéresis más angostos en el óxido de $\mathrm{ZrO}_{2}$ sugiere que el absorbato se mueve con mayor facilidad y que, tanto la condensación como la evaporación de las moléculas de $\mathrm{N}_{2}$ se producen fácilmente sin la intervención de fenómenos cooperativos o bloqueo de poros, en contraste con los materiales de $\mathrm{TiO}_{2}$ en el que probablemente al formarse la red de óxido sobre la especie $\mathrm{H}_{2} \mathrm{~T}(p-\mathrm{COOH}) \mathrm{PP}$ se forman interconexiones entre los poros los cuales obstruyen la difusión del $\mathrm{N}_{2}$. Del conjunto de isotermas es posible observar que en el caso del $\mathrm{Zr}$ que los materiales que contienen en su estructura los alcóxidos órgano sustituidos (AOS) VyTEOS, AmTEOS y dMeDEOS presentan mayor ciclo de histéresis lo cual se relaciona con la posible formación de interconexiones entre los poros. También se observa que el único material que absorbe por arriba del blanco es el que tiene en su estructura al VyTEOS. En contraste los materiales de $\mathrm{TiO}_{2}$ con mayor ciclo de histéresis son los que presentan en su estructura los AOS VyTEOS, dMeDEOS y DoTEOS. Los materiales que absorben por arriba del blanco son los que presentan al dMeDEOS y la porfirina sin AOS. Estas diferencias nos indican que la capacidad de adsorción se encuentra asociada con la identidad de los grupos arilo o alquilo que se encuentran en la red de los poros de los dos óxidos, de acuerdo con Quiroz-Segoviano et al. [66]. Estas diferencias son asociadas con interacciones repulsivas o atractivas entre las moléculas de porfirina y grupos alquilo o arilo que interaccionan o no con ella y cuyas atracciones o repulsiones modifican la distancia a la que se forman las paredes de los poros. Es decir, las interacciones aludidas inducen la expansión o contracción de la cavidad de los poros formados alrededor de las moléculas de porfirina durante el proceso de consolidación de la matriz. 

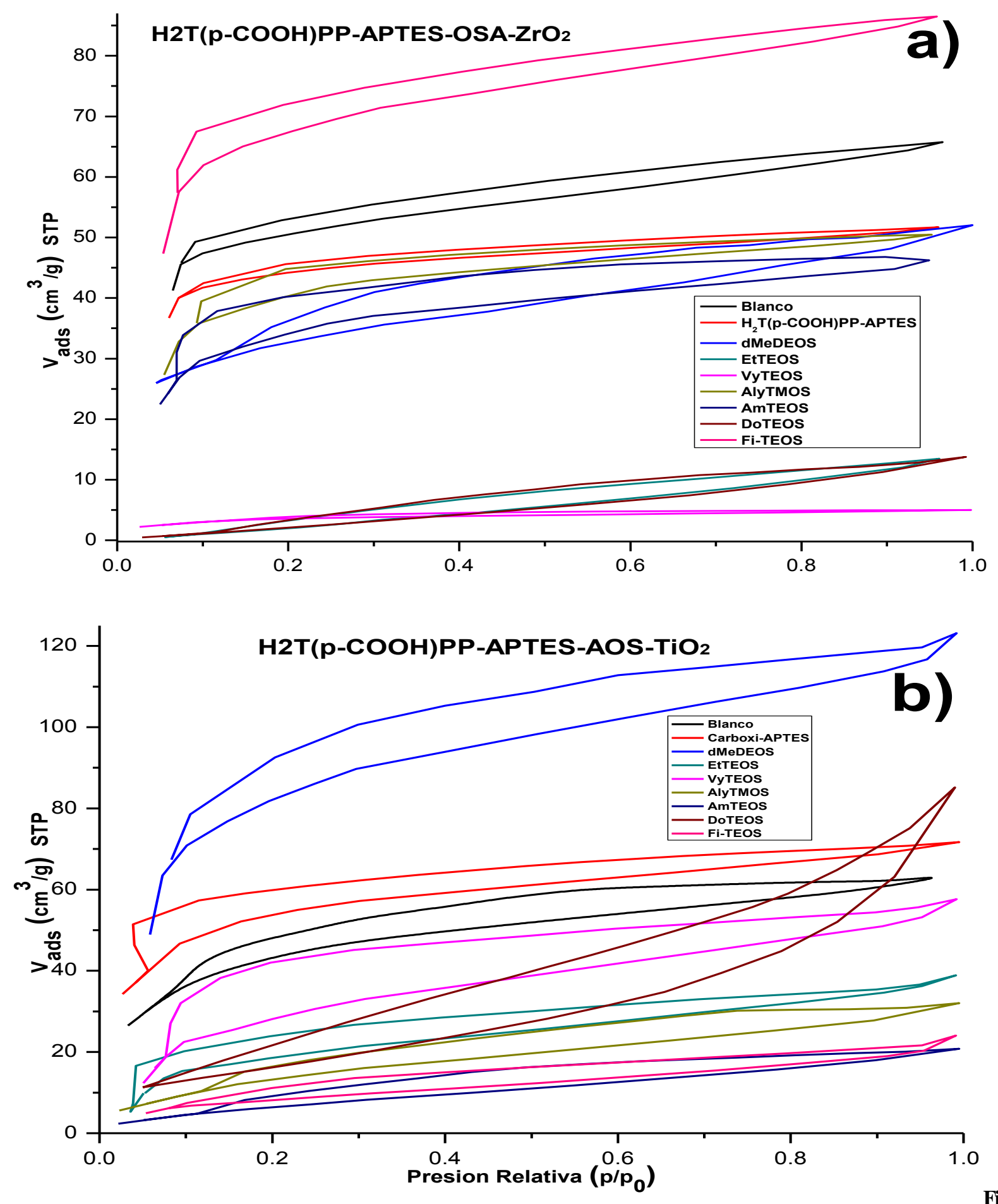

ura 4.10 Isotermas Adsorción $\mathrm{H} 2 \mathrm{~T}(\mathrm{p}-\mathrm{COOH}) \mathrm{PP}-\mathrm{APTES}-\mathrm{OSA}$ en a) $\mathrm{ZrO}_{2}$ y b) $\mathrm{TiO}_{2}$

La distribución de tamaño de poro (DTP) se calculó a través de las isotermas de $\mathrm{N}_{2}$, este parámetro se obtuvo a partir de la aplicación del enfoque funcional de densidad no local 
(NLDFT) a la curva límite de desorción del bucle de histéresis de la isoterma, asumiendo cavidades esféricas. En el caso de las muestras sintetizadas con $\mathrm{ZrO}_{2}$ figura 4.11 a) es posible observar que los materiales sintetizados Ф-TEOS, AlyTMOS, Blanco, AmTEOS y $\mathrm{H}_{2} \mathrm{~T}(p$ COOH)PP-APTES revelan una población de poros muy parecidos de 2 a $2.26 \mathrm{~nm}$ representad as por los máximos en el gráfico. Para el caso de los materiales sintetizados con dMeDEOS, EtTEOS y DoTEOS se observa tamaño de poros más grandes dentro del rango de 2.54 a 3.6nm, siendo la muestra VyTEOS la que presenta un poro menor al de todas las mues tras al promedia solo $2.0 \mathrm{~nm}$.

Para el caso de los materiales de $\mathrm{TiO}_{2}($ Figura 4.11 b), se observa una distribución mucho menos homogénea que la anterior, con tamaños de poro de 2.0 a $3.4 \mathrm{~nm}$, aproximadamente. Cabe destacar que los tamaños de poro más pequeños (2.06 y $2.03 \mathrm{mn}$ ) son de las muestras blanco y del sistema $\mathrm{H}_{2} \mathrm{~T}(p-\mathrm{COOH}) \mathrm{PP}-\mathrm{APTES}$, respectivamente, como era de esperarse al no contener AOS. Los poros de mayor dimensión son los de las muestras con AlyTMOS, AmTEOS, DoTEOS (3.5 a 4nm). Si consideramos que las muestras fueron sintetizadas con las mismas mezclas molares, las diferencias de tamaño de poro son solo atribuidas a los grupos arilo o alquilo unidos a las paredes de los poros modifican la matriz de ambos óxidos. 

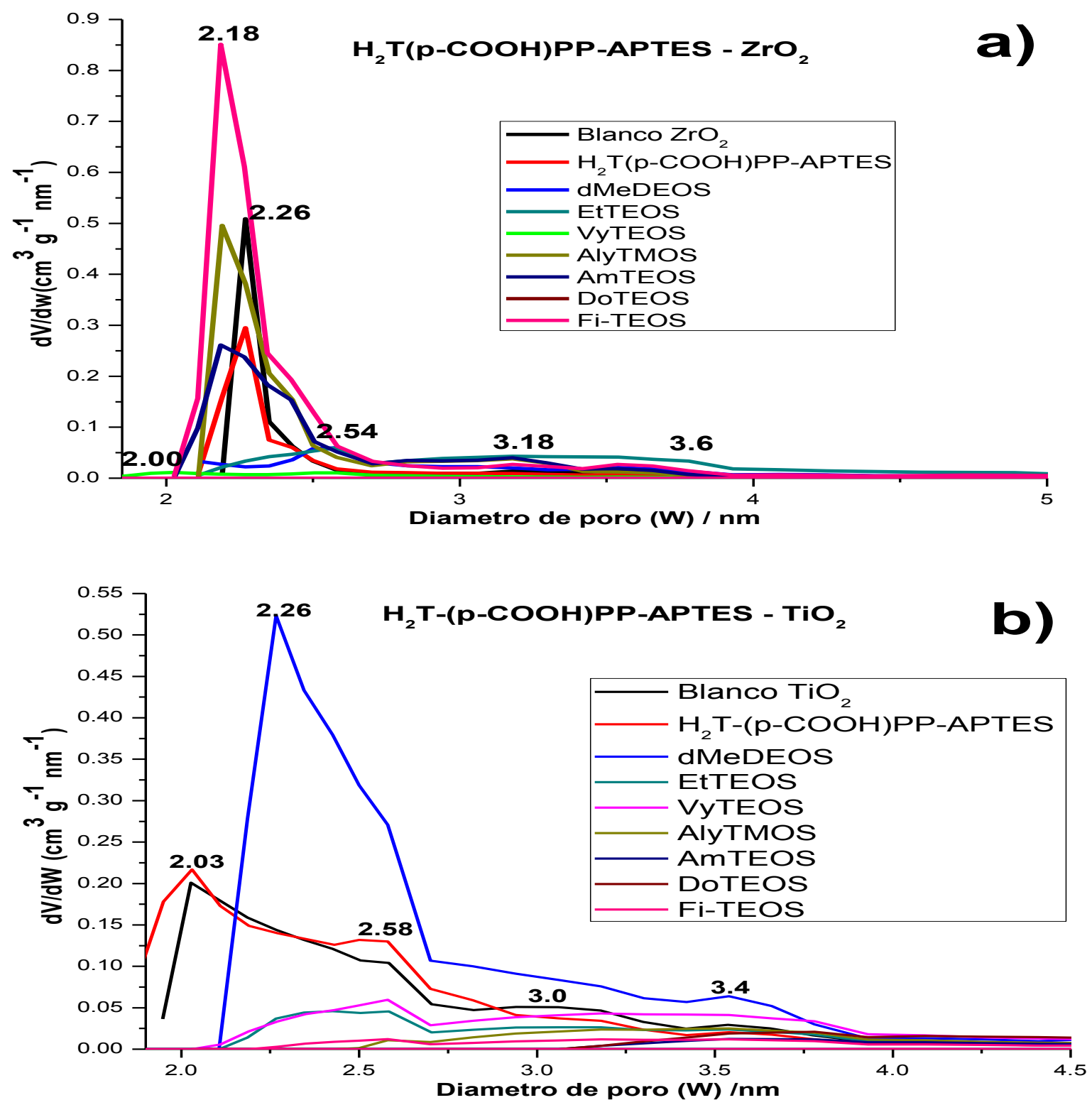

Figura 4.11 Distribución de ta maño de poro (DTP) calculado, asumiendo poros esféricos, de las isotermas de adsorción de $\mathrm{N}_{2}$ de los xerogeles de a) $\mathrm{ZrO}_{2}$ y b) $\mathrm{TiO}_{2}$ órgano-modificados con la especie $\mathrm{H} 2 \mathrm{~T}(\mathrm{p}-\mathrm{COOH}) \mathrm{PP}$ utilizando como puente APTES

Los diámetros de poro promedio $(\Phi)$, el área de la superficie específica y los volúmenes de poro se calcularon a partir del tratamiento de las isotermas de $\mathrm{N}_{2}$ mediante el método ya especificado (NLDFT). Para el caso de las muestras con $\mathrm{ZrO}_{2}$, las áreas superficiales de los materiales con $\mathrm{H}_{2} \mathrm{~T}(\mathrm{p}$-COOH)-APTES, AlyTMOS, AmTEOS y $\Phi$-TEOS presentan un área mayor mientras que en las muestras restantes disminuyen. 
Los diámetros de poro de las cavidades en el $\mathrm{ZrO}_{2}$ se encuentran dentro del rango de $2 \mathrm{a}$ 4.88nm. Para los casos de las muestras con cadenas de carbonos que presentan dobles enlaces en su estructura se tienen los diámetros de poro más pequeños con respecto al blanco, esto se atribuye [58] a que la cercanía de estos grupos con el anillo de la especie $\mathrm{H}_{2} \mathrm{~T}(\mathrm{p}-\mathrm{COOH}) \mathrm{PP}$ provoca atracciones del tipo Van Der Walls con las regiones aromáticas de aquella especies.

En lo referente a los materiales sintetizados con $\mathrm{TiO}_{2}$ se puede observar que todos los sistemas que presentan AOS en su estructura presentan mayores diámetro de poro. En particular, los que tienen cadenas de carbonos con dobles enlaces en su estructura tienen diámetros de poro mayores a los $3.0 \mathrm{~nm}$. Aún más interesante resulta el hecho de que los poros de los materiales modificados con cadenas orgánicas con enlaces sencillos en su estructura crece en función del número de carbonos presentes. Por ello, resulta importante destacar que los materiales que poseen en su estructura DoTEOS, además de tener el diámetro de poro mayor a todos, presenta también la mayor intensidad de fluorescencia: estos hechos sugieren que el ambiente químico favorece el despliegue de las propiedades de la porfirina dentro de los xerogeles y nuevamente, puede asociar a la especie orgánica que se encuentra unida a la matriz del xerogel.

En lo referente a las áreas superficiales se puede ver que, exceptuando la muestra en donde no existen AOS y en la que se encuentra el dMeDEOS, todas la demás se encuentran por debajo del área de la matriz prístina de $\mathrm{TiO}_{2}$. Nuevamente, este notable efecto solo puede asociarse a las interacciones de la porfirina con los grupos orgánicos adheridos a la superficie en crecimiento, las cuales modulan los diámetros de poro finales, pero como los datos espectroscópicos indican, tal situación también afecta estas propiedades.

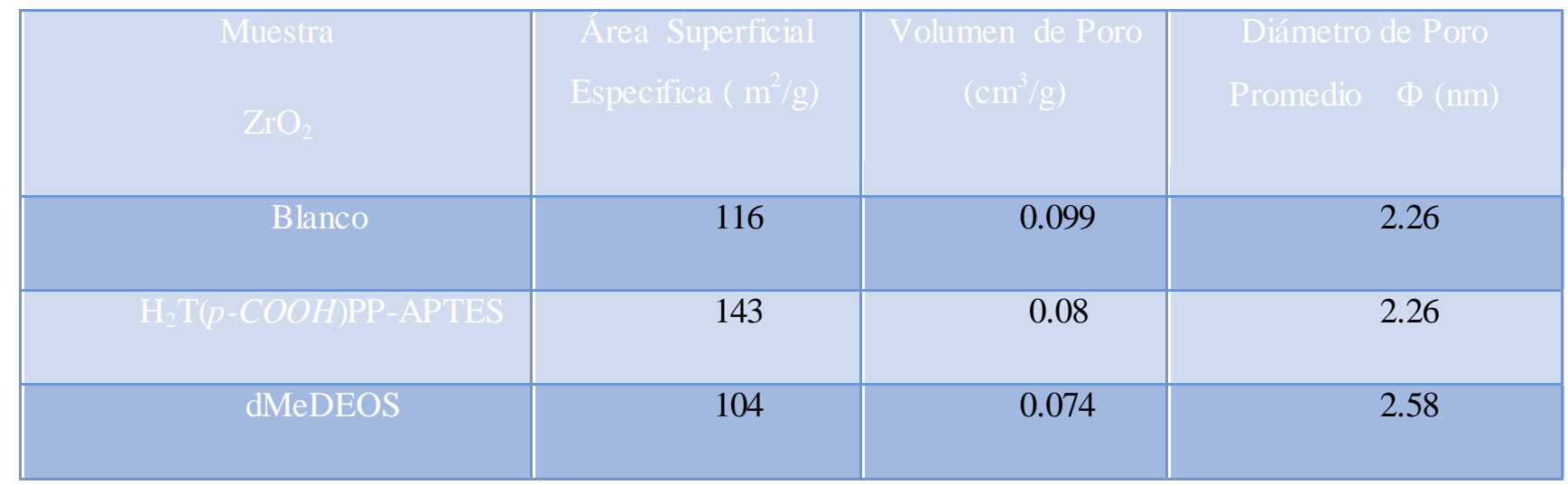




\begin{tabular}{|c|c|c|c|}
\hline ETTEOS & 21 & 0.020 & 4.88 \\
\hline VyTEOS & 12 & 0.007 & 2.00 \\
\hline Aly TMOS & 139 & 0.078 & 2.18 \\
\hline AmTEOS & 122 & 0.069 & 4.88 \\
\hline DoTEOS & 16 & 0.021 & 2.18 \\
\hline
\end{tabular}

Tabla 4.3 Áreas superficiales específicas, volu men de poro y diámetro de poro promed io de xerogeles órgano modificados con AOS y la especie $\mathrm{H}_{2} \mathrm{~T}(\mathrm{p}-\mathrm{COOH}) \mathrm{PP}-\mathrm{APTES}$ de $\mathrm{ZrO}_{2}$.

\begin{tabular}{|c|c|c|c|}
\hline $\begin{array}{c}\text { Muestra } \\
\mathrm{TiO}_{2}\end{array}$ & $\begin{array}{l}\text { Area Superficial } \\
\text { Especifica }\left(\mathrm{m}^{2} / \mathrm{g}\right)\end{array}$ & $\begin{array}{l}\text { Volumen de Poro } \\
\qquad\left(\mathrm{cm}^{3} / \mathrm{g}\right)\end{array}$ & $\begin{array}{l}\text { Diámetro de Poro } \\
\text { Promedio } \Phi(\mathrm{nm})\end{array}$ \\
\hline Blanco & 157 & 0.096 & 2.02 \\
\hline $\mathrm{H}_{2} \mathrm{~T}(\mathrm{p}-\mathrm{COOH}) \mathrm{PP}-\mathrm{APTES}$ & 175 & 0.10 & 2.02 \\
\hline dMeDEOS & 280 & 0.18 & 2.26 \\
\hline EtTEOS & 67 & 0.056 & 2.42 \\
\hline VyTEOS & 105 & 0.082 & 3.1 \\
\hline Aly TMOS & 54 & 0.04 & 3.53 \\
\hline AmTEOS & 28 & 0.027 & 3.53 \\
\hline DoTEOS & 62 & 0.097 & 3.77 \\
\hline$\Phi \mathrm{TEOS}$ & 31 & 0.031 & 3.17 \\
\hline
\end{tabular}

Tabla 4.4 Áreas superficiales específicas, volu men de poro y diámetro de poro promed io de xerogeles órgano modificados con AOS y la especie $\mathrm{H}_{2} \mathrm{~T}(\mathrm{p}-\mathrm{COOH}) \mathrm{PP}-\mathrm{APTES}$ de $\mathrm{TiO}_{2}$. 


\subsection{Microscopía Electrónica de Barrido (SEM) y Análisis EDS}

Se eligieron los monolitos sintetizados con el AOS ( $\Phi-$ TEOS), que presentan una coloración marrón, debido a la presencia de la $\mathrm{H}_{2} \mathrm{~T}(p-\mathrm{COOH}) \mathrm{PP}$. La imagen de SEM (Figura 4.12) indica que el material presenta una superficie suave con algunas irregularidades (Figuras 4.12 a y b) para los materiales de $\mathrm{ZrO}_{2}$. Para el caso de los xerogeles de $\mathrm{TiO}_{2}$ las (figuras $4.12 \mathrm{c}$ y d) las imágenes revelan que los materiales son más frágiles que los de zirconio y con mayores irregularidades.

El análisis EDS (Figura 4.13) para los xerogeles de $\mathrm{ZrO}_{2}$ revela los siguientes porcentajes en peso: \%: 0.24 de Si (1 mol), 1.77 de Al (7.6 mol), 0.34 de Ni $(0.67 \mathrm{~mol}), 24.96$ de C ( 243 mol), 43.58 de O ( $318 \mathrm{~mol}$ ) y $29.11 \mathrm{de} \mathrm{Zr}$ (37.34 mol). El Si se puede asociar a la presencia del APTES, la presencia de $\mathrm{Al}$ y $\mathrm{Ni}$ se puede asociar a impurezas en la síntesis de los materiales y el exceso de oxigeno podrían atribuirse a la existencia de grupos propoxi $\left(\mathrm{OC}_{3} \mathrm{H}_{7}\right) \mathrm{o}$ a la acetilacetona remanentes. La relación molar $\mathrm{O} / \mathrm{Zr}$ es de aproximadamente 9 y sugiere la presencia de grupos $\mathrm{Zr}-\mathrm{OH}$ en la red.

Para el caso de xerogeles de $\mathrm{TiO}_{2}$ el análisis EDS (Figura 4.14) detecta los siguientes porcentajes en peso: \%:0.92 de Si (1 mol), $0.55 \mathrm{de} \mathrm{Al}$ (0.62 mol), 17.39 de C (44.2 mol), 46.34 de $\mathrm{O}(88.5 \mathrm{~mol})$ y $34.8 \mathrm{de} \mathrm{Ti}$ ( $22.2 \mathrm{~mol})$, nuevamente el $\mathrm{Si}$ se asocia al APTES y la presencia de Al a las impurezas de la síntesis del material. El exceso de oxígeno a los grupos propoxi $\left(\mathrm{OC}_{3} \mathrm{H}_{7}\right)$ y a la acetilacetona remanentes. La relación molar $\mathrm{O} / \mathrm{Ti}$ es de aproximadamente 4 y atribuye a la presencia de grupos Ti-OH en la red, aunque en menor número si se compara con aquellos presentes en la matriz de $\mathrm{ZrO}_{2}$, lo que sugiere la formación de una matriz más estructurada de $\mathrm{TiO}_{2}$ que de $\mathrm{ZrO}_{2}$. 


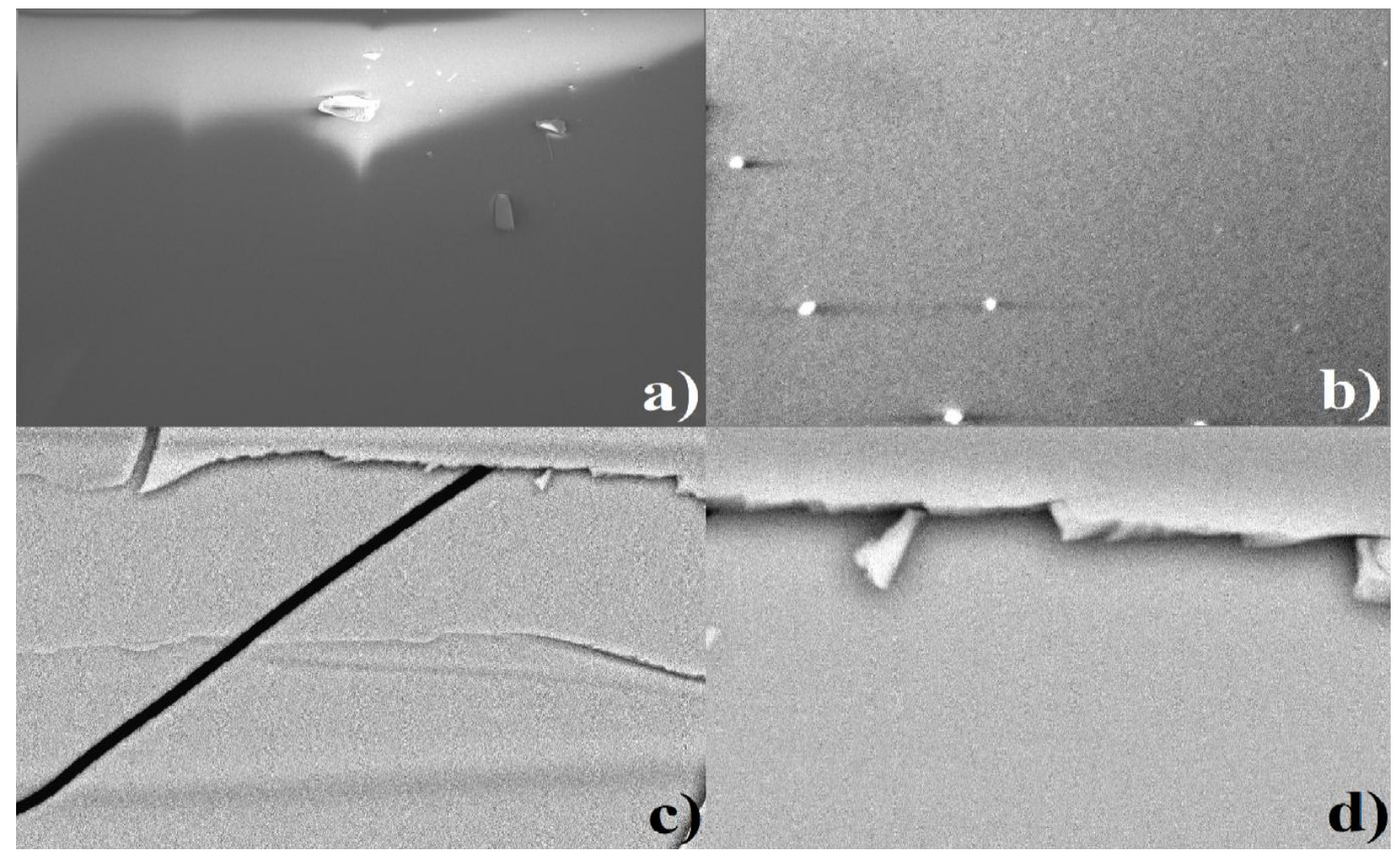

Figura 4.12. Imagen de microscopía de barrido (SEM) de xerogeles órgano modificados con $\Phi$-TEOS y la especie $\mathrm{H}_{2} \mathrm{~T}(\mathrm{p}-\mathrm{COOH}) \mathrm{PP}$-APTES de $\mathrm{ZrO}_{2}$ a) $1 \mu \mathrm{mb}$ ) $10 \mu \mathrm{m}$ y $\mathrm{TiO}_{2} \mathrm{TiO}_{2}$ c) $1 \mu \mathrm{m}$ d) $10 \mu \mathrm{m}$ con $\mathrm{H}_{2} \mathrm{~T}(p-\mathrm{COOH}) \mathrm{PP}$ -

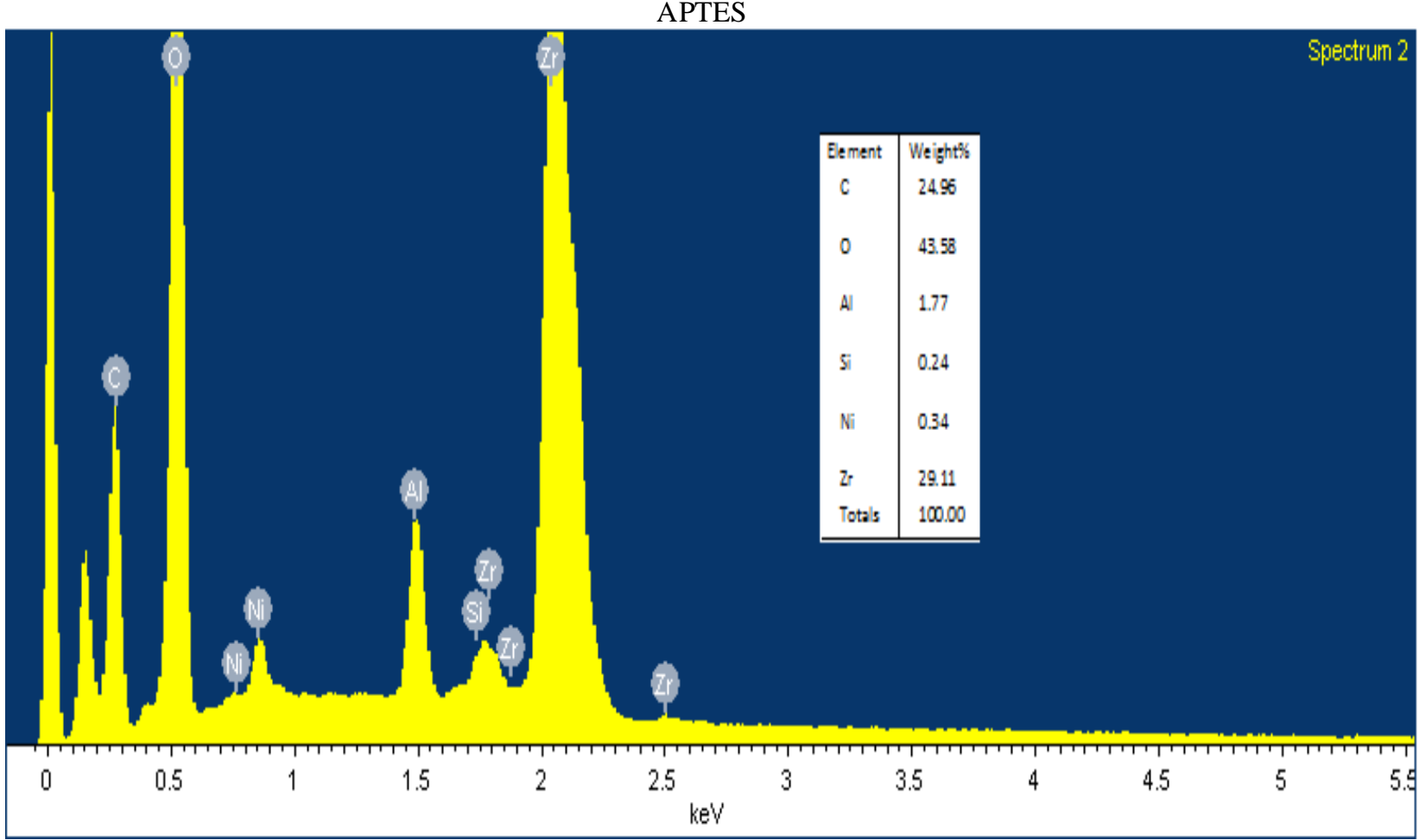

Figura 4.13 Porcentaje de elementos detectados por EDS en el xerogel de $\mathrm{ZrO}_{2}$ órgano-modificado con $\Phi-$ TEOS 


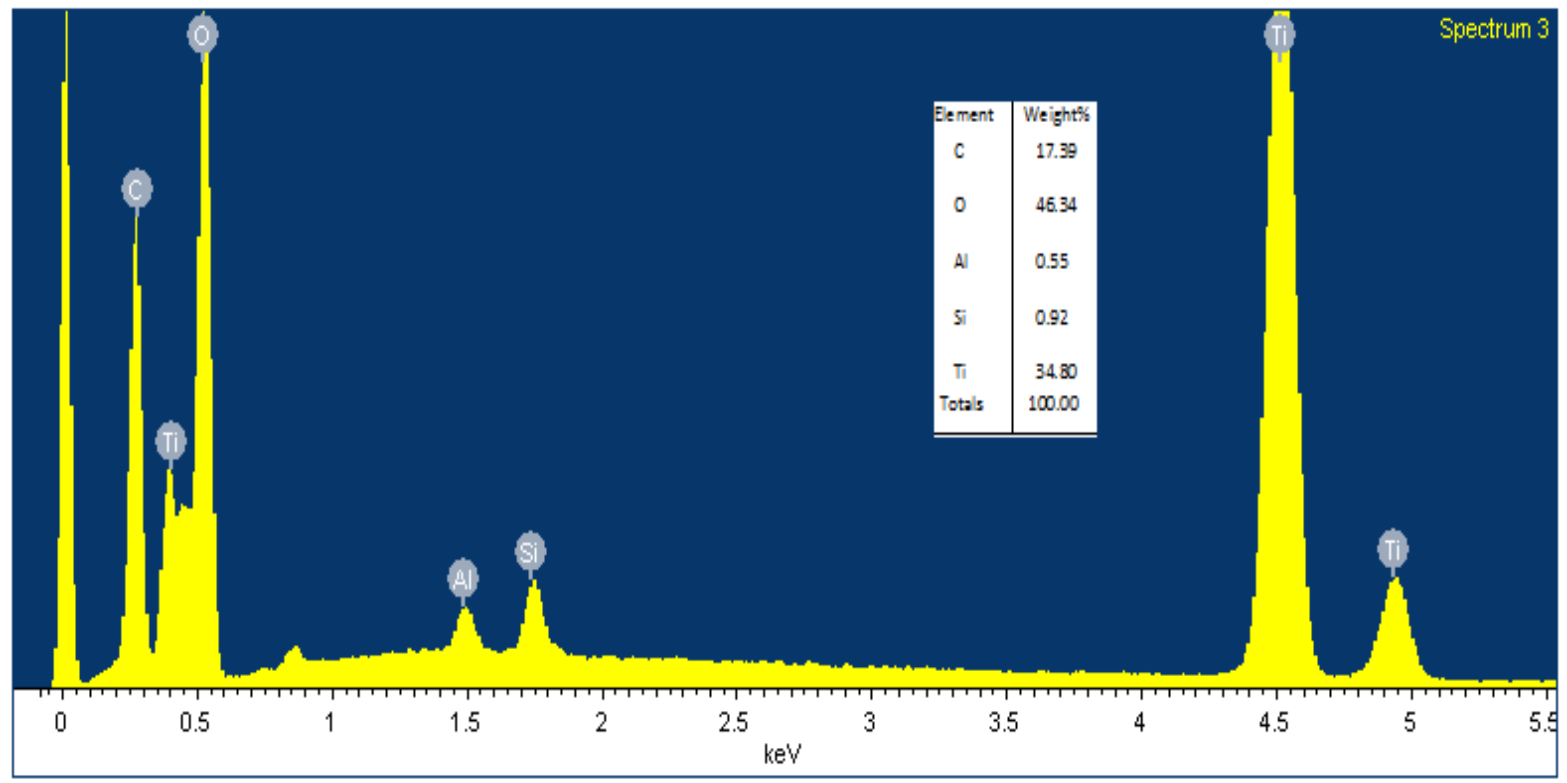

Figura 4.14 Porcentaje de elementos detectados por EDS en el xerogel de $\mathrm{TiO}_{2}$ órgano-modificado con $\Phi-$ TEOS

Para el caso de los monolitos sintetizados con el VyTEOS, se observa que también presentan una coloración marrón. La imagen de SEM (Figura 4.15) indica que el material rugoso y fracturas (Figuras 4.15 a y b) para los xerogeles de $\mathrm{ZrO}_{2}$. En el caso de los xerogeles de $\mathrm{TiO}_{2}$ (figuras $4.15 \mathrm{c}$ y d) se revela que los materiales son lisos y con fracturas, al acercar la imagen (resolución de $1 \mu$ ) se puede observar que no se presentan poros y existen algunas irre gularidades.

El análisis EDS (Figura 4.16) para los xerogeles de $\mathrm{ZrO}_{2}$ detecta los siguientes porcentajes en peso: \%:0.33 de Si (1 mol),1.23 de $\mathrm{Al}$ ( $3.8 \mathrm{~mol}), 0.80$ de Ni (0.40 mol),23.39 de C (59.5 mol) , 56.01 de O ( $106.8 \mathrm{~mol})$ y 18.23 de $\mathrm{Zr}$ (6.1 mol). Cabe señalar que como en el caso anterior el Si se puede asociar al uso del APTES, la presencia de Al y Ni se asocia con impurezas derivadas de la síntesis de los materiales y el exceso de oxigeno podrían atribuirse a la existencia de grupos propoxi $\left(\mathrm{OC}_{3} \mathrm{H}_{7}\right)$ y de la acetilacetona remanentes. La relación molar $\mathrm{O} / \mathrm{Zr}$ es de aproximadamente 18 y se atribuye a la presencia de grupos $\mathrm{Zr}-\mathrm{OH}$ en la red.

Para el caso de xerogeles de $\mathrm{TiO}_{2}$ el análisis EDS (Figura 4.17) detecta los siguientes porcentajes en peso: \%:0.86 de Si (1 mol), 16.94 de C (46mol) ,46.75 de O (95 mol) y 35.46 de Ti (24.2 mol), el Si se asocia al APTES y el exceso de oxígeno a los grupos propoxi $\left(\mathrm{OC}_{3} \mathrm{H}_{7}\right)$ y 
a la acetilacetona remanentes. La relación molar O/Ti es de aproximadamente 4 y que también se atribuyen a la presencia de grupos Ti-OH en la red. Esto reafirma lo comentado sobre la mayor estructuración de las matrices de este tipo, asociado seguramente a la rápida formación de la misma y la mayor reactividad de su alcóxido precursor.

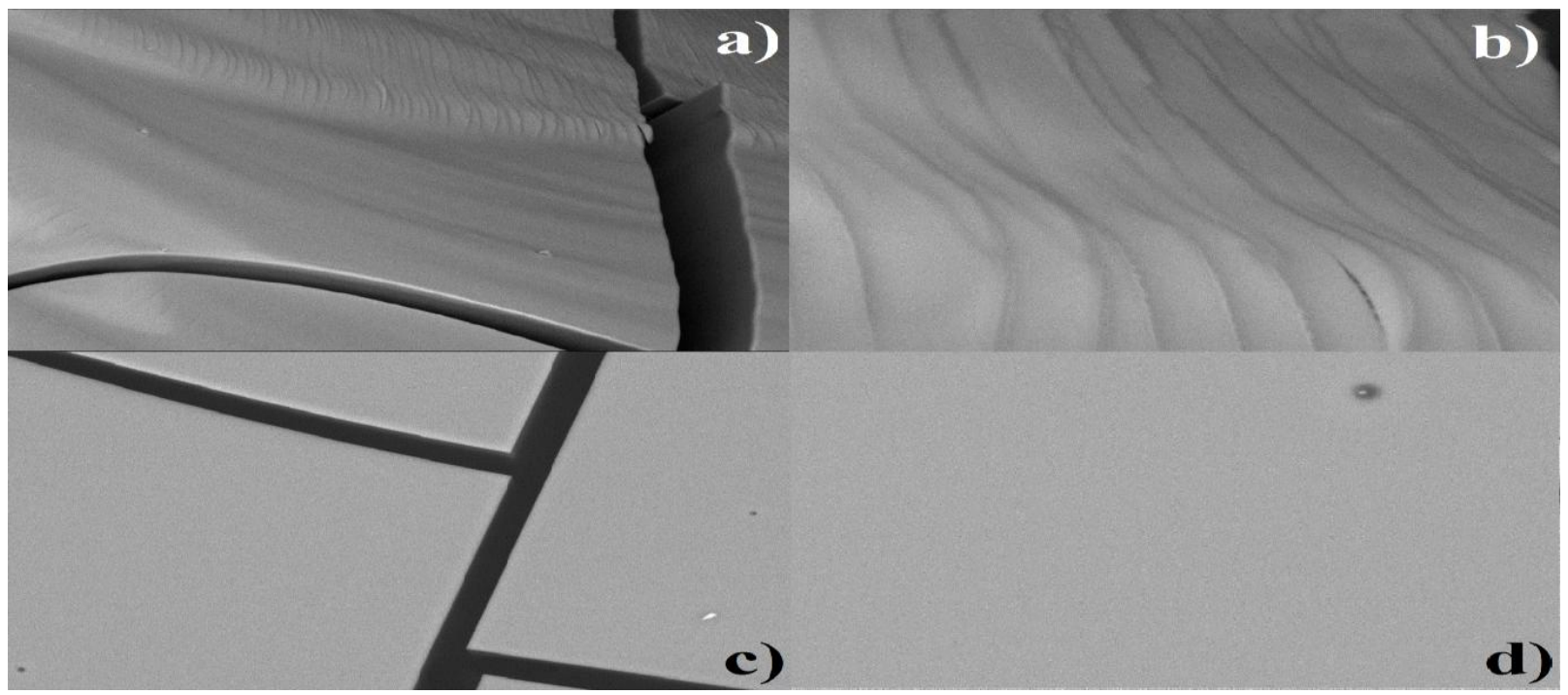

Figura 4.15 Imagen de microscopía de barrido (SEM) de xerogeles órgano modificados con VyTEOS y la especie $\mathrm{H}_{2} \mathrm{~T}(\mathrm{p}-\mathrm{COOH}) \mathrm{PP}-\mathrm{APTES}$ de $\mathrm{ZrO}_{2}$ a) $1 \mu \mathrm{mb}$ ) $10 \mu \mathrm{m}$ y $\mathrm{TiO}_{2} \mathrm{TiO}_{2}$ c) $1 \mu \mathrm{m}$ d) $10 \mu \mathrm{m}$ con $\mathrm{H}_{2} \mathrm{~T}(p-C O O H) \mathrm{PP}-$

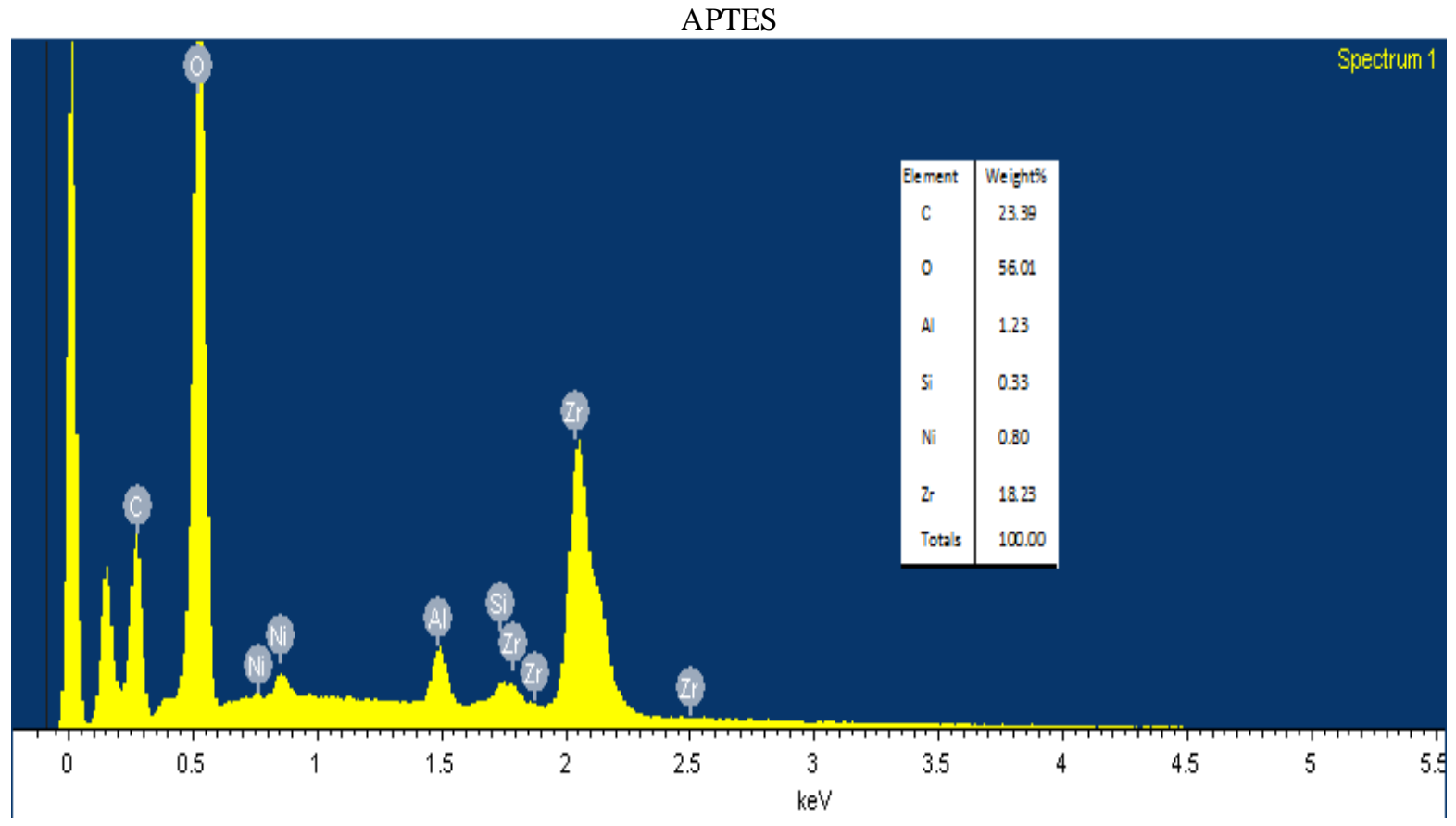

Figura 4.16 Porcentaje de elementos detectados por EDS en el xerogel de $\mathrm{ZrO}_{2}$ órgano-modificado con VyTEOS. 


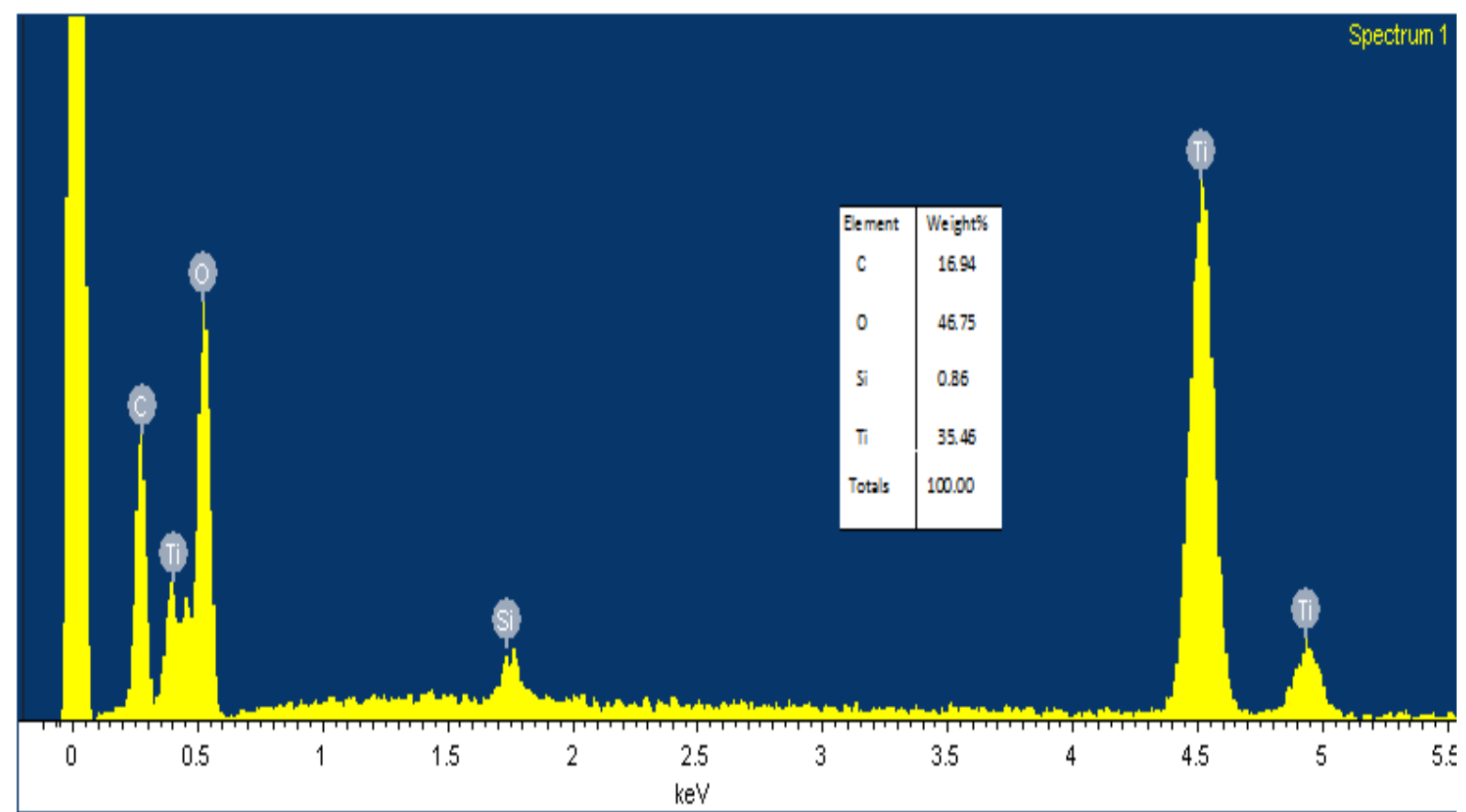

Figura 4.17 Porcentaje de elementos detectados por EDS en el xerogel de $\mathrm{TiO}_{2}$ órgano-modificado con VyTEOS.

4.8 Contraste de los xerogeles con las especies $\mathrm{H}_{2} \mathrm{~T}(p-\mathrm{COOH}) \mathrm{PP}$ unidas a $\mathrm{ZrO}_{2}$ y $\mathrm{TiO}_{2}$ y $\mathrm{SiO}_{2}$.

La determinación y el análisis de los parámetros texturales generados al unir de manera covalente la especie porfirinicas de los sistemas sintetizados en este y en otros trabajos [75] resulta importante ya que nos proporciona información del ambiente físico en la que se encuentra inmersa la especie macrociclica. En la tabla 4.5 se presentan los diámetros de poro promedio obtenidos al unir de manera covalente la $\mathrm{H}_{2} \mathrm{~T}(p-\mathrm{COOH}) \mathrm{PP}-\mathrm{F}$ a matrices de $\mathrm{SiO}_{2}, \mathrm{TiO}_{2}$ y $\mathrm{ZrO}_{2}$ órgano modificadas. Los valores de la especie en $\mathrm{SiO}_{2}$ son aquellos reportados por R.I Quiroz y M.A García Sánchez [73] para la misma especie. En dicha tabla es posible observar, en primera instancia, que en las tres matrices órgano modificadas con grupos dodecilo se presentan los diámetros de por mayores, esto sugiere que la molécula se encuentra más alejada de las paredes del poro. Otra observación importante resulta ser el hecho de que los diámetros de poro de los xerogeles de $\mathrm{SiO}_{2}$ y $\mathrm{TiO}_{2}$ modificadas con grupos alquil que presentan enlaces sencillos, dependen del número de carbonos en dichas cadenas. Esta tendencia se rompe en los materiales de $\mathrm{ZrO}_{2}$, lo que podría atribuirse a la reactividad del mismo. También es evidente que en los xerogeles de $\mathrm{SiO}_{2}$ y $\mathrm{TiO}_{2}$ la existencia de grupos dodecilo y Amilo propician la generación de 
poros mayores, mientras que en los sistemas de $\mathrm{ZrO}_{2}$ los poros más grandes son producidos cuando se introducen grupos dodecilo y etilo. En general los diámetros de poro promedio en las matrices de $\mathrm{SiO}_{2}$ y $\mathrm{TiO}_{2}$ son semejantes, lo que sugiere que las matrices son de similar polaridad, hecho que nuevamente se atribuiría a las especies que modifican el poro y a la reactividad de los alcóxidos utilizados en la síntesis.

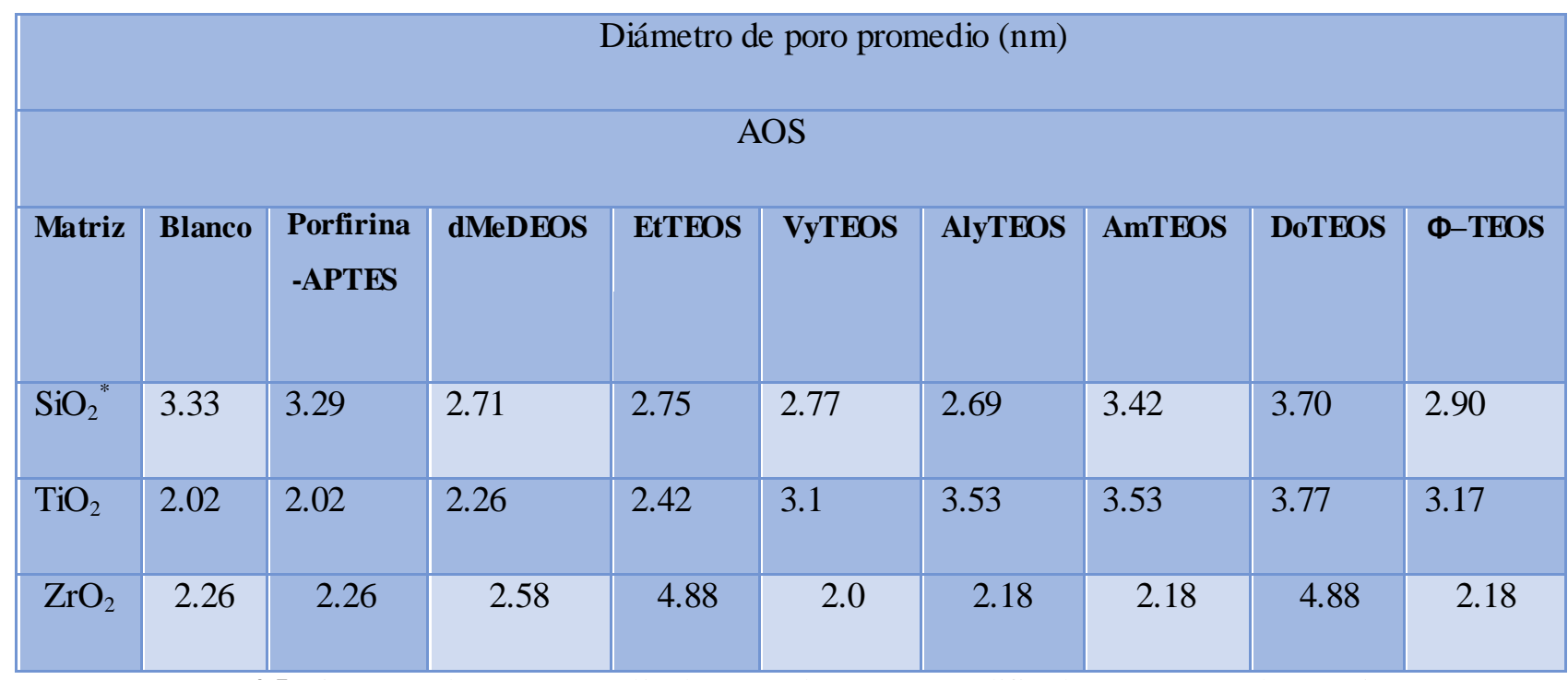

Tabla 4.5 Diámetros de poro promed io de xerogeles órgano modificados con AOS y la especie $\mathrm{H}_{2} \mathrm{~T}(\mathrm{p}$ $\mathrm{COOH}$ )PP-APTES de $\mathrm{SiO}_{2}, \mathrm{TiO}_{2}$ y $\mathrm{ZrO}_{2} *$ Datos reportados por R.I Qu iro z y M.A. García Sánchez [73]

En lo referente al parámetro de área superficial específica, R.I Quiroz y M.A. García Sánchez reportan que la adición de AOS aumenta las áreas de todos los materiales sintetizados, sin reportar alguna tendencia en específico [73]. La tabla 4.6 que se presenta a continuación muestra algunas similitudes entre los sistemas sintetizados, desatacando el hecho de que en las matrices de $\mathrm{SiO}_{2}$ y $\mathrm{ZrO}_{2}$ el área de los materiales con VyTEOS son menores en ambos sistemas, que las áreas en donde no se introdujo AOS son mayores en los tres casos con respecto a las matrices prístinas y que, en general, la diferencia de áreas en los todos materiales se atribuye a la presencia del AOS que modifica de manera importante el área superficial. Esta información resulta valiosa en el área de catálisis en donde se requiere que los materiales sintetizados cuenten con una mayor área de contacto. 


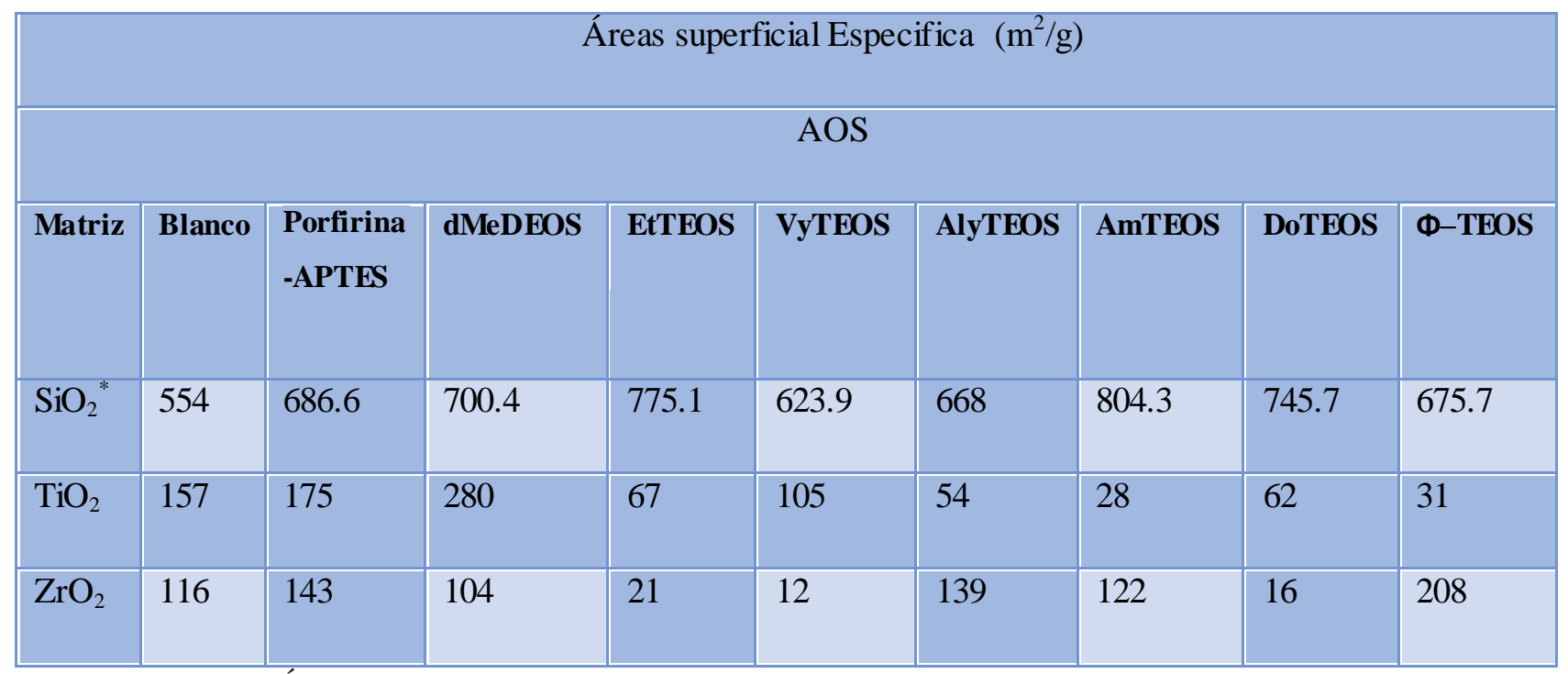

Tabla 4.6 Áreas Superficiales Especificas de xerogeles órgano modificados con AOS y la especie $\mathrm{H}_{2} \mathrm{~T}(\mathrm{p}-$ COOH)PP-APTES de $\mathrm{SiO}_{2}, \mathrm{TiO}_{2}$ y $\mathrm{ZrO}_{2} *$ Datos reportados por R.I Qu iroz y M.A. García Sánchez [73]

$\mathrm{La}$ intensidad de los espectros de fluorescencia de la $\mathrm{H}_{2} \mathrm{~T}(p-C O O H) \mathrm{PP}-\mathrm{APTES}$ en los sistemas órgano-modificados de los tres óxidos nos permite establecer el ambiente químico más favorable para que la porfirina despliegue tal propiedad. Es de esperarse que debido a la naturaleza de los materiales sintetizados, la fluorescencia de cada sistema presente diferencias sustanciales. A continuación se presenta la serie en orden decreciente de las intensidades de emisión de cada material sintetizado, cabe señalar una vez más que los datos de los sistemas de $\mathrm{SiO}_{2}$ son los reportados por R.I Quiroz y M.A García Sánchez* y son expuestos con el objeto de realizar la comparación correspondiente.

Intensidad de las señales de emisión en xerogeles de $\mathrm{SiO}_{2} * \quad\left(\lambda_{\text {exc }}=420 \mathrm{~nm}\right): \Phi-$ TEOS $>$ dMeDEOS $>$ EtTEOS $>\mathrm{H}_{2}$ T $($ p-COOH $)$ PP-APTES $>$ VyTEOS $>$ DoTEOS $>$ AmTEOS $>$ AlyTMOS.

Intensidad de las señales de emisión en xerogeles de $\mathrm{TiO}_{2}\left(\lambda_{\text {exc }}=516 \mathrm{~nm}\right)$ : DoTEOS $>\Phi-$ TEOS $>\mathrm{H}_{2}$ T(p-COOH)PP-APTES $>$ AmTEOS $>$ EtTEOS $>$ AlyTMOS $>$ dMeDEOS VyTEOS.

Intensidad de las señales de emisión en xerogeles de $\mathrm{ZrO}_{2}\left(\lambda_{\text {exc }}=516 \mathrm{~nm}\right)$ : AmTEOS $>\Phi$ TEOS $>$ dMeDEOS $>$ Do TEOS $>$ VyTEOS $>$ AlyTMOS $>$ EtTEOS $>\mathrm{H}_{2} \mathrm{~T} \quad$ (p-COOH)PP-APTESDe esta información se desprende que los sistemas en los cuales la porfirina se encuentra más libre para desplegar sus propiedades son para el caso de las matrices de $\mathrm{SiO}_{2}$ [73] y modificadas con 
$\Phi-T E O S$ en su estructura. Para el caso del $\mathrm{TiO}_{2}$ el Do-TEOS y para los xerogeles de $\mathrm{ZrO}_{2}$ el AmTEOS. Cabe destacar que para el caso de los materiales de $\mathrm{TiO}_{2}$ la diferencia de intensidades entre las emisiones de la porfirina entre los sistemas sintetizados con DoTEOS y $\Phi$-TEOS resulta muy pequeña, lo que nuevamente sugiere que el ambiente químico generado con los óxidos de silicio y titanio órgano-modificados podría ser semejante. 


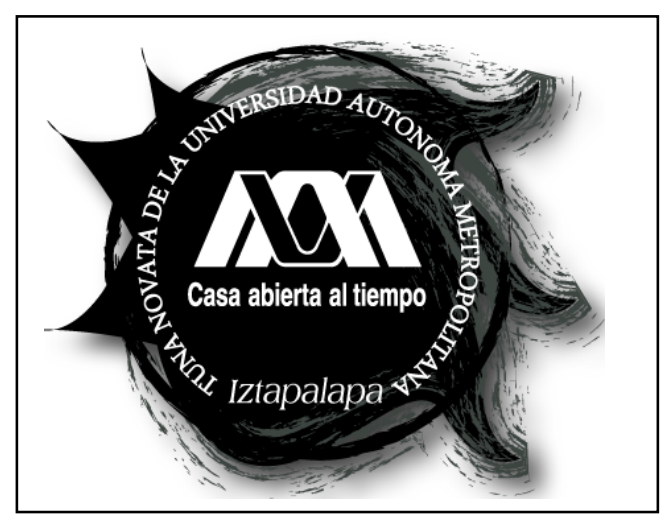

UAM-I

\section{Conclusiones y perspectivas}




\section{Conclusiones.}

Se establecieron las relaciones molares que permiten la síntesis de Xerogeles translucidos y transparentes de $\mathrm{ZrO}_{2}$ y TiO${ }_{2}$ utilizando agentes quelantes para reducir las reactividades de los alcóxidos, estableciéndose también propiedades importantes dentro de las que destacan la diferencia de rehidratación seguida mediante espectros NIR (Infrarrojo cercano) y asociada a la existencia de grupos $\mathrm{M}-\mathrm{OH}$ y que contribuyen al aumento de polaridad en los xerogeles. Con base en esto se estableció que los materiales de $\mathrm{TiO}_{2}$ son más hidrofilicos que los de zirconio que a su vez son más resistentes que los de $\mathrm{TiO}_{2}$, lo que sugiere que pueden utilizarse en aplicaciones ópticas con mejores resultados.

Mediante la metodología establecida es posible atrapar físicamente en xerogeles de $\mathrm{ZrO}_{2}$ y $\mathrm{TiO}_{2}$ especies del tipo de las MTSPc. De estos estudios se puede establecer que la especie CuTSPc se mantiene en forma monomérica en $\mathrm{ZrO}_{2}$, no así en $\mathrm{SiO}_{2}$ y $\mathrm{TiO}_{2}$, lo que reafirma la observación de diferente medioambiente químico (polaridad) al interior de los poros. Mientras que la especie $(\mathrm{OH}) \mathrm{FeTSPc}$ se mantienen como monómero en $\mathrm{ZrO}_{2}$ y SiO 2 , no asíen el $\mathrm{TiO}_{2}$.

Los tamaños de poro promedio en los dos óxidos son similares a los generados en materiales homólogos de $\mathrm{SiO}_{2}$ lo que sugiere que las MTSPc se encuentran atrapadas dentro de cavidades de la red que se han formado en torno a aquellas especies; las dimensiones de dichas cavidades dependen de la identidad del catión presente en tales complejos. Dado que los complejos MTSPc tienen un tamaño aproximado de 1.8 a $2.0 \mathrm{~nm}$, dimensiones muy próximas a las determinadas en las muestras sintetizadas, se puede determinar también que las diferencias entre las áreas superficiales son atribuibles a la naturaleza de las matrices las cuales según el siguiente orden en magnitud. $\mathrm{SiO}_{2}>\mathrm{TiO}_{2}>\mathrm{ZrO}_{2}$.

La especie $\mathrm{H}_{2} \mathrm{~T}(\mathrm{COOH}) \mathrm{PP}-\mathrm{APTES}$ se mantienen unida covalentemente, como monómero y estable dentro de los óxidos, al parecer el ambiente químico menos polar del $\mathrm{ZrO}_{2}$ y la unión covalente con el APTES intervienen para que la molécula presente propiedades parecidas a las que despliega en solución. La fluorescencia roja de la especie $\mathrm{H}_{2} \mathrm{~T}(\mathrm{COOH}) \mathrm{PP}-\mathrm{F}$ en los 
xerogeles de óxido de titanio se preservo, no así en los xerogeles de $\mathrm{ZrO}_{2}$ en donde predomino la de la matriz de óxido. Al unirse la especie porfirinica en la red de $\mathrm{ZrO}_{2}$ se logra un aumento considerable en el área del material, lo cual puede resultar interesante en catálisis. Los diámetros de poro promedio calculados por el método (NLDFT) muestran que ante la presencia de la porfirina, predominan los poros de 2 a $2.2 \mathrm{~nm}$ en el material, aquellos de más de $3 \mathrm{~nm}$ prácticamente desaparecen. El diámetro de poro y el área superficial reportada para sistemas de $\mathrm{TiO}_{2}$ presentan semejanza con las tendencias reportadas en sistemas análogos de $\mathrm{SiO}_{2}$ por Quiroz y M.A.Garcia, en contraste los sistemas de $\mathrm{ZrO}_{2}$ presentan una tendencia a la inversa.

Se logró la unió de manera covalente de la clorofila $a$ en las redes de $\mathrm{ZrO}_{2}$ y $\mathrm{TiO}_{2}$, en los que se mantiene estable y principalmente como monómero a concentraciones por debajo de 1.1 $\mathrm{X} 10^{-2}$. La fluorescencia roja de la clorofila $a-\mathrm{F}$ en los xerogeles de óxido de titanio se preservo, no así en los xerogeles de $\mathrm{ZrO}_{2}$ en los que domina la fluorescencia de la matriz del óxido. En estos materiales los diámetros de poro de ambos óxidos oscilan entre 1.2 y $1.34 \mathrm{~nm}$. y concuerdan con los reportados para el $\mathrm{SiO}_{2}$.

Se diseñó la metodología para unir de manera covalente la especie $\mathrm{H}_{2} \mathrm{~T}(p-C O O H) \mathrm{PP}-$ APTES a xerogeles transparente y translucidos de $\mathrm{ZrO}_{2}$ y $\mathrm{TiO}_{2}$ órgano-modificados con alcoxidos órgano sustituidos (AOS) por el método sol-gel. Con base en el análisis espectroscópico se puede decir que la molécula $\mathrm{H}_{2} \mathrm{~T}(p-C O O H) \mathrm{PP}-\mathrm{APTES}$ se mantiene estable y dentro de los xerogeles consolidados en los tres sistemas sintetizados y en la mayoría de los casos, las intensidades y patrón de las 4 bandas Q sugieren nula o mínima protonación [75]. Estos resultados son interesantes ya que permiten elegir el método de síntesis de uno o más de los materiales presentados para dar un uso específico en áreas como la catálisis, medicina u óptica.

Los materiales sintetizados con $\mathrm{TiO}_{2}$ y la porfirina presentan una coloración roja característica de la especie al someterse a luz UV-Vis, mientras que los materiales sintetizados con $\mathrm{ZrO}_{2}$ y la porfirina presentan una coloración naranja, mezcla de absorciones de la matriz y la especie unida. La especie $\mathrm{H}_{2} \mathrm{~T}(p-\mathrm{COOH}) \mathrm{PP}$-APTES despliega mejor la fluorescencia al modificar la matriz de $\mathrm{TiO}_{2}$ con Do-TEOS y $\Phi$-TEOS, mientras que para el caso de los xerogeles de $\mathrm{ZrO}_{2}$ los mejores resultados se obtienen con AmTEOS. En los materiales de $\mathrm{TiO}_{2}$ 
órgano-modificados el diámetro de poro parece depender del número de carbonos presentes en los AOS utilizados y que tienen enlaces simples en su estructura; los diámetros de poro mayores se presentan en los materiales en donde la matriz se modificó con el DoTEOS, lo que se atribuye a que la presencia de la cadena larga de carbonos genera que la especie macrociclica se encuentre más alejadas de las paredes del poro.

\section{Perspectivas.}

Una vez sintetizados xerogeles de $\mathrm{ZrO}_{2}$ y $\mathrm{TiO}_{2}$ translúcidos y trasparentes con ftalocianinas atrapadas físicamente, demostrar su estabilidad dentro de ellos y establecer diferencias y similitudes, es posible funcionalizar algunas ftalocianinas utilizado alcóxidos de tipo APTES y NAEPTMES unirlas de manera covalente a xerogeles de $\mathrm{SiO}_{2}, \mathrm{ZrO}_{2}$ y $\mathrm{TiO}_{2}$.

Extender la metodología anterior para alas ftalocininas a xerogeles órgano-modificados utilizando para ello AOS y analizar la influencia de los grupos orgánicos en los materiales.

Asumir para el cálculo de las propiedades texturales de los monolitos sintetizados que las cavidades de los poros que se forman alrededor de las especies atrapadas son elípticas y contrastar los resultados con los aquíobtenidos.

Una vez establecidas las relaciones molares, concentraciones y metodología para sintetizar xerogeles de $\mathrm{SiO}_{2}, \mathrm{ZrO}_{2}$ y $\mathrm{TiO}_{2}$ transparentes y translúcidos con especies porfirinicas, es posible utilizar esta información para atrapar y unir otras moléculas de diferente naturaleza y tratar de preservar sus propiedades en los sólidos propuestos. 


\section{Bibliografía.}

[1]- A. B. P. Lever, Advances Inorganic Chemistry and Radiochemistry, 1965, 7, 27.

[2]- F. H. Moser, A. L. Thomas, The Phthalocyanines, CRC, press Inc., Boca Ratón, Florida, 1983, 1:127.

[3]- C. C. Leznoff and A. B. P. Lever, Phtalocyanines Properties and Applications, Edited by C. C. Leznoff and A. B. P. Lever, VCH Publishers, Inc., New York, US A, vol I, 1989; vol II, 1993; vol III, 1993, vol IV, 1996.

[4]- R.P. Linstead, J. Chem. Soc.,1934, 1016.

[5]- C.E.Dent, R .P. Linstead, A.R. Lowe, J. Chem. Soc., 1934, 1033.

[6]- M.A. García Sánchez, Síntesis y caracterización de Complejos Macrocíclicos mixtos Lantanoides, Tesis de Maestría Universidad Autónoma Metropolitana-Iztapalapa, México, 1993.

[7]- D.D. Eley, Nature, 1948, 20, 4125.

[8]- P.E. Fielding, A.G. MacKay, Aust. J. Chem., 1964, 17, 750.

[9]- J.P. Linsky, T.R.Paul, Inorg. Chem, 1980, 19, 3131.

[10]- J.H. Weber, D.H. Busch, Inorg. Chem. 1965, 4, 469.

[11]- J.H. Weber, D.H. Busch, Inorg. Chem. 1965, 4, 472.

[12]- J. Zagal, R. K. Sen, E. Yeager, J. Electroanal. Chem., 1977, 88 , 213.

[13]- Hanack M.; Polley R.; Deger S. cyano-2,3-naphthalocyaninatocobalt(III). Synthetic Metals 1997, 89, 47-49.

[14]- E. Yeager, Electrochim. Acta, 1984, 29, 1527.

[15]- M. A. García Sánchez, A. Campero, J. of Sol Gel Scie and Technol. 13, 1998, 651-655.

[16]- M. A. García Sánchez, A. Campero, Polyhedron, 19, 2000, 2383-2386. 
[17]- John Jairo Cabrera López, José Luis Narváez, Jorge Enrique Rodríguez Páez, Rev.fac.ing.univ. Antioquia no.47 Medellín Jan./Mar. 2009,1.

[18]- www.labnano.org.mx/esp\%20fotocatalisis.htm

[19] - G. De, J. Mat. Sci. Lett. 9, 1990, 845.

[20]- E. Sánchez González, anales de mecánica de la fractura vol. 22 ,2005.

[21]- Estíbaliz Sánchez González, Efecto de los recubrimientos sol-gel de zirconia sobre la fractura de materiales frágiles, Anales de la mecánica de la fractura , 2005, 242-247

[22] Maria Luisa Roxana Licona, Cálculo de la estructura electrónica de la superficie de $\mathrm{TiO}_{2}$, Tesis de Maestría, UAMI- México D.F. 1996.

[23]-Enrique Sánchez Mora, síntesis y caracterización de $\mathrm{TiO}_{2}$, Tesis de Maestría, UAMI, México D.F. Octubre de 1991.

[24]- José Escobar Aguilar, Síntesis, Caracterización y Propiedades Catalíticas Hidrogenantes de Sistemas a Base de Ni Soportado en A12O3-TiO2 Sol-Gel, Tesis de Doctorado, UAMI, México D.F. Marzo 2001.

[25]- http://phycomp.technion.ac.il/ ira/types.html\#TiO2

[26]- M.R. Hoffman, S.T. Martin, W.choi. D. Bahnemann, Chem. Rev 95, 19995, 69.

[27]- I.H. Arabatzis, T.Stergiopolus,M.C Bernard,D. labos, S.G. Neophytides.P Falaras, Appl. Catal. B: Environ. 42, 2003, 127.

[28]- B. Yao, L. Zhang, J. Mater. Sci. 34, 1999, 5983.

[29]- Bing Guoa, Zhaolin Liu, Liang Hong, Huixin Jiang, Jim Yang Lee, Thin Solid Films 479, 2005, 310-315.

[30]-L. El Mir, A. Amlouk, E. Elaloui , M. Saadoun , A.C. Pierre , Materials Science and Engineering B 146, 2008, 69-73. 
[31]- Petra Novotná, Jirí Zita, Josef Krysa, Vit Kalousek, Jirí Ratho usky , Applied Catalysis B: Environmental 79, 2007, 179-185

[32]- Campostini, R.; Carturan, G.; Ferrari, M.; Montagna, M.; Pilla, O. Luminescence of Eu ${ }^{3+}$ Ions During Thermal Densification of $\mathrm{SiO}_{2}$ Gel. J.Mater. Res. 1992, 7, 745-753.

[33]- Pouxviel, J.C.; Dunn, B.; Zink, J.I. Fluorescence Study of Aluminosilicate Sols and Gels Doped with Hydroxy Trisulfonated Pyrene J. Phys. Chem. 1989, 93, 2134-2139.

[34]- Miller, J.M., Dunn, B.; Valentine, J.S.; Zink, J.I. Synthesis Conditions for Encapsulating Cytochrome c and Catalase in SiO2 Sol-gel Materials. J. Non-Cryst. Solids 1996, 202, 279-289.

[35]- Menaa, B.; Miyagawa, Y.; Takahashi, M.; Herrero, M.; Rives, V.; Menaa, F.; Eggers, D.K. Bioencapsulation of Apomyoglobin in Nanoporous Organosilica Sol-gel glasses: Influence of the Siloxane Network on the Conformation and Stability of a Model Protein. Biopolymers 2009, 91, 895-906.

[36]- Campostrini, R.; Carturan, G.; Caniato, R.; Piovan, A.; Filippin,i R.; Innocenti, G.; Cappelletti, E.M. Immobilization of Plant Cells in Hybrid Sol-gel Materials J. Sol-Gel Sci. and Tech. 1996, 7, 87-97.

[37]- Nassif, N.; Roux, C.; Coradin, T.; Rager, M.N.; Bouvet, O.M.M.; Livage, J. A Sol-gel Matrix to Preserve the Viability of Encapsulated Bacteria. J. Mater. Chem. 2003, 13, 203-208.

[38]- A. B. P. Lever, Advances Inorganic Chemistry and Radiochemistry, 1965, 7, 27

[39]- D. C. Bradley, R. C. Merhotra, D. P. Gaur, Metal Alkoxides, Acad. Press, London, 1978.

[40]- Y. C. Yang, J. R. Ward, R. P. Seiders, Inorg. Chem., 1985, 24, 1765.

[41]- C. Sanchez, J. Livage, M. Henry, F. Babonneau, J. of Non-Cryst. Solids 1988, 100, 65.

[42]- J. Livage, M. Henry, Ultrastructure Processing of Advanced Ceramics, Edited by J. D. Mckenzie and D. R. Ulrich, Wiley, New York 1988.

[43]- C. Alquier, M. T. Vandenborre, M. Henry, J. Non-Cryst. Solids 1986, 79, 383. 
[44]- G. Winter, Oil and Colour Chemist's Association, 34, 30, 1959.

[45]- García-Sánchez, M.A., De La Luz, V., Coahuila-Hernández, M.I., Rojas-González, F., Tello-Solís, S.R., Campero, A., Effects of the structure of entrapped substituted porphyrins on the textural characteristics of silica networks, Journal of Photochemistry and Photobiology A: Chemistry, 2011, 223 (2-3), pp. 172-181.

[46]-S. Braun, S. Shtelzer, S. Rapoport, D. Avnir, M. Ottolenghi, J. Non-Cryst. Solids 1992, 147\&148, 739 .

[47]-V. De la Luz, M. A García Sánchez, A. Campero, J Non-Cryst. Solids , 2007, 353, 2143 2149.

[48]-R.I.Y. Quiroz-Segoviano, F. Rojas-González, M.A. García-Sánchez, Journal of NonCrystalline Solids 358 , 2012, 2868-2876

[49]-L. A. Rodrigues; D. R. Mulinari; M. L. C. P. Silva, Cerâmica vol.55 no.333 São Paulo Jan./Mar. 2009.

[50]-Yasser Ochoa, Yamileth Ortegón, Jorge Enrique Rodríguez Páez, fac.ing.univ. Antioquia No.52 Medellín Apr./June 2010, pag29-40.

[51]- Leofanti et al. Surface Area and Pore Texture of Catalysts, 1998.

[52]-García-Sánchez, M.A.; Campero, A. Aggregation properties of metallic tetrasulphophtalocyanines encapsulated in sol-gel materials. J. Sol Gel Sci. Technol. 1998, 37, 651-655.

[53]-Lv, Y.-Y.; Wu, S.-W.; Li, J. Porphyrinic polymers for gas sensing: An overview. Curr. Org. Chem. 2014, 18, 475-88.

[54]-García-Sánchez, M.A.; Campero, A. Aggregation properties of metallic tetrasulfophthalocyanines embedded in sol-gel silica. Polyhedron 2000, 19, 2383-2386. 
[55]-J. Guzmán-López, Efecto del método de preparación en las propiedades de los óxidos mixtos Zr-Ti, Rev. Mex. Ing. Chim., 2000, 29-36.

[56]-H. Zou, Y. S. Lin, Structural and surface chemical properties of sol-gel derived TiO2ZrO2 oxides, Appl. Catal. A: Gen. 265, 2004, 35-42.

[57]-Shen C,Wen Y,Shen Z,Wu J,Liu W. Facile, green encapsulation of cobalt tetrasulfophthalocyanine monomers in mesoporous silicas for the degradative hydrogen peroxide oxidation of azo dyes, J Hazard Mater. 2011.

[58]-Rosa Iris Yahel Quiroz Segoviano, Propiedades de materiales híbridos a base de macrociclos enlazados a sílice translúcida y órgano modificada, tesis de doctorado, universidad autónoma metropolitana - unidad iztapalapa, méxico, d.f., 7 de diciembre de $\mathbf{2 0 1 5}$.

[59]- Héctor García Ortega, Porfirinas Solubles en Agua: Síntesis, Homoasociación y Propiedades Fotofísicas de Porfirinas Sulfonadas 5,15-Difenilsustituidas,tesis de doctorado, Universidad de Barcelona Barcelona, Abril de 2003.

[60]-M. A. García-Sánchez, I. N. Serratos , R. Sosa , T. Tapia-Esquivel , F. González-García ,F. Rojas-González, S. R. Tello-Solís , A. Y. Palacios-Enriquez , J. M. Esparza Schulz and A. Arrieta, Chlorophyll a Covalently Bonded to Organo-Modified Translucent Silica Xerogels: Optimizing Fluorescence and Maximum Loading, Molecules 2016, 21, 961.

[61]-I.N. Serratos, F. Rojas-González, R. Sosa-Fonseca, J.M. Esparza-Schulz,V. Campos-Peña, S.R. Tello-Solís, M.A. García-Sánchez, Fluorescence optimization of chlorophyll covalently bonded to mesoporous silica synthesized by the sol-gel method, Journal of Photochemistry and Photobiology A: Chemistry $272,2013,28-40$.

[62]-J. Linnanto, J. Korppi-Tommola, Phys. Chem. Chem. Phys. 2 , 2000, 4962.

[63]-H.H. Strain, M.R. Thomas, J.J. Katz, BBA 75 , 1963, 306.

[64]-A.F.H. Anderson, M. Calvin, Arch. Biochem. Biophys. 107 , 1964, 251. 
[65]-Riischepov, A.S.; Gurinovich, G.P. Aggregation of chlorophyll isomers in a mixture of polar solvents. Zh. Prikl. Spektrosk. 1975, 23, 458-463.

[66]-Victor Hugo Romero Arellano, Propiedades luminescentes de nanocristales de $\mathrm{ZrO}_{2}$ dopados con iones de $\mathrm{dy}^{3+} \mathrm{y} \mathrm{lu}^{3+}$, tesis de maestría, centro de investigaciones en optica a.c. León Gto. Méx. Diciembre 2006.

[67] - Mário Rui da Cunha Pereira, Fotofísica de Porfirinas e Ftalocianinas em Matrizes de TiO2 preparadas pelo método de Sol-Gel, tesis doctorado, Universidade do Minho Braga 2004.

[68]-César Augusto Silva Henriques, síntesis de meso-porfirinas mixtas. Estudios fotofísicos y térmicos, Tesis de Maestría del Departamento de Química FCTUC Septiembre de 2011.

[69]-K. M. Smith, Porphyrins and Metalloporphyrins; Elsevier Scientific Publishing Co: Amsterdam, The Netherlands, 1976.

[70] D. Dolphin, The Porphyrins, Physical Chemistry, Part A and B; Academic Press: New York, NY, USA, 1979.

[71] (a) A. Harriman, J. Chem. Soc. Faraday Trans. 1980, 76, 1979; (b) A.Harriman, J. Chem. Soc. Faraday Trans. 1981, 77, 369; (c) A. Harriman, J. Chem. Soc. Faraday Trans. 1981, 77, 1281.

[72]-K. Kamitani, M. Uo, H. Inoue, A. Makishima, J. Sol Gel Sci. Technol. 1993, 1, 85.

[73]-Rosa I. Y. Quiroz-Segoviano, Iris N. Serratos, Miguel A. García-Sánchez, On Tuning the Fluorescence Emission of Porphyrin Free Bases Bonded to the Pore Walls of Organo-Modified Silica, Molecules 2014, 19, 2261-2285.

[74]-M. Goutterman, The Porphyrins. In Physical Chemistry, Part A; Dolphin, D., Ed.; Academic Press: New York, NY, USA, 1979.

[75]-M. Goutterman, J. Chem. Phys. 1959, 30, 1139. 
[76]-Carlos Escudero Rodriguez, Homoasociación de Porfirinas solubles en agua, Tesis de doctorado, departamento de química inorgânica, universidad de Barcelona, Barcelona españa octubre 2007.

[77] N. Petkova, et al., Preparation and optical properties of transparent zirconia sol-gel materials, J. Non-Cryst. Solids, 2011.

[78] (a) F. Orgaz, H. Rawson, J. Non-Crysty. Solids 1986, 82, 57; (b) R. S. McDonald, J. Phys. Chem. 1958, 62, 1168; (c) D. L. Wood, E. M. Rabinovich, J. of Non-Cryst. Solids 1986, 82 171. 
MACROCICLOS TETRAPIRROLICOS COVALENTEMENTE UNIDOS A XEROGELES TRANSPARENTES DE OXIDO DE ZIRCONIO Y DE TITANIO
En la Ciudad de México, se presentaron a las 12:00 horas del día 8 del mes de septiembre del año 2017 en la Unidad Iztapalapa de la Universidad Autónoma Metropolitana, los suscritos miembros del jurado:

DR. ANTONIO CAMPERO CELIS

DRA. MARIA LUISA OJEDA MARTINEZ

DR. CELSO VELASOUEZ ORDOÑEZ

DR. RUBEN ARROYO MURILLO

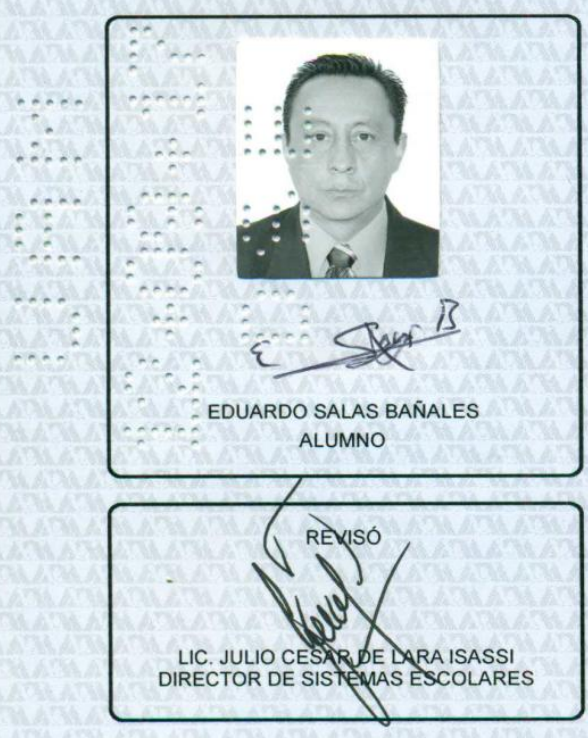

DIRECTOR DE LA DIVISIÓN DE CBI

DR. JOSE GILBERTO CORDOBA HERRERA

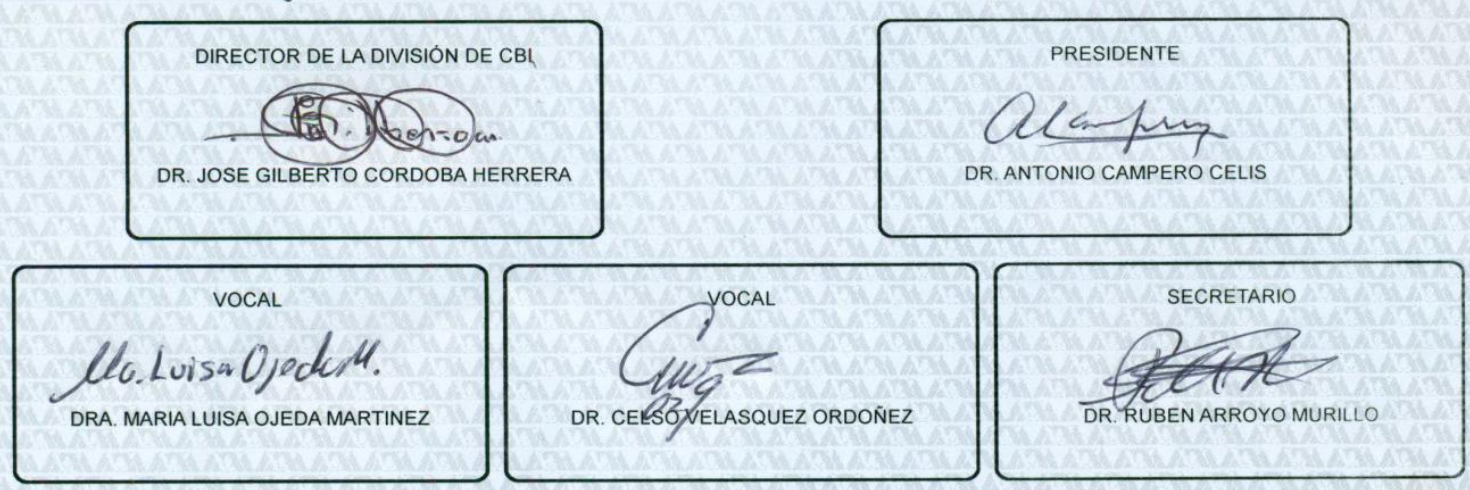

Bajo la Presidencia del primero y con carácter de Secretario el último, se reunieron a la presentación de la Disertación Pública cuya denominación aparece al margen, para la obtención del grado de:

DOCTOR EN CIENCIAS (QUIMICA)

DE: EDUARDO SALAS BAÑALES

y de acuerdo con el artículo 78 fracción IV del Reglamento de Estudios Superiores de la Universidad Autonoma Metropolitana, los miembros del jurado resolvieron:

\section{APROBAR}

Acto continuo, el presidente del jurado comunicó al interesado el resultado de la evaluación $y$, en caso aprobatorio, le fue tomada la protesta. 